\title{
Effect of Pentosans on Gluten Formation and Properties
}


Promotor: $\quad$ Prof. dr. R. J. Hamer

Hoogleraar in de technologie van Graaneiwitten, leerstoelgroep levensmiddelenchemie

Co-promotor: Dr. Ton van Vliet

Universitair hoofddocent, leerstoelgroep Fysica en fysische chemie van levensmiddelen

Promotiecommissie: Prof. dr. ir. M. A. J. S. van Boekel, Wageningen Universiteit Prof. dr. ir. A. G. J. Voragen, Wageningen Universiteit Prof. J. A. Delcour, Katholieke Universiteit Leuven Dr. J. W. G. De Meester, Cerestar-A Cargill Company, België 


\section{Effect of Pentosans on Gluten Formation and Properties}

\section{Mingwei Wang}

Proefschrift

Ter verkrijging van de graad van doctor

op gezag van de rector magnificus

van Wageningen Universiteit,

Prof. dr. Ir. L. Speelman,

In het openbaar te verdedigen

op maandag 30 juni 2003

Des namiddags vier uur in de Aula 
The research described in this thesis was carried out at the Department of Agrotechnology and Food Sciences, Food chemistry and food physics group, Wageningen University, The Netherlands.

Mingwei Wang

Effect of Pentosans on Gluten Formation and Properties

Thesis Wageningen University, The Netherlands- with references

ISBN 90-5808-828-6

The research in this thesis was financially supported by Wageningen University, Wageningen Centre for Food Sciences, The Netherlands, Wuhan Polytechnic University, China, CSM Bakery Supplies Division Europe, Amylum Europe N.V. and Cargill B.V. 


\section{Abstract}

The gluten protein polymeric network plays a pivotal role in determining the end-use quality of wheat in many food products. The properties of this polymeric network are strongly affected by wheat flour composition (protein, starch and pentosans etc.), ingredients (i.e. salt, fat), processing aids (i.e. enzymes) and process parameters (mixing time, mixing water, temperature). Although the content of pentosans, usually divided into water unextractable solids (WUS) and water extractable pentosans (WEP) in wheat flour is low $(1-2 \% \mathrm{w} / \mathrm{w})$, these polymers play an important role in gluten formation and properties. Unravelling the underlying relationships and understanding the effect of pentosans on gluten network formation is, therefore, of extreme importance. The aim of this thesis is to clarify the mechanism of action of pentosans on gluten formation and properties. The study was greatly facilitated by the use of a miniaturized set-up for gluten-starch separation. This allowed us to systematically study the effect of pentosans on gluten formation and properties.

The results show that both WUS and WEP affect gluten yield, composition and properties in a similar fashion. Pretreatment of WUS and WEP with xylanase did not remove the negative effect on gluten yield, but addition of xylanase or ferulic acid (FA) during gluten extraction did. Added pentosans hinder gluten agglomeration even if they are only present during the dough dilution phase. This is only partly related to a viscosity effect. FA related interactions are more important here. Both act on the ability of glutenin macropolymer (GMP) particles to form gluten, affecting both gluten yield and gluten rheological properties. We propose that pentosans interfere with gluten formation in both an indirect and a direct way. The indirect effect is related to water availability. The direct effect is related to an interaction between pentosans and gluten in which FA plays an important role.

The interference of WUS or WEP with gluten formation caused an incomplete aggregation of gluten protein, which was reflected in a larger average GMP particle size and a smaller tendency of these particles to aggregate. If xylanase or FA were added, aggregation was more complete, which was reflected in a smaller average GMP particle size and a larger tendency of these particles to aggregate. Now, also smaller GMP particles were recovered. The same trend was found with three wheat cultivars of very different qualities. Based on our results, we propose a possible explanation for the effect of pentosans on gluten formation and properties. Both a physical effect and a chemical effect are involved. The physical effect is related to viscosity and likely also depletion attraction between protein particles. The chemical effect is related to FA and 'controls' the tendency of the particles to aggregate and hence also gluten yield. In our explanation pentosans do not so much affect the growth of these particles directly after mixing, but hinder the further agglomeration of especially smaller particles to end up in the gluten. The partial agglomeration of GMP particles will result in turn in GMP with a different GMP particle size distribution and hence in gluten with changed rheological properties.

Key words pentosans, gluten yield, gluten properties, glutenin macropolymer 


\section{Abbreviations}

$\mathrm{AX}=$ arabinoxylans,

$\mathrm{DDT}=$ dough development time

$\mathrm{DS}=$ degree of softening

$\mathrm{E}$ at break $=$ extensibility at break point

$\mathrm{E}$ at $\mathrm{R}_{\max }=$ extensibility at maximum resistance to extension,

$\mathrm{EC}=$ extent of coagulation

$\mathrm{E}_{\mathrm{xt}}=$ extensibility

$\mathrm{FA}=$ ferulic acid

GMP = glutenin macropolymer,

$\mathrm{GY}=$ gluten yield

HMW-GS = high molecular weight glutenin subunits

$\mathrm{HRP}=$ horseradish peroxidase

LMW-GS = low molecular weight glutenin subunits

$\mathrm{MT}=$ mixing time

$\mathrm{MTI}=$ mixing tolerance index

$\mathrm{MW}=$ molecular weight

$\mathrm{PR}=$ peak resistance

$\mathrm{RB}=$ resistance breakdown

$\mathrm{R}_{\max }=$ maximum resistance to extension,

$\mathrm{ST}=$ stability time

$\mathrm{S}_{\mathrm{OH}}=$ soluble pentosans (WUS modified by $\mathrm{NaOH}$ )

$\mathrm{S}_{\mathrm{X}}=$ soluble pentosans (WUS modified by xylanase)

$\mathrm{WA}=$ water absorption

$\mathrm{WEP}=$ water extractable pentosans

$\mathrm{WEP}_{\mathrm{OH}}=$ WEP modified by $\mathrm{NaOH}$

$\mathrm{WEP}_{\mathrm{p}}=\mathrm{WEP}$ modified by HRP

$\mathrm{WEP}_{\mathrm{x}}=\mathrm{WEP}$ modified by xylanase

WHC $=$ water holding capacity

WUS = water unextractable solids

WUS $_{\mathrm{OH}}=$ WUS modified by $\mathrm{NaOH}$

WUS $_{\mathrm{p}}=$ WUS modified by HRP

WUS $_{\mathrm{x}}=$ WUS modified by xylanase 


\section{Preface}

As a visiting scholar sponsored by the China Scholarship Council, I had my first chance to visit Wageningen University in September 1999. This visit actually led to my $\mathrm{PhD}$ study. Travelling between China and the Netherlands for 4 times enriched my professional life and allowed me to broaden the horizons of my personal life as well. This venture has been one of the most important experiences in my life.

The work presented in this thesis would not have been accomplished without the support, encouragement and help of many people.

First of all, I owe special thanks to my promotor, Prof. Rob Hamer. Without his critical and detailed comments with regard to the experimental design, the discussion and the writing and with his research expertise, there could have been no guarantee of the academic quality of this dissertation. I was so impressed by his tremendous ideas about the research project. I have also learned from him how to behave like a scientific researcher, which will benefit me for my entire lifetime.

I am so grateful to my co-promotor, Dr. Ton van Vliet. Without him, it would not have been possible for me to learn such a great number of skills in the area of food physics. He taught me how to prepare a scientific manuscript in every detail, including textual and grammatical details, and how to think scientifically.

I am also very grateful to Prof. Fons Voragen. He helped my supervisors to find one of the three industrial sponsors, which made it possible for me to carry out all the experimental work in the lab of Wageningen University.

I am very indebted to Dr. Fre Pepping. He is the person from Wageningen University who initially contacted me and made my first visit possible.

I very much appreciate the practical help from the people of the labs of both Food Chemistry and Food Physics. Many thanks go to Dr. Harry Gruppen. I still remember how he helped me to isolate water unextractable pentosans from wheat flour. Many thanks also go to the following people: Gerrit van Koningsveld, Harmen de Jongh, Jolanda van den Boomgaard, Jolan de Groot, Margaret Bosveld, Ben van den Broek, Jan Cozijnsen, Aagje Legger, Edwin Bakx, Hans Koster, Toos Kroef, Gideon Oudgenoeg, Katja Grolle, Franklin Zoet, Harry Baptist.

Many colleagues, including my friends in the Food Chemistry lab, have shown great concern with regard to my study and have given me a lot of encouragement. I wish to express my sincerest thanks to Lynn Heng, Zhenghong Chen, Taihua Mu, Stephanie Prigent, Laurice Pouvreau, Francesca O'Kane. I also wish to extend my thanks to all my colleagues in the labs.

I am also very grateful to my industrial sponsors. Many thanks go to Dr. Udo Scharf from CSM Bakery Supplies Division Europe, Dr. Johan de Meester and Dr. Raymond Vehaert from Cargill BV., Dr. Stefaan Roels from Amylum Europe N.V., Dr. Johan Plijter and Clyde Don from TNO for their valuable discussions. Many thanks also go to Han Marseille from TNO for his excellent technical assistance in using TNO Glutomatic system and to Wim Lichtendonk from TNO for excellent technical assistance in GMP isolation and the rheological measurements. 
It was such a wonderful opportunity that I could meet Mrs Louise Lindsey when she worked in the lab of Food Physics. She arranged housing and insurance for me during my first visit. In the course of time a lasting friendship developed and she and her family became my closest Dutch friends. Louise, many thanks for the hospitality you extended to me and for sharing my happiness and sadness in the past years. Your home appears to have become my home, a home away from home. Also, many thanks for correcting my English in the propositions and preface of this thesis and for translating the English summary into Dutch.

I would like to take this opportunity to express my sincere gratitude to my home university, Wuhan Polytechnic University. I owe deep gratitude to Prof. Yin Zhaoqing and his family for their encouragement, understanding and moral support throughout all the years of my scientific career. Special thanks go to Prof. Xu Guangwen, the former president of the university, for the solid support to advance my scientific development and for granting me such an extended stay in the Netherlands for my $\mathrm{PhD}$ study. Many thanks go to Prof. Liu Dachuan, Prof. Zhou Jian, Prof. Wang Zuoqiao, Prof. Zeng Qilin, Prof. Wei Yiliang, Prof. He Dongping, Prof. Liu Zhangwu, Liu Nanfang, Li Changling and Xu Ganlin for their constant support and understanding. My profound appreciation goes to $\mathrm{Li}$ Xiaorui, Lu Shaofen, Qu Lingli, Liu Ying, Xiao Anhong, Xu Jie for their help in one way or another, with regard to my research. Many thanks also go to all my colleagues in my department for taking over all my teaching responsibilities in China while I was in the Netherlands.

I thank all my Chinese friends in Wageningen for their help and the enjoyable time in the Netherlands. In this regard, I would like to specifically acknowledge Mr. Hu Fucai's family, Huang Jiang, Liu Chunming, Han Beizhong, Chen Xinwen, Ji Qin, Wen Jun, Jia Li, Li Yaling, Huang Sanwen, Guo Fucun, Wan Xi, Li Shipeng, Zhang Lizheng, Xie Conghua, Yang Yehua, Wang Xuekui, Chen Jing.

I would like to express my gratitude with deep feelings to my parents for teaching me the values of life, how to lead and enjoy a wonderful life and for encouraging me to pursue higher education. Particular thanks go to my brothers and sister for taking care of my parents when they were ill.

Last but not least, I am so indebted to my husband, Ni Lansun, and my son, Ni Tianshao for their selfless love, understanding and constant support. Thank you, Lansun for taking over all my duties as a mother by taking care of Tianshao. Thank you, Tianshao for understanding me and doing your utmost in your studies so that I felt relieved and did not have to worry about you. I am also very indebted to my parents-in-law, for helping to take care of Tianshao.

To the people I love,

Mingwei Wang

Wageningen, the Netherlands, April 18, 2003 


\section{Contents}

Chapter 1 General introduction 1

Chapter 2 Effect of water unextractable solids on gluten formation and 37

properties: Mechanistic considerations. published

Chapter 3 Interaction of water extractable pentosans with gluten protein:

Effect on dough properties and gluten quality. published

Chapter 4 Interaction of water unextractable solids with gluten protein:

Effect on dough properties and gluten quality. in press

Chapter 5 How gluten properties are affected by pentosans. submitted 103

$\begin{array}{lll}\text { Chapter } 6 & \text { Interaction of water unextractable solids and xylanase with } & 121\end{array}$

gluten protein: Effect of wheat cultivars. submitted

Chapter 7 Evidence that pentosans and xylanase affect the

re-agglomeration of the gluten network. submitted

$\begin{array}{lll}\text { Chapter } 8 \text { General discussion } & 163\end{array}$

$\begin{array}{ll}\text { Summary } & 171\end{array}$

$\begin{array}{ll}\text { Samenvatting } & 177\end{array}$

概述 183

$\begin{array}{ll}\text { Curriculum vitae } & 187\end{array}$

$\begin{array}{lr}\text { List of publications } & 189\end{array}$ 


\section{1}

General introduction 


\subsection{Wheat}

Wheat is the most important and widely cultivated cereal crop in the world. It is grown in very different climates from the arctic cold of Russia to the extreme heat of India. It is obvious that the different varieties of wheat, grown under such different climate and other conditions, will greatly vary in appearance and in characteristics.

In general terms, wheat can be divided into red and white wheat according to the colour of the outer skin of the grain. Commercial wheat cultivars have been classified into different classes according to technologically relevant properties such as kernel hardness, bran colour, and protein content. Typical distinctions are hard or soft, strong or weak.

The structure of the wheat kernel is shown in Fig.1.1. The constituent tissues of the kernel are bran, endosperm and embryo (germ) ${ }^{1}$. The bran coat consists of several distinct layers as is evident from the graphic details in Fig.1.1.

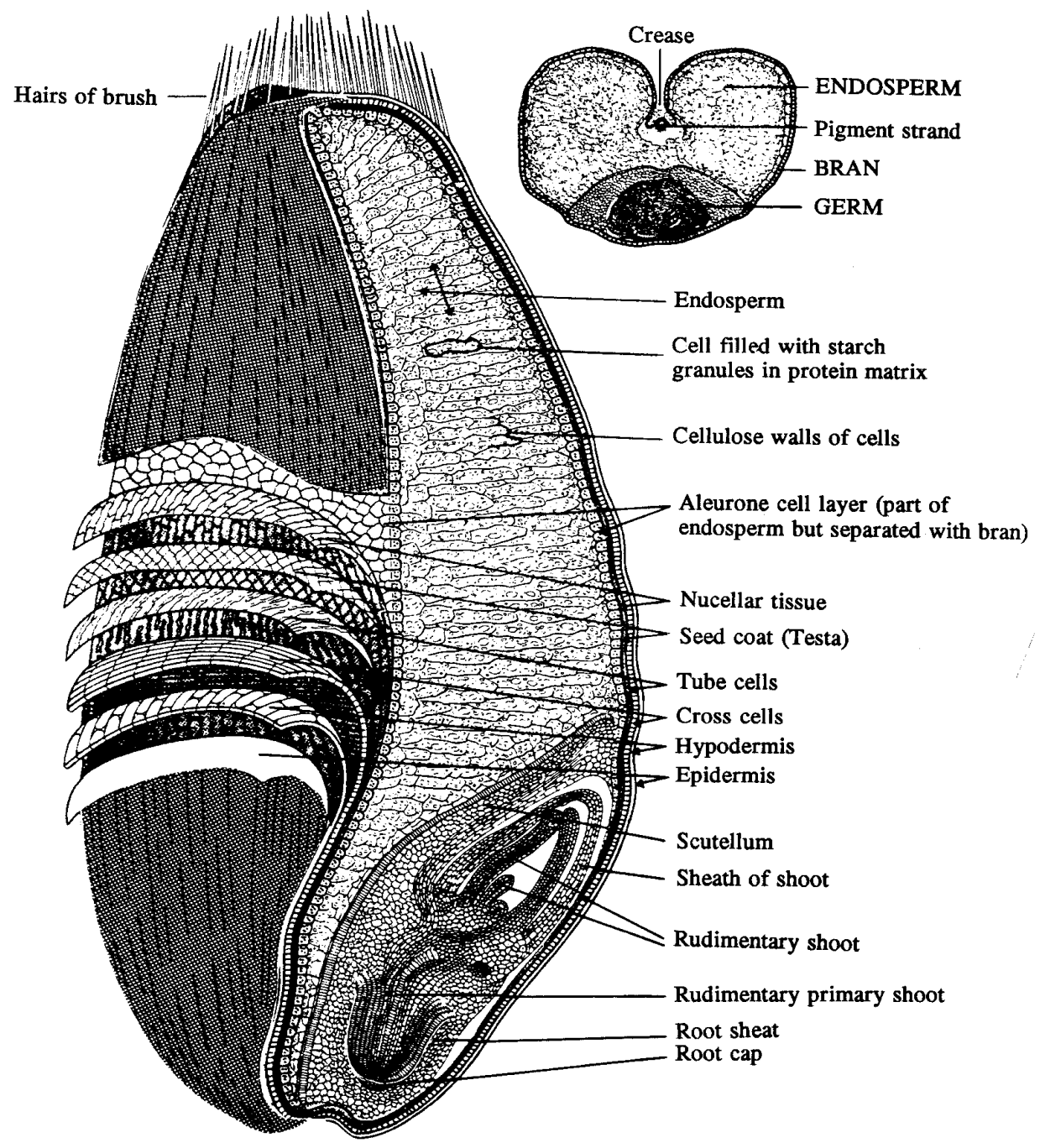

Figure 1.1 The structure of the wheat kernel 
The outer bran layers consist of the outermost epidermis cells, the hypodermis, tube cells and cross-cells. The inner bran layers are the testa or seed coat, nucellar epidermis, and aleurone cell layer. The embryo or germ lies at the base of the grain on its dorsal side and consists of the plumule or stem tip and the radicle or root tip. The plumule and radicle are connected by the cotyledon, which is surrounded by a layer of epithelial cells forming the so-called scutellum. The largest part of the wheat kernel is endosperm.

Wheat kernels contain $13-17 \%$ of bran, $2-3 \%$ of germ and $81-84 \%$ of endosperm ${ }^{2}$. The bran layers are rich in protein, cellulose, hemicelluloses, and ash; pericarp and aleurone contain more pentosans ( $35 \%$ and $39 \%$ respectively) ${ }^{2}$; the germ is rich in protein, fats, sugars, and ash; the endosperm largely consists of starch.

\subsection{Milling wheat into flour}

Wheat kernels are separated into flour, bran and germ by milling and sieving. Flour primarily consists of the ground endosperm. The main object of the miller is to obtain maximum yield of endosperm at minimal contamination of bran and aleurone ${ }^{2}$. The separation comprises a sequence of grinding, purifying and sieving operations. The main machines used for the separation are the roller mill for grinding, the purifier for purifying, the plan sifter for sieving and the bran finisher for removing bran from flour.

A complete milling process is usually divided into four systems (Fig.1.2), which are the break system, purification system, sizing system and reduction system ${ }^{2}$. The break system (4-5 stages) is the beginning of the actual milling process. The aim of the first break is to shear open the wheat kernel and to scrape the endosperm away from the bran skin in as large pieces as possible and, at the same time leaving the bran in the form of as large flat flakes as possible. The goal of the later breaks is to scrape off the remaining endosperm from the wheat skin leaving it as clean as possible. After sieving, the main fractions obtained are large bran flakes with adhering endosperm material, mixtures of small bran flakes, endosperm particles attached with bran fragments (semolina) and endosperm particles (middlings), and flour (break flour). The final products of the break system are different break flour and coarse bran. The purification system (2-4 stages) is to separate the mixtures into small bran flakes, which are transported to the next break stage, semolina to the sizing system and middlings to the reduction system. The sizing system (1-3 stages) is to grind the semolina into small bran flakes, which go to the next break stage, middlings, to the next reduction stage and flour (scratch flour). The aim of the reduction system (7-10 stages) is to reduce middlings into flour (reduction flour) and to separate fine bran from middlings, which are also transported to the next break stage. The final products of this 
system are different reduction flours and fine bran (shorts).

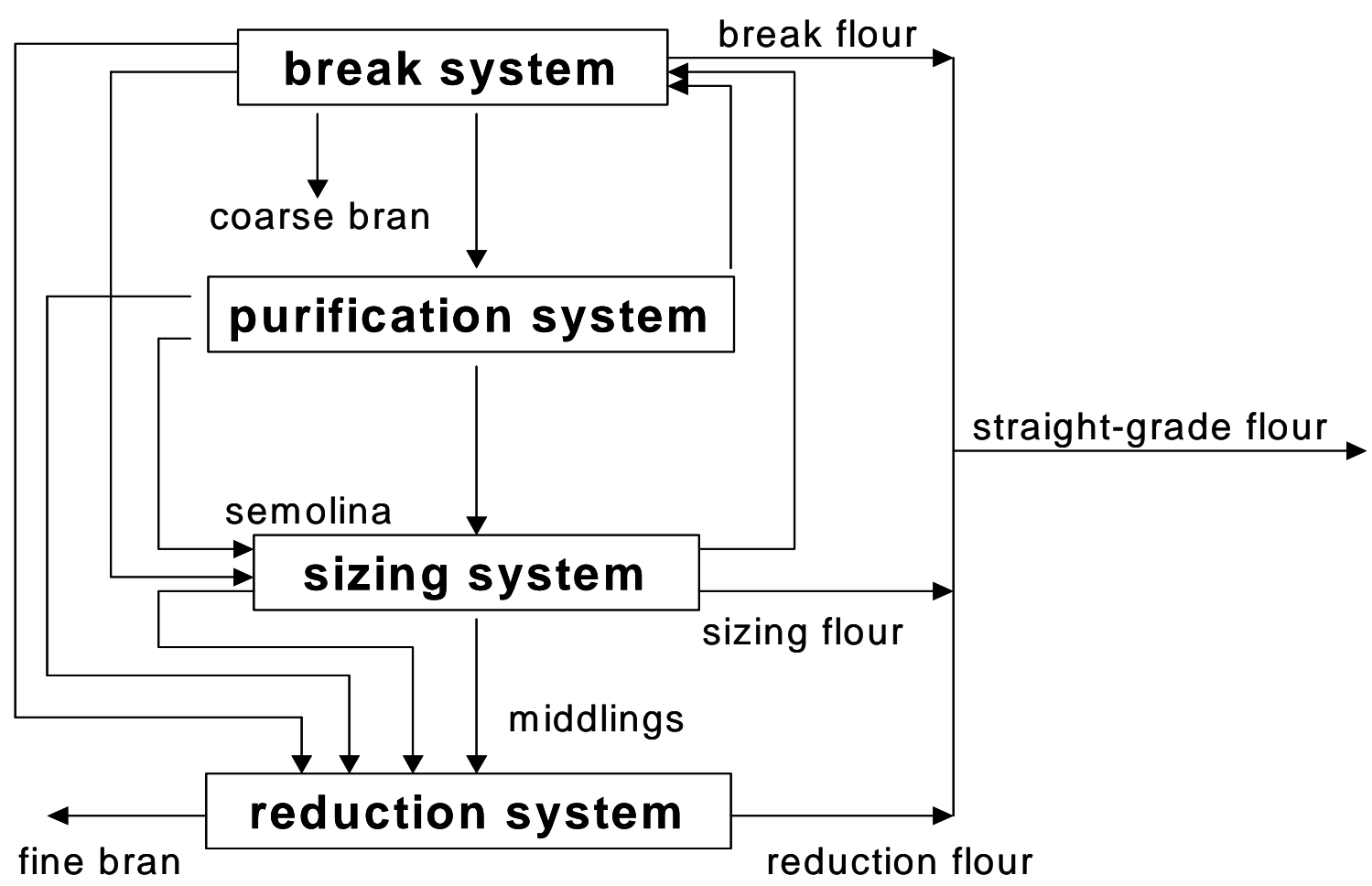

Figure 1.2 Block diagram of milling process

The earlier flour streams mainly consist of endosperm whereas the latter ones contain more fine bran particles and are darker in colour. If all flour streams are combined, the flour is known as straight-run flour. Frequently, the more highly refined (white) streams are taken off and sold separately as patent flours. The remaining streams, which contain some bran and germ, are called clear flours. Some clear flours are dark in colour and low in bread-making quality. Some of the better, lighter, clear flours are used in blends with rye and/or whole wheat flours in the production of speciality breads. The darker grades of clear flours, which contain more aleurone layer, are used for the manufacture of gluten, starch, monosodium glutamate, and pet foods.

\subsection{Chemical composition of wheat flour}

Wheat flour, mainly consisting of the starchy endosperm of the kernel, contains carbohydrates (70-80\%), proteins (8-18\%), lipids (1.5-2.5\%) and non-starch polysaccharides $(2-3 \%)$ all expressed as percentage on dry matter ${ }^{3-4}$. 


\subsubsection{Starch}

Starch is the most abundant component of wheat flour. It consists of two populations of starch granules: the large, lenticular (A type) granules having diameters from 14-40 $\mu \mathrm{m}$, and the small, spherical (B type) granules with a diameter from 1-10 $\mu \mathrm{m}^{5}$. Starch granules consist of amylose and amylopectin ${ }^{6}$.

\subsubsection{Protein}

Proteins are the most important components of wheat flour with respect to bread-making characteristics. Wheat flour proteins have been classified into four types based on their solubility according to Osborne ${ }^{7}$ : albumins, soluble in water; globulins, soluble in salt solutions; gliadins, soluble in $70 \%$ ethanol and glutenins, partly soluble in dilute acid or alkali. Albumins and globulins account for $20 \%$ of the total protein in flour; gliadins and glutenins represent about $80 \%$ of the total protein in flour ${ }^{8}$.

\subsubsection{Gliadins}

Gliadins comprise a heterogeneous group of proteins. When these proteins are fractionated by one-dimensional gel electrophoresis at low $\mathrm{pH}$ using aluminum lactate buffer, the components separate and are grouped into $\alpha-, \beta-, \gamma$ - and $\omega$-gliadins, the latter having the lowest mobility ${ }^{9}$. The molecular masses of the $\alpha-, \beta$-, and $\gamma$-gliadins (as determined by SDS-PAGE) vary between $30-40 \mathrm{kDa}$, whereas the $\omega$-gliadins are larger, up to $78 \mathrm{kDa}{ }^{10}$. Gliadins are monomeric proteins, $\alpha$-gliadins contain six cysteine residues and form three inter-chain disulfide bonds, while $\gamma$-gliadins contain eight cysteine residues and form four inter-chain disulfide bonds.

\subsubsection{Glutenins}

Glutenins are generally believed to exist as large complexes formed by subunits linked together by inter-chain disulfide bonds ${ }^{11-12}$. These complexes are extremely polydisperse with respect to size; the molecular mass of glutenin polymers ranges from a few hundred thousands to several millions $\mathrm{Da}{ }^{13-15}$. Glutenin can be fractionated into at least 15 subunits (in a single wheat cultivar) after reduction by SDS-PAGE ${ }^{10,16-17}$. There are two major groups of subunits. One is called low molecular weight glutenin subunits (LMW-GS), having molecular masses between ca 31 and $48 \mathrm{kDa}$. The other is named high molecular weight glutenin subunits (HMW-GS), with molecular masses between ca 80 and $145 \mathrm{kDa}$. At least 20 different HMW-GS have been identified by SDS-PAGE ${ }^{17,18-21}$. 
Based on their mobilities on SDS-PAGE, three groups of LMW-GS have been identified. There are similarities between LMW-GS and HMW-GS in terms of their solubility and sequence characteristics and conformation ${ }^{22}$.

\subsubsection{Lipids}

Wheat flour lipids can be divided into free lipids and bound lipids ${ }^{23}$. Both fractions consist of non-polar and polar components. Polar lipids can be divided into glycolipids and phospholipids. Triglycerides are a major component of non-polar lipids. Monogalactosyldiglycerides and Digalactosyldiglycerides are a major component of glycolipids; lysophosphatidylcholines and phosphatidylcholines are major components of phospholipids ${ }^{24}$.

\subsubsection{Non-starch polysaccharides}

Non-starch polysaccharides (NSP), originating from the cell wall of the aleurone and endosperm of wheat kernel, represent different polysaccharides, which are built up of pentose sugars [named pentosans, mainly arabinoxylans (AX)] and hexose sugars. AX together with cellulose, $\beta$-glucan, arabinogalactan-peptide and other minor constituents like glucomannan and xyloglucan are referred to as NSP. Pentosans are usually divided into water extractable pentosans (WEP, mainly water extractable AX) and water unextractable solids (WUS, mainly water unextractable AX), which comprises $25 \%$ and $75 \%$ of all pentosans present in wheat flour, respectively ${ }^{25}$. Pentosan content in wheat flour increases with the extraction rate of the flour due to the contamination with bran and aleurone fragments. Wheat gluten industry aiming for maximal starch yield uses high extraction rate flour, which contains more pentosans. Although WEP and WUS constitute a polydisperse group of molecules, a general structure exists. The structure of AX is a linear backbone of $\beta-1,4$ linked xyloses carrying single arabinose residues on C-3 or on both C-2 and C-3 ${ }^{26}$. A few of the arabinose are esterified with ferulic acid (FA) (Fig. 1.3). Molecular weight of AX was reported to be in the range between 22,000-5,000,000 $\mathrm{Da}^{27-31}$.

FA (4-hydroxy-3-methoxycinnamic acid) is concentrated in the cell wall of the outer coverings of wheat where it is mainly esterified to the arabinose backbone of $\mathrm{AX}^{32-33}$. Therefore, it is the natural component of WEP and WUS. Free, soluble-bound and insoluble-bound FA has been found in wheat flour and gluten ${ }^{34-35}$. 


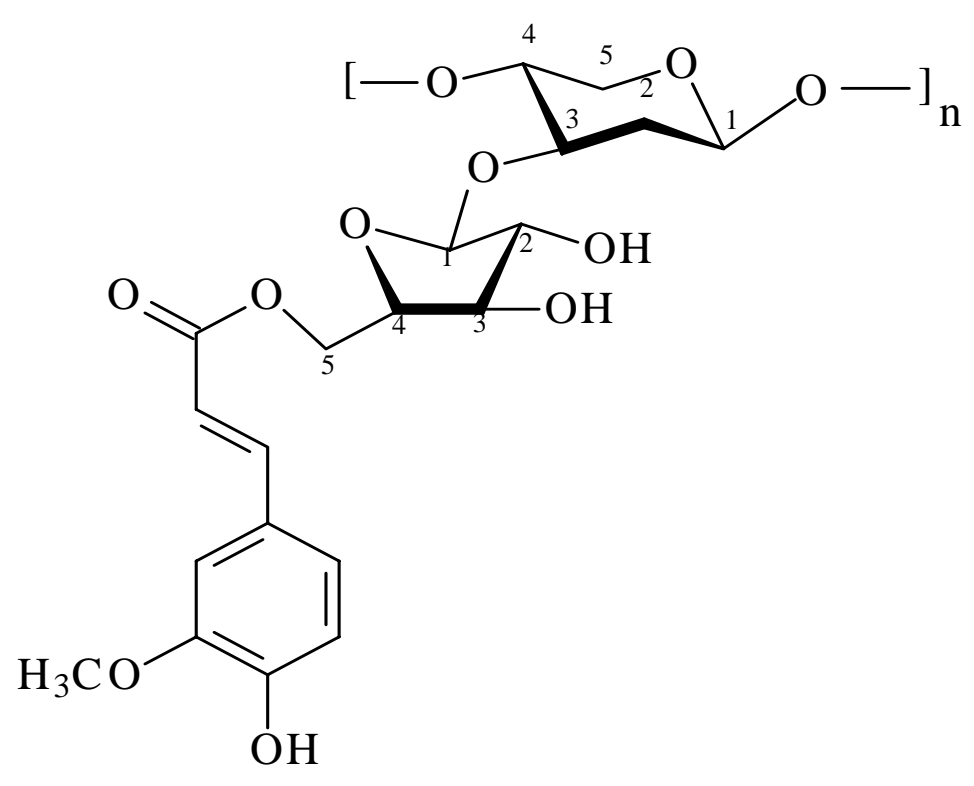

Figure 1.3 Structure of FA bound to arabinoxylan

D-xylopyranosyl residue substituted on C (O)-3 with L-arabinofuranosy residues. The link of FA to $\mathrm{C}(\mathrm{O})-5$ of a L-arabinofuranosyl residue.

\subsection{Gluten}

\subsubsection{Composition of gluten}

When flour-water dough is gently washed in an excess of water, soluble proteins and starch are removed and a rubbery mass, gluten (Latin for glue) is obtained. Usually, gluten consists of $75-85 \%$ protein (dry weight), depending on the thoroughness of washing, the remainder being $10-15 \%$ carbohydrates (mainly starch) and $5-10 \%$ lipids ${ }^{8}$.

\subsubsection{Gluten protein}

Gluten protein largely consists of two groups of proteins, the sulphur rich glutenins, able to form polymeric networks, and the sulphur poor gliadins, largely present as monomers. The glutenins consist of a HMW group and a LMW group of polypeptides, able to form disulfide linked polymeric networks. Gluten proteins affect dough mixing time and rheological properties ${ }^{36-37}$. Dimler ${ }^{38}$ has demonstrated that gliadin behaves as a viscous liquid and glutenin behaves as cohesive elastic solid when hydrated. Because of the specific viscoelastic properties of wheat flour dough, gas cells are retained in the dough during the bread-making process. It is this property that allows wheat flour to be used for production of a wide range of leavened food products. 


\subsubsection{Factors affecting glutenin networks}

The composition of the glutenin networks is in part determined by the presence and abundance of individual glutenin subunits. The relative amount of each subunit in wheat is determined by a combination of genetic factors, growing conditions (temperature, humidity) and fertilisation. In flour and dough, glutenin polymeric proteins are extremely polydisperse ${ }^{39}$, varying both in composition and size as reflected by differences in extractability. Moonen et al found that the SDS insoluble gel protein fraction highly correlated with SDS sedimentation values and loaf volume ${ }^{40}$. This fraction was later named the Glutenin Macro Polymer (GMP) to reflect the importance of glutenins and the highly aggregated nature of this fraction ${ }^{41}$. Weegels et al studied this fraction in great detail and presented firm evidence for its importance as a wheat quality parameter ${ }^{42}$.

Cereal scientists have gained considerable knowledge of wheat gluten and its constituting proteins. Its composition is now known in detail ${ }^{43}$, relations between specific alleles, gluten proteins and product quality have been established ${ }^{44}$, and a large number of HMW glutenin proteins have been sequenced ${ }^{45}$. Also, even single fragments have been visualised using scanning tunnelling microscopy ${ }^{46}$. However, at the same time much is still unknown. This is mainly due to the polydispersity and complexity of the glutenin polymeric network or aggregate. The composition and properties of this fraction are determined by many factors and can reflect both effects of genetic background, growing, milling, formulation, and processing. Recently, two review papers appeared. In one review paper ${ }^{47}$, composition-functionality relationships are discussed in some detail showing the limitations of our understanding. Although individual effects are known (e.g. of HMW/LMW-GS ratio, protein content) the interplay of different effects is yet unclear. Part of the reason is outlined in the second review ${ }^{48}$ in which a hypothetical model is presented explaining the elastic behaviour of wheat gluten using a 'loop-train' model. Although this model can be disputed, the main message of the paper is clear: it is the interplay of proteins, which determines gluten behaviour. The value of the paper is that it extends this interplay to hydrogen bonds. With some exceptions ${ }^{49}$, most of the other literature on this topic is related to disulfide bridge formation and its effect on dough properties.

\subsubsection{Glutenin hyperaggregation model}

Recently, a model for glutenin hyperaggregation has been developed by Hamer and Van Vliet ${ }^{50}$ in which both covalent and non-covalent processes are included (Fig. 1.4).

This model provides a basis to study the combined effect of different parameters on glutenin aggregation and can be briefly described as follows: 
At level one, HMW and LMW glutenin subunits form a covalent polymer. By definition, only covalent bonds are encountered at this level of aggregation. The position of these disulfide bridges will be determined by protein conformation, position of reactive sulphydryl groups and stabilising effects like formation of hydrogen and other bonds. This aggregation will hence be determined by the presence of individual subunits and their ability to propagate or terminate the network ${ }^{47}$. At this level, the genetically determined glutenin subunit composition will be important. At a second level of aggregation, covalent aggregates will form larger aggregates by physical interactions, stabilised by hydrogen and other bonds like electrostatic and hydrophobic ones and possibly additional disulfide bridges. The size and incidence of such aggregates will be largely determined by both the amount and size of aggregates at level one. At a third level, further aggregation occurs by physical interactions. Here, by definition, covalent bonds do not play a role. The formation of aggregates at this level is thought to be predominantly affected by process conditions (shear, stress) and other polymers interfering with physical interactions (hard fat, arabinoxylans).

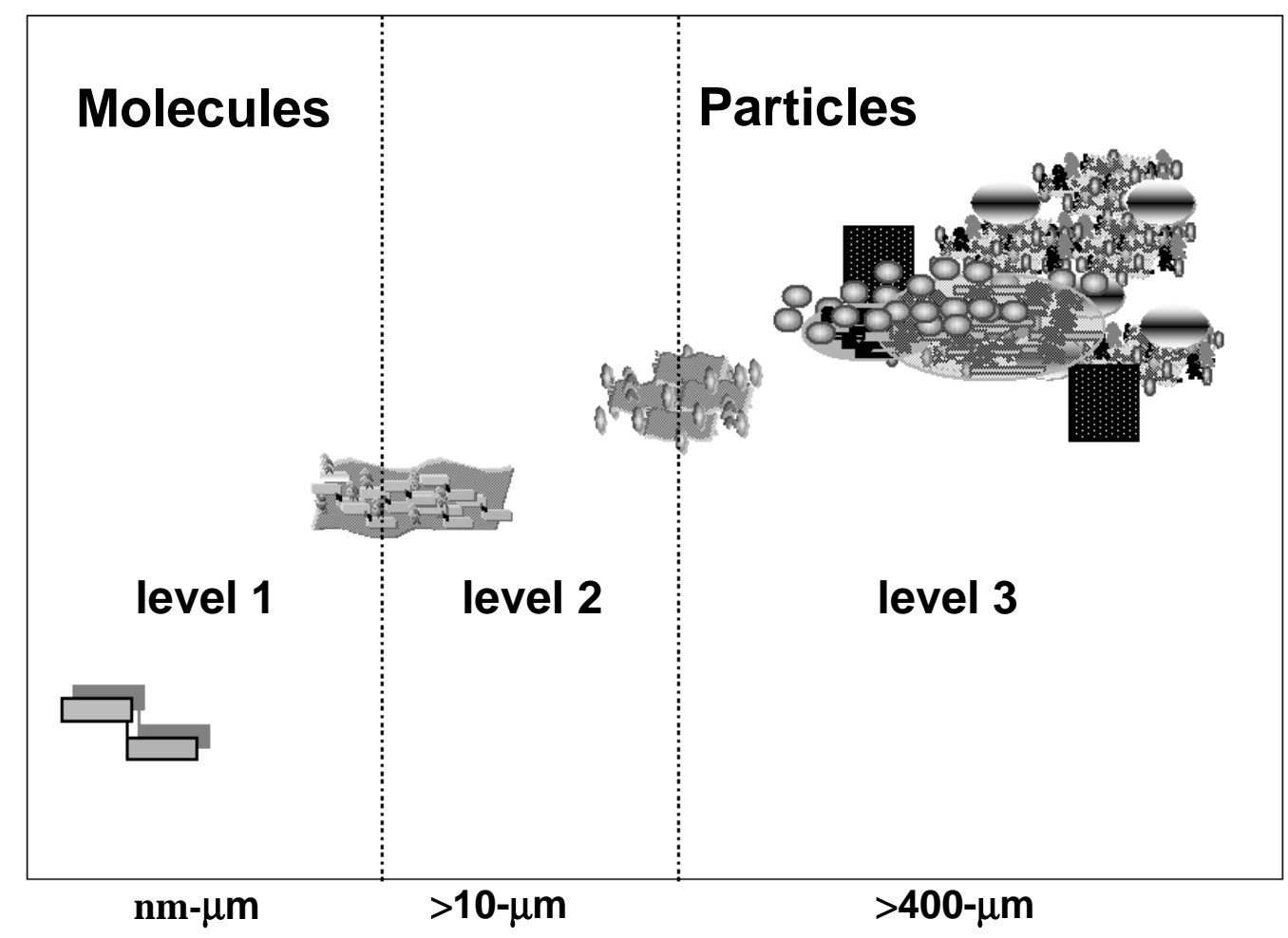

Figure 1.4 A model for glutenin hyperaggregation $\curvearrowright$ LMW glutenin, $\square$ HMW glutenin, $\bigcirc$ gliadin,

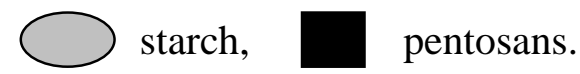




\subsection{Rheology of dough and gluten}

\subsubsection{A short introduction to rheology}

Rheology is the science that deals with deformation of a material in relation to the applied stress (force per unit of area) and the time scale. Depending on the relations between deformation, stress and time scale, materials can be divided into three groups:

- elastic (like a steel spring),

- viscous (like water),

- viscoelastic materials (like dough and gluten).

The rheological properties of ideally elastic and viscous materials can be described by a single value. The deformability of an elastic material can be defined by Hooke's constant (a modulus of elasticity). An ideally viscous material has a constant viscosity regardless of shear rate; the material shows so-called Newtonian behaviour and can be defined by a constant viscosity. However, many fluid systems show a more complicated so called Non-Newtonian flow behaviour. The viscosity often decreases as the shear rate is increased, which means deformation and stress depend on the time scale (shear rate). As a consequence, the system has to be defined by an apparent viscosity at each shear rate ${ }^{1}$. These materials are called shear-thinning materials. Viscoelastic materials are even more complicated in their behaviour and show a combination of viscous and elastic behaviour. Their reaction on an applied stress or strain consists partly of an elastic contribution and partly of a viscous one. The ratio of the elastic over the viscous contribution depends on the time scale (oscillation frequency in a dynamic experiment).

\subsubsection{Rheological measurement of dough and gluten}

Since both dough and gluten belong to viscoelastic materials, we use rheological theory to study their properties. Measurements taken with farinograph, mixograph or extensigraph are referred to as rheological measurements, because they measure how dough deforms and flows.

\subsubsection{Farinograph}

The Brabender farinograph is one of the most widely used recording dough mixers ${ }^{51}$. The two Z-shaped blades of the farinograph mixer rotate at constant speeds and subject the dough to mixing at constant temperature. A representative farinogram, with the commonly measured indices is defined by ICC method ${ }^{52}$. Dough development time (DDT) and stability time (ST) increase with increasing strength of flour. Whereas mixing tolerance 
index (MTI) and degree of softening (DS) decrease with increasing strength of flour. To express the strength of the tested flour as a single score, the value can be determined from the dough-development time and the descending slope of the curve by means of a valorimeter. The higher the value, the stronger the flour. Stronger flours with higher protein content and better gluten quality are characterized by higher water absorptions $(\mathrm{WA})^{2}$.

\subsubsection{Mixograph}

The mixograph is another widely used recording mixer (Fig. 1.5). The mixing action is provided by four planetary pins revolving about three stationary pins attached to the bottom of the mixing bowl. The mixing can be described as a pull, fold and repull action, which is more severe than that produced by the farinograph. The shape of a mixogram can be characterized by indices similar to those defined for the farinograph (AACC Method $54-40)^{53}$. Mixing time (MT) is similar to DDT. Peak resistance (PR) provides information about flour strength and absorption. Resistance breakdown (RB) is similar to MTI. Alower $\mathrm{RB}$ and a larger angle between the ascending and descending portions of the curve at the peak indicate a greater tolerance to overmixing. A higher tolerance to overmixing and overall flour strength can also be judged from the area under the curve.

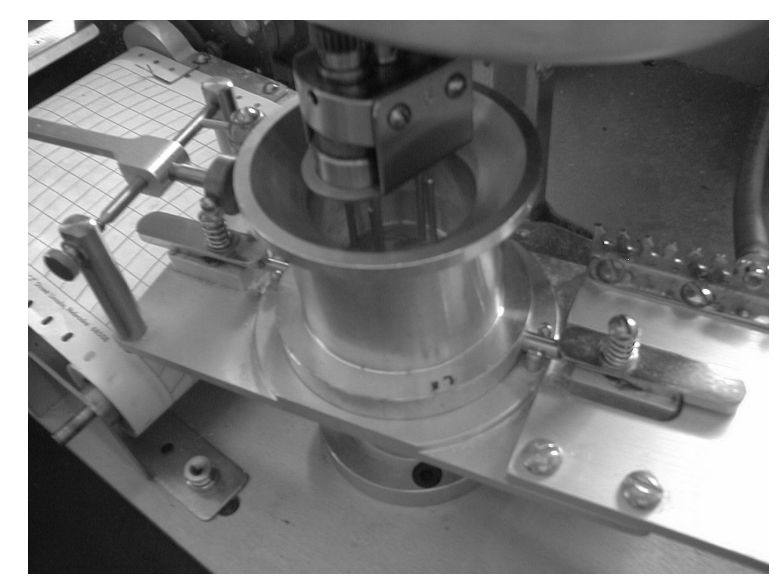

Figure 1.5 Mixograph

Flour sample $(10 \mathrm{~g})$ was mixed by four planetary pins revolving about three stationary pins attached to the bottom of the mixing bowl.

\subsubsection{Extensigraph}

The Brabender extensigraph stretches a cylindrically shaped dough piece until it 
ruptures while the resulting force on the test piece is transmitted through a balanced lever system to a recorder. When the dough test piece is stretched, a curve of force versus time, or extensigram is recorded. Four parameters are used to characterise the extensigram: maximum resistance to extension $\left(R_{\max }\right)$, extensibility $\left(E_{x t}\right)$, the ratio of $R_{\max }$ to $E_{x t}$ and the area under the curve. $R_{\max }$ is an indicator of the strength of the dough. A higher $R_{\max }$ implies a stronger dough. $\mathrm{E}_{\mathrm{xt}}$ represents the deformation of the dough before it ruptures. The larger $E_{x t}$, the further the dough can be extended before it ruptures. The ratio of $R_{\max }$ to $E_{x t}$ gives an estimation of the dough's viscoelastic balance. The area is proportional to the energy required to stretch the test piece to its rupture point. The stronger the flour, the more energy is required to stretch the dough.

\subsubsection{Kieffer dough and gluten extensibility rig}

Recently, an apparatus similar to the Brabender extensigraph was developed by Kieffer named the Kieffer dough and gluten extensibility rig, also called a Micro-extensigraph ${ }^{54-55}$ (Fig.1.6).

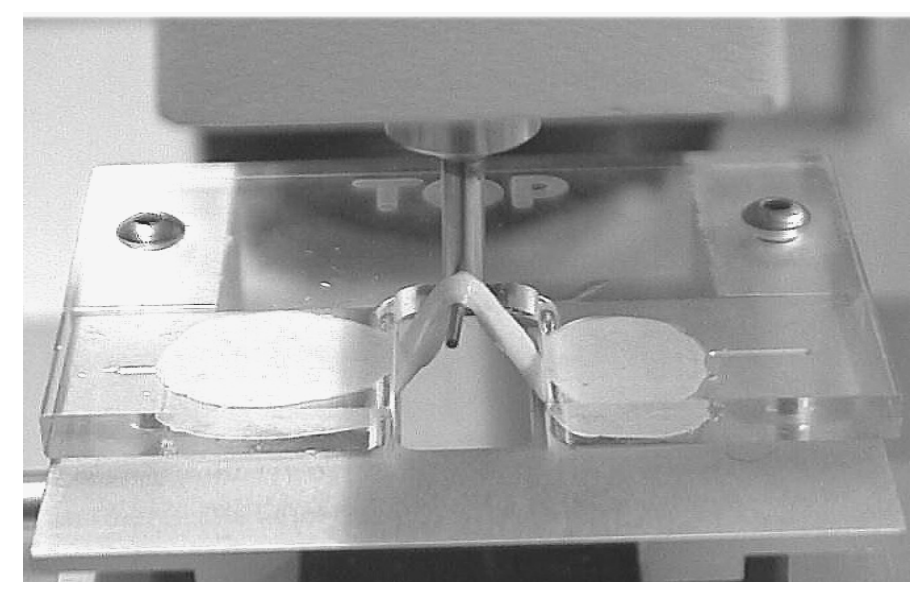

Figure 1.6 Microextensigraph test

The extension test of a strip of gluten was performed using the Kieffer extensibility rig fitted onto a Texture Analyser equipped with a $5 \mathrm{~kg}$ load cell.

In this apparatus a test can be performed with only about $1 \mathrm{~g}$ of dough or gluten and the apparatus can be fitted on a texture analyser, so the force can be measured in Newtons. The test speed can be adjusted and data can be stored in computer files for further calculations. Kieffer et al ${ }^{55-56}$ have successfully compared the test with tests in a Brabender extensigraph and also related it to bread-making performance. Dunnewind et al 
${ }^{57}$ reported how the uniaxial extension test can be used to determine real stress versus strain curves.

\subsubsection{Dynamic rheometer}

Although the above described instruments are very useful to characterize dough properties, most of them do not give the stress on the sample at any moment of time during the test. Moreover, during the measurement dough structure is broken down. This is not the case for dynamic measurements at small applied strains. The type and geometry of a dynamic rheometer can vary rather widely, but the basic measuring principles are the same regardless of the testing geometry. A sample is placed between two parallel plates ${ }^{1}$, in which one plate is fixed to a force transducer and the other plate is oscillated in a sinusoidal motion. As the top plate is moved, stress is applied to the sample between the plates. This causes the test piece to deform from which the strain (relative deformation) can be calculated. For two parallel plates, strain is given by the displacement of the moving plate divided by the distance between the plates ${ }^{1}$. Shear strain is usually referred to by the symbol $\gamma$ and is often given as a percentage. The top plate is caused to oscillate sinusoidally at a set frequency $\omega\left(\mathrm{rad} \mathrm{s}^{-1}\right)$ and angular amplitude. The stress and strain as a

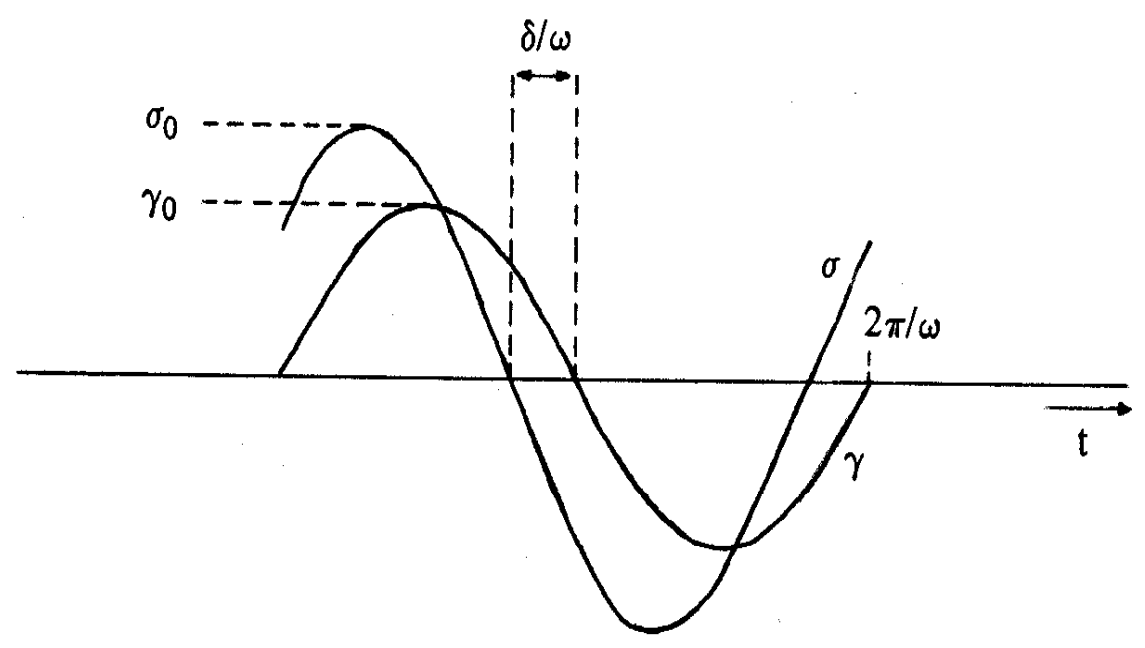

Figure 1.7 Sinusoidal signal output from the force and deformation transducers $\sigma_{0}=$ shear stress amplitude, $\gamma_{0}=$ shear strain amplitude, $\delta=$ phase angle, $\omega=$ angular frequency.

The $\sigma$ curve represents the shear stress and the $\gamma$ curve indicates the shear strain. If the sample would be completely elastic, the two curves would peak together, and if it would be 
completely viscous, the two curves would be out of phase by $90^{\circ}(=1 / 2 \pi)$. The phase angle $(\delta)$, gives a measure how much the system is out of phase. The complex modulus $\left(G^{*}\right)$ is equal to $\sigma_{0} / \gamma_{0}$ and consist of a real part, the storage modulus $\left(G^{\prime}\right)$ and an imaginary part, the loss modulus (G”). The storage modulus and the loss modulus are given by the following equations ${ }^{1}$ :

$$
\begin{aligned}
& G^{\prime}=\left(\sigma_{0} / \gamma_{0}\right) \times \cos \delta \\
& G^{\prime \prime}=\left(\sigma_{0} / \gamma_{0}\right) \times \sin \delta
\end{aligned}
$$

$\mathrm{G}^{\prime}$ is a measure of the part of the energy that is stored during a periodic cycle, and G' of the part that is lost. $\tan \delta$ is the ratio of G" to G', which is a simple index of the relative contribution of the elastic and viscous past to the resistance against a stress or strain of the material under test.

\subsection{Factors affecting dough properties, gluten and bread quality}

Dough properties, gluten and bread quality are strongly affected by flour composition (protein, starch and pentosans etc.), ingredients (i.e. salt, fat), processing aids (i.e. enzymes) and process parameters (mixing time/ work input, mixing water, temperature). In the following, each of these aspects is discussed.

\subsubsection{Protein}

The gluten proteins are the quantitatively most important protein fraction in dough. It has been suggested that the gliadins generally contribute to the viscosity of dough and gluten, whereas the glutenins contribute to their elasticity ${ }^{58-61}$. Addition of total gliadins resulted in a decrease in mixograph $\mathrm{MT}$, PR, extensigraph $\mathrm{R}_{\max }$, and loaf height, and an increase in $\mathrm{RB}$ and $\mathrm{E}_{\mathrm{xt}}{ }^{62-65}$. Gliadin fractions, in general, show the same effects on dough functionality as the total gliadins ${ }^{63-69}$. Uthayakumaran ${ }^{65}$ demonstrated that the various gliadin fractions showed differences in functional properties, with $\gamma$-gliadin reducing MT and $R_{\max }$ to the greatest extent, $\omega$-gliadin contributing to the greatest reduction in loaf height, and $\alpha$ - and $\beta$-gliadins having the least effect on reducing loaf height.

The investigations of the effects of glutenin subunits on dough properties have shown that flour with a higher HMW-GS to LMW-GS ratio has better bread-making quality than lower ratio $^{70}$. Recently, Uthayakumaran also reported that when the HMW-GS to LMW-GS ratio increased, MT, PR, $\mathrm{R}_{\max }$ and loaf height increased; but $\mathrm{RB}$ and $\mathrm{E}_{\mathrm{xt}}$ decreased ${ }^{71}$. Many correlative studies have also shown that HMW-GS 5+10 confer stronger dough properties than the allelic combination $2+12^{72-73}$. Incorporation studies of single and paired glutenin subunits, HMW-GS 5+10 demonstrated a synergistic effect 
increasing MT, $\mathrm{R}_{\max }$, and loaf height as compared with HMW-GS 5 or 10 separately. In contrast, HMW-GS 7 and HMW-GS 8 incorporated separately had a higher MT, $\mathrm{R}_{\max }$ and loaf height than HMW-GS $7+8^{71}$. The total protein content and glutenin to gliadin ratio of flour independently affected dough and baking properties. When glutenin to gliadin ratio was constant, MT, PR, $\mathrm{R}_{\max }, \mathrm{E}_{\mathrm{xt}}$ and loaf volume increased as the protein content increased. At constant protein content, increases in glutenin to gliadin ratios were associated with increases in MT, PR, $\mathrm{R}_{\max }$, and loaf volume, and with a decrease in $\mathrm{E}_{\mathrm{xt}}{ }^{64}$. In addition, several authors have shown a clear quantitative correlation between GMP gel quantity, GMP rheological properties, dough properties and bread loaf volume ${ }^{40,42,74-77}$. Weegels et al ${ }^{75}$ reported that GMP content of dough after 45 min rest was related to $\mathrm{R}_{\max }$; whereas the GMP contents of flour was better related to $E_{x t}$ and loaf volume. Sapirstein et al ${ }^{76}$ reported that GMP content was strongly related to loaf volume. Recently, Bekkers et al ${ }^{74}$ demonstrated a very high and positive correlation between the G'of GMP and DDT of dough.

\subsubsection{Starch}

The most abundant carbohydrate in dough is starch. Its gelatinisation is an essential step in the transformation of dough into bread. Gelatinisation of native starch grains embedded in the glutinous matrix of bread dough seems to be essential to the formation of a porous, elastic crumb ${ }^{78}$. According to Sandsted ${ }^{78}$, starch in a bread dough dilutes the gluten to a desired consistency; furnishes sugar through amylase action; provides a surface suitable for a strong union with the gluten; becomes flexible during partial gelatinisation, thereby permitting further stretching of the gas-cell film; takes water from the gluten by gelatinisation, thus causing the film to set and become rigid. In gelatinising, wheat starch can take up several times its weight in water from the gluten and retain this moisture, allowing the surrounding dehydrated gluten matrix to maintain a semi-rigid form ${ }^{79}$.

All flour with perhaps the exception of laboratory preparations contains damaged starch (4-10\%). This is the result of a dry-milling process ${ }^{80}$. Damaged starch differs from intact starch in two important aspects: they are significantly more susceptible to attack by $\alpha$-amylase, and they have an increased ability to take up water (3 times of undamaged starch) ${ }^{81-82}$. The interaction of an optimum level of damaged starch and amylase enzymes produces three characteristics that are desirable during bread-making. As the dough is being developed, damaged starch plays a large role in determining water. During fermentation, proofing and baking, maltose and other fermentable sugars produced by amylase action ensure yeast activity and thus adequate gas production. During baking, 
amylase enzymes are inactivated and the resulting dextrins are available for crust browning reactions. Excessive starch damage will cause a decrease in bread quality. The content of damaged starch should not exceed $9 \%$. Tipples ${ }^{83}$ reported that the loss of loaf volume was attributed to the instability of the air/dough interface during baking. As a result, there was not enough gluten to cover the increased surface area caused by the increase in damaged starch. This led to a loss of gas retention capacity.

The interaction between starch and gluten also plays a role in dough and gluten rheology ${ }^{84}$. He and Hoseney ${ }^{85}$ reported that there were more rheologically effective cross-links or interactions in flour-water dough than gluten-water dough. This shows that starch is not an inert (non-interacting) ingredient in flour-water doughs. Also, the sources of starch and gluten have a significant effect on dough rheology. Petrofsky ${ }^{84}$ reported that there is more gluten-starch interaction in soft wheat gluten-starch doughs than in hard wheat gluten-starch dough.

\subsubsection{Pentosans}

Pentosans, despite their low content (2-3\%) in wheat flour, are very important in determining dough properties, gluten and bread quality ${ }^{86-87}$. These components may affect dough and gluten properties by interacting with the gluten proteins ${ }^{87-92}$.

WEP exhibit some unique physical properties that have been the subject of many studies. The ability to immobilise water ${ }^{89,93-94}$ and to form viscous solutions or gels by covalent cross-linking ${ }^{95-97}$ are important attributes that also can have direct functional implications in gluten formation and properties. The water holding capacity of pentosans probably affects the distribution of moisture among dough constituents and thereby affects the rheological properties of dough, leading to a longer mixing time ${ }^{88,90}$. Although conflicting results have been published about the functional role of WEP in bread-making, WEP are generally believed to have a positive effect ${ }^{88,98}$. The different results may depend on their gross content in flour, their water extractability and fine structure ${ }^{98-102}$.

WUS, consisting for a large extent of water unextractable AX, are reported to have a strong, negative effect on bread-making quality ${ }^{88,90,102}$. It is for this reason that pentosan modifying enzymes are now widely used in bread-making ${ }^{103}$. It has been reported that addition of WUS to wheat flour markedly increases farinograph WA ${ }^{87,89-91,104}$, DDT ${ }^{87}$, ${ }^{89,92}$ and extensigraph $\mathrm{R}_{\max }$ of dough ${ }^{88,92}$, but decreases $\mathrm{E}_{\mathrm{xt}}$ and gluten yield ${ }^{87}$. Also, with WUS contradictory results have been reported with respect to its role in the bread-making process ${ }^{4,105}$. The reason for these inconsistencies may lie in the fractionation procedures used to obtain the pentosan fraction as well as in the inherent differences in structure and 
properties of these materials isolated from different wheat varieties ${ }^{91}$. Nevertheless, in general, WUS are considered to have a negative effect on bread-making quality ${ }^{88,106}$. Weegels et al ${ }^{107}$ using a pilot scale gluten-starch separation system could monitor effects of pentosans on the aggregation of small dispersed protein particles to gluten. The findings of Weegels and coworkers indicate that pentosans significantly influence gluten formation. This is corroborated by the work of Roels et al ${ }^{108}$.

Many studies have been carried out on the oxidative gelation of WEP ${ }^{35,95-97,109-118}$. WUS have also been reported to be amenable to further cross-linking via free FA molecules in the polymeric matrix ${ }^{91}$. The mechanisms proposed for oxidative cross-linking are quite different. Neukom and Markwalder ${ }^{109}$ suggested three possible mechanisms: 1) cross-linking of two FA residues by covalently joining the aromatic rings, 2) cross-linking of protein (at a tyrosine residue) and a FA residue at their aromatic rings, and 3) cross-linking of the aromatic rings of tyrosine in protein. Hoseney and Faubion ${ }^{96}$ suggested that FA side chains on AX would be oxidised by hydroxyl free radicals and this would lead to cross-linking with cysteine amino acids residues in protein. They postulated that it was the activated double bond on FA, rather than the aromatic group, that was active in oxidative gelation. Moore et al ${ }^{110}$ and Vinkx et al ${ }^{112}$ suggested that the aromatic group of the FA groups on WEP served as the site of cross-linking. Recently, Oudgenoeg ${ }^{116,118}$ et al proposed a hypothesis so-called cinnamic switch in which they demonstrated that the peptide oligomers always appeared to be blocked for further oligomerization by two non-decarboxylated FA molecules linked by dehydrogenation to the growing peptide oligomer ${ }^{116}$. Low concentrations of the FA monomer in plants can block possible sites for growth either on an esterified FA or on a protein-tyrosine template. High levels of FA statistically enhance dimerization to the decarboxylated FA dimers that enable further polymerization $^{118}$.

\subsubsection{Salt}

In bread-making, common salt generally forms part of the dough ingredients. A few percent of sodium chloride stiffens the dough and makes it less sticky. It has been reported that addition of sodium chloride to wheat flour produced a dough with a lower farinograph WA and consistency ${ }^{119-120}$, a higher farinograph DDT and $\mathrm{ST}^{121-122}$, a higher mixograph MT and $P R^{123-124}$, a higher extensigraph $\mathrm{R}_{\max }$ and $\mathrm{E}_{\mathrm{xt}}{ }^{120,125-126}$. According to Galal et al ${ }^{121}$, interaction between salt ions and wheat gluten proteins reduces the water binding capacity of gluten by changing the physical state of protein molecules. Sodium chloride is thought to screen the repellent action of molecular charges by interacting with polar groups of 
proteins. Furthermore, Preston ${ }^{127}$ reported that the general dough-strengthening effect at low salt concentrations can be attributed mainly to stronger inter protein interactions that result from electrostatic shielding of charged amino acids on the surface of the gluten proteins.

\subsubsection{Fat}

Although wheat lipids are a minor component in flour, they have a significant effect on baking quality ${ }^{128-133}$. Several studies have shown that free non-polar lipids are deleterious and that free polar lipids are beneficial in bread-making ${ }^{129}$. The deleterious effects of non-polar lipids can be counteracted by polar lipids, and the effect on loaf volume has been shown to depend on the levels of non-polar and polar lipids as well as on their ratio ${ }^{129}$. The mixing time requirement was also reported to be curvi-linearly related to polar lipids, the ratio of non-polar lipids to polar lipids and glycolipids in hard red winter wheats ${ }^{129}$. It has been stated that free polar lipids would interact with proteins and with added shortening to enhance adequate protein aggregation, which produce bread with good loaf volume and crumb grain ${ }^{134}$. Also, it has been suggested that interaction of free polar lipids and protein increase and stabilize the dough gas cells by decreasing surface tension ${ }^{135-137}$. The free polar lipids enhance gas retention and stabilize gas cell by forming polar lipids film at the gas-liquid interface of gas cells ${ }^{135}$.

\subsubsection{Added enzymes}

\subsubsection{Pentosanase}

Various studies have been performed to correct the negative effect of pentosans by use of pentosanases ${ }^{26,94,98,103,138-143}$. Extensive hydrolysis of wheat AX by xylanase leads to slack, wet and sticky dough ${ }^{138}$. When used at an appropriate level of addition, however, certain pentosan modifying enzymes (like xylanase) improve loaf volume and crumb structure of bread without giving rise to negative effects on dough handling and machinability $^{139}$.

The role of endoxylanases in the modification of pentosans has been ascribed to first, by cutting xylan backbones of water unextractable AX without solubilizing them ${ }^{142}$; secondly, by reducing the level of water unextractable AX present by solubilizing them, which leads to an increase in the level of solubilized AX, thirdly, by reducing the molecular weight of the solubilized $\mathrm{AX}^{141}$.

Another possible effect of pentosanases is that they could offset the lower gluten 
coagulation caused by pentosans present in the flour. Hamer et al ${ }^{143}$ reported that the use of even minute amounts of pentosanase in a batter of a slowly coagulating gluten/starch mixture greatly increased gluten coagulation. The resulting gluten was shown to have a higher performance in a bread-making test. Biochemical analysis revealed, as major difference, that this gluten had virtually no pentosans in its SDS insoluble high molecular weight glutenin fraction. In comparison, gluten produced in the absence of pentosanases has about $2-3 \%$ pentosans in this fraction. Weegels et $\mathrm{al}^{144}$ suggested that glutenin-associated pentosans could sterically hinder gluten protein network formation. It is possible that this could have a specific action on the rate of gluten formation and the quality of the gluten. Although much remains to be proven, this may explain the reported beneficial effect of these enzymes.

\subsubsection{2 $\alpha$-amylases}

Newly harvested wheat is often too low in $\alpha$-amylase activity for bread-making. Therefore, $\alpha$-amylase is often added for increasing its activity in this kind of wheat flour. It has been reported that addition of $\alpha$-amylase improves dough-handling properties, increases loaf volume and shelf life of bread ${ }^{145-147}$. It is generally believed that $\alpha$-amylases may affect dough properties in three ways, namely, by the formation of sugars that can be fermented by yeast, by the break down of the damaged-starch fraction, and by the formation of dextrins. The formation of fermentable sugars will increase the potential gas formation by yeast in dough, and may therefore lead to a larger loaf volume. However, according to Collins ${ }^{148}$, the quantity of gas produced by the yeast is not increased by $\alpha$-amylase addition, but gas retention by the baking dough is improved. Silberstein ${ }^{149}$ attributed the softening effect of bacterial $\alpha$-amylase to a reduction of the starch level available to retrograde (by degrading part of the starch to dextrins). Martin and Hoseney 150 assigned the effect of amylase to starch-protein or protein-protein entanglement interference by low molecular weight dextrins.

\subsubsection{Protease}

Protease is normally used to produce special flour for biscuits and wafers making. Addition of protease can shorten farinograph dough consistency, DDT and ST, increase extensigraph $\mathrm{E}_{\mathrm{xt}}$, decrease gluten strength; can improve dough uniformity, as a result, control bread texture and can also improve bread flavour ${ }^{151-153}$. Small amounts of protease can already have large effects on gluten physical properties. Oka et al ${ }^{154}$ demonstrated that cleavage of a few peptide bonds resulted in a rapid decrease in the viscosity of glutenin 
dispersions. Redman ${ }^{155}$ also reported evidence supporting the hypothesis that gluten softening is the direct result of peptide bond scission catalysed by protease. Also, the role of proteases has been reported for improving the quality of heat-damaged gluten ${ }^{156}$. Damaged gluten gives a less elastic and stiffer dough and therefore an inferior product. Since heat damage makes the gluten more susceptible to proteolysis, proteases can be used to alleviate this problem by specifically modifying these damaged structures in a dough ${ }^{157}$.

\subsubsection{Mixing time}

Dough mixing has several functions in the bread-making process ${ }^{157}$. The first is to blend the ingredients into a reasonably homogeneous mixture (dough). It is during the early stage of mixing that the flour particles become hydrated and gradually cohere together into underdeveloped (undermixed) dough. Mixing promotes hydration by exposing new surfaces of flour particles for interaction with water. As mixing proceeds, flour particles lose their identity and the dough gets a relatively homogeneous appearance as dough development proceeds. Dough development, reflected by a rise in dough consistency, can be followed during mixing by recording the torque on the mixer blades (as in the farinograph or mixograph) or the power consumed by the mixer/developer. Under appropriate mixing conditions, i.e. above the critical speed ${ }^{158}$, the mixing curve will peak at a time characteristic for the cultivar indicating optimum development.

An increase in mixing time or in mechanical energy input during mixing (above the optimum consistency) induces large changes in mechanical properties of wheat flour dough. The softening effect at longer mixing time is manifested by a decrease in farinograph dough consistency and ST, and also in viscoelastic properties of dough when measured immediately after mixing ${ }^{51,159-160}$. Changes in extensional properties and a softening effect on dough properties are also reported as a function of resting time ${ }^{161-162}$. The resting time is reported to be very important for gluten isolation from wheat flour damaged by either low or high temperature. A decrease in the size of the protein aggregates due to breaking of non-covalent bonds (disaggregation) ${ }^{159}$ and/or breaking of disulfide (S-S) bonds (depolymerisation) ${ }^{163-164}$ is believed to take place when overmixing. Depolymerisation has been indicated by a reduction in the molecular weight of the proteins extracted from overmixed dough ${ }^{163-164}$.

\subsubsection{Mixing water}

Flour particles are highly hygroscopic and will quickly absorb water when the two substances are brought together. Flour constituents vary in water absorption (WA) ${ }^{162}$. 
Starch (granular and damaged) takes up about $46 \%$ of the water in dough because it forms a high proportion of the flour ${ }^{157}$. The WA of damaged starch is about as 3 times as that of undamaged starch. The WA of protein is higher than of starch. The WA of pentosan is the highest one among the three constituents. It absorbs about 10 times its own weight of water. It is generally believed that flours milled from different wheat varieties differ in their WA. Hard wheat, usually contains more protein than soft wheat, therefore, has a higher WA than soft wheat.

It is well known that a decrease in dough water content below the optimum is detrimental to the volume of the loaf of baked bread, whereas an increase in water content does not necessarily result in lower bread quality. The handling properties, however, limit the amount of water that can be added ${ }^{166-167}$. Increased dough water content is also reported to result in a lower $\mathrm{G}^{\prime}$ of dough ${ }^{168-169}$.

\subsubsection{Temperature}

Temperature, especially during heating, has a strong effect on dough properties, gluten and bread quality ${ }^{170-173}$. According to Weegels et al ${ }^{173}$, extensigraph $E_{x t}$ and $R_{\max }$ of dough made from flour containing $4 \%$ gluten decreased sharply for gluten that had been heated at moisture contents between 20 and $25 \%$; outside this moisture content range, $\mathrm{R}_{\max }$ increased. Attenburrow et al ${ }^{172}$ reported that when hydrated gluten was heated, G' decreased steadily until about $60^{\circ} \mathrm{C}$, when it began to increase, and at about $90^{\circ} \mathrm{C}$ it increased dramatically. Schofield et al also ${ }^{171}$ demonstrated that the baking performance of gluten declined progressively on heating and most of its functionality was destroyed at $75^{\circ} \mathrm{C}$. It has been suggested that large deformation tensile properties are dependent on both water content and heat-setting temperature. For heat-set gluten the tensile modulus decreased with increasing water content ${ }^{172}$.

\subsection{Problem and aim of the study}

The gluten protein polymeric network plays a pivotal role in determining the end-use quality of wheat in many food products. The properties of this polymeric network are strongly affected by many factors as mentioned above. Changes in the quantity and properties of this polymeric fraction are reflected in changes in dough and gluten rheological properties and hence final product quality. Unravelling the underlying relationships is therefore of extreme importance. A great deal of work has been carried out to relate protein composition and quantity to network and final product properties. However, a lack of understanding exists on the effect of another important flour 
component: Pentosans are becoming more and more important in view of the increased use of 'dark' (high pentosans containing) flour for the production of wheat gluten and bakery products. Analysis of the literature presented above shows that in spite of the number of papers published on pentosans and pentosan modifying enzymes, no clear view exists on their functionality during gluten formation and properties.

Several theories exist to explain the effect of pentosans and pentosan modifying enzymes, based either on an indirect or on a direct effect of pentosans. Pentosans can indirectly effect gluten formation by competing for water. Pentosan modifying enzymes can then act by reducing the water binding capacity of pentosans thus inducing water redistribution ${ }^{138}$. Another indirect effect of pentosans (soluble and insoluble) could be caused by their ability to form a network, limiting the movement of glutenin proteins towards a larger aggregate. The beneficial action of pentosanase would then be exerted by breakdown of this pentosan network ${ }^{98}$. A direct effect of pentosans envisages pentosans to become covalently linked or associated to glutenin proteins, thus hindering further formation of gluten protein. Pentosan modifying enzymes would then act by cleaving gluten associated pentosans.

In all, the mechanism of action of pentosans in relation to glutenin hyperaggregation is far from clear and deserves detailed study. Therefore, the aim of the study described in this thesis is to clarify the mechanism of action of pentosans on gluten formation and properties. To achieve this, the following steps were undertaken:

- A miniaturised gluten and starch separation system was set up to study the effect of WUS systematically and to distinguish different effects of WUS (chapter 2).

- The effects of modified pentosans on dough properties and gluten quality were studied to elucidate the mechanism of pentosans and xylanase on gluten formation and properties (chapter 3 and 4).

- Isolated GMP particles were characterised in terms of their size and aggregation properties in order to find an explanation for the different gluten properties observed caused by pentosans (chapter 5 and 6).

- The miniaturised gluten and starch separation system was modified and it allows us to add pentosans and xylanase during the re-agglomeration phase in order to further clarify the mechanism of pentosans and xylanase on gluten formation and properties (chapter 7).

In this way, the study provides a better insight into the mechanism by which pentosans and xylanase affect gluten formation and properties. 


\section{References}

1. Hoseney, R.C. Principles of Cereal Science and Technology. $2^{\text {nd }}$ ed. American Association Cereal Chemists, Inc. St. Paul, Minnesota, USA. (1994) pp 1-13, 213-227.

2. Posner, E. Wheat. In 'Handbook of Cereal Science and Technology'. $2^{\text {nd }}$ ed. (eds. K, Kulp and J.G. Ponte, Jr.) Marcel Dekker, Inc. New York. (2000) pp 9-19.

3. MacRitchie, F. Baking quality of wheat flours. Advanced Food Research 29 (1984) 201-277.

4. Meuser, F. and Suckow, P. Non-starch polysaccharides. In 'Chemistry and Physics of Baking' (eds. J.M.V. Blanshard, P.J. Frazier and T. Galliard) The Royal Society of Chemistry, London. (1986) pp 42-61.

5. Evers, A.D. Scanning electron microscopy of wheat starch. III. Granule development in the endosperm. Starch 23 (1971) 157-162.

6. Medcalf, D.G. and Gilles, K.A. Wheat Starches. I. Comparison of physicochemical properties. Cereal Chemistry 42 (1965) 558-568.

7. Bushuk, W. and Wrigley, C.W. In 'Wheat: Production and Utilization' (ed. G.E. Inglett,) Avi Publ. Co., Westport, CT. (1974) pp 119-145.

8. Wrigley, C.W. and Bietz, J. A. Proteins and amino acids. In 'Wheat Chemistry and Technology' vol. I (ed. Y. Pomeranz) American Association Cereal Chemists, Inc. St. Paul, Minnesota, USA. (1988) pp 159-275.

9. Woychik, J.H., Boundy, J.A. and Dimler, R. J. Archives Biochemistry Biophysics 94 (1961) 477-482.

10. Bietz, J.A. and Wall, J.S. Wheat gluten subunits: Molecular weights determined by sodium dodecyl sulfate-polyacrylamide gel electrophoresis. Cereal Chemistry 49 (1972) 416-430.

11. Kasarda, D.D., Bernardin, J.E. and Nimmo, C.C. In 'Advances in Cereal Science and Technology' vol. I (Y. Pomeranz) American Association Cereal Chemists, Inc. St. Paul, Minnesota, USA. (1976) pp 158-236.

12. Field, J. M., Shewry, P.R. and Miflin, B.J. Solubilisation and characterisation of wheat gluten proteins: Correlations between the amount of aggregated proteins and baking quality. Journal of Science and Food and Agriculture 34 (1983) 370-377.

13. Huebner, F.R. and Wall, J. S. Fractionation and quantitative differences of glutenin from wheat varieties varying in baking quality. Cereal Chemistry 53 (1976) 258-269.

14. Huebner, F.R. and Wall, J. S. Wheat glutenin: Effect of dissociating agents on molecular weight and composition as determined by gel filtration chromatography. Journal Agriculture and Food Chemistry 28 (1980) 433-438. 
15. Bottomley, R.C., Kearns, H.F. and Schofield, J.D. Characterisation of wheat flour and gluten proteins using buffers containing sodium dodecyl sulphate. Journal of Science and Food and Agriculture 33 (1982) 481-491.

16. Orth, R.A. and Bushuk, W. Studies of Glutenin. III. Identification of subunits coded by the D-genome and their relation to breadmaking quality. Cereal Chemistry 50 (1973) 680-687.

17. Bietz, J.A., Shepherd, K.W. and Wall, J.S. Single-kernel analysis of gluten: Use in wheat genetics and breeding. Cereal Chemistry 52 (1975) 513-532.

18. Orth, R.A. and Bushuk, W. Studies of glutenin. II. Relation of variety, location of growth, and baking quality to molecular weight distribution of subunits. Cereal Chemistry 50 (1973) 191-197.

19. Payne, P. I., Holt, L.M., Krattinger, A. F. and Carrillo, J.M. Relationships between seed quality characteristics and HMW glutenin subunit composition determined using wheats grown in Spain. Journal of Cereal Science 7 (1988) 229-235.

20. Ng, P.K.W. and Bushuk, W. Statistical relationships between high molecular weight subunits of glutenin and breadmaking quality of Canadian-grown wheats. Cereal Chemistry 65 (1988) 408-413.

21. Karpati, E.M., Lasztity, R., Kuroczi, L. G. and Czirak, L. In 'Gluten Proteins' (eds. W. Bushuk and R.Tkachuk) American Association Cereal Chemists, Inc. St. Paul, Minnesota, USA. (1991) pp 245-252.

22. Shewry, P.R., Tatham, A.S. and Lazzeri, P. Biotechnology of wheat quality. Journal of Science and Food and Agriculture 73 (1997) 397-406.

23. Pomeranz, Y., Chung, O.K. Interaction of lipids with proteins and carbohydrates in breadmaking. Journal of American Oil Chemistry Society 55 (1978) 285-289.

24. MacMurray, T.A. and Morrison, W.R. Composition of wheat flour lipids. Journal of Science and Food and Agriculture 21 (1970) 520.

25. Meuser, F. and Suckow, P. Non-starch polysaccharides. In 'Chemistry and Physics of Baking' (eds. J.M.V. Blanshard, P.J. Frazier and T. Galliard) The Royal Society of Chemistry, London. (1986) pp 42-61.

26. Gruppen, H., Kormelink, F.J.M. and Voragen, A.G.J. Water-unextractable cell-wall material from wheat-flour. 3. A structural model for arabinoxylans. Journal of Cereal Science 18 (1993) 111-128.

27. Jelaca, S.L. and Hlynka, I. Water-binding capacity of wheat flour crude pentosans and their relation to mixing characteristics of dough. Cereal Chemistry 48 (1971) 211-222.

28. Patil, S.K., Tsen, C.C. and Lineback, D.R. Water-soluble pentosans of wheat flour. I. 
Viscosity properties and molecular weights estimated by gel filtration. Cereal Chemistry 52 (1975) 44-56.

29. Yeh, Y.F., Hosency, R.C. and Lineback, D.R. Changes in wheat flour pentosans as a result of dough mixing and oxidation. Cereal Chemistry 57 (1980) 144-148.

30. Rattan, O., Izydorczyk, M. and Biliaderis, C.G. Structure and rheological behaviour of arbinoxylans from Canadian bread wheat flours. Food Science and Technology 27 (1994) 550-555.

31. Dervilly, G., Rimsten, L., Saulnier, L., Andersson, R. and Aman, P. Water-extractable arabinoxylan from pearled flours of wheat, barley, rye and triticale. Evidence for the presence of ferulic acid dimers and their involvement in gel formation. Journal of Cereal Science 34 (2001) 207-214.

32. Faush, H., Kundig, W. and Neukom, H. Ferulic acid as a component of a glycoprotein from wheat flour. Nature 199 (1963) 287.

33. Geissmann, T. and Neukom, H. A note on ferulic acid as a component of the water-insoluble pentosans of wheat flour. Cereal Chemistry 50 (1973) 414-416.

34. Sosulski, F., Krygier, K. and Hogge, L. Free, esterified and insoluble-bound phenolic acid. 3. Composition of phenolic acids in cereal and potato flours. Journal of Agricultual and Food Chemistry 30 (1982) 337-340.

35. Jackson, G.M. and Hoseney, R.C. Effect of endogenous phenolic acids on the mixing properties of wheat flours doughs. Journal of Cereal Science 4 (1986) 79-85.

36. Hamer, R.J., Weegels, P.L., and Marseille, J.P. Prediction of the breadmaking quality of wheat: The use of HMW glutenin-A subunit based quality scoring systems. Journal of Cereal Science 15 (1992) 91-102.

37. Pritchard, P.E. and Brock, C.J. The glutenin fraction of wheat protein: The importance of genetic background on its quantity and quality. Journal of the Science of Food and Agriculture 65 (1994) 401-406.

38. Dimler, R. J. Gluten -The key to wheat's utility. Baker's Digest 37 (1963) 52-57.

39. Graveland, A. Extraction of wheat proteins with sodium dodecyl sulphate. Annales de Technologie Agricole 29 (1980)113-123.

40. Moonen, J.H.E., Scheepstra, A. and Graveland, A. Use of the SDS-sedimentation test and SDS-polyacrylamide gel electrophoresis for screening breeder's samples of wheat for bread-making quality. Euphytica 31(1986) 677-690.

41. Weegels, P.L., Hamer, R.J. and Schofield, J.D. Depolymerisation and re-polymerisation of wheat glutenin during dough processing. II. Changes in composition. Journal of Cereal Science 25 (1997) 155-163. 
42. Weegels, P.L. Depolymerisation and repolymerisation of the glutenin macropolymer in dough and effects of low molecular weight wheat proteins. $\mathrm{PhD}$ thesis. Reading University, Reading, UK. (1994) pp 351.

43. Pomeranz, Y. Wheat: chemistry and technology. American Association Cereal Chemists, Inc. St. Paul, Minnesota, USA. (1989) pp1.

44. Payne, P.I., Holt, L.M., Jackson, E.A. and Law, C.N. Wheat storage proteins: Their genetics and their potential for manipulation by plant breeding. Philosophical Transactions of the Royal Society of London, Biological Sciences 304 (1984) 359-371.

45. Shewry, P.R., Halford, N.G. and Tatham, A.S. The high molecular weight subunits of wheat, barley and rye: Genetics, molecular biology, chemistry and role in wheat structure and functionality. Oxford Surveys on Plant Molecular Cell Biology 6 (1989) 163-219.

46. Miles, M.J., Carr, H.J., McMaster, T.J., Tanson, K.J., Belton, P.S., Morris, V.J, Field, J.M., Shewry, P.R and Tatham, A.S. Scanning tunnelling microscopy of wheat seed storage protein reveals details of an unusual supersecondary structure. Proceedings National Academy of Sciences 88 (1991) 68-71.

47. MacRitchie, F. Wheat Proteins: Characterization and role in flour functionality. Cereal Foods World 44 (1999) 188-193.

48. Belton, P.S. On the elasticity of wheat gluten. Journal of Cereal Science 29 (1999) 103-107.

49. Tkachuk, R. and Hlynka, I. Some properties of dough and gluten in $\mathrm{D}_{2} \mathrm{O}$. Cereal Chemistry 45 (1968) 80-87.

50. Hamer, R. J. and van Vliet, T. Understanding the structure and properties of gluten: An overview. In 'Wheat Gluten--- proceedings of the $7^{\text {th }}$ International Gluten Workshop' (eds. P.R. Shewry and A.S. Tatham) Royal Society of Chemistry. (2000) pp125-131.

51. D' Appolonia, B. L. and Kunerth, W. H., eds., The Farinograph Handbook, American Association Cereal Chemists, Inc. St. Paul, Minnesota, USA.(1984).

52. ICC, method for using the Brabender Farinograph, ICC-standard No.115, Standard Methods of the International Association of Cereal Science Technology, Detmold Federal Republic of Germany. (1972).

53. AACC, Approved Methods of the American Association of Cereal chemists, 8 th ed. American Association Cereal Chemists, Inc. St. Paul, Minnesota, USA. (1983).

54. Kieffer, R., Kim, J. J. and Belitz, H.D. Zugversuche mit Weizenkleber im Mikromaßstab. Z. Lebensm. Unters. Forsch. 172 (1981) 190-192. 
55. Kieffer, R., Garnreiter, F. and Belitz, H.D. Beurteilung von Teigeigenschaften durch Zugversuche im Mikromaßstab. Z. Lebensm. Unters. Forsch. 172 (1981) 193-194.

56. Kieffer, R., Wieser, H., Henderson, M.H. and Graveland, A. Correlations of the breadmaking performance of wheat flour with rheological measurements on a micro-scale. Journal of Cereal Science 27 (1998) 53-60.

57. Dunnewind, B., Sliwinski, E.L., Grolle, K. and van Vliet, T. The 'Kieffer dough and gluten extensibility rig'. Journal of Texture submitted.

58. Khatkar, B.S., Bell, A.E. and Schofield, J.S. The dynamic rheological properties of glutens and gluten sub-fractions from wheats of good and poor bread making quality. Journal of Cereal Science 22 (1995) 29-44.

59. Janssen, A.M., van Vliet, T. and Vereijken, J.M. Rheological behaviour of wheat glutens at small and large deformations. Effect of gluten composition. Journal of Cereal Science 23 (1996) 33-42.

60. Khatkar, B.S. and Schofield, J.S. Molecular and physicochemical basis of breadmaking-properties of wheat gluten proteins: A critical appraisal. Journal of Food Science and Technology 34 (1997) 85-102.

61. Chiruta, J., van den Berg, R., Hugyen, Q. D., Middelberg, A.P.J., Cornish, G. and Palmer, G. A study of the effects of starch-protein interaction on rheological properties of wheat flour doughs. In ' Proceeding $47^{\text {th }}$ Australian Cereal Chemistry Conference. (eds, A.W. Tarr, A.S. Ross, and C.W. Wrigley) RACI: North Melbourne, Australia. (1997) pp 373-377.

62. MacRitchie, F. Evaluation of contributions from wheat protein fractions to dough mixing and breadmaking. Journal of Cereal Science 6 (1987) 259-268.

63. Fido, R.J., Bekes, F., Gras, P.W. and Tatham, A.S. Effect of $\alpha-, \beta-, \gamma$ - and $\omega$-gliadins on the dough mixing properties of wheat flour. Journal of Cereal Science 26 (1997) 259-268.

64. Uthayakumaran, S., Gras, P.W., Stoddard, F.L. and Bekes, F. Effect of varying protein content and glutenins-to-gliadin ratio on functional properties of wheat dough. Cereal Chemistry 76 (1999) 389-394.

65. Uthayakumaran, S., Tömösközi, S., Tatham, A.S., Savage, A.W.J., Gianibelli, M.C., Stoddard, F.L. and Bekes, F. Effect of gliadin fractions on functional properties of wheat dough depending on molecular size and hydrophobicity. Cereal Chemistry $\mathbf{7 8}$ (2001) 138-141.

66. Branlard, G. and Dardevet, M. Diversity of grain proteins and bread wheat quality. I. Correlation between gliadin bands and flour quality characteristics. Journal of 
Cereal Science 3 (1985) 329-343.

67. Dong, H., Sears, R.G., Cox, T.S., Hoseney, R.C., Lookhart, G.L. and Shogren, M.D. Relationships between protein composition and mixograph and loaf characteristics in wheat. Cereal Chemistry 69 (1992) 132-136.

68. van Lonkhuijsen, H.J., Hamer, R.J. and Schreuder, C. Influence of specific gliadins on the breadmaking quality of wheat. Cereal Chemistry 69 (1992) 174-177.

69. Weegels, P.L., Marseille, J.P., Bosveld, P. and Hamer, R.J. Large-scale separation of gliadins and their bread-making quality. Journal of Cereal Science 20 (1994) 253-264.

70. Gupta, R.B., Batey, I.L. and MacRitchie, F. Relationships between protein composition and functional properties of wheat flours. Cereal Chemistry 69 (1992) 125-131.

71. Uthayakumaran, S., Stoddard, F.L., Gras, P.W. and Bekes, F. Effect of incorporated glutenins on functional properties of wheat dough depending on molecular size and hydrophobicity. Cereal Chemistry 77 (2000) 737-743.

72. Branlard, G. and Dardevet, M. Diversity of grain protein and bread wheat quality. II. Correlation between high molecular weight subunits of glutenin and flour quality characterics. Journal of Cereal Science 3 (1985) 345-354.

73. Payne, P.I., Nightingale, M.A., Krattiger, A.F. and Holt, L.M. The relationship between HMW glutenin subunit composition and the bread-making quality of British-grown wheat varieties. Journal of the Science of Food and Agriculture 40 (1987) 51-65.

74. Pritchard, P.E. The glutenin fraction (gel protein) of wheat protein: A new tool in the prediction of baking quality. Aspects of Applied Biology 36 (1993) 75-84.

75. Weegels, P.L., Hamer, R.J. and Schofield, J.D. Depolymerisation and re-polymerisation of wheat glutenin during dough processing. I. Relationships between glutenin macropolymer content and quality parameters. Journal of Cereal Science 23 (1996) 103-111.

76. Sapirstein, H.D. and Suchy, J. SDS-protein gel test for prediction of bread loaf volume. Cereal Chemistry 76 (1999) 164-172.

77. Bekkers, A.C.A.P.A., Lichtendonk, W.J., Graveland, A. and Plijter, J.J. Mixing of wheat flour dough as a function of the physico-chemical properties of the SDS-gel proteins. In 'Wheat Gluten---proceedings of the $7^{\text {th }}$ International Gluten Workshop' (eds. P.R. Shewry and A.S. Tatham) Royal Society of Chemistry. (2000) pp 408-412.

78. Sandsted, R.M. The function of starch in the baking of bread. Baker's Digest 35 (1961) 36-44. 
79. Madcalf, D.G. Wheat starch properties and their effect on bread quality. Baker's Digest 42 (1968) 48-52.

80. Morrison, W.R. and Karkalas, J. Starch. In ' Method in Plant Biochemistry' Vol. II (ed. P.M. Dey). Academic Press, London, (1990) pp 323-352.

81. Pomeranz, Y. Composition and functionality of wheat flour components, In ' Wheat Chemistry and Technology”, Vol. II, $3^{\text {rd }}$ ed. (ed. Y. Pomeranz ). American Association Cereal Chemists, Inc. St. Paul, Minnesota, USA. (1988) pp 219-370.

82. Shelton, D.R. and D' Appolonia, B.L. Carbohydrate functionality in the baking process. Cereal Foods World 30 (1985) 437-442.

83. Tipples, K.H. The relation of starch damage to the baking performance of flour. Baker's Digest 43 (1969) 28-32, 44.

84. Petrofsky, K.E. and Hoseney, R.C. Rheological properties of dough made with starch and gluten from several sources. Cereal Chemistry 72 (1995) 53-58.

85. He, H. and Hoseney, R.C. Differences in gas retention, protein solubility and rheological properties between flours of different baking quality. Cereal Chemistry 68 (1991) 526-530.

86. Delcour, J. A., Vanhamel, S. and Hoseney, R.C. Physicochemical and functional properties of rye nonstarch polysaccharides. II Impact of a fraction containing water-solubles pentosans and proteins on gluten-starch loaf volumes. Cereal Chemistry 68 (1991) 72-76.

87. Michniewicz, J., Biliaderis, C. G. and Bushuk, W. Effect of added pentosans on some physical and technological characteristics of dough and gluten. Cereal Chemistry $\mathbf{6 8}$ (1991) 252-258.

88. Jelaca, S.L. and Hlynka, I. Effect of wheat-flour pentosans in dough, gluten and bread. Cereal Chemistry 49 (1972) 489-495.

89. Jelaca, S.L. and Hlynka, I. Water-binding capacity of wheat-flour crude pentosans and their relation to mixing characteristics of dough. Cereal Chemistry 48 (1971) 211-222.

90. Kim, S.L. and D'Appolonia, B.L. Bread staling studies. III. Effect of pentosans on dough, bread and bread staling rate. Cereal Chemistry 54 (1977) 225-229.

91. Michniewicz, J., Biliaderis, C.G. and Bushuk, W. Water-insoluble pentosans of wheat: Composition and some physical properties. Cereal Chemistry 67 (1990) 434-439.

92. Courtin, C.M., Bulck, K.V. and Delcour, J.A. Understanding arabinoxylan functionality in bread-making. Proceeding in $84^{\text {th }}$ AACC Meeting (Seattle, 1999).

93. Patil, S.K., Tsen, C.C. and Lineback, D.R. Water-soluble pentosans of wheat flour. 
I. Viscosity properties and molecular weights estimated by gel filtration. Cereal Chemistry 52 (1975) 44-56.

94. Rouau, X. and Moreau, D. Modification of some physicochemical properties of wheat flour pentosans by an enzyme complex recommended for baking. Cereal Chemistry $\mathbf{7 0}$ (1993) 626-632.

95. Geissmann, T. and Neukom, H. On the composition of the water-soluble wheat flour pentosans and their oxidative gelation. Lebensmittel Wissenschaft und Technologie 6 (1973) 59-62.

96. Hoseney, R.C. and Faubion, J.M. A mechanism for the oxidative gelation of wheat flour water-soluble pentosans. Cereal Chemistry 58 (1981) 421-424.

97. Izydorczyk, M.S., Biliaderis, C.G. and Bushuk, W. Oxidative gelation studies of water-soluble pentosans from wheat. Journal of Cereal Science 11 (1990) 153-169.

98. Rouau, X. Ei-Hayek, M.L. and Moreau, D. Effect of an enzyme preparation containing pentosanases on the bread-making quality of flours in relation to changes in pentosan properties. Journal of Cereal Science 19 (1994) 259-272.

99. Ciacco, C.F. and D'Appolonia, B.L. Characterization of pentosans from different flour classes and of their gelling capacity. Cereal Chemistry 59 (1982) 96-100.

100. Ciacco, C.F. and D'Appolonia, B.L. Characterization and gelling capacity of water-soluble pentosans isolated from different millstreams. Cereal Chemistry 59 (1982) 163-166.

101. Izydorczyk, M.S., Biliaderis, C.G. and Bushuk, W. Comparison of the structure and composition of water-soluble pentosans from different wheat varieties. Cereal Chemistry 68 (1991) 139-144.

102. Izydorczyk, M.S., Biliaderis, C.G. and Bushuk, W. Physical properties of watersoluble pentosans from different wheat varieties. Cereal Chemistry 68 (1991) 145-150.

103. Weegels, P.L., Marseille, J.P. and Hamer, R.J. Enzymes as a processing aid in the separation of wheat flour into starch and gluten. Starch 44 (1992) 44-48.

104. Denli, E. and Ercan, R. Effect of added pentosans isolated from wheat and rye grain on some properties of bread. European Food Research Technology 212 (2001) 374-376.

105. Hoseney, R.C. Functional properties of pentosans in baked goods. Food Technology 1 (1984) 114-117.

106. Hanh, P.P. and Rasper, V. The effect of nonstarchy polysaccharides from yam, sorghum, and millet flours on the rheological behavior of wheat doughs. Cereal 
Chemistry 51 (1974) 734-750.

107. Weegels, P.L., Marseille, J.P. and Hamer, R.J. Small scale separation of wheat flour into starch and gluten. Starch 40 (1988) 342-346.

108. Roels, S.P., Grobet, P.J. and Delcour J.A. Distribution of carbohydrates in gluten fractions isolated from European wheats (Triticum aestivum L.) in a batter system. Journal of Agricultural and Food Chemistry 46 (1998) 1334-1343.

109. Neukom, H. and Markwalder, H.U. Oxidative gelation of wheat flour pentosans: A new way of cross-linking polymers. Cereal Foods World 23 (1978) 374-376.

110. Moore, A.M., Martinez-Munoz, I. and Hoseney, R.C. Factors affecting the oxidative gelation of wheat water-solubles. Cereal Chemistry 67 (1990) 81-84.

111. Vinkx, C.J.A., VanNieuwenhove, C. G. and Delcour, J.A. Physicochemical and functional properties of rye non-starch polysaccharides III Oxidative gelation of a fraction containing water-soluble pentosans and protein. Cereal Chemistry $\mathbf{6 8}$ (1991) 617-622.

112. Girhammar, U. and Nair, B.M. Isolation, separation and characterization of water soluble non-starch polysacchrides from wheat and rye. Food Hydrocolloids 6 (1992) 285-299.

113. Figueroa-Espinoza, M.C. and Rouau, X. Oxidative cross-linking of pentosans by a fungal laccase and horseradish peroxidase: Mechanism of linkage between feruloylated arainoxylans. Cereal Chemistry 75 (1998) 259-265.

114. Schooneveld-Bergmans, M.E.F., Dignum, M.J.W., Grabber, J.H., Beldman, G. and Voragen, A.G. J. Studied on the oxidative cross-linking of feruloylated arabinoxylans from wheat flour and wheat bran. Carbohydrate Polymers 38 (1999) 309-317.

115. Labat, E., Morel, M.H. and Rouau, X. Effect of laccase and ferulic acid on wheat flour dough. Cereal Chemistry 77 (2000) 823-828.

116. Oudgenoeg, G., Hilhorst, R., Piersma, S.R., Boeriu, C.G., Gruppen, H., Hessing, M., Voragen, A.G. and Laane, C. Peroxidase-mediated cross-linking of a tyrosine-containing peptide with ferulic acid. Journal of Agricultural and Food Chemistry 49 (2001) 2503-2510.

117. Labat, E., Morel, M.H. and Rouau, X. Effect of laccase and manganese peroxidase on wheat gluten and pentosans during mixing. Food Hydrocolloids 15(2001) 47-52.

118. Oudgenoeg, G., Dirksen, E., Ingemann, S., Hilhorst, R., Gruppen, H., Boeriu, C.G., Piersma, S.R., Berkel, W.J.H. van, Laane, C. and Voragen, A.G. J. Horseradish peroxidase catalyzed oligomerization of ferulic acid on a template of a 
tyrosion-containing tripeptide. Journal of Biological chemistry 277 (2002) 21332-21340.

119. Hlynka, I. Influence of temperature, speed of mixing, salt on some rheological properties of dough in the farinograph. Cereal Chemistry 39 (1962) 286-303.

120. Linko, P. Herkonen, H. and Linko, Y.Y. Effect of sodium chloride in processing of bread baked from wheat, rye and barley flours. Journal of Cereal Science 2 (1984) 53-62.

121. Galal, M.A., Varriano-Marston, E. and Johnson, J.A. Rheological dough properties as affected by organic acids and salt. Cereal Chemistry 55 (1978) 683-691.

122. Harinder, K. and Bains, G.S. High alpha-amylase flours: Effect of pH, acid, and salt on the rheological properties of dough. Cereal Chemistry 67 (1990) 588-594.

123. Danno, G. and Hoseney, R.C. Effect of sodium chloride and sodium dodecyl sulfate on mixograph properties. Cereal Chemistry 59 (1982) 202-204.

124. Lang, C.E. Neises, E.K. and Walker, C.E. Effects of additives on flour-water dough mixograms. Cereal Chemistry 69 (1992) 587-591.

125. Tanaka, K. Furukaea, K. and Matsumoto, H. The effect of acid and salt on the farinogram and extensigram of dough. Casutt, V. Cereal Chemistry 44 (1967) 675-680.

126. Preston, K.R. and Kilborn, R.H. Effect of fermentation time, inherent flour strength, and salt level on extensigraph properties of full formula remix-to-peak processed doughs. Cereal Chemistry 61 (1984) 454-459.

127. Preston, K.R. Effects of neutral salts of the lyotropic series on the physical dough properties of a Canadian red spring wheat flour. Cereal Chemistry 66 (1989) 144-148.

128. MacRitchie, F. Flour lipids and their effects in baking. Journal of Science and Food and Agriculture 28 (1977) 53-58.

129. Chung, O.K., Pomeranz, Y. and Finney, K.F. Relation of polar lipid content to mixing requirement and loaf volume potential of hard red winter wheat flour. Cereal Chemistry 59 (1982) 14-20.

130. Bekes, F., Zawistowska, U., Zillman, R.R. and Bushuk, W. Relationship between lipid content and composition and loaf volume of twenty-six common wheats. Cereal Chemistry 63 (1986) 327-331.

131. Larsen, N.G., Humphrey-Taylor, V. J. and Baruch, D.W. Glycolipid content as a breadmaking quality determinant in flour from New Zealand wheat blends. Journal of Cereal Science 9 (1989) 149-157. 
132. McCormack, G., Panozzo, J., Bekes, F. and MacRitchie, F. Contributions to breadmaking of inherent variations in lipid content and composition of wheat cultivars. I. Result of survey. Journal of Cereal Science 13 (1991) 255-261.

133. Graybosch, R., Peterson, C.J., Moore, K.J., Sterns, M. and Grant, D.L. Comparative effects of wheat flour protein, lipid, and pentosan composition in relation to baking and milling quality. Cereal Chemistry 70 (1993) 95-101.

134. Chung, O.K., Pomeranz, Y. Shogren, M.D.and Finney, and K.F. Response to shortening addition and lipid removal in flours that vary in bread-making quality. Cereal Chemistry 57 (1980) 111-117.

135. Gan, Z., Angold, R.E., Williams, M. R., Ellis, P.R., Vaughan, J.G. and Galliard, T. The microstructure and gas retention of bread dough. Journal of Cereal Science 12 (1990) 15-24.

136. Gan, Z., Ellis, P.R. and Schofield, J.D. Gas cell stabilization and gas retention in wheat bread dough. Journal of Cereal Science 21 (1995) 215-230.

137. Carr, N.O., Daniels, W.R. and Frazier, P.J. Lipid interactions in breadmaking. Critical Reviews in Food Sciences and Nutrition 31 (1992) 237-258.

138. McCleary, B. V. Enzymic modification of plant polysaccharides. International Journal of Biological Macromolecules 8 (1986) 433-436.

139. Maat, J., Roza, M,Verbakel, J., Santos da Silva, J.M., Bosse, M., Egmond, M.R., Hagemans, M.L.D.,v. Gorcom, R.F.M., van, Hessing, J.G.M., Hondel, C.A.M.J.J. van de and Rotterdam, C. van. Xylanase and their application in bakery. in 'Xylans and Xylanases', Progress in Biotechnology Series Vol.7, (J.Visser, G. Beldman, M.A.Kusters-van Someren, and A.G.J. Voragen, eds.), Elsevier, Amsterdam (1992) pp349-360.

140. Courtin, C.M., Roelants, A. and Delcour, J.A. Fractionation-reconstitution experiments provide insight into the role of endoxylanases in bread-making. Journal of Agricultural and Food Chemistry 47 (1999) 1870-1877.

141. Hilhorst, R., Dunnewind, B., Orsel, R., Stegeman, P., van Vliet, T., Gruppen, H.and Schols, H.A. Baking performance, rheology, and chemical composition of wheat dough and gluten affected by xylanase and oxidative enzymes. Journal of Food Science 64 (1999) 808-813.

142. Gruppen, H., Kormelink, F.J.M. and Voragen, A.G. J. Enzymic degradation of water-unextractable cell wall material and arabinoxylans from wheat flour. Journal of Cereal Science 18 (1993) 129-143.

143. Hamer, R.J. and Lichtendonk, W.J. In ' Proceedings of the $3^{\text {nd }}$ international 
workshop on gluten proteins'. (eds, R. Lasztity, F. Bekesz ) Budapest, Hungary. (1987) pp227.

144. Weegels, P.L., de Jager, A.M., Voorpostel, A.M.B. and Harte, M. In ' Advances in Dutch Agrobiotechnology. PUDOC. Wageningen.

145. Chamberlain, N., Collins, T.H. and Mc Dermott, Alpha-amylase and bread properties. Journal of Food Technology 16 (1981) 127-152.

146. Cauvain, S.P. and Chamberlain, N. The bread improving effect of fungal $\alpha$-amylase. Journal of Cereal Science 8 (1988) 239-248.

147. Hamer, R.J. Enzymes in the baking industry. In 'Enzymes in Food Processing. (eds.G.A.Tucker and L.F.J. Woods ) Blackie, Glasgow and London. (1991) 168-193.

148. Collins, T.H. In ' The Master Baker's Book of Breadmaking' (ed. J. Brown). Turret, Press, London. (1982) pp1-46.

149. Silberstein, O. Heat-stable bacterial $\alpha$-amylase in baking applications to white bread. Bakers Digest 38 (1964) 66-72.

150. Martin, M. L. and Hoseney, R.C. A mechanism of bread firming. II. Role of starch hydrolyzing enzymes. Cereal Chemistry 68 (1991) 503-507.

151. Barret, F.F. In 'Enzymes in Food Processing' $2^{\text {nd }}$ ed. (ed. G. Reed) Academic Press, New York. (1975) pp301.

152. Kruger, J.E. and Lineback, D.R. In 'Enzymes and their role in Cereal Technology'. (eds. J.E. Kruger, D. R. Lineback and C.E. Stauffer) American Association Cereal Chemists, Inc. St. Paul, Minnesota, USA. (1987) pp 117.

153. Drapron, R. and Gordon, B. Roles of enzymes in baking. In 'Enzymes and their Roles in Cereal Technology'. (eds. J.E. Kruger, D. R. Lineback and C.E. Stauffer) American Association Cereal Chemists Inc. St. Paul, Minnesota, USA. (1987) pp 281-324.

154. Oka, S., Babel, F.J. and Draudt, H.N. Proteolytic action of Pepsin on glutenin. Journal of Food Science 30 (1965) 212-217.

155. Redman, D.G. Softening of gluten by wheat protease. Journal of the Science and Food and Agriculture 22 (1971) 75-78.

156. Weegels, P.L. and Hamer, R.J. Predicting the baking quality of gluten. Cereal Foods World 34 (1989) 210-212.

157. Bushuk, W. Interactions in wheat doughs. In ' Interactions: The keys to Cereal Quality'. (eds. R.J. Hamer and R.C. Hoseney). American Association Cereal Chemists, Inc. St. Paul, Minnesota, USA. (1998) pp 1-16.

158. Kilborn, R.H. and Tipples, K.H. Factors affecting mechanical dough development. 
I.Effect of mixing intensity and work input. Cereal Chemistry 49 (1972) 34-47.

159. Dreese, P.C., Faubion, J.M. and Hoseney, R.C. Dynamic rheological properties of flour, gluten and gluten-starch doughs. II. Effect of various processing and ingredients changes. Cereal Chemistry 65 (1988) 354-359.

160. Mani, K., Tragardh, C. Eliasson, A.C. and Lindahl, L. Water content, water soluble fraction, and mixing affect fundamental rheological properties of wheat flour doughs. Journal of Food Science 57 (1992) 1198-1200,1209.

161. Rasper, V.F. and Preston, K.P. The extensigraph Handbook. American Association Cereal Chemists, Inc. St. Paul, Minnesota, USA. (1991).

162. Edwards, N.M., Dexter, J.E., Scanlon, M.G. and Cenkowaki, S. Relationship of creep-recovery and dynamic oscillatory measurements to durum wheat physical dough properties. Cereal Chemistry 76 (1999) 638-645.

163. Daano, G. and Hoseney, R.C. Effect of dough mixing and rheologically active compounds on relative viscosity of wheat proteins. Cereal Chemistry 53 (1982) 196-198.

164. Tanaka, K. and Bushuk, W. Changes in flour proteins during dough-mixing. I. Solubility results. Cereal Chemistry 50 (1973) 590-596.

165. Bushuk, W. Distribution of water in dough and bread. Baker's Digest 40 (1966) 38-40.

166. Web, T., Heaps, P.W., Russell Eggitt, P.W. and Coppock, J.B.M. A rheological investigation of the water in wheat flour doughs. Journal of Food Technology 5 (1970) 65-76.

167. Larsen, N.G. and Greenwood, D.R. Water addition and the physical properties of mechanical dough development doughs and breads. Journal of Cereal Science $\mathbf{1 3}$ (1991) 195-205.

168. Dreese, P.C., Faubion, J.M. and Hoseney, R.C. Dynamic rheological properties of flour, gluten and gluten-starch doughs. II. Effect of various processing and ingredient changes. Cereal Chemistry 65 (1988) 354-359.

169. Edwards, N.M., Scanlon, M.G., Kruger, J.E. and Dexter, J.E. Oriental noodle dough rheology: Relationship to water absorption, formulation and work input during dough sheeting. Cereal Chemistry 73 (1996) 708-711.

170. Jean, M.F. Damidaux, R. and Feillet, P. Effect of heat treatment on protein solubility and viscoelastic properties of wheat gluten. Cereal Chemistry 57 (1980) 325-331.

171. Schofield, J.D. Bottomley, R.C., Timms, M.F. and Booth, M.R. The effect of heat 
on wheat gluten and the involvement of sulphydryl-disulphide interchange reactions. Journal of Cereal Science 1 (1983) 241-253.

172. Attenburrow, G., Barnes, D.J., Davies, A.P. and Ingman, S.J. Rheological properties of wheat gluten. Journal of Cereal Science 12 (1990) 1-14.

173. Weegels, P.L., Verhoek, J.A, de Groot, A.M.G. and Hamer, R.J. Effects on gluten of heating at different moisture contents. I. Changes in functional properties.

Journal of Cereal Science 19 (1994): 31-38. 


\title{
2
}

\section{Effect of water unextractable solids on gluten formation and properties: Mechanistic considerations}

\begin{abstract}
A miniaturised set-up for gluten-starch separation was used to systematically study the effect of water unextractable solids (WUS) on the formation and properties of gluten. The results showed that WUS not only have a negative effect on gluten yield, but also affect gluten and glutenin macropolymer (GMP) composition and rheological properties. The negative effect of WUS on gluten yield could be compensated for to a large extent, but not completely, by increasing mixing time and mixing water. Adding xylanase can effectively counteract the effect of WUS. On the basis of these results we hypothesize that WUS interfere with gluten formation in both a direct and an indirect way. WUS interfere indirectly by competing for water and thus changing conditions for gluten development. This effect can be corrected for by the combination of adding more $0.2 \% \mathrm{NaCl}$ solution during dough mixing and a longer mixing time. The particulate nature of WUS requires that the direct effect occurs through an interaction between WUS particles and gluten particles. Both effects of WUS can be counteracted through the use of xylanase.
\end{abstract}

Wang, M-W, Hamer, R.J., van Vliet, T., Gruppen, H., Marseille, J.P. and Weegels, P.L. Journal of Cereal Science 37 (2003) 55-64. 


\subsection{Introduction}

Gluten plays a pivotal role in determining the end-use quality of wheat in many food products ${ }^{1}$. The properties of this polymeric network are strongly affected by wheat flour composition (protein, starch and pentosans etc.), ingredients (i.e. salt, fat), processing aids (i.e. enzymes) and process parameters (mixing time/ work input, mixing water, temperature). Changes in the quantity and properties of gluten reflect changes in dough rheological properties and hence quality of the original flour and the final product ${ }^{2}$. Unraveling the underlying relationships and understanding gluten formation is therefore of extreme importance. Most of the studies regarding gluten formation are related to reduction or oxidation conditions and processing. On the other hand, there is substantial evidence that non-starch polysaccharides like water unextractable solids (WUS) are also important.

WUS, consisting to a large extent of pentosans, are reported to have a strong, negative effect on bread-making quality ${ }^{3,4,5}$. It is for this reason that pentosan modifying enzymes are now widely used in bread-making ${ }^{6}$. It is also known that the contents of WUS in wheat flour increase with increasing milling extraction. The wheat starch industry usually uses wheat flour of high extraction rate. Weegels and coworkers ${ }^{7}$ using a pilot scale gluten-starch separation system could monitor effects of WUS, soluble pentosans (hereafter called WEP) and pentosan-modifying enzymes on the aggregation of small dispersed protein particles to gluten. The findings of Weegels and coworkers indicate that WUS and WEP significantly influence gluten formation. This is corroborated by the work of Roels et $\mathrm{al}^{8}$. This phenomenon is also relevant in breadmaking. Many papers have appeared describing beneficial effects of pentosan modifying enzymes on dough properties and final product quality ${ }^{9}$. However, little is known about the underlying mechanism of WUS or pentosan modifying enzymes on gluten formation and properties.

Several theories exist to explain the effect of pentosans and pentosan modifying enzymes, based either on an indirect or on a direct effect of pentosans. Pentosans can indirectly effect gluten formation by competing for water. Pentosan modifying enzymes can then act by reducing the water binding capacity of pentosans thus inducing water redistribution ${ }^{10}$. Another indirect effect of pentosans (soluble and insoluble) could be caused by their ability to form a network limiting the movement of glutenin proteins towards a larger aggregate. The beneficial action of pentosanase would then be exerted by breakdown of this pentosan network ${ }^{3}$. A direct effect of pentosans envisages pentosans to become covalently linked or associated to glutenin proteins, thus hindering further formation of gluten protein. Pentosan modifying enzymes would then act by cleaving 
gluten associated pentosans. However, recently Labat ${ }^{11}$ et al reported that no covalent complex between arabinoxylan (AX) and protein could be detected in mixed and oxidised gluten/WEP. On the other hand, Oudgenoeg ${ }^{12}$ et al presented positive evidence for a ferulic acid (FA) mediated AX-protein cross-linking reaction. In all, the mechanistic action of WUS in relation to gluten formation is far from clear and deserves further detailed study.

Several authors have shown a clear quantitative correlation between GMP-gel quantity, GMP rheological properties, dough properties and bread loaf volume ${ }^{13,14}$. Weegels et al ${ }^{13}$ reported that GMP content of dough after 45 min rest was rather well related to $\mathrm{R}_{\max }$; whereas the GMP contents of flour was better related to extensibility and loaf volume. Recently, Bekkers et al ${ }^{14}$ reported a very high and positive correlation between the storage modulus (G') of GMP and dough development time. Therefore, we also studied the properties of GMP isolated from the gluten formed in the absence and presence of WUS and xylanase.

In this chapter we report the use of a miniaturised technique to study gluten formation. We used this technique to study the effects of WUS, a xylanase, and processing conditions on gluten yield, properties and composition of gluten. Also, GMP was isolated from the gluten and characterised in terms of its wet weight, protein content and rheological properties. Using these results, a possible mechanism regarding the effect of WUS and xylanase on gluten formation and properties will be discussed.

\subsection{Experimental}

\subsubsection{Materials}

MM Wheat flour (untreated, 9.4\% protein, $0.7 \%$ WUS and $0.61 \%$ ash) was kindly donated by Meneba Meel, Rotterdam. The Soissons flour used for isolation of GMP was supplied by TNO, Zeist, the Netherlands.

Xylanase I (batch ppj 4482) was a gift by NOVO Nordisk. The activities of xylanase, protease and amylase (mean \pm S.D.) are $88.3 \pm 0.2 \mathrm{U} / \mathrm{mg}$ enzyme, $5.9 \pm 0.1 \mathrm{U} / \mathrm{mg}$ enzyme and $4.7 \pm 0.1 \mathrm{U} / \mathrm{g}$ enzyme respectively.

Porcine $\alpha$-amylase was purchased from Merck art. The activity is $400 \mathrm{U} / \mathrm{mg}$ enzyme.

All other chemicals used were of analytical grade or better.

\subsubsection{Isolation of WUS}

WUS were isolated according to the method of Gruppen et al ${ }^{15}$ with the following 
modifications: Distilled water $(300 \mathrm{~mL})$ and sodium chloride $(10 \mathrm{~g})$ were added to wheat flour (500 g). The mixture was kneaded into dough in a Hobart mixer (Model N-50G) at setting 1 for $1 \mathrm{~min}$ and setting 2 for $4.5 \mathrm{~min}$. The dough was hand washed under running tap water. The gluten was rejected and the slurry was sieved $(32 \mu \mathrm{m})$. The overs fraction was sieved again under rinsing with distilled water. The throughs fraction was discarded. Half of the overs were freeze-dried [hereafter called WUS (-)]. Another half was suspended in buffer $(0.8 \mathrm{~L}$, pH 6.5) containing $10 \mathrm{mM}$ sodium maleate, $10 \mathrm{mM}$ sodium chloride, $1 \mathrm{mM}$ calcium chloride and $0.05 \%(\mathrm{w} / \mathrm{v})$ sodium azide. The suspension was heated at $63^{\circ} \mathrm{C}$ for $1 \mathrm{~h}$. After cooling to $30^{\circ} \mathrm{C}$, $\alpha$-amylase (50 Units per g of residue) was added and the mixture was incubated for $16 \mathrm{~h}$ at $30^{\circ} \mathrm{C}$. The reaction mixture was then centrifuged for $30 \mathrm{~min}$ at $18,900 \times \mathrm{g}$. The $\alpha$-amylase incubation was carried out twice. The residue after centrifugation was washed for $1 \mathrm{~h}$ at $63^{\circ} \mathrm{C}$ with distilled water $(1 \mathrm{~L})$ and centrifuged $(30 \mathrm{~min}, 18,900 \times \mathrm{g})$. This step was repeated two times. The remaining residues were resuspended in a small volume of water and freeze-dried [hereafter called WUS (+)]. The dried WUS materials were ground to $200 \mu \mathrm{m}$ before use.

\subsubsection{Characterisation of WUS preparations}

\subsubsection{Water holding capacity}

The water holding capacity of WUS preparations was determined by the method of Robertson and Eastwood ${ }^{16}$ by measuring the wet weight $(\mathrm{g})$ of the final residue after washing.

\subsubsection{Botanical composition}

The botanical composition of WUS preparations was studied by light microscopy.

\subsubsection{Gluten yield experiments}

The gluten yield of dough was measured using a modified Glutomatic 2200 system (Perten, modified by TNO, in short the TNO Glutomatic). The system was fitted with a custom built pin mixer head, thermostatted at $30^{\circ} \mathrm{C}$ (see Fig.2.1). Flour $(12 \mathrm{~g} \pm 0.03 \mathrm{~g}$ ) and 6.5-8.5 mL 0.2\% (w/v) sodium chloride solution (hereafter called mixing water) was mixed for 3-6 min (hereafter called mixing time) to make dough. This dough was diluted to a slurry with a total of $25 \mathrm{~mL} 0.2 \%(\mathrm{w} / \mathrm{v}$ ) sodium chloride solution for $5 \mathrm{~min}$ at a flow rate of $5 \mathrm{~mL}$ per min. Then the slurry was transferred into the washing chamber which was equipped with two sieves (top $400 \mu \mathrm{m}$ for separating, bottom $800 \mu \mathrm{m}$ for supporting) and 
rinsed with distilled water for $5 \mathrm{~min}$ at a flow rate of $56 \mathrm{~mL}$ per min. Finally, the separated wet gluten was collected and dried using a drying oven (Perten) for $5 \mathrm{~min}$. Gluten yield was calculated from the weight of the dried gluten and the weight of the flour used.

\subsubsection{Kieffer extensibility test}

Gluten samples were characterised using a miniature extensibility rig according to Kieffer et al ${ }^{17}$ as follows:

Wet gluten samples (10 g), prepared as above and combined, were placed in a Teflon mould to produce at least 8 test pieces [dimensions: $50 \mathrm{~mm}$ long, $4 \mathrm{~mm}$ high, base $3 \mathrm{~mm}$, top $5 \mathrm{~mm}$ ]. The whole mould was placed in a chamber at $30^{\circ} \mathrm{C}$ and $70 \%(\mathrm{RH})$ for $1 \mathrm{~h}$ to allow stress relaxation. This assures a good reproducibility of the results. The extension test of a strip of gluten was performed using the Kieffer extensibility rig fitted onto a Texture Analyser equipped with a $5 \mathrm{~kg}$ load cell. For each kind of gluten sample, eight measurements were performed. After testing, the gluten strips were freeze-dried and used for further chemical analysis.

\subsubsection{Analytical methods}

\subsubsection{Protein content}

Protein content $(\mathrm{N} \times 5.7)$ of flour and gluten samples was determined by the Dumas method ${ }^{18}$ using an NA2100 Nitrogen and Protein Analyser (CE INSTRUMENTS). Casein is used as a standard.

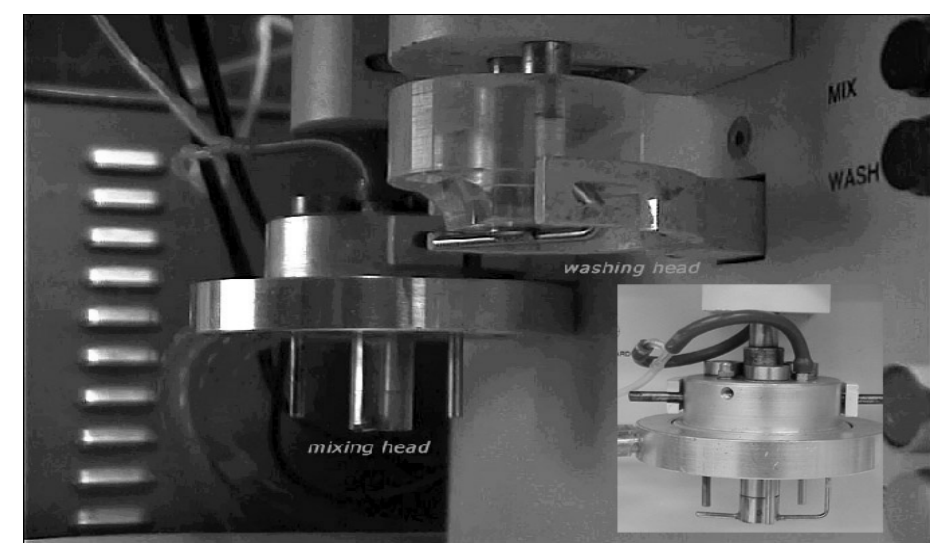

Figure 2.1. The TNO Glutomatic

The original mixing heads of the Glutomatic are modified. On the left a custom made pin mixer head is mounted, the right mixer is used with a washing chamber. Insert: detail of the custom made 4 pin mixing head, which is temperature controlled and allows continuous addition of diluting water. 


\subsubsection{Starch content}

Starch content of WUS preparations and gluten samples was determined enzymatically using the test kit supplied by Boehringer, Mannheim.

\subsubsection{Neutral sugar content}

Neutral sugar content of WUS preparations and gluten samples was analysed using the alditol acetate method with inositol as internal standard ${ }^{19}$. Samples were pretreated with $72 \%(\mathrm{w} / \mathrm{w})$ sulphuric acid for $1 \mathrm{~h}$ at $30^{\circ} \mathrm{C}$ prior to further hydrolysis with $1 \mathrm{M}$ sulphuric acid for $3 \mathrm{~h}$ at $100{ }^{\circ} \mathrm{C}$. Neutral sugars in samples were released and analysed as their alditol acetates. Alditol acetates were separated on a $15 \mathrm{~m} \times 0.53 \mathrm{~mm}$ i.d. column (DB-225) in a Carlo Erba 5160 Gas chromatograph operated at $200^{\circ} \mathrm{C}$ and equipped with a F.I.D. detector set at $250^{\circ} \mathrm{C}$.

\subsubsection{GMP isolation}

\subsubsection{Gluten defatting}

Freeze-dried gluten sample ( $3 \mathrm{~g}$ ) was dispersed in $75 \mathrm{~mL}$ petroleum ether, mixed for $20 \mathrm{~min}$ and centrifuged $\left(18,900 \times \mathrm{g}, 10 \mathrm{~min}\right.$ at $\left.5^{\circ} \mathrm{C}\right)$. The whole procedure was repeated. Petroleum ether residues in the defatted gluten sample were evaporated for overnight in a fume hood.

\subsubsection{GMP isolation}

Defatted gluten sample (80 mg) was dispersed in $10 \mathrm{~mL} \mathrm{1.5 \% (w/v)} \mathrm{SDS} \mathrm{solution} \mathrm{and}$ ultracentrifuged $\left(69,000 \times \mathrm{g}, 30 \mathrm{~min}\right.$ at $\left.20^{\circ} \mathrm{C}\right)$. The supernatant was discarded and the gel-like layer found on top of the starch pellet (called GMP) was weighed as GMP wet weight.

\subsubsection{Protein content of GMP}

The protein content of GMP gel was determined using the Dumas method ${ }^{18}$ after drying GMP gel at $80^{\circ} \mathrm{C}$ for $2 \mathrm{~h}$.

\subsubsection{Rheometer measurement}

Fresh GMP gel $(1 \mathrm{~g})$ was carefully taken from the isolated gel layer and put onto a plate (30 mm diameter) of a Bohlin VOR rheometer (Bohlin, Sweden). The stiffness of the 
GMP-gels was measured in a frequency sweep and strain sweep experiment at $20^{\circ} \mathrm{C}$ using a plate-plate geometry, a gap of $1 \mathrm{~mm}$, and a $0.315 \mathrm{gcm}$ torsion bar. Frequency sweep measurements were performed over a range from 0.05 until $5 \mathrm{HZ}$ at a strain of 0.02 . During the strain sweep measurements, strain was increased from 0.0022 to 0.222 at a frequency of $0.15 \mathrm{HZ}$.

\subsubsection{Characterisation of xylanase}

\subsubsection{Xylanase activity}

Xylanase activity was measured using xylan from oat spelts (Sigma, No.X-0376) as a substrate. One unit was defined as $1 \mu \mathrm{mol}$ reducing sugars formed in 1 minute under standard conditions $\left(\mathrm{pH} 5,30^{\circ} \mathrm{C}\right)$ per mg enzyme ${ }^{20}$.

\subsubsection{Protease activity}

Protease activity was determined with azocasein as a substrate. One unit of protease was arbitrarily defined as a change in absorbance at $440 \mathrm{~nm}$ of 0.01 after $2 \mathrm{~h}$ at $\mathrm{pH} 6$ and $35^{\circ} \mathrm{C}^{21}$.

\subsubsection{Amylase activity}

Amylase activity was tested with the dye-labelled substrate ( $p$-nitrophenyl D-maltoheptaoside) supplied by Megazyme (prod nr R-AMHR2).

\subsubsection{Free alpha amino nitrogen}

Free alpha amino nitrogen was determined using a ninhydrin method ${ }^{22}$. Flour, lyophilized dough and gluten $(100 \mathrm{mg})$ were suspended in $1 \mathrm{ml} 1.5 \%(\mathrm{w} / \mathrm{v})$ SDS solution, vortex mix for $1 \mathrm{~min}$, extracted for 30min at room temperature and centrifuged for $5 \mathrm{~min}$. The supernatants can be used for this test.

\subsubsection{Protein content}

Protein content of SDS extracted sample solution was measured by using Lowry protein assay $^{23}$.

\subsubsection{Statistical analysis}

Statistical analysis was made using the statistical software SPSS 8.0 for windows 
(SPSS Inc.). An ANOVA test was performed and followed by multiple comparison tests. The means was compared against the control.

\subsection{Results and discussion}

\subsubsection{Characterisation of WUS preparations}

\subsubsection{Chemical composition of WUS preparations}

Two WUS preparations were isolated. WUS (-) and WUS (+) differing in the extent of starch removal. These fractions represent WUS $>32 \mu \mathrm{m}$. Based on the yield, we estimated the content of isolated WUS (-) and WUS (+) as a percent of flour to be $0.60 \pm$ $0.05 \%$ (mean \pm S.D.) and $0.30 \pm 0.03 \%$ respectively. WUS $(+)$ are the starch free preparation and obtained from WUS (-) by $\alpha$-amylase treatment and additional washing/freeze drying. The AX content of WUS (-) and WUS (+) are 44\% \pm 0.4 and $73 \%$ \pm 0.6 respectively, the protein content of WUS (-) and WUS (+) are $19.1 \pm 1.9 \%$ and 10.0 $\pm 0.6 \%$ respectively, and the starch content of WUS (-) and WUS (+) are $26.4 \% \pm 0.12$ and $1.5 \% \pm 0.04$ respectively, indicating the successful removal of starch.

\subsubsection{Water holding capacity}

Water holding capacities of WUS (-) and WUS (+) are $7.6 \mathrm{~g} / \mathrm{g} \pm 0.1$ and $10.7 \mathrm{~g} / \mathrm{g} \pm 0.1$ respectively. These data are in agreement with literature of Patil et al ${ }^{24}$.

\subsubsection{The botanical composition}

The heterogeneous nature of WUS was demonstrated using light microscopy. Fig. 2.2 revealed various botanical components of the wheat kernel (endosperm cell walls, pericarp fragments, aleurone fragments and brush hairs) present in WUS. It was also demonstrated by wet sieving that the isolated WUS quantitatively passed the $400 \mu \mathrm{m}$ sieve used in the TNO Glutomatic system.

\subsubsection{Effect of WUS on gluten yield}

\subsubsection{Performance of the TNO Glutomatic system}

The TNO Glutomatic system is optimised to give maximal sensitivity towards gluten yield. In contrast to the Perten Gluten washing system, the system is not set up to give a maximal yield of gluten from the flour, but to study the amount of gluten formed under sub-optimal conditions. When the slurry is poured in the washing/sieving chamber, only 
gluten particles that have developed to macroscopic gluten remain on top of the sieve. Undeveloped or 'under'developed gluten particles pass into the 'throughs' fraction together with the starch. This allows us to study the rate dependent gluten coagulation, as reported earlier for a $5 \mathrm{~kg}$ pilot scale system ${ }^{7}$. A typical experiment uses $12 \mathrm{~g}$ flour and separates it in ca 13 min into ca 0.7 gram (dry weight) gluten and $280 \mathrm{~mL}$ starch milk. For one flour, variation in gluten yield between separate runs was ca $5 \%$ within a day and ca $8 \%$ between different days. All experiments were typically carried out in triplicate on one day and repeated on a separate day.

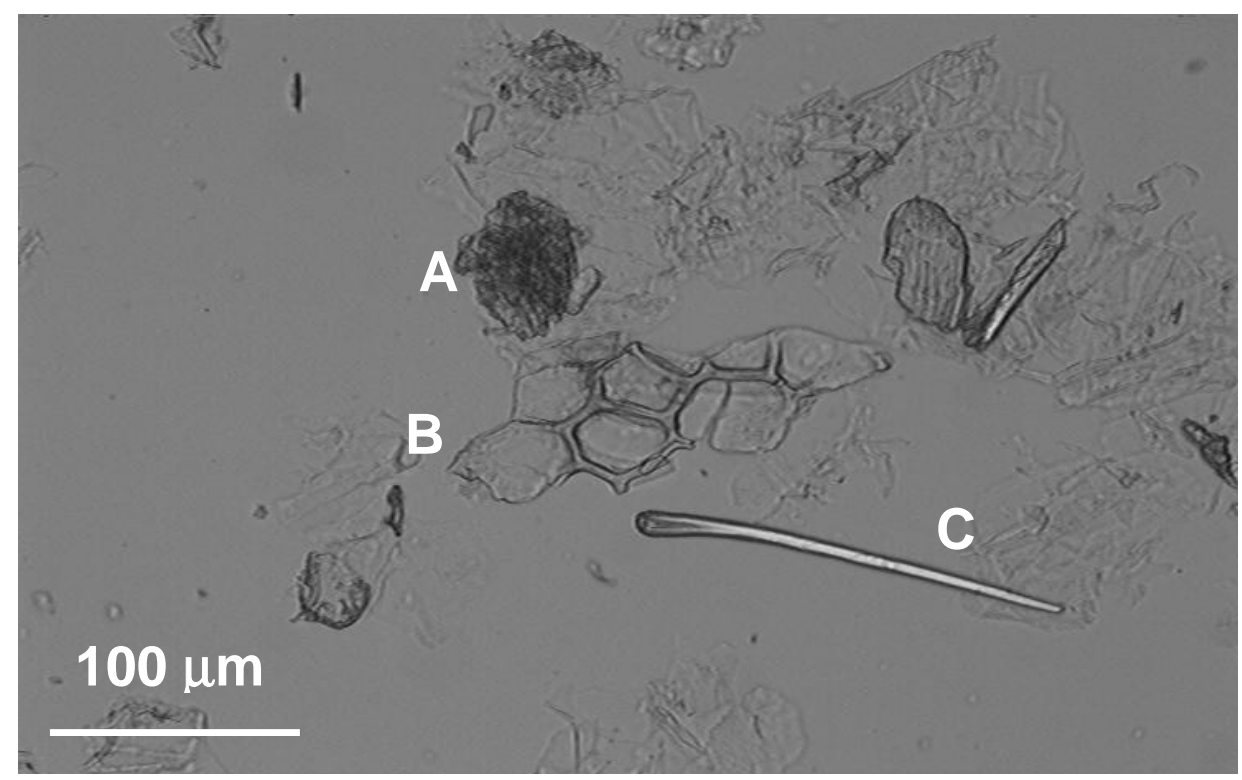

Figure 2.2. The botanical composition of WUS

$\mathrm{A}=$ pericarp and aleurone fragments, $\mathrm{B}=$ endosperm cell walls, $\mathrm{C}=$ brush hairs.

\subsubsection{Effect of amount and type of WUS on gluten yield}

WUS (-) were added to flour at three levels, $1 \%, 2 \%$ and $4 \%$ (by weight) and mixed with the flour for 1 min using the mixing head of the Glutomatic to obtain a homogeneous powder for the gluten yield experiments. In all cases a decrease in gluten yield was observed. A decrease of ca $20 \%$ was obtained at $2 \%$ WUS (-) addition (see Fig. 2.3). The effects of the two types of WUS preparations [WUS (-) and WUS (+)] on gluten yield were also tested. No significant differences were observed. Therefore, in our experiments, the WUS (-) preparation was used.

\subsubsection{Compensation by increasing mixing time and increasing mixing water}

Addition of WUS can affect the availability of water for gluten development. Adding 
water to correct for this effect also influences dough mixing. Therefore, both the effect of a higher water addition and increasing mixing time on gluten formation were studied.

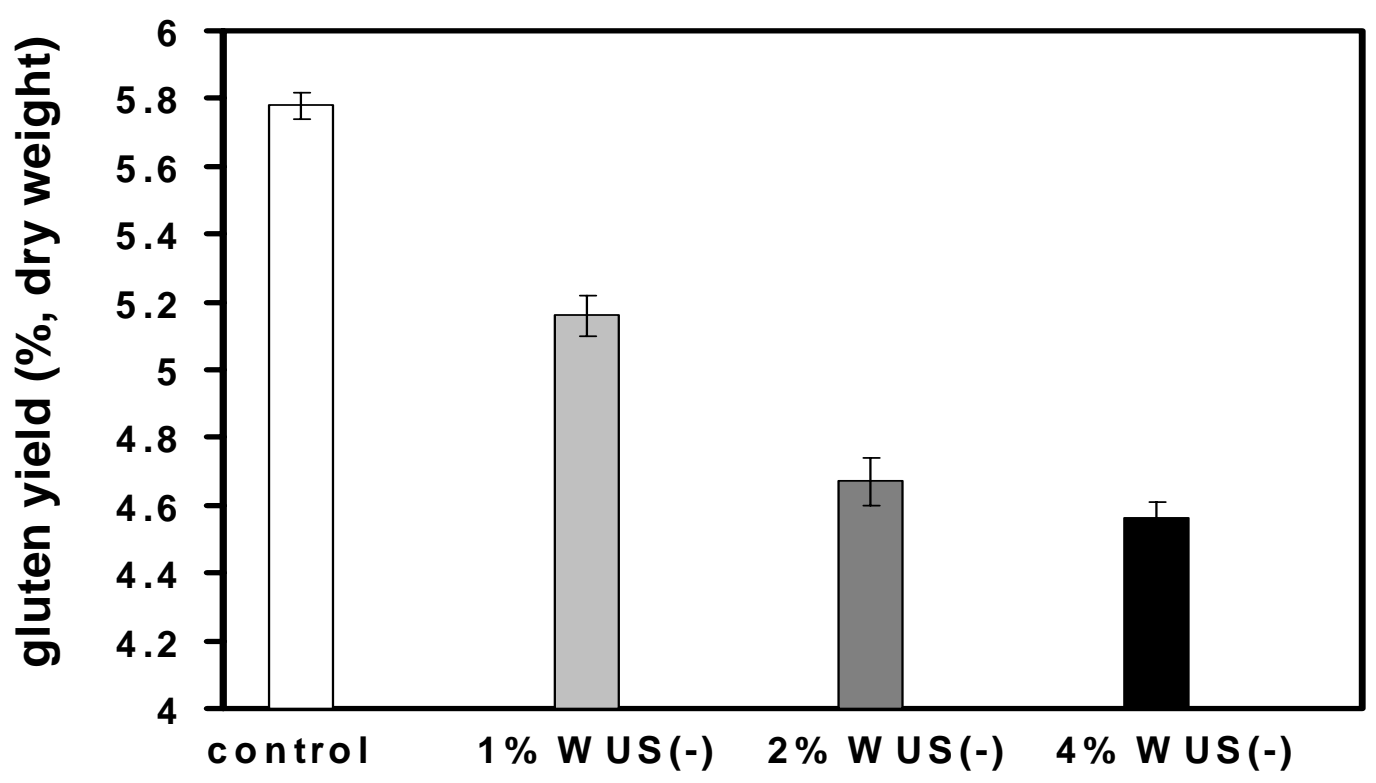

Figure 2.3. Effect of WUS amount on gluten yield Control: 3 min mixing, $7.7 \mathrm{~mL}$ water.

The results, shown in Fig. 2.4 and Fig. 2.5, demonstrated the important effects of varying mixing time and mixing water. The effect of WUS on gluten yield was maximal at 3 min mixing time and $7.7 \mathrm{~mL}$ mixing water. WUS addition led to an increase in optimal mixing water required. The negative effect of WUS on gluten yield could be corrected to ca $92 \%$ of control ( $5 \mathrm{~min} \operatorname{mix}, 7.7 \mathrm{~mL}$ water) by increasing mixing time (from 3 min to 5 min) and mixing water (from $7.7 \mathrm{~mL}$ to $8.2 \mathrm{~mL}$ ) (see Fig. 2.6).

\subsubsection{Correction by xylanase}

Adding xylanase to the control flour decreased the optimum amount of mixing water (optimal for gluten yield) to $6.45 \mathrm{~mL}$ and at this condition yielded more gluten $(8.1 \% \mathrm{vs}$ $5.5 \%$ for the control at optimum mixing water, see Fig. 2.7). From the data in Table 2.1 it becomes clear that xylanase also more than corrects for the loss of yield when the flour contains $2 \%$ added WUS ( $112 \%$ of control). This may be due to that xylanase releases some water and this extra water compensate for the high water holding of WUS. The increased gluten yield obtained with xylanase was typically accompanied by an increase in the starch content of gluten. 


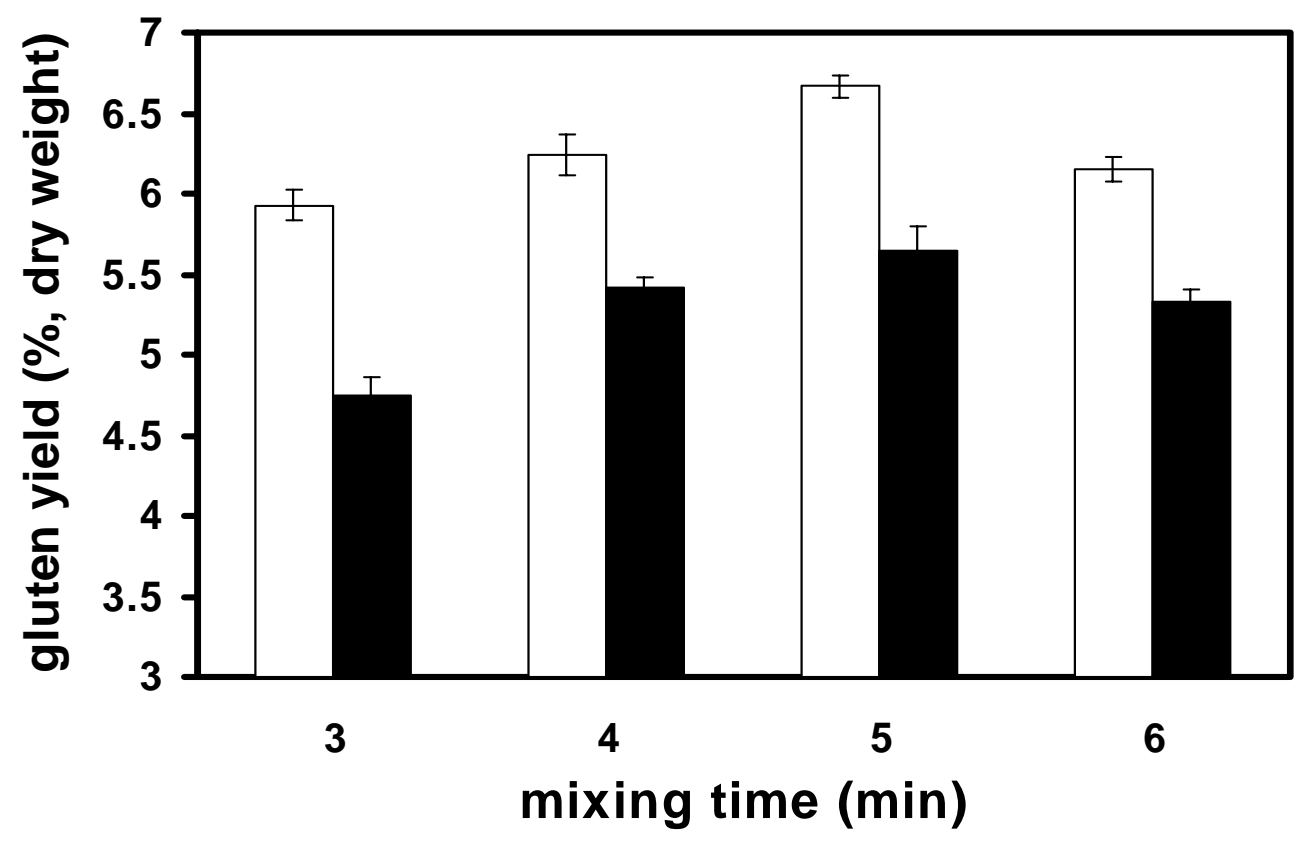

Figure 2.4. Effect of mixing time on gluten yield

White column: control, black column: 2\%WUS, Mixing water: $7.7 \mathrm{~mL}$.

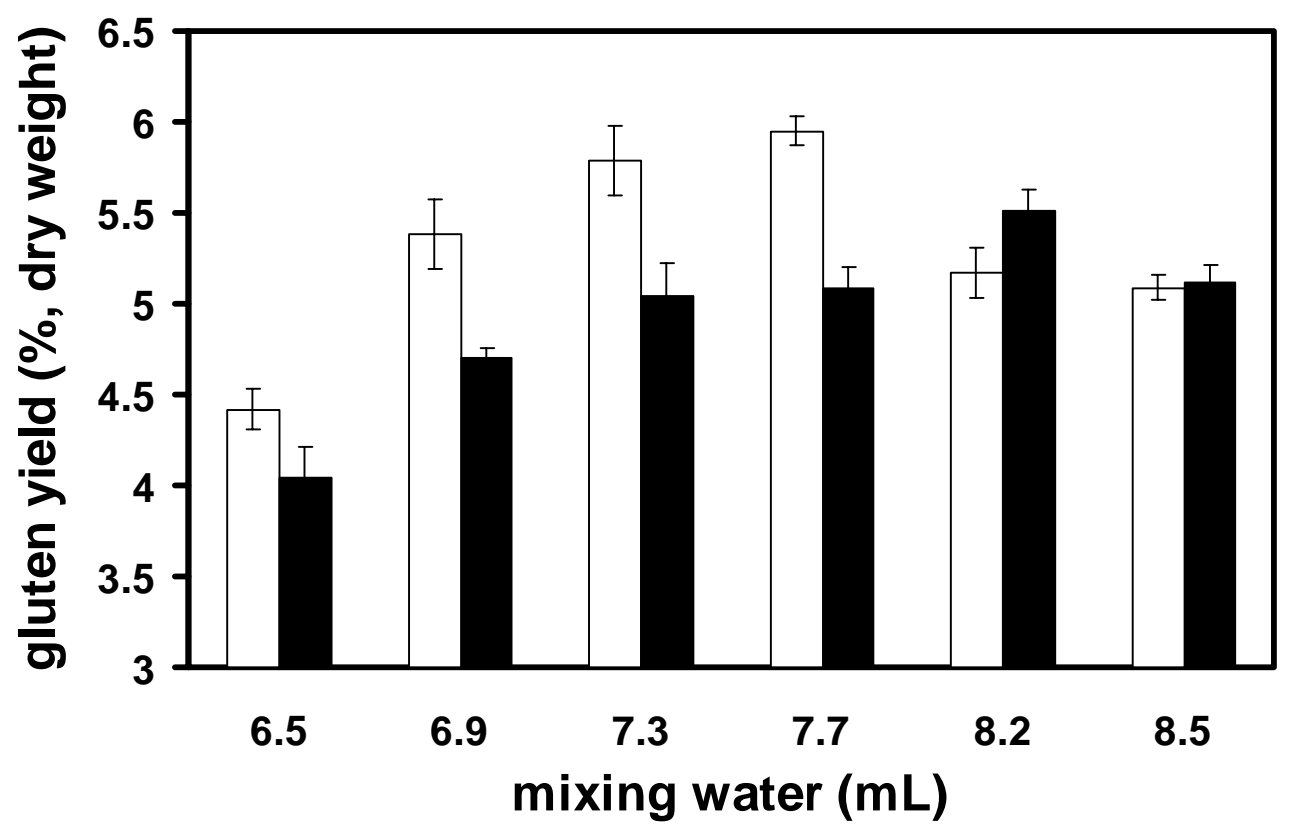

Figure 2.5 Effect of mixing water on gluten yield

White column: control, black column: 2\%WUS, Mixing time: 3 min. 


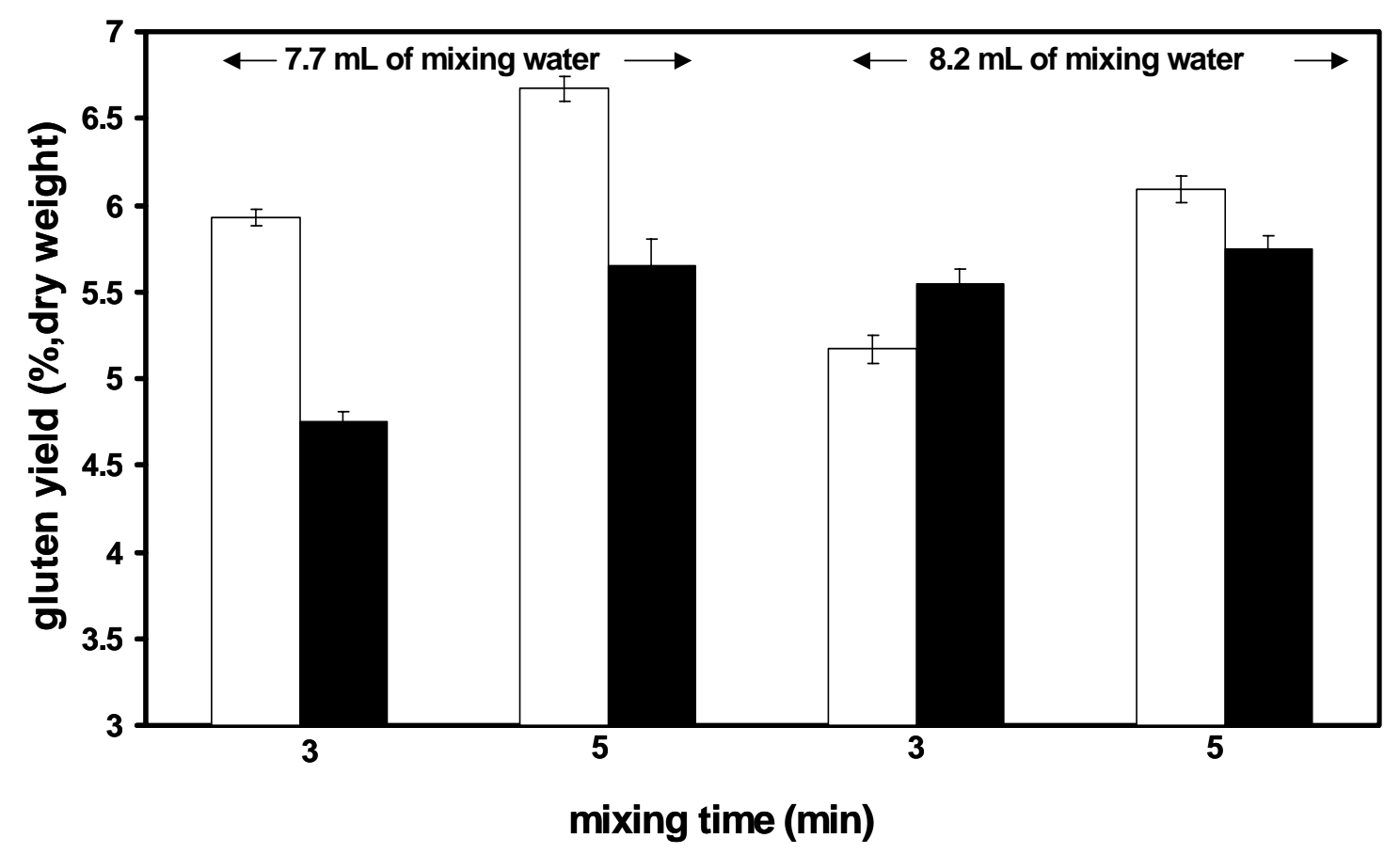

Figure 2.6. Compensating for the effect of WUS by increasing mixing time and mixing water

White column: control, black column: $2 \%$ WUS.

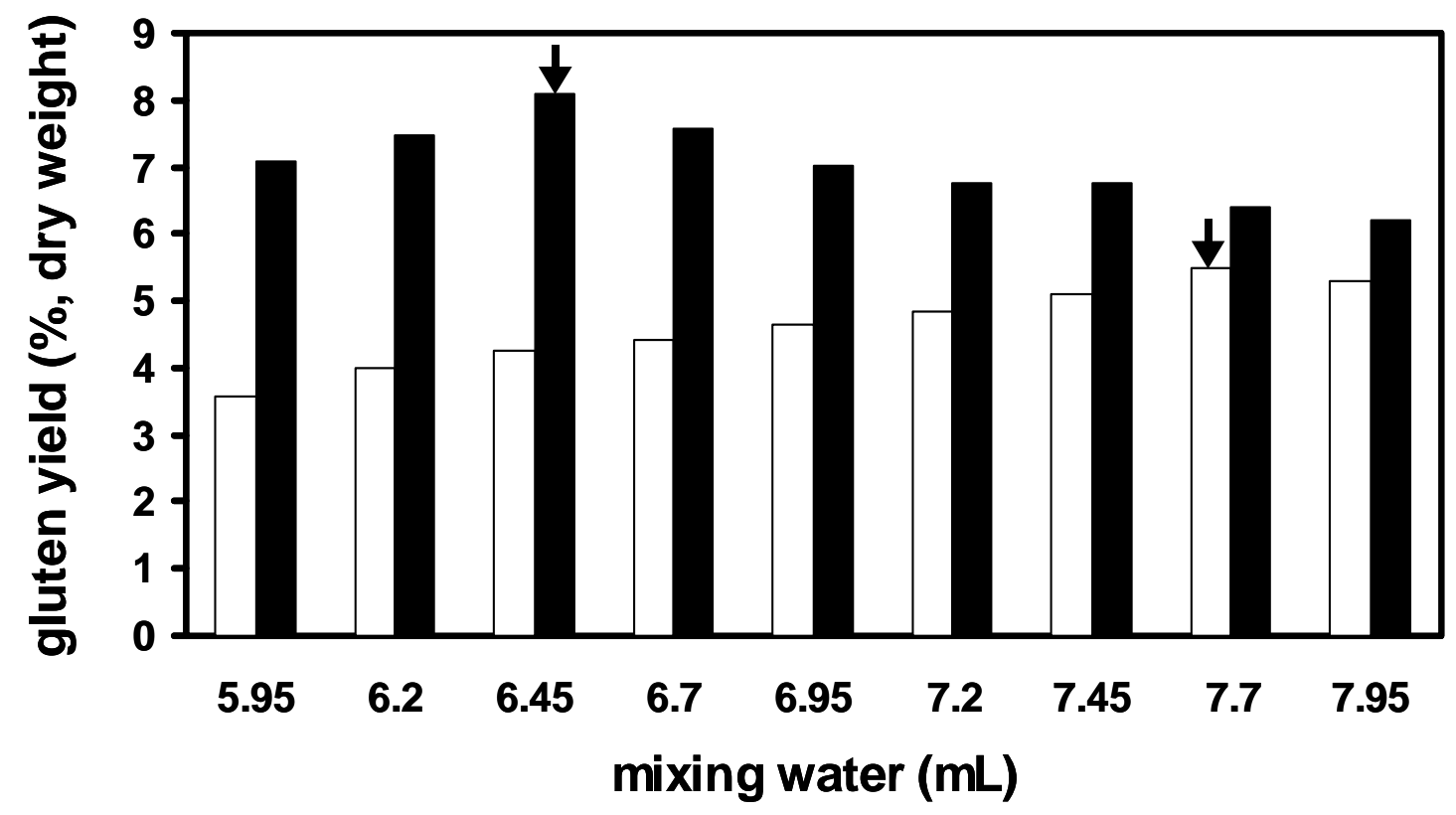

Figure 2.7 Effect of mixing water on gluten yield with addition of xylanase

White column: control, black column: 100ppm xylanase,

Mixing time: $3 \mathrm{~min}, \downarrow$ indicates optimal condition. 


\subsubsection{Characterisation of gluten}

\subsubsection{Chemical characterisation---chemical composition}

Gluten samples were analysed for their content of protein, starch and arabinoxylans (AX) to allow a better interpretation of yield and Kieffer extensibility data. Results are presented in Table 2.1.

Addition of WUS led to a significant decrease in protein yield (about $80 \%$ of control). The AX content of gluten is almost the same as the control, indicating that WUS are not preferentially bound to gluten or that even larger WUS particles were formed. Increasing mixing time and mixing water can improve protein yield (up to 97\% of control), but did not completely correct it. Also, increasing mixing time led to a higher starch content of gluten (about $125 \%$ of control). Addition of xylanase resulted in a significant increase in protein yield (about 106\% of control) and a significant decrease in AX yield (about $77 \%$ of control). Adding both WUS and xylanase caused a similar increase in protein yield (about $107 \%$ of control) and also a significant decrease in AX yield (about $85 \%$ of control). Remarkably, this combination resulted in an even higher starch yield (about $375 \%$ of control). Effects of xylanase on gluten and protein yield are in agreement with earlier findings ${ }^{6}$. Effects of xylanase on starch yield have not been reported earlier.

\subsubsection{Physical characterisation -----Kieffer extensibility test}

The rheological properties of gluten samples with five different treatments were studied using the Kieffer extensibility test (see Table 2.1). Three parameters were used to characterise the extensigram: extensibility at break point, extensibility at maximum resistance to extension ( $E$ at $R_{\max }$ ) and maximum resistance to extension $\left(R_{\max }\right)$. Extensibility gives the deformation of the dough before it ruptures. However, the rupture process of the dough piece takes some time and during this time the dough is further extended. Therefore, the measured extensibility at break is determined by the extensibility of the dough and the speed by which the dough piece ruptures. Fracture often starts at or closely after $\mathrm{R}_{\max }$. Therefore, we also take $\mathrm{E}$ at $\mathrm{R}_{\max }$ as a characteristic of the extensibility. The larger extensibility, the further the dough can be extended before it ruptures. $R_{\max }$ is an indicator of the strength of the dough. A higher $\mathrm{R}_{\max }$ implies a stronger dough.

The results demonstrated that addition of WUS typically produced a gluten with a higher $\mathrm{R}_{\max }$ (about $118 \%$ of control) and a significant smaller $\mathrm{E}$ at break (about $80 \%$ of control) or $\mathrm{E}$ at $\mathrm{R}_{\max }$ (about $75 \%$ of control). These results indicate that WUS affect not 
only gluten yield but also gluten properties. No significant difference was found in the chemical compostion of gluten with WUS and without WUS (Table 2.1). Therefore, we assume both gluten samples could have different structures of the protein network, which could explain the rheological differences observed.

Increasing mixing time and mixing water led to a gluten with both higher $\mathrm{R}_{\max }$ and $\mathrm{E}$ at break or $\mathrm{E}$ at $\mathrm{R}_{\max }$ compared to gluten produced from flour with $2 \%$ WUS. The control conditions are those which gave maximum negative effect of WUS on gluten yield and are not optimal for gluten formation. Increasing mixing time and mixing water improved conditions for gluten formation.

Addition of xylanase produced a gluten with lower $\mathrm{R}_{\max }$ (about $82 \%$ of control) and a significant larger $\mathrm{E}$ at break (about $124 \%$ of control) or $\mathrm{E}$ at $\mathrm{R}_{\max }$ (about $127 \%$ of control). Adding both WUS and xylanase resulted in gluten with lower $\mathrm{R}_{\max }$ and much longer $\mathrm{E}$ at break or $\mathrm{E}$ at $\mathrm{R}_{\max }$ compared to gluten produced from flour with $2 \%$ of WUS. The fact that addition of xylanase led to gluten with lower $\mathrm{R}_{\max }$ and a larger $\mathrm{E}$ at $\mathrm{R}_{\max }$ may be due to more starch entrapped in the gluten network. An effect of xylanase on protein network structure cannot be excluded at this point.

\subsubsection{Characterisation of GMP}

Since effect of WUS or xylanase on gluten protein network structure could not be ruled out, we also studied the composition and rheological properties of GMP.

The GMP wet weight for the control, with WUS and with xylanase were $25.9 \pm 0.6$, $22.6 \pm 1.4$ and $29.1 \pm 0.2 \mathrm{~g} / \mathrm{g}$ gluten (mean \pm S.D.) respectively. The result showed that GMP content with WUS was significantly lower than the control. This points at a lower reassembly of GMP, assuming that GMP breaks down during mixing. The GMP content with xylanase was significantly higher than the control. This is a strong indicator for a faster reassembly of GMP.

The protein content of GMP for the control, with WUS and xylanase were 10.0 \pm 0.1 , $13.7 \pm 0.4$ and $11.3 \pm 0.3 \mathrm{mg} / \mathrm{g}$ GMP gel (mean \pm S.D.) respectively. The data demonstrated that more protein was recovered from GMP with WUS in spite of its low GMP wet weight, leading to a more concentrated gel. No significant difference in protein content of GMP with xylanase was observed, however GMP wet weight was higher, indicating a less concentrated gel.

The rheological properties of GMP are shown in Fig.2.8. The storage modulus G', a measure of the stiffness of the gel, is governed by both GMP protein concentration and its structural properties. The G' of the three GMP samples was quite different (see Fig. 2.8a). 


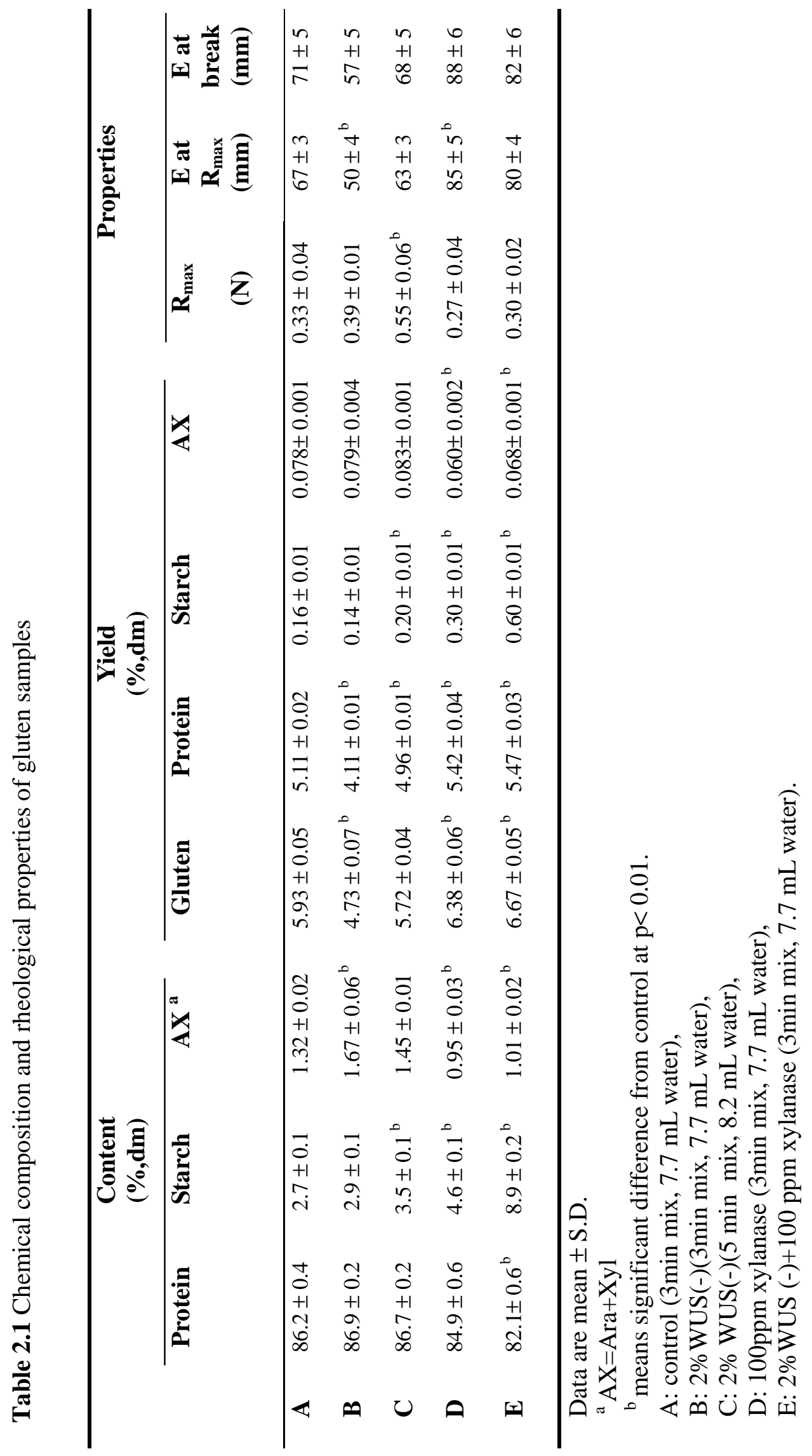


The G' of GMP with WUS was much higher (15 vs 8.9 Pa), indicating a stiffer gel, but the protein concentration was also higher. The G' of GMP with xylanase was much lower (5.9 vs $8.9 \mathrm{~Pa}$ ), indicating a weaker gel, especially since the protein concentration was higher than the control (11.3 vs $10.0 \mathrm{mg} / \mathrm{g}$ GMP). This confirms that there must be structural differences between both gels.
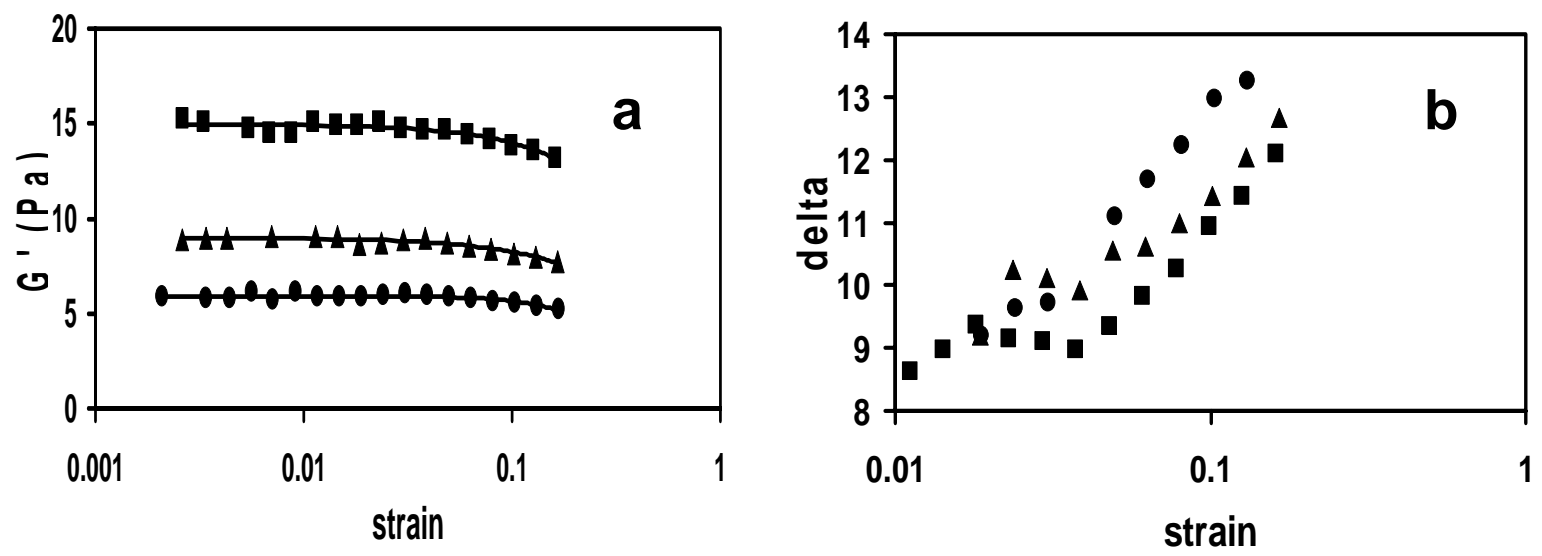

Figure 2.8 Effect of WUS and xylanase on rheological properties of GMP gel

Fig.8a Effect of WUS and xylanase on G'of GMP gel

Fig.8b Effect of WUS and xylanase on delta of GMP gel

\ control, - 2\%WUS, 100 ppm xylanase.

The phase angle delta, obtained from the loss modulus G" divided by storage modulus G', is an indicator of the ratio of viscous to elastic behavior of gel. A low delta implies a more elastic gel structure. The delta of GMP with WUS was lower than the control, indicating a more elastic structure. The delta of GMP with xylanase was significantly higher than the control (outside the linear region, see Fig.2.8b). This also points at a difference in structure between these two gels.

Although our data do not justify hard conclusions to be drawn at this time, the data presented in Fig. 2.8 point at a clear effect of WUS and xylanase on the structure of the protein network generated during gluten formation.

\subsubsection{Characterisation of xylanase preparation}

\subsubsection{Free alpha amino nitrogen and protein content}

The xylanase preparation contained minor protease and amylase activities. We therefore checked the effect of xylanase on protein hydrolysis in various samples. Total protein content, SDS extractable protein and SDS extractable total amino nitrogen of flour, dough, gluten and slurry were tested (see Table 2.2). 
The results show that the presence of xylanase did not lead to a significant increase in SDS extractable total amino nitrogen. However, interestingly, addition of xylanase led to a lower protein extractability in SDS either flour, dough or gluten. This may be caused by an increased aggregation of the glutenin proteins.

Table 2.2 SDS extractable protein and total alpha amino nitrogen

\begin{tabular}{ccccc}
\hline $\begin{array}{c}\text { Sample } \\
\text { name }\end{array}$ & $\begin{array}{c}\text { Total sample } \\
\text { weight } \\
(\mathbf{d} . \mathbf{m} . \mathbf{g})\end{array}$ & $\begin{array}{c}\text { Total protein } \\
\text { content } \\
(\mathbf{m g})\end{array}$ & $\begin{array}{c}\text { SDS extractable } \\
\text { protein } \\
(\mathbf{m g})\end{array}$ & $\begin{array}{c}\text { SDS extractable } \\
\text { total } \\
\text { amino nitrogen } \\
(\mathbf{m M})\end{array}$ \\
\hline Flour & 10.53 & 994.56 & 592.06 & 0.299 \\
Dough & 10.38 & 972.61 & 526.28 & 0.436 \\
Dough+ & 10.47 & 985.23 & 408.38 & 0.453 \\
Gluten & 0.80 & 645.32 & 119.45 & 0.096 \\
Gluten+ & 0.90 & 729.05 & 98.20 & 0.106 \\
Slurry & 0.88 & 58.96 & 44.74 & 0.030 \\
Slurry+ & 0.48 & 37.25 & 25.40 & 0.013 \\
xylanase & 0.0012 & 0.34 & 0.27 & 0.006 \\
\hline
\end{tabular}

+ means addition of 100ppm xylanase.

\subsection{Conclusions}

It was demonstrated that WUS not only had a negative effect on gluten yield, but also affected gluten and GMP composition and rheological properties. WUS interfere with gluten formation in both a direct and an indirect way. WUS interfere indirectly by competing for water and thus changing conditions for gluten development. This effect on 'physical dough development conditions' can be largely corrected for by the combination of adding more water and a longer mixing time. In addition, WUS have a direct effect on the process of gluten formation and gluten properties. The particulate nature of WUS requires that the effect occurs through an interaction between WUS particles and gluten particles. As a result, also gluten properties are affected. The resulting gluten sample has a lower extensibility, a lower content of GMP of a different structure. We propose that WUS addition causes a lower rate of aggregation of these particles to continuous gluten protein mass. This particle aggregation is reflected both in a lower yield of gluten and GMP and a 
changed network structure.

With xylanase, the opposite effect occurs, either by releasing water or by hydrolysing pentosan ${ }^{3}$. We have demonstrated (Fig.2.7) that xylanase lowers the optimal amount of water needed for maximal gluten yield. Our data also demonstrate that gluten yield at this level is significantly higher than for the control without xylanase (8.1\%vs $5.5 \%)$. The observation that the content of included starch in gluten is increased when using xylanase (Table 2.1) is a strong indication for an increased rate of gluten formation. This is supported by the finding that also the yield of GMP is increased. Formation of GMP after mixing is also a time dependent process ${ }^{13}$. The resulting GMP gel also displays a different structure.

Our results at this time do not allow for a full explanation of the phenomena observed. However, they point out an important direct effect of non-starch polysaccharides (and xylanase) on gluten formation and properties that could be corrected for by modifying dough mixing conditions and/or adding xylanase. These findings are of particular relevance for the gluten/starch industry. Since this industry is using more and more flour of high extraction rate, which contains higher levels of WUS.

\section{Acknowledgements}

This research work is partly financed by the China Scholarship Council. Also, the financial support by Wageningen Centre for Food Sciences is gratefully acknowledged.

We are also grateful to Katja Grolle for excellent technical assistance in Kieffer extensibility measurements.

\section{References}

1. MacRitchie, F. Wheat Proteins: Characterization and role in flour functionality. Cereal Foods World 44 (1999) 188-193.

2. Graybosch R., Peterson C.J., Moore K.J., Stearns M., and Grant, D.L. Comparative effects of wheat flour protein, lipid, and pentosan composition in relation to baking and milling quality. Cereal Chemistry 70 (1993) 95-101.

3. Rouau, X. Ei-Hayek, M-L and Moreau, D. Effect of an enzyme preparation containing pentosanases on the bread-making quality of flours in relation to changes in pentosan properties. Journal of Cereal Science 19 (1994) 259-272.

4. Jelaca, S.L. and Hlynka, I. Effect of wheat- flour pentosans in dough, gluten and bread. Cereal Chemistry 49 (1972) 489-495.

5. Kim, S.L. and D'Appolonia, B.L. Bread staling studies. III, Effect of pentosans on 
dough, bread and bread staling rate. Cereal Chemistry 54 (1977) 225-229.

6. Weegels, P.L., Marseille, J.P., and Hamer, R.J. Enzymes as a processing aid in the separation of wheat flour into starch and gluten. Starch/ Staerke 44 (1992) 44-48.

7. Weegels, P.L., Marseille, J.P., and Hamer, R.J. Small scale separation of wheat flour into starch and gluten. Starch/Staerke 40 (1988) 342-346.

8. Roels, S.P., Grobet, P.J. and Delcour J.A. Distribution of carbohydrates in gluten fractions isolated from European wheats (Triticum aestivum L.) in a batter system. Journal of Agricultural and Food Chemistry 46 (1998) 1334-1343.

9. Hamer, R.J. Enzymes in the baking industry. In 'Enzymes in Food Processing', (G.A. Tucker and L.F.J. Woods, eds), Blackie, Glasgow and London. (1991) pp168-193.

10. Maat, J., Roza, M.,Verbakel, J., Santos da Silva, J.M., Bosse, M., Egmond, M.R.,Hagemans, M.L.D.,v. Gorcom, R.F.M., Hessing, J.G.M.,v.d.Hondel, C.A.M.J.J.and v.Rotterdam, C. in 'Xylans and Xylanases', Progress in Biotechnology Series Vol.7, (J.Visser, G.Beldman, M.A.Kusters-van Someren, and A.G.J. Voragen, eds.), Elsevier, Amsterdam (1992) pp349-360.

11. Labat, E., Morel, M.H. and Rouau, X. Effect of laccase and manganese peroxidase on wheat gluten and pentosans during mixing. Food Hydrocolloids 15 (2001) 47-52.

12. Oudgenoeg G, Hilhorst R, Piersma SR, Boeriu CG, Gruppen H, Hessing M, Voragen AG, Laane C. Peroxidase-mediated cross-linking of a tyrosine-containing peptide with ferulic acid. Journal of Agricultural and Food Chemistry 49 (2001) 2503-2510.

13. Weegels, P.L., R.J. Hamer, and J.D. Schofield. Depolymerisation and re-polymerisation of wheat glutenin during dough processing. I. Relationships between glutenin macropolymer content and quality parameters. Journal of Cereal Science 23 (1996)103-111.

14. August, C.A., Bekkers, P.A., Lichtendonk, W.J., Graveland, A., Plijter, J.J. 2000. Mixing of wheat flour dough as a function of the physico-chemical properties of the SDS-gel proteins. In Wheat Gluten---proceedings of the $7^{\text {th }}$ International Gluten Workshop, edited by P.R. Shewry and A.S. Tatham. pp 408-412.

15. Gruppen, H., Marseille, J.P., Voragen, A.G.J., Hamer, R.J. and Pilnik, W. Mild isolation of water-insoluble cell wall material from wheat flour: Composition of fractions obtained with emphasis on non-starch polysaccharides. Journal of Cereal Science $\mathbf{9}$ (1990) 247-260.

16. Robertson, J.A. and Eastwood, M.A. An investigation of the experimental conditions which could affect water holding capacity of dietary fibre. Journal of the Science of Food and Agriculture 32 (1981) 819-825. 
17. Kieffer,R., Wieser, H., Henderson, M.H. and Graveland, A. Correlations of the breadmaking performance of wheat flour with rheological measurements on a micro-scale. Journal of Cereal Science 27 (1998) 53-60.

18. Sebecic, B. and Balenovic, J. Rapod ecologically acceptable method for wheat protein content determination-comparison of methods. Deutsche Lebensmittel Rundschau 97 (2001) 221-225.

19. Englyst, H.N. and Cummings, J.H. Simplified method for the measurement of total non-starch polysaccharides by Gas-Liquid Chromatography of constituent sugars as alditol acetates. Analyst 109 (1984) 937-942.

20. Nelson, N. A photometric adaption of the Somogyi method for the determination of glucose. Journal of Biological Chemistry 153 (1944) 375-380.

21. Kruger, J.E. Changes in the levels of proteolytic enzymes from hard red spring wheat during growth and maturation. Cereal Chemistry 50 (1973) 122-131.

22. Lie, S. The EBC-ninhydrin method for determination of free alpha amino nitrogen. Journal of Institute of Brewing 79 (1973) 37-41.

23. Harrington, C.R. Lowry protein assay containing sodium dodecyl sulfate in microtiter plates for protein daterminations on fraction from brain tissue. Analytical Biochemistry 186 (1990) 285-287.

24. Patil, S.K., Tsen, C.C. and Lineback, D.R. Water-soluble pentosans of wheat flour. I. Viscosity properties and molecular weights estimated by gel filtration. Cereal Chemistry 52 (1975) 44-56. 


\title{
3
}

\section{Interaction of water extractable pentosans with gluten protein: Effect on dough properties and gluten quality}

\begin{abstract}
The effects of modified water extractable pentosans (WEP) on gluten yield, dough properties, gluten quality and composition were studied. The results show that WEP interfere with gluten formation in both a direct and an indirect way. WEP interfere indirectly by competing for water and thus changing conditions for gluten development. This results in a lower gluten yield (GY) and an increased resistance of gluten against extension. The effect on GY can be corrected completely by adding more $0.2 \% \mathrm{NaCl}$ solution during dough mixing. There is however also a direct effect of WEP on gluten formation. This effect is reflected in a lower extensibility of dough and gluten, which cannot be corrected by adding more $0.2 \% \mathrm{NaCl}$ solution during dough mixing. It is demonstrated that the effect on extensibility of dough and gluten is related to the ferulic acid (FA) content of WEP. Also, addition of free FA leads to a more extensible dough and gluten together with a higher GY. We propose that WEP bound FA plays a key role in determining this effect of WEP. Our results also provide an indication that the effect of WEP on extensibility of dough and gluten may partly be due to cross-linking between protein and WEP.
\end{abstract}

Wang, M-W, Hamer, R.J., van Vliet, T. and Oudgenoeg, G. Journal of Cereal Science 36 (2002) 25-37. 


\subsection{Introduction}

The major non-starch polysaccharides of wheat flour are pentosans. Pentosans originate from the endosperm, cell wall and bran of wheat grain. Non-starch polysaccharides can be divided into water extractable pentosans (WEP) and water unextractable solids (WUS), which comprise $25 \%$ and $75 \%$ respectively of all pentosans present in wheat flour ${ }^{1}$. Arabinoxylans (AX) are the major constituent of non-starch polysaccharides. Some of the arabinose side-chains are esterified with phenolic acids, mostly ferulic acid $(\mathrm{FA})^{2}$. In solutions of WEP, this FA is involved in the oxidative cross-linking reaction of individual AX to form a larger network ${ }^{3-5}$.

WEP exhibit some unique physical properties that have been the subject of many studies. The ability to immobilise water ${ }^{6-8}$ and to form viscous solutions or gels by covalent cross-linking ${ }^{3-5}$ are important attributes that also can have direct functional implications in gluten formation and properties. The water holding capacity (WHC) of pentosans probably affects the distribution of moisture among dough constituents and thereby affects the rheological properties of dough, leading to a longer mixing time ${ }^{9-10}$. Although conflicting results have been published about the functional role of WEP in bread-making, it appeared that the water extractable AX content of wheat flours was positively correlated to their bread-making potential in a French-type bread-making process, whereas total AX were detrimental to dough and bread quality ${ }^{11}$. The different results may depend on their gross content in flour, their water extractability and fine structure ${ }^{12-15}$. Extensive hydrolysis of wheat dough pentosans by xylanase leads to slack, wet and sticky dough ${ }^{16}$. When used at an appropriate level of addition, however, certain pentosan modifying enzymes improve loaf volume and crumb structure of breads without giving rise to negative effects on dough handling and machinability ${ }^{17}$. The release of $\mathrm{AX}$ by xylanase, together with the preservation of the molecular size characteristics of the WEP, are considered important in improving dough and bread properties ${ }^{18}$. However, the mechanisms of action of pentosans and pentosanases on dough properties and gluten quality have not yet been fully understood.

FA is involved in the oxidative cross-linking of $\mathrm{WEP}^{3-5}$. It is not unlikely that a similar combination reaction can occur between AX bound FA and for example cysteine side chains of gluten. Hence, either di-ferulic acid bridges ${ }^{19}$ or covalent linkages between FA and cysteine molecules ${ }^{4}$, present in protein, can be formed. Although the latter mechanism is disputed ${ }^{20}$, other results ${ }^{1,21}$ have indicated the presence of protein-AX interaction via FA.

Free FA acts as an anti-oxidant and is also reported to effect dough properties and 
gluten quality. Several studies have been made on the effect of FA on wheat flour dough during mixing. Jackson and Hoseney ${ }^{22}$ hypothesised that during dough breakdown during mixing FA in the water soluble fraction of wheat flour interacts with the gluten /starch fraction to cause a fundamental change in the gluten proteins. The fundamental change results in the lack of resilience, i.e. the dough is broken down. Labat and co-workers ${ }^{23}$ declared that addition of FA to wheat flour can shorten the dough development time, increase the rate of dough breakdown and make the dough sticky. They reported a tentative mechanism of action in which FA interferes with the important disulphide interchange reaction. But the potential role of AX bound FA on dough properties and gluten quality is still unclear.

The aim of this chapter is to elucidate the functional role of AX bound FA on dough properties and gluten quality. WEP and WUS will be treated with alkaline, xylanase and peroxidase/hydrogen peroxide to generate fractions differing in both WHC and capacity to form FA mediated cross-links. The modified water extractable pentosans will be characterised in terms of viscosity, molecular weight distribution and aggregation behaviour, and content of AX and FA. A miniaturised set-up for gluten-starch separation (TNO Glutomatic) will be used to systematically study the effect of modified WEP on gluten formation. The effects of modified WEP on GY, dough properties, gluten quality and composition will be discussed.

\subsection{Experimental}

\subsubsection{Materials}

The MM flour (untreated) was kindly donated by Meneba Meel, Rotterdam, the Netherlands. The Soissons flour used for isolation and purification of WEP from the starch slurry after gluten formation was kindly supplied by TNO, Zeist, the Netherlands.

WEP (medium viscosity: 27cSt) was supplied by Megazyme (lot 90601).

Xylanase I (batch ppj 4482) was a gift by NOVO Nordisk. The activities of xylanase, protease and amylase (mean \pm S.D.) are $88.3 \pm 0.2 \mathrm{U} / \mathrm{mg}$ enzyme, $5.9 \pm 0.1 \mathrm{U} / \mathrm{mg}$ enzyme and $4.7 \pm 0.1 \mathrm{U} / \mathrm{g}$ enzyme respectively.

Horseradish peroxidase (HRP) and protease (pronase E) and FA was obtained from Sigma.

Amyloglucosidase was purchased from Boehringer.

All other chemicals used were of analytical grade or better. 


\subsubsection{Isolation of WUS}

WUS was isolated according to the following method:

Distilled water $(300 \mathrm{~mL})$ and sodium chloride $(10 \mathrm{~g})$ were added to wheat flour $(500$ g). The mixture was kneaded into dough in a Hobart mixer (Model N-50G) at setting 1 for $1 \mathrm{~min}$ and setting 2 for $4.5 \mathrm{~min}$. The dough was hand washed under running tap water. The gluten was rejected and the slurry was sieved $(32 \mu \mathrm{m})$. The overs fraction was sieved again under rinsing with distilled water. The throughs fraction was discarded. The overs fraction was freeze-dried [hereafter called WUS].

\subsubsection{Modification of WEP and WUS}

\subsubsection{Treatment of WEP and WUS by alkaline}

$1 \mathrm{~g}$ WEP preparation (Megazyme) or WUS preparation was dispersed in $10 \mathrm{~mL} \mathrm{95 \%}$ (v/v) ethanol and dissolved in $490 \mathrm{~mL}$ of $0.4 \mathrm{M} \mathrm{NaOH}$ solution under stirring. The slurry was continuously stirred overnight in a cold room $\left(4^{\circ} \mathrm{C}\right)$ and neutralised with $0.4 \mathrm{M} \mathrm{pH} 5$ sodium acetate buffer to $\mathrm{pH}$ 7. With WEP, the incubation mixture was dialysed against distilled water and freeze-dried (hereafter called $\mathrm{WEP}_{\mathrm{OH}}$ ). For WUS, the incubation mixture was centrifuged for $10 \mathrm{~min}$ at $14,800 \times \mathrm{g}$. The supernatant was collected and the residue was extracted with $100 \mathrm{~mL}$ distilled water for $1 \mathrm{~h}$ and centrifuged again for $10 \mathrm{~min}$ at $14,800 \times \mathrm{g}$. Both supernatant fractions were combined, dialysed against distilled water and freeze-dried (hereafter called $\mathrm{S}_{\mathrm{OH}}$ ).

\subsubsection{Preincubation of WEP and WUS by xylanase}

$1 \mathrm{~g}$ WEP preparation (Megazyme) or WUS preparation was dispersed in $10 \mathrm{~mL} \mathrm{95 \%}$ (v/v) ethanol and dissolved in $50 \mathrm{mM} 90 \mathrm{~mL}$ sodium acetate buffer (pH 5) under stirring. The slurry was incubated with $0.1 \mathrm{~mL}$ xylanase solution $(1 \mathrm{mg} / \mathrm{mL})$ at $30^{\circ} \mathrm{C}$ for $24 \mathrm{~h}$ with the presence of $0.05 \% \mathrm{NaN}_{3}$, inactivated at $100^{\circ} \mathrm{C}$ for $10 \mathrm{~min}$ and neutralised with $0.5 \mathrm{M}$ $\mathrm{NaOH}$ solution to $\mathrm{pH} 7$. The incubation mixture was centrifuged for $10 \mathrm{~min}$ at $14,800 \times \mathrm{g}$. With WEP, the supernatant was collected and freeze-dried (hereafter called $\mathrm{WEP}_{\mathrm{x}}$ ). For WUS, the supernatant was collected and the pellet was extracted with $100 \mathrm{~mL}$ distilled water for $1 \mathrm{~h}$ and centrifuged again for $10 \mathrm{~min}$ at 14,800 $\times \mathrm{g}$. Both supernatant fractions were combined and freeze-dried (hereafter called $S_{\mathrm{x}}$ ).

\subsubsection{Modification of WEP by FA, $\mathrm{HRP}$ and $\mathrm{H}_{2} \mathrm{O}_{2}$}

$1 \mathrm{~g}$ WEP preparation (Megazyme) was dispersed in $10 \mathrm{~mL} \mathrm{95 \%} \mathrm{(v/v)} \mathrm{ethanol} \mathrm{and}$ 
dissolved in $10 \mathrm{mM} 100 \mathrm{~mL}$ ammonium acetate buffer (pH 5) under stirring. Then $1 \mathrm{~mL}$ $0.5 \mathrm{M} \mathrm{FA}, 100 \mu \mathrm{L}$ HRP $(1 \mathrm{mg} / \mathrm{mL})$ and $100 \mu \mathrm{L} 5 \mathrm{mM} \mathrm{H}_{2} \mathrm{O}_{2}$ were sequentially added in 5 portions $^{21}$ into the dispersion. HRP was also dissolved in $10 \mathrm{mM}$ ammonium acetate buffer (pH 5). FA was dissolved in $0.1 \mathrm{M} \mathrm{KH}_{2} \mathrm{PO}_{4}$ and $\mathrm{K}_{2} \mathrm{HPO}_{4}$ buffer ( $\mathrm{pH} 7$ ). The mixture was incubated for $2 \mathrm{~h}$ at room temperature, after which the reaction was stopped by bringing the mixture to $100^{\circ} \mathrm{C}$ for $10 \mathrm{~min}$ and neutralised with $0.5 \mathrm{M} \mathrm{NaOH}$ solution to $\mathrm{pH}$ 7. The incubation mixture was centrifuged for $10 \mathrm{~min}$ at $14,800 \times \mathrm{g}$ and freeze-dried (hereafter called $\mathrm{WEP}_{\mathrm{p}}$ ).

\subsubsection{Isolation and purification of WEP from starch slurry after gluten formation}

Isolation and purification of WEP from starch slurry after gluten formation was according to the method of Rouau $^{8}$ with the following modifications: the first lot of starch slurry from the TNO Glutomatic system (obtained from the separation of $12 \mathrm{~g}$ Soissons flour $\pm 0.3 \% \mathrm{WEP} \pm 30 \mathrm{ppm} \mathrm{FA})$ was centrifuged $\left(14,800 \times \mathrm{g}, 20 \mathrm{~min}\right.$ at $\left.20^{\circ} \mathrm{C}\right)$. The supernatant was collected and placed in a boiling water bath for $10 \mathrm{~min}$ to inactivate endogenous enzymes and to insolubilise proteins. The residue was discarded. Then the solution was cooled and centrifuged again $\left(14,800 \times \mathrm{g}, 20 \mathrm{~min}\right.$ at $\left.20^{\circ} \mathrm{C}\right)$ to remove insoluble protein. The supernatant was collected and incubated with amyloglucosidase (5 $\mathrm{mg}$ ) at $60^{\circ} \mathrm{C}$ for $3 \mathrm{~h}(\mathrm{pH} 5)$. The residue was discarded. After cooling to $40^{\circ} \mathrm{C}$, the solution was mixed with protease $(3 \mathrm{mg})$ and phosphate buffer $(0.5 \mathrm{~mL}, 1 \mathrm{M}, \mathrm{pH} 7.5)$ at $37^{\circ} \mathrm{C}$ for 4 $\mathrm{h}$ and placed in a boiling water bath for $10 \mathrm{~min}$ to inactivate amyloglucosidase and protease, cooled and passed through filter paper. Then, five volumes of $95 \%$ ethanol were added to the clear solution under agitation. The precipitated material was allowed to settle overnight at $4{ }^{\circ} \mathrm{C}$. The supernatant was partially removed by suction. The WEP pellets were washed by ethanol to further remove the fractions with smaller molecular weight, centrifuged and then dried in an incubator at $50{ }^{\circ} \mathrm{C}$ for $24 \mathrm{~h}$.

\subsubsection{Characterisation of modified WEP}

\subsubsection{Viscosity}

The flow time of a filtered (filter paper, $589^{1}$, Black ribbon) solution of modified WEP was measured at $25 \pm 0.1^{\circ} \mathrm{C}$ using an Ubbelohde capillary viscometer. The relative viscosity ( $\eta_{\text {rel }}=$ flow time of sample/flow time of solvent $)$ and specific viscosity $\left(\eta_{\text {sp }}=\eta_{\text {rel }}-1\right)$ were calculated using the viscosity of $0.2 \%(\mathrm{w} / \mathrm{v}) \mathrm{NaCl}$ solution as solvent. Reduced viscosity $\left(\eta_{\text {red }}=\eta_{\text {sp }}\right.$ /sample concentration $)$ was plotted against the sample concentration 
and extrapolated to zero concentration using the Martin equation ${ }^{24}$ to determine the intrinsic viscosity $([\eta], \mathrm{mL} / \mathrm{g})$. The so-called Huggins constant $\left(\mathrm{K}^{\prime}\right)$ is a characteristic of a given solute-solvent system ${ }^{24}$ and can be calculated from the slope divided by $[\eta]^{25}$.

\subsubsection{High performance size exclusion chromatography (HPSEC)}

Samples of various modified WEP with concentrations of $4-5 \mathrm{mg} / \mathrm{mL}$ were analysed by HPSEC using a set of three Bio-Gel TSK columns in a series of 60XL-40XL-30XL in combination with a TSK XL guard column for WEP, $\mathrm{WEP}_{\mathrm{OH}}, \mathrm{WEP}_{\mathrm{p}}, \mathrm{S}_{\mathrm{OH}}$ and a series of 40XL-30XL-20XL in combination with a TSK XL guard column for $\mathrm{WEP}_{\mathrm{x}}, \mathrm{S}_{\mathrm{x}}$ and eluted at $30^{\circ} \mathrm{C}$ with $0.2 \mathrm{M} \mathrm{NaNO}_{3}$ at a flow rate of $0.8 \mathrm{~mL} / \mathrm{min}$. The eluent was monitored using a Shodex RI 71 refractive index detector. Dextrans $T_{2000}$ (molecular weight 2,000,000 Da), $\mathrm{T}_{500}$ (molecular weight 500,000 Da) from Pharmacia and glucose were used to calibrate the system. Chromatograms were analysed using Peak Fit 4 software (SPSS Inc.).

\subsubsection{FA content}

$10 \mathrm{mg}$ FA and various modified WEP were dissolved in $10 \mathrm{~mL} 0.1 \mathrm{M} \mathrm{KH}_{2} \mathrm{PO}_{4}$ and $\mathrm{K}_{2} \mathrm{HPO}_{4}$ buffer (PH7) respectively. Serial dilutions of the FA calibration solutions and various sample solutions were made using this buffer. The intensity at a wavelength of 420 $\mathrm{nm}$ of diluted FA standard or various sample solutions was measured using a LS50B Fluorimeter (Perkin Elmer) which was operated at an excitation wavelength of $312 \mathrm{~nm}$. From this the FA content could be calculated.

\subsubsection{Characterisation of dough and gluten samples}

\subsubsection{Dough preparation}

Dough was prepared using a mixograph (National Manufacturing Co.) with a $10 \mathrm{~g}$ mixing bowl. In general, flour was mixed using either $50 \%$ of water $(0.2 \% \mathrm{NaCl})$ and $3 \mathrm{~min}$ of mixing time or $53 \%$ of water and 4 min of mixing time at ambient temperature.

\subsubsection{Gluten yield experiments}

The gluten yield of dough was measured using a modified Glutomatic 2200 system (Perten, modified by TNO, in short the TNO Glutomatic). The system was fitted with a custom built pin mixer head, thermostatted at $30^{\circ} \mathrm{C}$. Flour $(12 \mathrm{~g} \pm 0.03 \mathrm{~g})$ and $6.5-8.5 \mathrm{~mL}$ $0.2 \%(\mathrm{w} / \mathrm{v})$ sodium chloride solution (hereafter called mixing water) was mixed for 3-6 min (hereafter called mixing time) to make dough. This dough was diluted to a slurry with 
a total of $25 \mathrm{~mL} 0.2 \%(\mathrm{w} / \mathrm{v})$ sodium chloride solution for $5 \mathrm{~min}$ at a flow rate of $5 \mathrm{~mL}$ per min. Next, the slurry was transferred into the washing chamber which was equipped with two sieves (top $400 \mu \mathrm{m}$ for separating, bottom $800 \mu \mathrm{m}$ for supporting) and rinsed with distilled water for $5 \mathrm{~min}$ at a flow rate of $56 \mathrm{~mL}$ per min. Finally, the separated wet gluten was collected and dried using a drying oven (Perten) for 5 min. Gluten yield was calculated from the weight of the dried gluten and the weight of the flour used. Wet gluten samples for Kieffer extensibility test were also prepared using TNO Glutomatic system.

\subsubsection{Kieffer extensibility test}

Dough and gluten samples were characterised using a miniature extensibility rig ${ }^{26}$ as follows:

Wet dough and gluten samples (10 g), prepared as above and combined, were placed in a Teflon mould to produce at least 8 test pieces [dimensions: $50 \mathrm{~mm}$ long, $4 \mathrm{~mm}$ high, base $3 \mathrm{~mm}$, top $5 \mathrm{~mm}$ ]. The whole mould was placed in a chamber at $30^{\circ} \mathrm{C}$ and $70 \%(\mathrm{RH})$ for $1 \mathrm{~h}$ to allow stress relaxation. This assures a good reproducibility of the results. The extension test of a strip of gluten was performed using the Kieffer extensibility rig fitted onto a Texture Analyser equipped with a $5 \mathrm{~kg}$ load cell. For each kind of gluten sample, eight measurements were performed. After testing, the gluten strips were freeze-dried and used for further chemical analysis.

\subsubsection{Analytical methods}

\subsubsection{Protein content}

Protein content $(\mathrm{N} \times 5.7)$ was determined by an NA2100 Nitrogen and Protein Analyser (CE INSTRUMENTS) using the automatic flash combustion method based on the quantitative combustion of the sample followed by reduction, GC separation and detection of molecular nitrogen using a T.C.D. detector. Casein is used as a standard.

\subsubsection{Starch content}

Starch content was determined enzymatically using the test kit supplied by Boehringer, Mannheim.

\subsubsection{Neutral sugar content}

Neutral sugar content was analysed using the alditol acetate method with inositol as internal standard ${ }^{27}$. Samples were pretreated with $72 \%(\mathrm{w} / \mathrm{w})$ sulphuric acid for $1 \mathrm{~h}$ at 
$30^{\circ} \mathrm{C}$ prior to further hydrolysis with $1 \mathrm{M}$ sulphuric acid for $3 \mathrm{~h}$ at $100{ }^{\circ} \mathrm{C}$. Neutral sugars in samples were released and analysed as their alditol acetates. Alditol acetates were separated on a $15 \mathrm{~m} \times 0.53 \mathrm{~mm}$ i.d. column (DB-225) in a Carlo Erba 5160 Gas chromatograph operated at $200^{\circ} \mathrm{C}$ and equipped with a F.I.D. detector set at $250^{\circ} \mathrm{C}$.

\subsection{Results and discussion}

\subsubsection{Characterisation of modified WEP}

\subsubsection{Viscosity, molecular weight distribution and aggregation behaviour}

The various modified WEP were characterised in terms of intrinsic viscosity, molecular weight distribution and aggregation behaviour (see Table 3.1 and Fig.3.1). [ $\eta$ ] can be used as a measure for the average viscometric molecular weight of the polymers. Table 3.1 shows that $\mathrm{WEP}, \mathrm{WEP}_{\mathrm{p}}, \mathrm{S}_{\mathrm{OH}}$ and $\mathrm{WEP}_{\mathrm{OH}}$ are of about the same $\left.\eta \eta\right]$, indicating an about similar molecular weight. The two samples pretreated with xylanase, $\mathrm{WEP}_{\mathrm{x}}$ and $S_{\mathrm{x}}$, have a much lower $[\eta]$, indicative for low molecular weight pentosan fragments.

These results are supported by HPSEC analysis (see Fig. 3.1). WEP, WEP ${ }_{\mathrm{OH}}$ and $\mathrm{WEP}_{\mathrm{p}}$ have about the same retention time, which means about the same high molecular weight distribution (see Fig.3.1a). $\mathrm{S}_{\mathrm{OH}}$ apparently contains higher molecular weight material although this is not reflected in a higher [ $\eta]$ (see Table 3.1). In contrast, $\mathrm{WEP}_{\mathrm{x}}$ and $S_{\mathrm{x}}$ have a longer retention time, indicating a markedly lower molecular weight (see Fig. 3.1b).
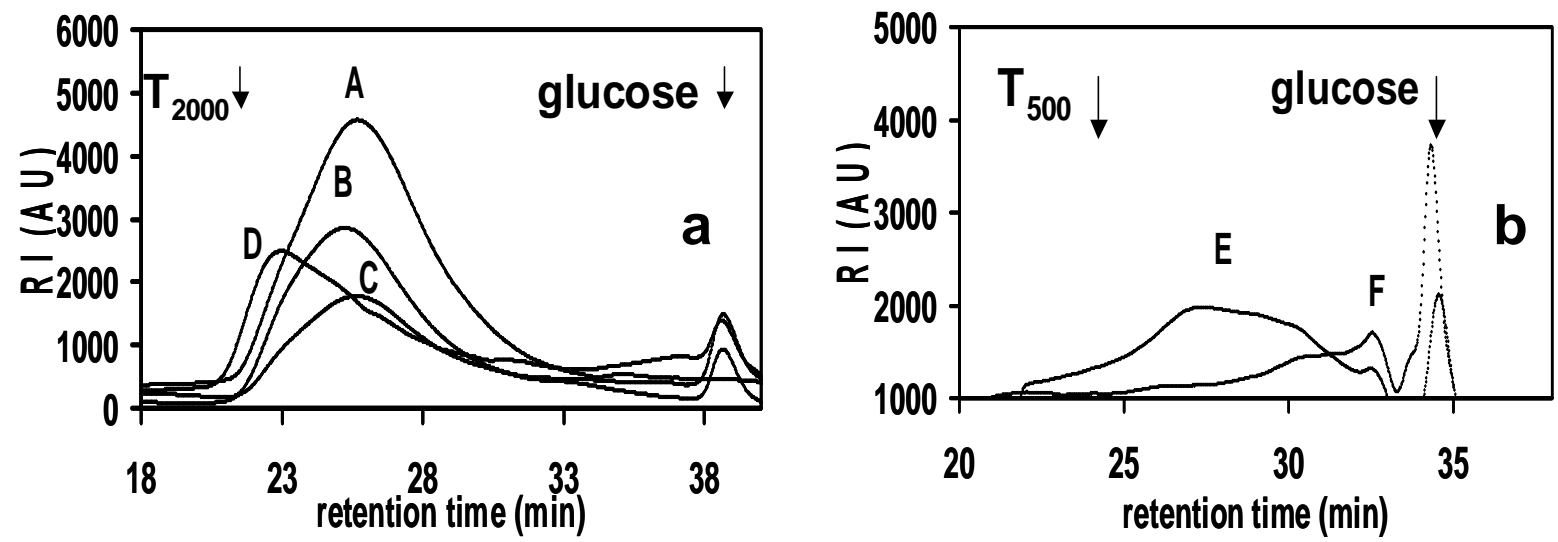

Figure 3.1.Molecular weight distribution of various modified WEP

Fig.3.1a: High molecular weight pentosans: WEP, $\mathrm{WEP}_{\mathrm{OH}}, \mathrm{WEP}_{\mathrm{p}}$ and $\mathrm{S}_{\mathrm{OH}}$.

Fig.3.1b: Low molecular weight pentosans: $\mathrm{WEP}_{\mathrm{x}}$ and $\mathrm{S}_{\mathrm{x}}$.

$\mathrm{A}=\mathrm{WEP}, \mathrm{B}=\mathrm{WEP}_{\mathrm{OH}}, \mathrm{C}=\mathrm{WEP}_{\mathrm{p}}, \mathrm{D}=\mathrm{S}_{\mathrm{OH}}, \mathrm{E}=\mathrm{WEP}_{\mathrm{x}}, \mathrm{F}=\mathrm{S}_{\mathrm{x}}$. 
Samples of pentosans were analysed using HPSEC as described under experimental. Dextrans $\mathrm{T}_{2000}$ (molecular weight 2,000,000 Da), T500 (molecular weight 500,000 Da) from Pharmacia and glucose were used to calibrate the system.

Table 3.1 Characterisation of various modified WEP

\begin{tabular}{crccc}
\hline $\begin{array}{c}\text { Type of } \\
\text { materials }\end{array}$ & $\begin{array}{c}{[\eta]} \\
(\mathbf{m L} / \mathbf{g})\end{array}$ & $\mathbf{K}^{\prime}$ & $\begin{array}{c}\text { AX content } \\
(\%)\end{array}$ & $\begin{array}{c}\text { FA content } \\
(\%)\end{array}$ \\
\hline $\mathbf{W E P}$ & $344 \pm 4$ & $0.64 \pm 0.01$ & $95 \pm 1.80$ & $0.09 \pm 0.004$ \\
$\mathbf{W E P}_{\mathbf{O H}}$ & $372 \pm 2$ & $0.43 \pm 0.00$ & $79 \pm 1.52$ & $0.03 \pm 0.001$ \\
$\mathbf{W E P}_{\mathbf{x}}$ & $28 \pm 0$ & $0.84 \pm 0.00$ & $47.2 \pm 0.78$ & $0.13 \pm 0.002$ \\
$\mathbf{W E P}_{\mathbf{p}}$ & $372 \pm 2$ & $0.63 \pm 0.01$ & $46.6 \pm 0.87$ & $0.06 \pm 0.001$ \\
$\mathbf{S}(-)_{\mathbf{O H}}$ & $327 \pm 2$ & $0.32 \pm 0.00$ & $58 \pm 1.29$ & $0.04 \pm 0.001$ \\
$\mathbf{S}(-)_{\mathbf{x}}$ & $25 \pm 0$ & $1.06 \pm 0.00$ & $92.1 \pm 0.90$ & $0.13 \pm 0.002$ \\
\hline
\end{tabular}

Data are mean \pm S.D.

$\mathrm{K}$ ' has been widely used to characterise the solvent quality of a solution for the standard macromolecules. It can also be used as an indicator of the aggregation behaviour of the material studied ${ }^{28}$. If $K^{\prime}>1$, the polymer solution has a stronger tendency to aggregate; If $\mathrm{K}^{\prime}<0.3$, the polymers do not exhibit a tendency to aggregate. The calculated $K$ ' values indicate a far stronger tendency to aggregate for $\mathrm{WEP}_{\mathrm{x}}$ and $\mathrm{S}_{\mathrm{x}}\left(0.84\right.$ for $\mathrm{WEP}_{\mathrm{x}}$ and 1.06 for $\mathrm{S}_{\mathrm{x} .}$ ) than for WEP, $\mathrm{WEP}_{\mathrm{p}}, \mathrm{WEP}_{\mathrm{OH}}$ and $\mathrm{S}_{\mathrm{OH}}$.

\subsubsection{AX content}

The AX content of both $\mathrm{WEP}_{\mathrm{OH}}$ and $\mathrm{WEP}_{\mathrm{x}}$ was found to be lower than that of WEP (see Table 3.1). This indicates that $\mathrm{AX}$ in WEP preincubated by $\mathrm{NaOH}$ and xylanase had been degraded. The extent of degradation depends on the concentration and the incubation time of alkaline and xylanase. These results are consistent with Gruppen et $\mathrm{al}^{29,30}$. The AX content of $\mathrm{WEP}_{\mathrm{p}}$ was also found to be lower than that of WEP. This is probably due to oxidation leading to undetectable residues, which could not be completely hydrolysed by sulfuric acid, causing underestimation of the $\mathrm{AX}$ content ${ }^{23}$.

\subsubsection{FA content}

Treatment of WEP with $\mathrm{NaOH}$ led to a loss in FA (see Table 3.1). This result is in agreement with the findings of DuPont ${ }^{31}$. In contrast, WEP preincubated by xylanase resulted in a higher FA content, since xylanase can hydrolyse WEP but cannot remove AX 
bound $\mathrm{FA}^{32}$, Therefore, the relative content of FA in WEP treated by xylanase is increased. This result is in agreement with the findings of Rouau ${ }^{8}$. WEP modified by $\mathrm{HRP} / \mathrm{H}_{2} \mathrm{O}_{2}$ and FA also caused a small decrease in FA content that might be due to the self-polymerisation or addition products.

\subsubsection{Effect of modified WEP on GY}

\subsubsection{Effect of WEP on $G Y$}

Our previous study ${ }^{33}$ showed that addition of $2 \%$ WUS, the water unextractable pentosans, negatively affected GY. We therefore studied if addition of the soluble fraction, WEP also influence GY. WEP were added to flour at four levels (see Fig. 3.2). In all cases a decrease in GY was observed. At a level of $1 \%$ added WEP no cohesive gluten was formed. At $0.2 \%$ WEP addition a decrease of ca $15 \%$ in GY was observed.

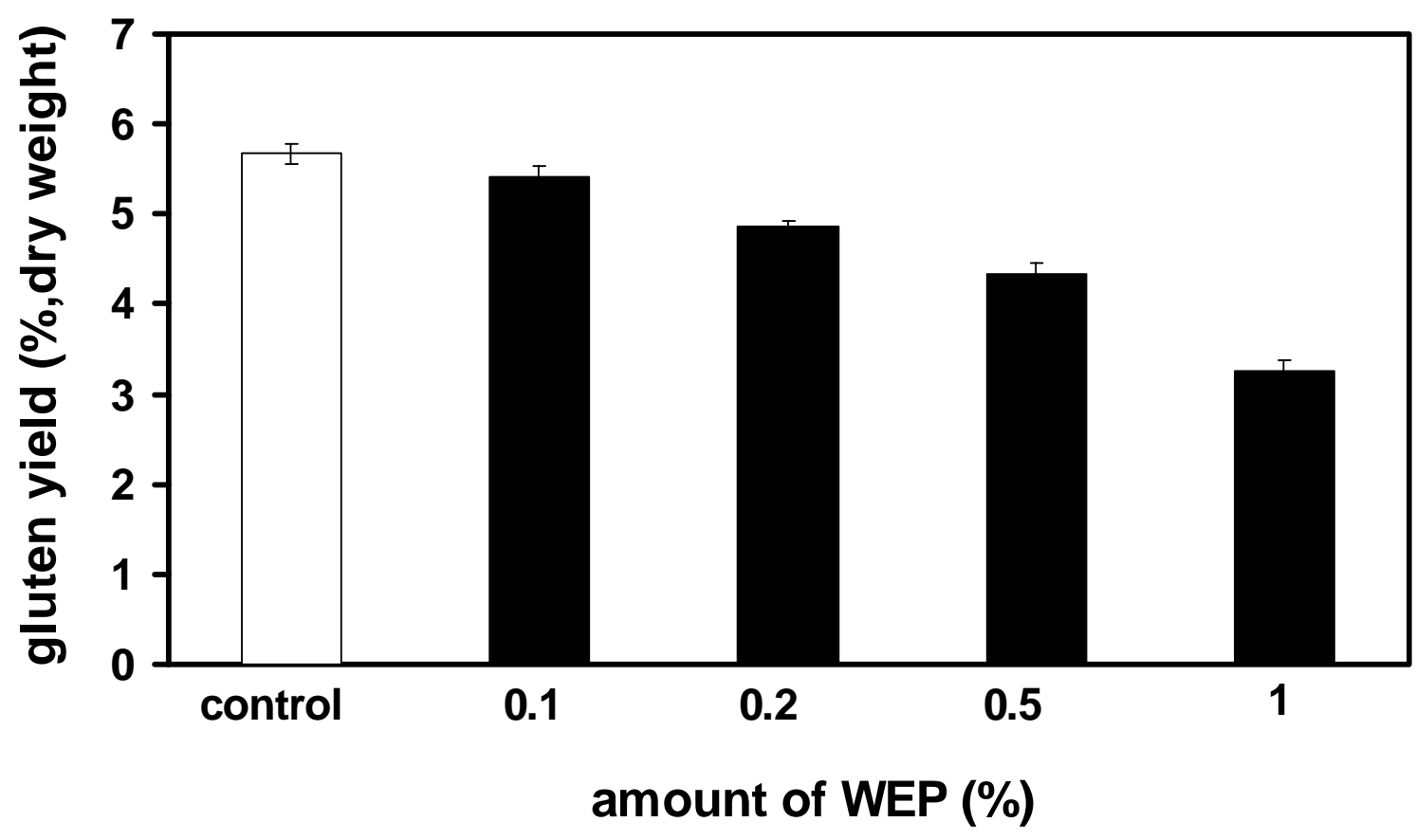

Figure 3.2 Effect of the amount of WEP on GY

Gluten was isolated from wheat flour adding WEP in dry matter at different levels with 3 min of mixing time and $7.3 \mathrm{~mL}$ of mixing water.

\subsubsection{Effect of modified WEP on GY}

Fig. 3.3 represents the effect of various modified WEP on GY. A decrease in GY was found with all modified WEP. This indicates that pre-treatment of WEP with $\mathrm{NaOH}$ or xylanase or HRP does not remove the ability of WEP to negatively effect gluten formation. 
It stands to reason that addition of soluble $\mathrm{AX}$ fractions of different size/intrinsic viscosity will affect the availability of water for gluten development. In order to study the effect of size/ intrinsic viscosity of WEP on GY, WEP and $S_{\mathrm{x}}$ were added to flour and dough was mixed at different levels of water. The results, shown in Fig. 3.4, demonstrated the important effects of varying water. The effects of both WEP and $S_{x}$ on GY were maximal at $7.3 \mathrm{~mL}$ of water. The negative effects of both WEP and $S_{\mathrm{x}}$ on GY could be corrected completely using $8 \mathrm{~mL}$ (for WEP) and $7.5 \mathrm{~mL}$ (for $\mathrm{S}_{\mathrm{x}}$ ) of water respectively. This reveals that soluble AX with a higher intrinsic viscosity (molecular weight) and hence a higher water holding capacity require more water to correct for the negative effect. This result is in agreement with data from literature ${ }^{34}$. WHC for starch, protein and pentosan are 1,2 and $10 \mathrm{~g} / \mathrm{g}$ respectively, which means starch, protein and especially pentosan compete for water. Hence more water needs to be added.

\subsubsection{Effect of FA on gluten yield}

In our previous paper ${ }^{33}$ both a direct and an indirect effects of WUS on gluten formation and properties were proposed. The indirect effect refered to WHC. The direct effect was caused by an interaction between $\mathrm{AX}$ and gluten. The soluble pentosans in this study were demonstrated to also negatively affect GY (Fig. 3.3). Again, an effect of WHC is involved (Fig. 3.4). But is there also a direct effect? With WEP, this direct effect could be mediated by AX bound FA ${ }^{1,21}$. Therefore the effect of addition of FA on GY was studied. In Fig. 3.5a and Fig. 3.5b experiments are shown where free FA was added together with WEP or $\mathrm{S}_{\mathrm{x}}$. These fractions had a clearly different FA content $(0.09 \%$ and $0.13 \%$, respectively, see Table 3.1). The results showed that the negative effects of both WEP and $S_{x}$ could be corrected for by adding FA. It is noted that this correction does not require a higher level of water addition as reported in Fig. 3.4. Furthermore, the optimal concentration of FA for WEP and $S_{x}$ is different. Since FA is only poorly soluble under the conditions used, it is not possible to interpret the effective concentration of FA in the system used. The optimal level of added FA does not correspond to the FA content of WEP or $S_{x}$. The different optima could therefore also reflect a different reactivity of WEP or $S_{x}$ bound FA.

\subsubsection{Characterisation of dough and gluten samples}

\subsubsection{Composition---Protein, starch and AX yield}

Gluten samples were analysed for protein, starch and AX content to allow a better interpretation of GY data. The results are presented in Table 3.2. 


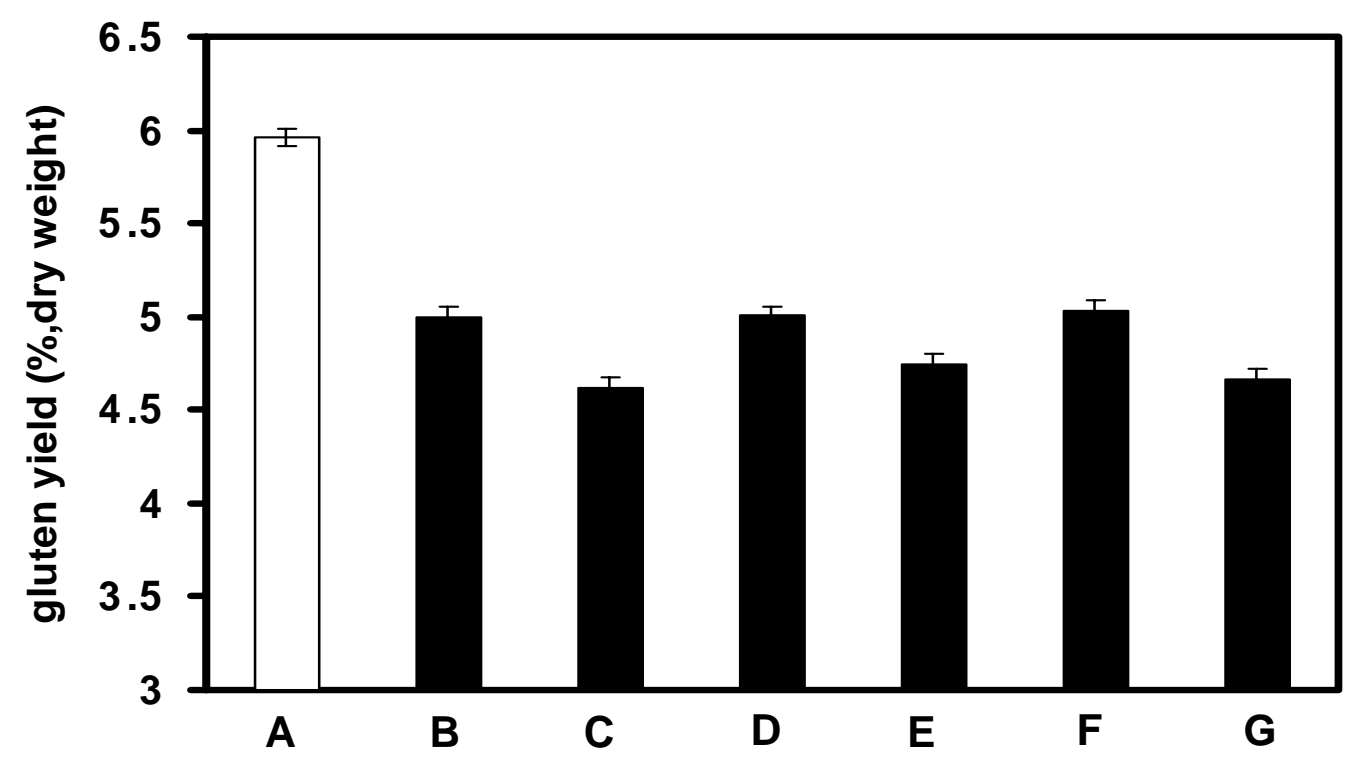

Figure 3.3.Effect of various modified WEP on GY

Various modified WEP were tested for their effect on GY under 3 min mix and $7.3 \mathrm{~mL}$ water. $\mathrm{A}=$ control, $\mathrm{B}=0.2 \% \mathrm{WEP}, \mathrm{C}=0.2 \% \mathrm{WEP}_{\mathrm{OH}}, \mathrm{D}=0.2 \% \mathrm{WEP}_{\mathrm{x}}, \mathrm{E}=0.2 \% \mathrm{WEP}_{\mathrm{p}}$, $\mathrm{F}=0.2 \% \mathrm{~S}_{\mathrm{x}}, \mathrm{G}=0.2 \% \mathrm{~S}_{\mathrm{OH}}$.

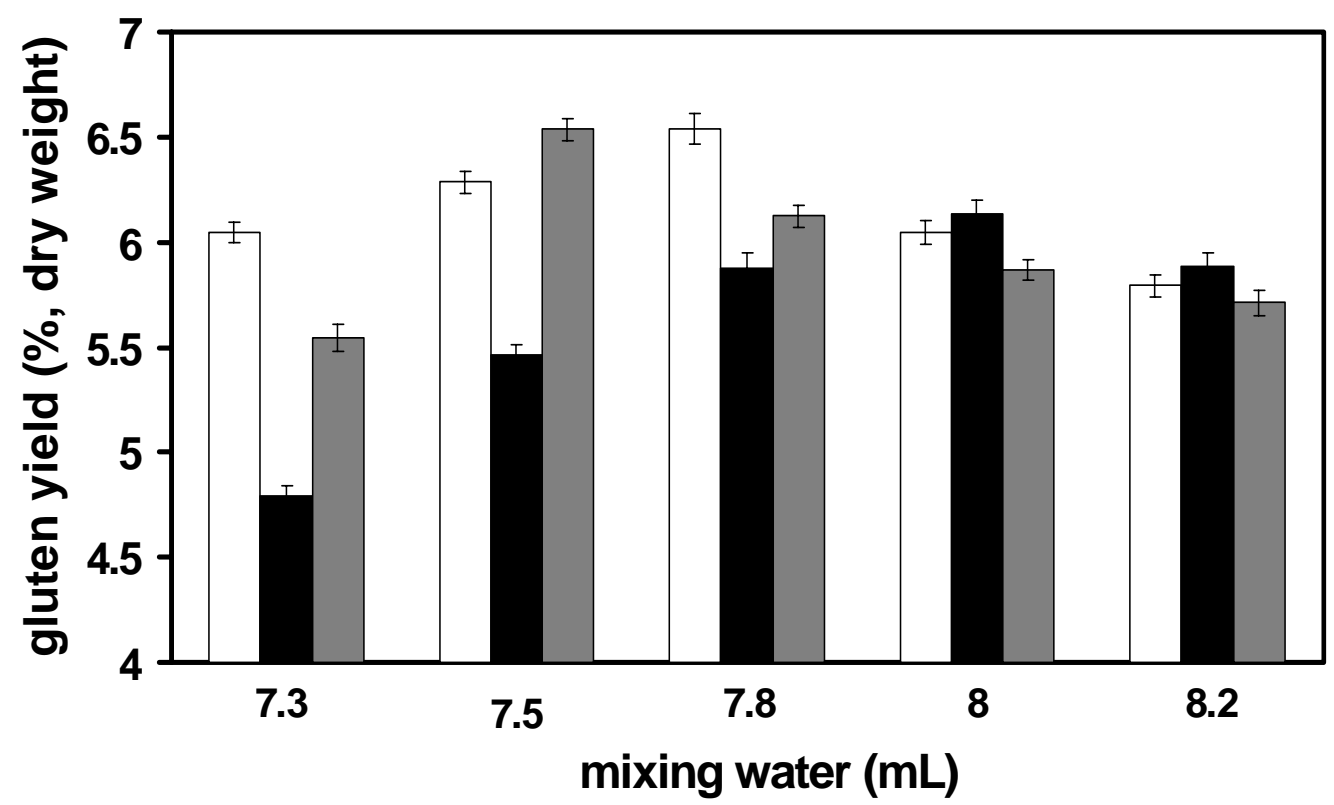

Figure 3.4 Effect of mixing water on GY with WEP and $S_{x}$

WEP and $S_{x}$ were added to wheat flour to test their effect of on GY for varying water addition at 3 min of mixing time. White column=control, black column $=0.3 \% \mathrm{WEP}$, grey column $=0.3 \% \mathrm{~S}_{\mathrm{x}}$. 

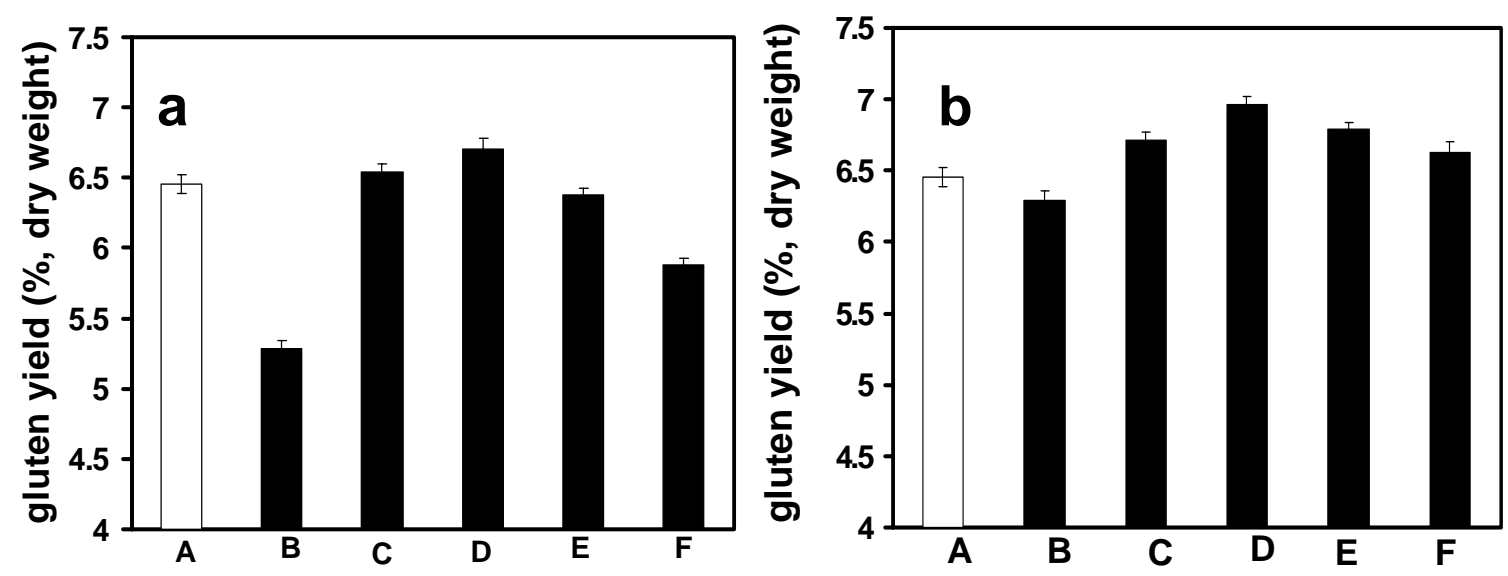

Figure 3.5 Effect of FA on GY

WEP in dry matter and FA solution with different concentrations were added to wheat flour. The gluten yield was measured at 4 min of mixing time and $7.3 \mathrm{~mL}$ of mixing water.

Fig. 3.5a: $\mathrm{A}=$ control, $\mathrm{B}=0.3 \% \mathrm{WEP}, \mathrm{C}=0.3 \% \mathrm{WEP}+50 \mathrm{ppm}$ FA, $\mathrm{D}=0.3 \% \mathrm{WEP}+100 \mathrm{ppm} \mathrm{FA}, \mathrm{E}=0.3 \% \mathrm{WEP}+150 \mathrm{ppm} \mathrm{FA}, \mathrm{F}=0.3 \% \mathrm{WEP}+200 \mathrm{ppm}$ FA Fig. 3.5b: $A=$ control, $B=0.3 \% \mathrm{~S}_{\mathrm{x}}, \mathrm{C}=0.3 \% \mathrm{~S}_{\mathrm{x}}+25$ ppm FA, $\mathrm{D}=0.3 \% \mathrm{~S}_{\mathrm{x}}+50 \mathrm{ppm}$ FA, $\mathrm{E}=0.3 \% \mathrm{~S}_{\mathrm{x}}+75$ ppm FA, $\mathrm{F}=0.3 \% \mathrm{~S}_{\mathrm{x}}+100$ ppm FA

Addition of WEP led to a significant decrease in protein yield (about $80 \%$ of control), starch content of gluten (yield: $85 \%$ of control) and a comparable AX yield. This reveals that WEP are not preferentially bound to gluten, which is consistent with the conclusion of Saulnier ${ }^{35}$. However, this does not exclude that WEP bind to gluten particles that are not recovered. Addition of free FA with WEP can restore protein yield completely. As a result, aggregation proceeds faster as indicated by a higher starch content of gluten (130\% of control). Addition of $S_{x}$ also resulted in a lower protein yield (95\% of control), but not to the same extent as with WEP. Adding $S_{\mathrm{x}}$ and free FA together again caused an increase in protein yield (108\% of control). This combination also resulted in an even higher starch content of gluten (yield: $144 \%$ of control). This demonstrates that the increased speed of aggregation could cause more starch to become physically entrapped in the gluten network. As far as we known, effects of FA on protein yield and starch content of gluten have not been reported earlier.

\subsubsection{Dough properties and gluten quality ----Kieffer extensibility test}

The dough properties with various modified WEP were studied using the Kieffer extensibility test at different mixing time and water addition (see Table 3.3). 


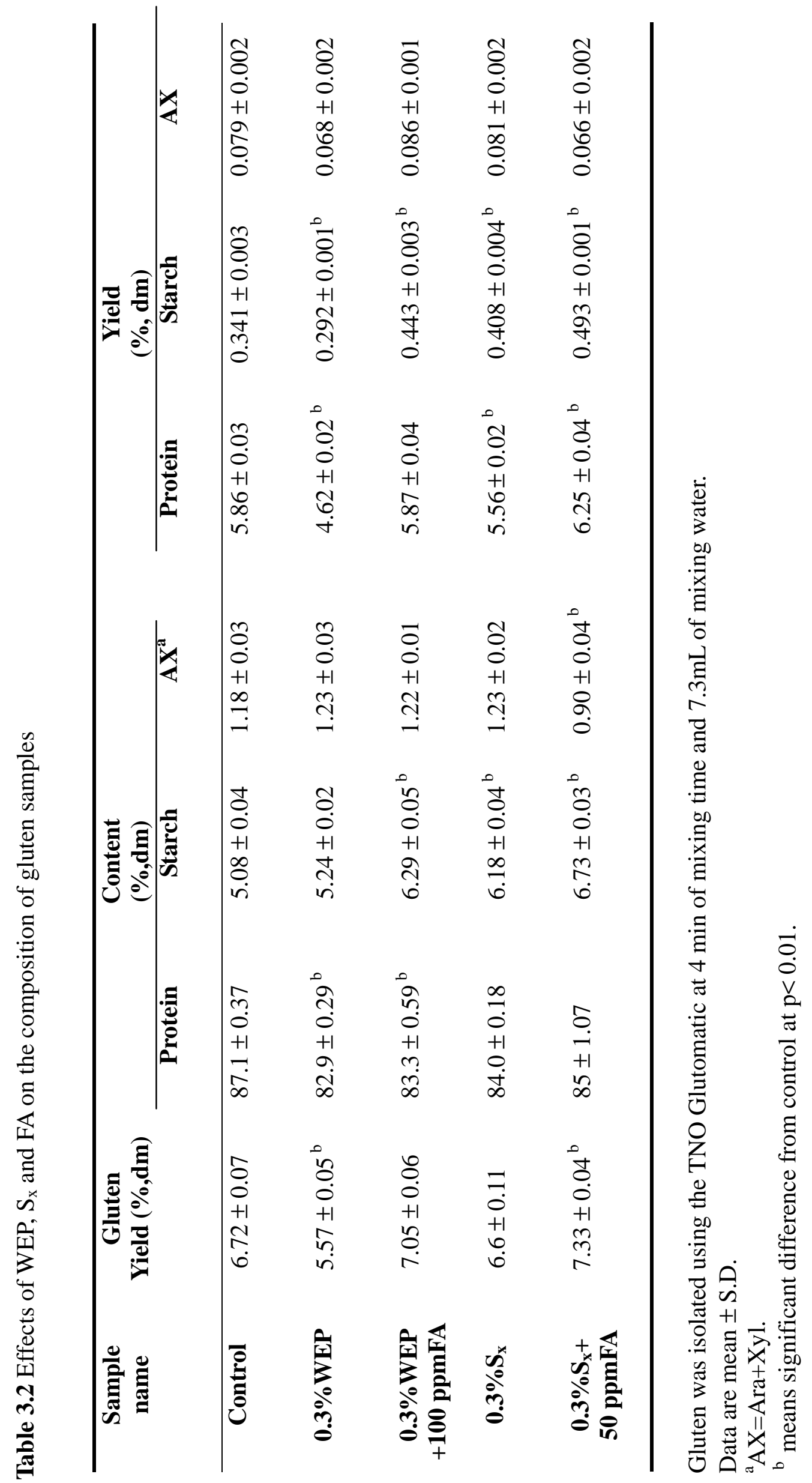


Three parameters were used to characterise the extensigram: extensibility at break point, extensibility at maximum resistance to extension ( $E$ at $R_{\max }$ ) and maximum resistance to extension $\left(\mathrm{R}_{\max }\right)$. Extensibility gives the deformation of the dough before it ruptures. However, the rupture process of the dough piece takes some time and during this time the dough is further extended. Therefore, the measured extensibility at break is determined by the extensibility and the speed by which the dough piece ruptures. Fracture often starts at or closely after $\mathrm{R}_{\max }$. Therefore, we take $\mathrm{E}$ at $\mathrm{R}_{\max }$ as a characteristic of the extensibility. The larger extensibility, the further the dough can be extended before it ruptures. $R_{\max }$ is an indicator of the strength of the dough. A higher $R_{\max }$ implies a stronger dough.

Table 3.3 Kieffer extensibility data of dough with various modified WEP

\begin{tabular}{|c|c|c|c|c|}
\hline \multirow[t]{2}{*}{ Sample name } & \multicolumn{2}{|c|}{$3 \mathrm{~min} \operatorname{mix}$ and $50 \%$ water } & \multicolumn{2}{|c|}{$4 \mathrm{~min}$ mix and $53 \%$ water } \\
\hline & $\begin{array}{l}\mathbf{R}_{\max } \\
(\mathbf{N}) \\
\end{array}$ & $\begin{array}{r}\mathbf{E} \text { at } \mathbf{R}_{\max } \\
(\mathbf{m m})\end{array}$ & $\begin{array}{l}\mathbf{R}_{\max } \\
(\mathbf{N})\end{array}$ & $\begin{array}{r}\mathbf{E} \text { at } \mathbf{R}_{\max } \\
(\mathbf{m m})\end{array}$ \\
\hline Control & $0.070 \pm 0.005$ & $23 \pm 2$ & $0.043 \pm 0.002$ & $35 \pm 3$ \\
\hline 0.3\%WEP & $0.082 \pm 0.006$ & $20 \pm 2$ & $0.056 \pm 0.003$ & $22 \pm 2$ \\
\hline $0.3 \% \mathrm{WEP}_{\mathrm{OH}}$ & $0.075 \pm 0.004$ & $24 \pm 2$ & $0.055 \pm 0.004$ & $25 \pm 2$ \\
\hline $0.3 \% \mathbf{W E P}_{x}$ & $0.072 \pm 0.005$ & $18 \pm 1$ & $0.048 \pm 0.003$ & $20 \pm 2$ \\
\hline $0.3 \% \mathrm{WEP}_{\mathrm{p}}$ & $0.096 \pm 0.009$ & $20 \pm 2$ & $0.064 \pm 0.005$ & $25 \pm 2$ \\
\hline $0.3 \% \mathrm{~S}_{\mathrm{OH}}$ & $0.087 \pm 0.008$ & $25 \pm 3$ & $0.052 \pm 0.003$ & $35 \pm 3$ \\
\hline $0.3 \% S_{x}$ & $0.067 \pm 0.006$ & $17 \pm 1$ & $0.048 \pm 0.002$ & $21 \pm 2$ \\
\hline
\end{tabular}

Data are mean \pm S.D.

Addition of various modified WEP led to an increase in $\mathrm{R}_{\mathrm{max}}$ in all cases. Addition of $\mathrm{WEP}_{\mathrm{x}}$ resulted in a significant decrease in $\mathrm{E}$ at $\mathrm{R}_{\max }$ (78\% of control). If water binding effects are corrected for (i.e. by mixing for $4 \mathrm{~min}$ at $53 \%$ of water), $\mathrm{R}_{\max }$ is lowered, but the effect on extensibility remains. Interestingly, $\mathrm{WEP}_{\mathrm{x}}$ is the most effective in lowering the extensibility of dough. It was already noted in Table 3.1 that $\mathrm{WEP}_{\mathrm{x}}$ displays a higher tendency to aggregate $\left(K^{\prime}=0.84\right.$ vs other fractions $\left.K^{\prime}<0.65\right)$.

Some important correlation values were observed based on the characterisation of modified WEP data and the Kieffer data of dough (see Table 3.4). The correlation between 
$\mathrm{K}^{\prime}$ and $\mathrm{E}$ at $\mathrm{R}_{\max }$ is noteworthy $\left(\mathrm{R}^{2}=0.93\right)$, since we have correlated a property of an isolated material ( $\mathrm{K}^{\prime}$ relates to WEP) to a property of a complex system ( $\mathrm{E}$ at $\mathrm{R}_{\max }$ relates to dough). Also, correlations between FA content and $\mathrm{K}^{\prime}$ of modified WEP $\left(\mathrm{R}^{2}=0.85\right)$, FA content of modified WEP and $E$ at $R_{\max }$ of dough $\left(R^{2}=0.86\right)$ were observed. This finding not only supports our hypothesis that FA is involved in the interaction between AX and gluten, but also points at a possible mechanism, namely that the ability of pentosans to aggregate, which is correlated to their FA content, is highly related to their ability to reduce extensibility of dough. No significant correlations between $R_{\max }$ and [ $\eta$ ] or $K$ 'or FA content were found.

Table 3.4 Correlation $\left(R^{2}\right)$ between $R_{\max }, E$ at $R_{\max }$ of dough and [ $\eta$ ], K', FA content of various modified WEP

\begin{tabular}{cccc}
\hline Item name & {$[\eta]$} & $\mathbf{K}^{\prime}$ & FA content \\
\hline $\mathbf{R}_{\text {max }}$ & 0.56 & 0.34 & 0.30 \\
$\mathbf{E}$ at $\mathbf{R}_{\text {max }}$ & 0.60 & $\mathbf{0 . 9 3}$ & $\mathbf{0 . 8 6}$ \\
{$[\eta]$} & 1.00 & $\mathbf{0 . 7 0}$ & $\mathbf{0 . 7 9}$ \\
$\mathbf{K} \boldsymbol{K}^{\mathbf{F A}}$ & $\mathbf{0 . 7 0}$ & 1.00 & $\mathbf{0 . 8 5}$ \\
& $\mathbf{0 . 7 9}$ & $\mathbf{0 . 8 5}$ & 1.00 \\
\hline
\end{tabular}

Correlation was calculated using all data in Table 3.1 and Table 3.3 at 3 min of mixing time and $50 \%$ of mixing water.

In order to further support our hypothesis on the functional role of FA on dough properties, the reduced viscosity of solutions of WEP and $S_{x}$ was determined at different concentrations of free FA. Fig. 3.6a and Fig. 3.6b showed that with increasing concentration of FA, the reduced viscosity of WEP and $S_{x}$ decreased first to a minimum and then increased again. The decrease in viscosity is probably due to free FA reacting with $\mathrm{AX}$ bound FA, thus preventing aggregation. The following increase in viscosity may be due to the fact that at higher concentrations of FA, the formation of di-ferulic acid is in competition with the former reaction. We hypothesize that at higher concentrations, FA preferentially forms di-ferulic acid and hence is not available for the reaction with FA bound to pentosan. This explanation is in agreement with the findings of Oudgenoeg et al 21. 

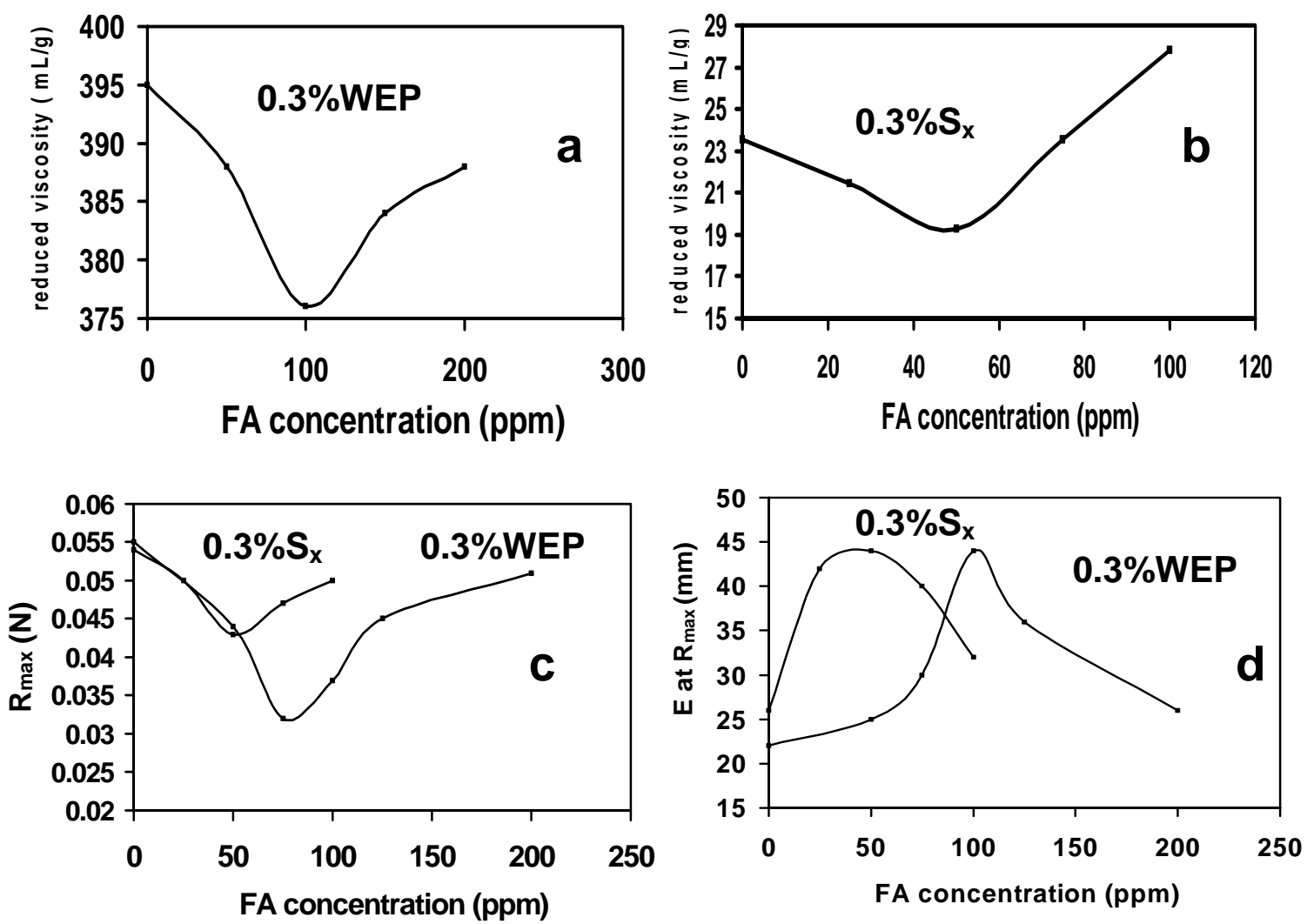

Figure 3.6 Effect of FA on viscosity and dough properties

Fig.3.6a Effect of FA on viscosity of WEP Fig.3.6b Effect of FA on viscosity of $S_{x}$ Fig.3.6c Effect of FA on $\mathrm{R}_{\max }$ of dough with WEP and $\mathrm{S}_{\mathrm{x}}$

Fig.3.6d Effect of FA on $E$ at $R_{\max }$ of dough with WEP and $S_{x}$ FA concentration was based on $12 \mathrm{~g}$ wheat flour for gluten yield test.

Moreover, also in dough samples, $\mathrm{R}_{\max }$ and $\mathrm{E}$ at $\mathrm{R}_{\max }$ were observed to change depending on the amount of FA added (Fig. 3.6c and Fig.3.6d respectively). The level of FA that gave the largest $E$ at $R_{\max }$ corresponded well with the level at which GY was maximal (see Fig. 3.5) and with the minimum in reduced viscosity (Fig.3.6a and 3.6b). The results of Kieffer extensibility test of the gluten samples (see Fig. 3.7) demonstrated that addition of $S_{x}$ typically produced a gluten with a comparable $R_{\max }$ to the control but a lower $E$ at $R_{\max }$, while addition of WEP led to a gluten with a higher $R_{\max }$ and an even lower $E$ at $R_{\max }$. Addition of free $F A$ with $S_{x}$ and WEP significantly increased $E$ at $R_{\max }$ of gluten with a comparable $R_{\max }$. Furthermore, the increase of $E$ at $R_{\max }$ for gluten with $S_{x}$ and FA was much larger than that for gluten with WEP and FA. These results indicate that FA has a direct effect on gluten development and properties since the FA content of $S_{x}$ is higher than that of WEP this effect is stronger for $S_{x}$ (see Table 3.1). It cannot be expected that small $\mathrm{S}_{\mathrm{x}}$ fragments form a network. We therefore propose that $\mathrm{S}_{\mathrm{x}}$ (or $\mathrm{WEP}_{\mathrm{x}}$ ) directly link to gluten protein and exert their effect by hampering the aggregation of such particles. 


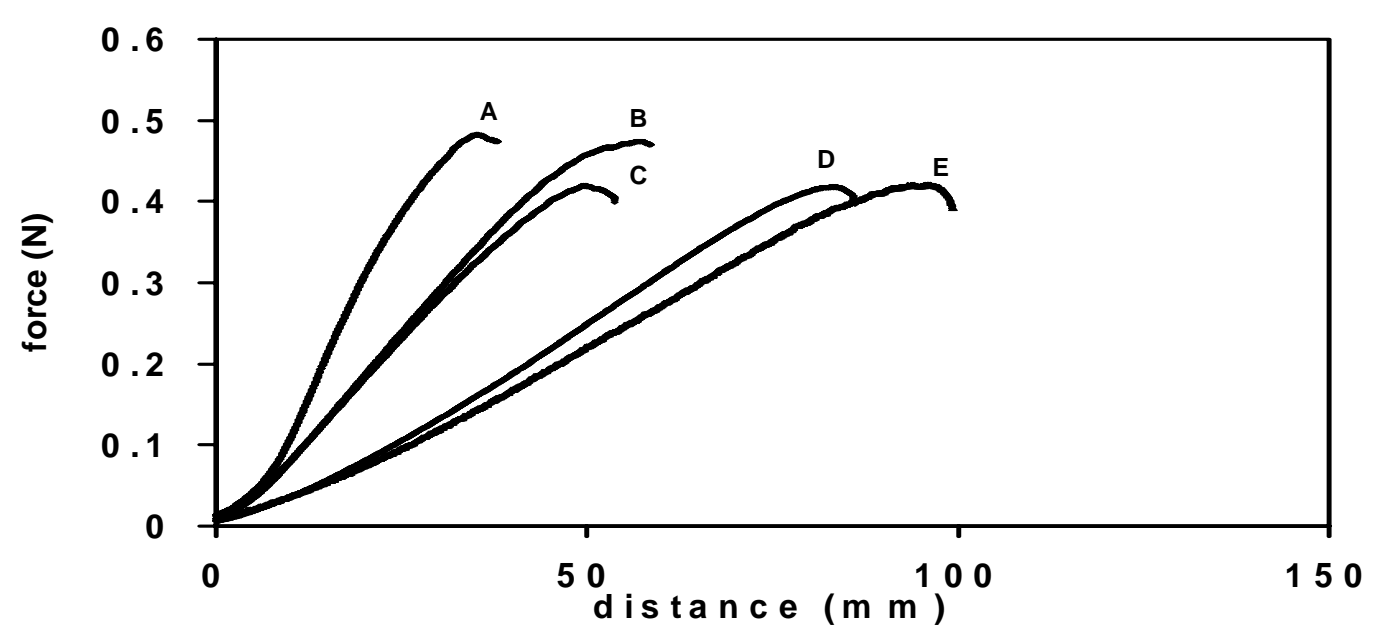

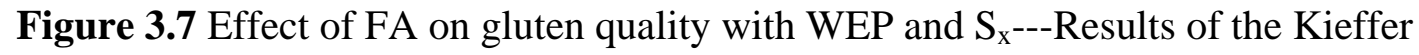
extensibility test. Gluten was isolated from TNO Glutomatic at $4 \mathrm{~min}$ mix and 7.3mLwater. $\mathrm{A}=0.3 \% \mathrm{WEP}, \mathrm{B}=0.3 \% \mathrm{WEP}+100 \mathrm{ppm} \mathrm{FA}, \mathrm{C}=0.3 \% \mathrm{~S}_{\mathrm{x}}, \mathrm{D}=0.3 \% \mathrm{~S}_{\mathrm{x}}+50 \mathrm{ppm}$ FA, $\mathrm{E}=$ control.

\subsubsection{Effects of $\mathrm{HRP} / \mathrm{H}_{2} \mathrm{O}_{2}$ and $\mathrm{FA}$ on viscosity and molecular weight distribution of WEP}

The reaction of FA requires the presence of peroxidase $/ \mathrm{H}_{2} \mathrm{O}_{2}$. We therefore studied the effect of $\mathrm{HRP} / \mathrm{H}_{2} \mathrm{O}_{2}$ and FA on viscosity and molecular weight distribution of a WEP solution (see Fig. 3.8).

Our data show that the viscosity of WEP on addition of $\mathrm{HRP} / \mathrm{H}_{2} \mathrm{O}_{2}$ increased within 10min and then decreased to the original viscosity (see Fig. 3.8a). HPSEC analysis showed that the addition of $\mathrm{HRP} / \mathrm{H}_{2} \mathrm{O}_{2}$ results in a shift in the molecular weight distribution. We identified two peaks (see Fig. 3.8b). The ratio between the area under peak 1 and peak 2 changed from 0.15 for WEP to 0.29 for WEP with $\mathrm{HRP} / \mathrm{H}_{2} \mathrm{O}_{2}$. Adding FA together with $\mathrm{HRP} / \mathrm{H}_{2} \mathrm{O}_{2}$ led to a decreased ratio of 0.06 . We therefore conclude that the increase in viscosity is the result of the cross-linking of WEP. Addition of FA prevents this cross-linking. This result is in agreement with the findings of Hoseney ${ }^{4}$, Labat $^{23}$ and Figueroa-Espinoza ${ }^{36}$.

To test these findings in the actual dough/slurry system of gluten separation, we isolated WEP from the starch slurry obtained after gluten formation. HPSEC again shows a shift towards higher molecular weight when WEP was isolated from flour and from flour with added WEP (see Fig. 3.9, trace C, D vs E). This indicated that during gluten separation larger complexes of WEP are formed. These results do not point at the formation of an extensive gel. Again, a shift towards lower molecular weight was noted when FA was present (see Fig. 3.9, trace A, B vs C, D). This indicates that adding free FA prevents the formation of higher molecular weight complexes during gluten separation. 

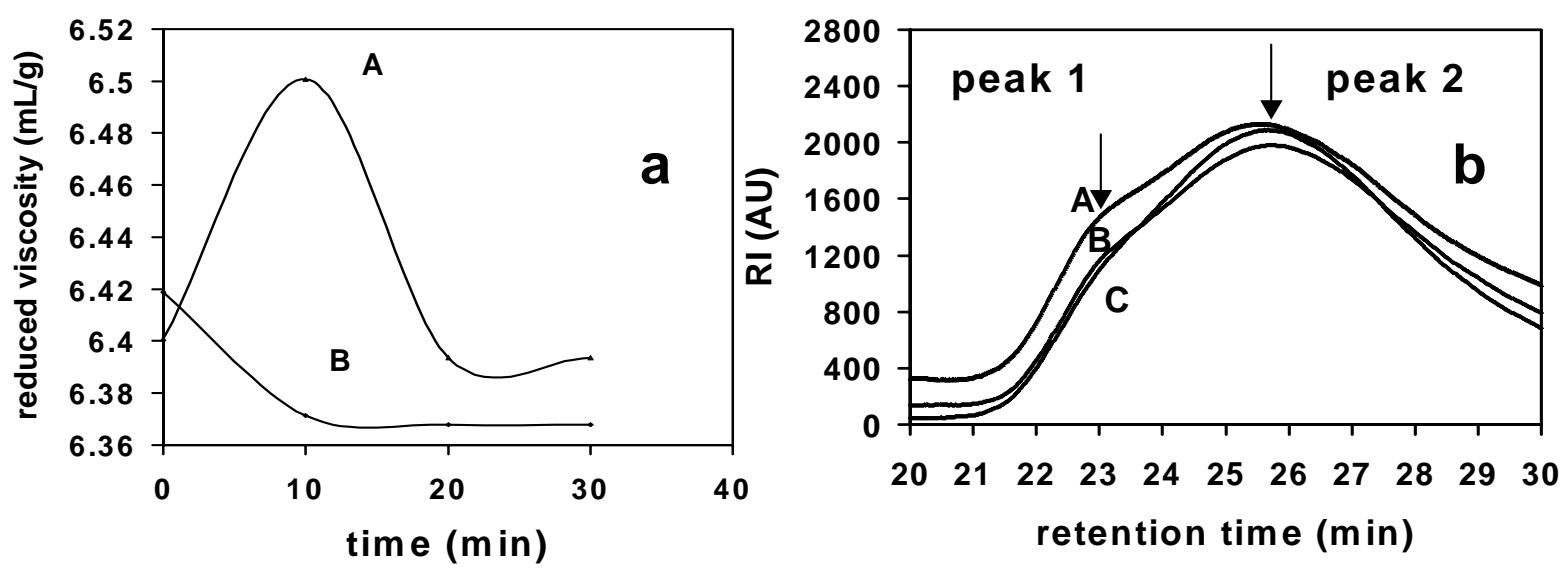

Figure 3.8 Effect of $\mathrm{HRP} / \mathrm{H}_{2} \mathrm{O}_{2}$ and $\mathrm{FA}$ on viscosity and molecular weight distribution of WEP

Fig. 3.8a: Changing in viscosity of WEP by $\mathrm{HRP} / \mathrm{H}_{2} \mathrm{O}_{2}$ and FA

$\mathrm{A}=0.3 \% \mathrm{WEP}+1 \mathrm{~mL} 20 \mathrm{mM}$ buffer $+100 \mu \mathrm{L} \mathrm{HRP}(\mathrm{mg} / \mathrm{mL})+100 \mu \mathrm{L} 5 \mathrm{mM} \mathrm{H}_{2} \mathrm{O}_{2}$,

$\mathrm{B}=0.3 \% \mathrm{WEP}+1 \mathrm{~mL} 20 \mathrm{mM} \mathrm{FA}+100 \mu \mathrm{L} \mathrm{HRP}(\mathrm{mg} / \mathrm{mL})+100 \mu \mathrm{L} 5 \mathrm{mM} \mathrm{H}_{2} \mathrm{O}_{2}$.

Fig.3.8b: HPSEC of WEP samples taken at reaction time of $30 \mathrm{~min}$.

$\mathrm{A}=0.3 \% \mathrm{WEP}+1 \mathrm{~mL} 20 \mathrm{mM}$ buffer $+100 \mu \mathrm{L} \mathrm{HRP}(\mathrm{mg} / \mathrm{mL})+100 \mu \mathrm{L} 5 \mathrm{mM} \mathrm{H}_{2} \mathrm{O}_{2}$,

$\mathrm{B}=0.3 \% \mathrm{WEP}+1 \mathrm{~mL} 20 \mathrm{mM} \mathrm{FA}+100 \mu \mathrm{L} \mathrm{HRP}(\mathrm{mg} / \mathrm{mL})+100 \mu \mathrm{L} 5 \mathrm{mM} \mathrm{H}_{2} \mathrm{O}_{2}$,

$\mathrm{C}=0.3 \% \mathrm{WEP}$.

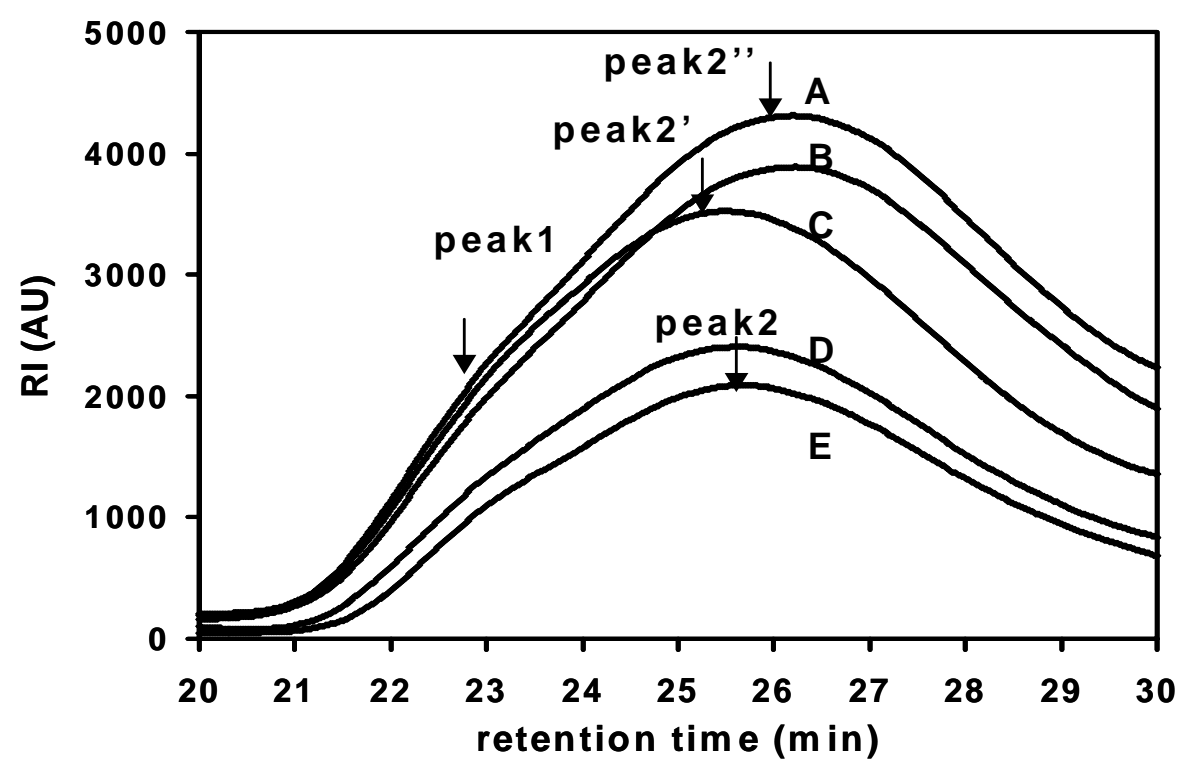

Figure 3.9 Molecular weight distribution of WEP isolated from starch slurry after gluten formation

$\mathrm{A}, \mathrm{B}, \mathrm{C}$ and $\mathrm{D}$ are isolated WEP from starch slurry after gluten formation

$\mathrm{A}=30 \mathrm{ppmFA}, \quad \mathrm{B}=0.3 \% \mathrm{WEP}+30 \mathrm{ppmFA}, \quad \mathrm{C}=$ control $, \quad \mathrm{D}=0.3 \% \mathrm{WEP}, \quad \mathrm{E}=0.3 \% \mathrm{WEP}$ (Megazyme). 


\subsection{Conclusions}

WEP not only have a negative effect on GY, but also affect dough properties, gluten quality and composition. WEP interfere with gluten formation both in a direct and an indirect way. Due to their nature, WEP interfere indirectly by competing for water and thus changing conditions for gluten development. This leads to a lower GY and an increased $\mathrm{R}_{\max }$. This effect can be corrected for completely by adding $0.2 \% \mathrm{NaCl}$ solution during dough mixing. In addition, AX bound FA is involved in the direct effect of WEP on gluten formation. This direct effect is reflected in a lower extensibility of dough and gluten. Addition of free FA leads to both a higher GY and a more extensible dough and gluten.

We conclude that AX bound FA is the key to the direct effect of WEP on gluten formation and properties. The AX bound FA moieties can act in two ways. First, by cross-linking WEP, leading to a higher viscosity in the liquid phase (see Fig.3.8). This finding is reported by many other authors. We have proven that this also occurs during flour processing in the TNO Glutomatic (Fig.3.9). However, we regard this effect on gluten formation to be indirect, because it is viscosity mediated and can be corrected for by adding more $0.2 \% \mathrm{NaCl}$ solution during dough mixing. Also, it does not occur with $\mathrm{S}_{\mathrm{x}}$ and $\mathrm{WEP}_{\mathrm{x}}$ (Table 3.3). The second way, by which AX bound FA can act, is by directly linking to gluten proteins. Oudgenoeg et $\mathrm{al}^{21}$ have demonstrated such a FA mediated cross-linking. We propose that this is the main effect when adding $S_{x}$ and $W_{E P}$. This effect is not viscosity mediated, cannot be corrected for by water addition and results in a decreased extensibility of dough and gluten. Adding free FA corrects for this effect by competing with AX bound FA.

\section{Acknowledgements}

This research work is partly financed by the China Scholarship Council. Also, the financial support by Wageningen Centre for Food Sciences is gratefully acknowledged.

\section{References}

1. Meuser, F. and Suckow, P. In 'Chemistry and physics of baking'. (M.V.Blanshard, P.J. Frazier and T. Galliard, eds.), The Royal Society of Chemistry, London (1986) pp 42-61.

2. Izydorczyk, M., and Biliaderis, C.G. Cereal arabinoxylans: Advances in structure and physicochemical properties. Carbohydrate Polymers 28 (1995) 33-48.

3. Geissmann, T. and Neukom, H. On the composition of the water-soluble wheat flour pentosans and their oxidative gelation. Lebensmittel Wissenschaft und Technologie 6 
(1973) 59-62.

4. Hoseney, R.C. and Faubion, J.M. A mechanism for the oxidative gelation of wheat flour water-soluble pentosans. Cereal Chemistry 58 (1981) 421-424.

5. Izydorczyk, M.S., Biliaderis, C.G. and Bushuk, W. Oxidative gelation studies of water-soluble pentosans from wheat. Journal of Cereal Science 11 (1990) 153-169.

6. Jelaca, S.L. and Hlynka, I. Water-binding capacity of wheat-flour crude pentosans and their relation to mixing characteristics of dough. Cereal Chemistry 48 (1971) 211-222.

7. Patil, S.K., Tsen, C.C. and Lineback, D.R. Water-soluble pentosans of wheat flour. I. Viscosity properties and molecular weights estimated by gel filtration. Cereal Chemistry 52 (1975) 44-56.

8. Rouau, $\mathrm{X}$ and Moreau, D. Modification of some physicochemical properties of Wheat flour pentosans by an enzyme complex recommended for baking. Cereal Chemistry $\mathbf{7 0}$ (1993) 626-632.

9. Jelaca, S.L. and Hlynka, I. Effect of wheat-flour pentosans in dough, gluten and bread. Cereal Chemistry 49 (1972) 489-495.

10. Kim, S.L. and D'Appolonia, B.L. Bread staling studies. III. Effect of pentosans on dough, bread and bread stating rate. Cereal Chemistry 54 (1977) 225-229.

11. Rouau, X., EI Hayek, M. L., and Moreau, D. Effect of an enzyme preparation containing pentosanases on the bread-making quality of flours in relation to changes in pentosan properties. Journal of Cereal Science 19 (1994) 259-272.

12. Ciacco, C.F. and D'Appolonia, B.L. Characterization of pentosans from different flour classes and of their gelling capacity. Cereal Chemistry 59 (1982) 96-100.

13. Ciacco, C.F. and D'Appolonia, B.L. Characterization and gelling capacity of water-soluble pentosans isolated from different millstreams. Cereal Chemistry 59 (1982) 163-166.

14. Izydorczyk, M.S., Biliaderis, C.G. and Bushuk, W. Comparison of the structure and composition of water-soluble pentosans from different wheat varieties. Cereal Chemistry 68 (1991) 139-144.

15. Izydorczyk, M.S., Biliaderis, C.G. and Bushuk, W. Physical properties of water-soluble pentosans from different wheat varieties. Cereal Chemistry 68 (1991) 145-150.

16. McCleary, B. V. Enzymic modification of plant polysaccharides. International Journal of Biological Macromolecules 8 (1986) 433-436.

17. Maat, J., Roza, M, Verbakel, J., Santos da Silva, J.M., Bosse, M., Egmond, M.R., Hagemans, M.L.D., v. Gorcom, R.F.M., Hessing, J.G.M., v.d.Hondel, C.A.M.J.J.and v. Rotterdam, C. in 'Xylans and Xylanases', Progress in Biotechnology Series Vol.7, 
(J.Visser, G.Beldman, M.A.Kusters-van Someren, and A.G.J. Voragen, eds.), Elsevier, Amsterdam (1992) pp349-360.

18. Rouau, X. Investigation into the effect of an enzyme preparation for baking on wheat flour dough pentosans. Journal of Cereal Science 18 (1993) 145-157.

19. Geissmann, T. and Neukom, H. A note on ferulic acid as a constituent of the water-insoluble pentosans of wheat flour. Cereal Chemistry 50 (1973) 414-416.

20. Amado, R. and Neukom, H. In 'New approaches to research on cereal carbohydrates' (R.D. Hill and L. Munck, eds.) Elseviser Sciences Publ., Amsterdam (1985) pp 241-251.

21. Oudgenoeg G, Hilhorst R, Piersma SR, Boeriu CG, Gruppen H, Hessing M, Voragen AG, Laane C. Peroxidase-mediated cross-linking of a tyrosine- containing peptide with ferulic acid. Journal of Agricultural and Food Chemistry 49 (2001) 2503-2510.

22. Jackson, G.M. and Hoseney, R.C. Effect of endogenous phenolic acids on the mixing properties of wheat flour doughs. Journal of Cereal Science 4 (1986) 79-85.

23. Labat, E., Morel, M.H. and Rouau, X. Effect of laccase and ferulic acid on wheat flour dough. Cereal Chemistry 77 (2000) 823-828.

24. Huggins, M. The viscosity of dilute solutions of long-chain molecules. IV. Dependence on concentration. Journal of American Chemical Society 64 (1942) 2716-2718.

25. Sakai, T. Extrapolation procedures for intrinsic viscosity and for Huggins constant K'. Journal of Polymer Science 6 (1968) 1659-1672.

26. Kieffer, R., Wieser, H., Henderson, M.H. and Graveland, A. Correlations of the breadmaking performance of wheat flour with rheological measurements on a micro-scale. Journal of Cereal Science 27 (1998) 53-60.

27. Englyst, H.N. and Cummings, J.H. Simplified method for the measurement of total non-starch polysaccharides by Gas-Liquid Chromatography of constituent sugars as alditol acetates. Analyst 109 (1984) 937-942.

28. Filiatrault, D. and Delmas, G. Intrinsic viscosities and Huggins constant for ethylene-propylene copolymers.1. Effect of the correlation of orientations in the pure components or in the solutions on the solvent quality. Viscosities in linear alkanes and three highly branched alkanes. Journal of American Chemical Society 12 (1979) 65-68.

29. Gruppen, H., Hamer, R.J. and Voragen, A.G.J. Water- unextractable cell wall material from wheat flour. I. Extraction of polymers with alkali. Journal of Cereal Science 16 (1992) 41-51.

30. Gruppen, H., Kormelink, F.J.M., Voragen, A.G.J. Enzymic degradation of water- 
unextractable cell wall material and arabinoxylans from wheat flour. Journal of Cereal Science 18 (1993) 129-143.

31. DuPont, M.S. and Selvendran, R.R. Hemicellulosic polymers from the cell walls of beeswing wheat bran: Part I. Polymer's solubilised by alkali at $2^{\circ} \mathrm{C}$. Carbohydrate Research 163 (1987) 99-113.

32. Faulds, C.B. and Williamson, G. Release of ferulic acid from wheat bran by a Ferulic acid esterase (FAE-III) from Aspergillus Niger. Applied Microbiology Biotechnology 43 (1995) 1082-1087.

33. Wang, M-W, Hamer, R.J., Vliet, T.V., Gruppen, H., Marseille, J.P. Weegles, P.L. Effect of water unextractable solids on formation and properties of gluten I.: Mechanistic considerations. Journal of Cereal Science 37 (2003) 55-64.

34. Bushuk, W. In 'Interactions: The keys to cereal quality’ (Rob J. Hamer and R. Carl Hoseney, eds.), American Association of Cereal Chemists, USA (1998) pp5.

35. Saulnier, L., Andersson, R.and Aman, P. A study of the polysaccharide components in gluten. Journal of Cereal Science 25 (1997) 121-127.

36. Figueroa-Espinoza, M.C. and Rouau, X. Oxidative cross-linking of pentosans by a fungal laccase and Horseradish Peroxidase: Mechanism of linkage between feruloylated arabinoxylans. Cereal Chemistry 75 (1998) 259-265. 
Chapter 3 


\title{
Interaction of water unextractable solids with gluten protein:
} Effect on dough properties and gluten quality

\begin{abstract}
In chapter 2 we have shown that water unextractable solids (WUS) interfere with gluten formation and affect the quality of the resulting gluten. In this chapter we aim to explain how WUS can effect the process of gluten formation. To this end, WUS were modified with $\mathrm{NaOH}$, xylanase, horseradish peroxidase (HRP) and hydrogen peroxide $\left(\mathrm{H}_{2} \mathrm{O}_{2}\right)$. Effects of modified WUS on gluten yield, dough properties, and gluten and glutenin macropolymer (GMP) composition and properties were studied. The results showed that addition of WUS to wheat flour led to a lower gluten yield and gluten starch yield, a higher $\mathrm{R}_{\max }$ and a lower $\mathrm{E}$ at $\mathrm{R}_{\max }$ of gluten and a more concentrated and elastic GMP gel. Pretreatment of WUS by $\mathrm{NaOH}$, xylanase, HRP and $\mathrm{H}_{2} \mathrm{O}_{2}$ cannot correct its negative effect on gluten yield, but addition of xylanase or free ferulic acid (FA) during gluten separation can remove or prevent the negative effect of WUS on gluten yield. Compared to addition of only WUS, addition of WUS and FA together to wheat flour resulted in a higher gluten yield, a higher $\mathrm{E}$ at $\mathrm{R}_{\max }$ of gluten, and a less concentrated and elastic GMP gel. Similar to water extractable pentosans (WEP), FA bound WUS plays a key role in the effect of WUS on gluten yield and properties. It appears that there is a common mechanism regarding the effect of WUS and WEP that the oxidative cross-linking during gluten formation could be prevented by FA addition. The difference between both is that WUS have a higher water binding capacity, which is reflected in a higher $\mathrm{R}_{\max }$ of dough and gluten in the presence of WUS.
\end{abstract}

Wang, M-W, Oudgenoeg, G, van Vliet T. and Hamer, R.J. Journal of Cereal Science in press. 


\subsection{Introduction}

Water unextractable solids (WUS), mainly containing water unextractable arabinoxylans (AX), have long been considered to be functionally important in dough properties and breadmaking quality due to their high affinity for water ${ }^{1-11}$. In order to study this effect, reconstitution experiments of wheat flour prior to dough development have been performed ${ }^{2,6-11}$. These experiments involved changing the level of WUS enriched preparations in the final dough and also included modification of isolated WUS fractions before reconstitution ${ }^{2,6-11}$. It has been reported that addition of WUS to wheat flour markedly increases water absorption ${ }^{6-11}$, development time ${ }^{6,9-10}$ and resistance to extension of dough ${ }^{2,10}$, but decreases dough extensibility and gluten yield ${ }^{9}$. Our previous study ${ }^{12}$ also showed that addition of WUS led to a lower gluten yield and produced a less extensible gluten with an increase in maximum resistance to maximal extension. Also, some contradictory results have been reported with respect to the role of WUS in the bread-making process ${ }^{3,5}$. The reason for this inconsistency may lie in the fractionation procedures used to obtain the pentosan fraction as well as in the inherent differences in structure and properties of materials isolated from different wheat varieties ${ }^{8}$. Nevertheless, in general, WUS are considered to have a negative effect on bread-making quality ${ }^{2,13}$; while water extractable pentosans (WEP) are generally believed to have a positive effect 14.

Various studies have been performed on the use of pentosanases ${ }^{14-22}$ to correct this negative effect of WUS. It has been stated that addition of this enzyme to a dough resulted in a loss of dough strength as well as height, but caused an increase in loaf volume ${ }^{15,21}$. Our previous study also showed that application of xylanase led to a more extensible gluten with a decrease in maximum resistance to extension ${ }^{12}$. In all these studies, the central question remains on the mechanism of action of WUS. As reported earlier, several possibilities exist related to the water binding properties, particle properties and potential cross-linking properties of WUS. For the latter, ferulic acid is required.

Ferulic acid (FA, 4-hydroxy-3-methoxycinnamic acid) is concentrated in the cell wall of the outer coverings of wheat where it is mainly esterified to the arabinose backbone of $\mathrm{AX}^{23-24}$. Free, soluble-bound and insoluble-bound FA have been found in wheat flour and gluten ${ }^{25-26}$. Many studies have been carried out on oxidative gelation of water extractable $\mathrm{AX}^{23,27-39}$. Water unextractable $\mathrm{AX}$ have also been reported to be amenable to further cross-linking via FA residues in the polymeric matrix ${ }^{8}$. Several mechanisms have been proposed for oxidative cross-linking that are quite different. Neukom and Markwalder ${ }^{28}$ suggested three possible mechanisms: 1) cross-linking of two FA residues by covalently 
joining the aromatic rings, 2) cross-linking of protein ( at a tyrosine residue) and a FA residue by their aromatic rings, and 3) cross-linking of the aromatic rings of tyrosine in protein. Hoseney and Faubion ${ }^{29}$ suggested that FA side chains on AX were oxidised by free hydroxyl radicals, leading to cross-linking with cysteine amino acids residues in protein. They postulated that it was the activated double bond on FA, rather than the aromatic group, that was active in oxidative gelation. Moore et al ${ }^{31}$ and Vinkx et al ${ }^{32}$ suggested that the aromatic group of the FA groups on WEP served as the site of cross-linking. Recently, Figueroa-Espinoza and Rouau ${ }^{34}$ showed that cross-linking of the pentosans was quite complicated, involving the formation of a number of cross-linking compounds. In chapter $3^{40}$ we demonstrated the importance of FA in water extractable pentosans (WEP) by showing that addition of FA could prevent this oxidative cross-linking during gluten formation. This removed the negative effect of water extractable pentosans (WEP) on gluten yield and properties.

The present study was undertaken to investigate the effect of water unextractable AX on dough properties and gluten quality as part of a systematic study on the effect of pentosans with gluten formation. WUS contain a high level of arabinoxylans and also FA residues. Therefore, similar to chapter 3 , WUS were treated with $\mathrm{NaOH}$, xylanase, horseradish peroxidase (HRP) and hydrogen peroxide $\left(\mathrm{H}_{2} \mathrm{O}_{2}\right)$ to generate fractions differing in both water holding capacity (WHC) and the capacity to form FA mediated cross-links. These materials were used in the preparation of a series of gluten samples, which were characterised with respect to chemical composition and rheological properties. To gain more insight in the background of differences in gluten properties, we also studied the SDS insoluble network protein of gluten, the Glutenin Macro Polymer fraction (GMP). The effects of modified WUS on gluten yield, gluten and GMP composition and properties are discussed

\subsection{Experimental}

\subsubsection{Materials}

Wheat flour (untreated) used for preparation of WUS and gluten experiments was kindly donated by Meneba Meel, Rotterdam. The Soissons flour used for isolation of GMP was supplied by TNO, Zeist, the Netherlands.

WUS (-) (without treating by amylase, hereafter called WUS) were isolated from wheat flour as described previously ${ }^{12}$. The AX, starch and protein content of WUS are 47.1 $\pm 0.5 \%, 26.4 \pm 0.2 \%$ and $19 \pm 2 \%$ respectively.

Xylanase I (batch ppj 4482) used was the same preparation as described previously. ${ }^{12}$ 
Horseradish peroxidase (HRP, type VI A) and FA were obtained from Sigma.

All other chemicals used were of analytical grade.

\subsubsection{Modification of WUS}

\subsubsection{Treatment of WUS by $\mathrm{NaOH}$}

WUS preparation ( $1 \mathrm{~g}$ ) was dispersed in $10 \mathrm{~mL} \mathrm{95 \%} \mathrm{(v/v)} \mathrm{ethanol} \mathrm{and} \mathrm{dissolved} \mathrm{in}$ $490 \mathrm{~mL} \mathrm{0.4} \mathrm{M} \mathrm{NaOH}$ solution under stirring. The slurry was continuously stirred overnight in a cold room $\left(4^{\circ} \mathrm{C}\right)$ and neutralised to $\mathrm{pH} 7$ with $0.4 \mathrm{M} \mathrm{pH} 5$ sodium acetate buffer. The incubation mixture was centrifuged for $10 \mathrm{~min}$ at $14,800 \times \mathrm{g}$. The residue was extracted with $100 \mathrm{~mL}$ distilled water for $1 \mathrm{~h}$, centrifuged again for $10 \mathrm{~min}$ at $14,800 \times \mathrm{g}$, and freeze-dried (hereafter called $\mathrm{WUS}_{\mathrm{OH}}$ ).

\subsubsection{Preincubation of WUS by xylanase}

WUS (1 g) was dispersed in $10 \mathrm{~mL}$ 95\% (v/v) ethanol and dissolved in $90 \mathrm{~mL} 50 \mathrm{mM}$ sodium acetate buffer $(\mathrm{pH}$ 5) under stirring. The slurry was incubated with $0.1 \mathrm{~mL}$ xylanase solution $(1 \mathrm{mg} / \mathrm{mL})$ at $30^{\circ} \mathrm{C}$ for $24 \mathrm{~h}$ in the presence of $0.05 \% \mathrm{NaN}_{3}$, and subsequently inactivated at $100^{\circ} \mathrm{C}$ for 10 min and neutralised to $\mathrm{pH} 7$ with $0.5 \mathrm{M} \mathrm{NaOH}$ solution. The incubation mixture was centrifuged for $10 \mathrm{~min}$ at $14,800 \times \mathrm{g}$. The pellet was extracted with $100 \mathrm{~mL}$ distilled water for $1 \mathrm{~h}$, centrifuged again for $10 \mathrm{~min}$ at 14,800 $\times \mathrm{g}$, and freeze-dried (hereafter called $\mathrm{WUS}_{\mathrm{x}}$ ).

\subsubsection{Modification of WUS by FA, $\mathrm{HRP}$ and $\mathrm{H}_{2} \mathrm{O}_{2}$}

WUS preparation ( $1 \mathrm{~g}$ ) was dispersed in $10 \mathrm{~mL} 95 \%(\mathrm{v} / \mathrm{v})$ ethanol and dissolved in $100 \mathrm{~mL} 10 \mathrm{mM}$ ammonium acetate (pH 5) under stirring. HRP was also dissolved in 10 $\mathrm{mM}$ ammonium acetate ( $\mathrm{pH}$ 5). FA was dissolved in $0.1 \mathrm{M} \mathrm{KH}_{2} \mathrm{PO}_{4}$ and $\mathrm{K}_{2} \mathrm{HPO}_{4}$ buffer (pH 7). Then $1 \mathrm{~mL} 0.5 \mathrm{M} \mathrm{FA}, 100 \mu \mathrm{L} \mathrm{HRP}(1 \mathrm{mg} / \mathrm{mL})$ and $100 \mu \mathrm{L} 5 \mathrm{mM} \mathrm{H} \mathrm{O}_{2}$ were each sequentially added in 5 portions to the WUS dispersion ${ }^{37}$. The mixture was incubated for 2 $\mathrm{h}$ at room temperature, after which was brought the mixture to $100^{\circ} \mathrm{C}$ for $10 \mathrm{~min}$ to stop the reaction. Then the solution was neutralised to $\mathrm{pH} 7$ with $0.5 \mathrm{M} \mathrm{NaOH}$ solution. The incubation mixture was centrifuged for $10 \mathrm{~min}$ at $14,800 \times \mathrm{g}$. The pellet was extracted with $100 \mathrm{~mL}$ distilled water for $1 \mathrm{~h}$, centrifuged again for $10 \mathrm{~min}$ at $14,800 \times \mathrm{g}$ and freeze-dried (hereafter called $\mathrm{WUS}_{\mathrm{p}}$ ).

\subsubsection{Characterisation of modified WUS preparations}




\subsubsection{WHC}

WHC of modified WUS preparations was determined using the method of Robertson and Eastwood ${ }^{41}$ by measuring the wet weight $(\mathrm{g})$ of the final residue after washing with distilled water.

\subsubsection{FA content}

WUS (50 mg) was weighed into a $10 \mathrm{~mL}$ centrifuge tube, to which $3.5 \mathrm{~mL} 0.1 \mathrm{M}$ sulfuric acid was added. After the sample was dispersed in the dilute acid, the tube was placed into a boiling water bath for $30 \mathrm{~min}$. Then, the sample extract was cooled by running tap water. A total of $0.5 \mathrm{~mL}$ of a $2 \%(\mathrm{w} / \mathrm{v})$ suspension of Porcine $\alpha$-amylase (Merck art.) in $2.5 \mathrm{M}$ aqueous sodium acetate solution was added to the tube, and the extract was incubated in a water bath $\left(30^{\circ} \mathrm{C}\right)$ for $60 \mathrm{~min}$ with periodic agitation. The sample was then centrifuged for $15 \mathrm{~min}$ at $14,800 \times \mathrm{g}$ and the supernatant was decanted into another $10 \mathrm{~mL}$ tube before fluorescence measurement. The fluorescence intensity of diluted FA standards and various sample solutions at a wavelength of $420 \mathrm{~nm}$ was measured using a LS50B Fluorimeter (Perkin Elmer), which was operated at an excitation wavelength of $312 \mathrm{~nm}$. The FA content of samples was calculated from the measured intensity.

\subsubsection{Characterisation of dough and gluten samples}

Dough was prepared using a mixograph (National Manufacturing Co.). Flour was mixed using either $50 \%$ of water $(0.2 \% \mathrm{NaCl})$ and 3 min of mixing time or $55 \%$ of water and 5 min of mixing time at ambient temperature.

Gluten yield of dough was determined and gluten samples were prepared using a modified Glutomatic 2200 system (Perten, modified by TNO) as described previously ${ }^{12}$. The mixing time and mixing water used are $3 \mathrm{~min}$ and $7.3 \mathrm{~mL}$ respectively.

Gluten rheological properties were measured using a Kieffer extensibility rig fitted onto a Texture Analyser equipped with a $5 \mathrm{~kg}$ load cell as described previously ${ }^{12}$.

\subsubsection{Characterisation of GMP gel}

\subsubsection{GMP isolation}

Freeze-dried gluten sample ( $3 \mathrm{~g}$ ) was dispersed in $75 \mathrm{~mL}$ petroleum ether, mixed for $20 \mathrm{~min}$ and centrifuged $\left(18,900 \times \mathrm{g}, 10 \mathrm{~min}\right.$ at $\left.5^{\circ} \mathrm{C}\right)$. The whole procedure was repeated. Petroleum ether residues in the defatted gluten sample were evaporated for overnight in a 
fume hood.

Defatted gluten sample (80 mg) was dispersed in $10 \mathrm{~mL} \mathrm{1.5 \% (w/v)} \mathrm{SDS} \mathrm{solution} \mathrm{and}$ ultracentrifuged $\left(69,000 \times \mathrm{g}, 30 \mathrm{~min}\right.$ at $\left.20^{\circ} \mathrm{C}\right)$. The supernatant was discarded and the gel-like layer found on top of the starch pellet (called GMP) was weighed as GMP wet weight.

The protein content of the GMP gel was determined using the Dumas method after drying the GMP gel at $80{ }^{\circ} \mathrm{C}$ for $2 \mathrm{~h}$.

Extent of coagulation (EC) is defined as the relative amount of GMP protein that can be isolated from wheat flour as described previously.

$$
E C=\frac{Y_{s} \cdot W_{s} \cdot P_{s}}{Y_{c} \cdot W_{c} \cdot P_{c}} \times 100
$$

where: $\mathrm{Y}=$ gluten yield ( $\mathrm{g} / \mathrm{g}$ flour $)$

$\mathrm{W}=\mathrm{GMP}$ wet weight $(\mathrm{g} / \mathrm{g}$ gluten $)$

$\mathrm{P}=$ GMP protein content $(\mathrm{mg} / \mathrm{g}$ wet $\mathrm{GMP})$

$\mathrm{s}=$ sample

$\mathrm{c}=$ control

\subsubsection{Rheometer measurements}

Rheometer measurements were performed to characterise GMP gels using a Bohlin VOR rheometer (Bohlin, Sweden) as described previously ${ }^{12}$.

\subsubsection{Analytical methods}

Protein content was determined using Dumas method as described previously ${ }^{12}$.

Starch content was measured enzymatically using the test kit supplied by Boehringer, Mannheim.

AX content was analysed using the alditol acetate method with inositol as internal standard as described previously ${ }^{12}$.

\subsection{Results and discussion}

\subsubsection{Characterisation of modified WUS}

\subsubsection{WHC}

The various modified WUS were characterised in terms of WHC, AX and FA content (see Table 4.1). Pretreatment of WUS by $\mathrm{NaOH}$ or $\mathrm{HRP}\left(\mathrm{WUS}_{\mathrm{OH}}\right.$ or $\mathrm{WUS}_{\mathrm{P}}$ ) led to a higher WHC of WUS; in contrast, preincubation of WUS by xylanase $\left(\mathrm{WUS}_{\mathrm{x}}\right)$ resulted in a lower 
WHC of WUS. The latter finding is consistent with Gruppen ${ }^{22}$ and Rouau ${ }^{18}$ and can be explained by a loss of water binding arabinoxylans by the action of the xylanase. The higher WHC of $\mathrm{WUS}_{\mathrm{OH}}$ can be explained by partial solubilisation of AX contained within the fibrous material, improving the ability of the material to absorb water ${ }^{8}$. However, this is only a speculation. Perhaps, there are more reasons leading to a higher $\mathrm{WHC}$ of $\mathrm{WUS}$ OH, since WUS $_{\mathrm{OH}}$ is different from WUS in many respects (Table 4.1). The increase in WHC of WUS as a result of HRP treatment is significant and has not been reported earlier. However, according to Izydorczyk et al ${ }^{30}$, water extractable pentosans upon oxidative gelation had a remarkable ability to swell and retain large amounts of water in their structure.

\subsubsection{AX content}

Table 4.1 shows that the AX content of $\mathrm{WUS}_{\mathrm{OH}}$ and $\mathrm{WUS}_{\mathrm{x}}$ was lower than that of WUS and the $\mathrm{A} / \mathrm{X}$ of $\mathrm{WUS}_{\mathrm{OH}}$ and $\mathrm{WUS}_{\mathrm{x}}$ was higher than that of WUS. These data are in agreement with the results of Michniewicz ${ }^{8}$ and Gruppen ${ }^{22,42}$ and show that both $\mathrm{NaOH}$ and xylanase have solubilized and degraded part of the AX in WUS. The extent of solubilisation and degradation depends on the purity of the isolated WUS, the concentrations and the incubation time of $\mathrm{NaOH}$ and xylanase, and also on the accessibility of WUS for the xylanase ${ }^{8,22}$. As expected, the AX content of WUS $\mathrm{W}_{\mathrm{p}}$ was comparable with that of WUS.

Table 4.1 Characterisation of various modified WUS

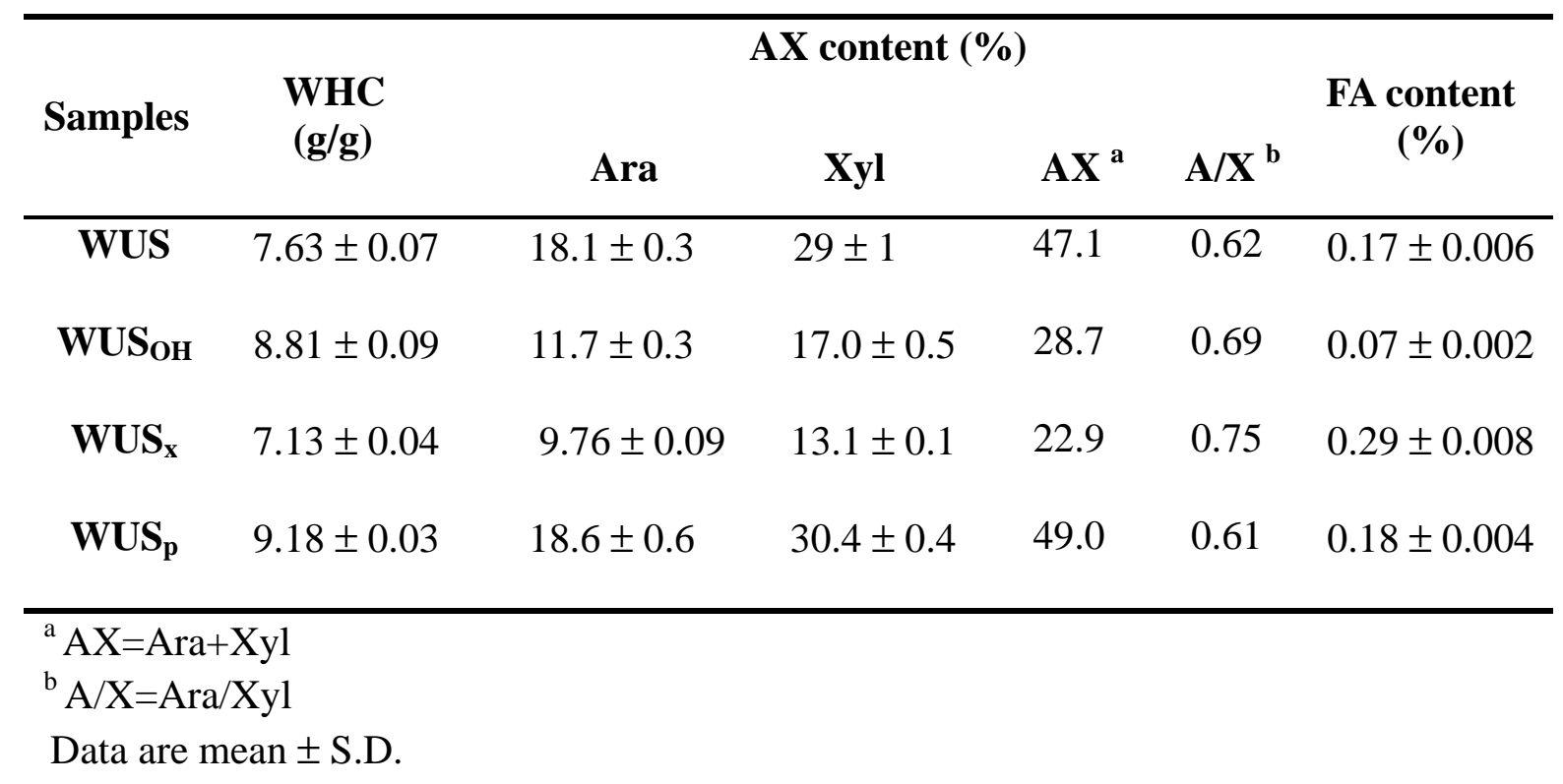




\subsubsection{FA content}

In agreement with results presented in chapter 3, pretreatment of WUS by $\mathrm{NaOH}$ led to a lower FA content, while preincubation of WUS by xylanase resulted in a higher FA content. The latter can be explained by the fact that xylanase preferentially liberates AX from the insoluble WUS, that are poor in FA. This has also been found by other authors studying the hydrolysis of fibers ${ }^{17-19}$. The FA content of WUS ${ }_{\mathrm{p}}$ was about the same as that of WUS.

\subsubsection{Effect of modified WUS and FA on gluten yield}

\subsubsection{Effect of modified WUS on gluten yield}

Fig. 4.1 demonstrates the effect of various modified WUS on gluten yield. A decrease in gluten yield was observed for all modified WUS. This means that pretreating WUS by $\mathrm{NaOH}$ or xylanase or HRP did not neutralize their negative effect. In view of the WHC of WUS we also studied the effect with increased mixing time and more added water during dough mixing (Fig. 4.1). In all cases gluten yield was improved but not to the level of the control. Since WHC of various modified WUS are different, Fig 4.1 does not represent the optimal result that can be achieved with mixing times and water additions. Nevertheless, the results presented in Fig. 4.1 are representative for the effects of WUS since similar effects occur at two different mixing time/water addition (see Table 4.2). Xylanase is efficient in neutralizing the negative effects. Here, in all cases, yield was higher than the control. Also, no differences were observed that could be related to the modified WUS preparations.

\subsubsection{Effect of FA on gluten yield}

Previous studies ${ }^{40}$, in which the effect of WEP was studied, showed that addition of free FA led to a loss of gluten yield in the control sample (without WEP addition), but resulted in a higher gluten yield in the presence with WEP. Does free FA also give a higher gluten yield in the presence of WUS? To answer this, the effect of added FA on gluten yield with or without WUS was studied (see Fig.4.2). A similar effect of FA on gluten yield with WUS was observed as for WEP. Addition of FA can correct for a loss of gluten yield caused by the addition of WUS to the flour.

We also studied to what extent free FA can correct for the negative effects of the various modified WUS (Fig.4.3). In all cases, addition of FA leads to a higher yield. It is 
noted that the degree to which a correction was possible differed for the different modified WUS preparations.

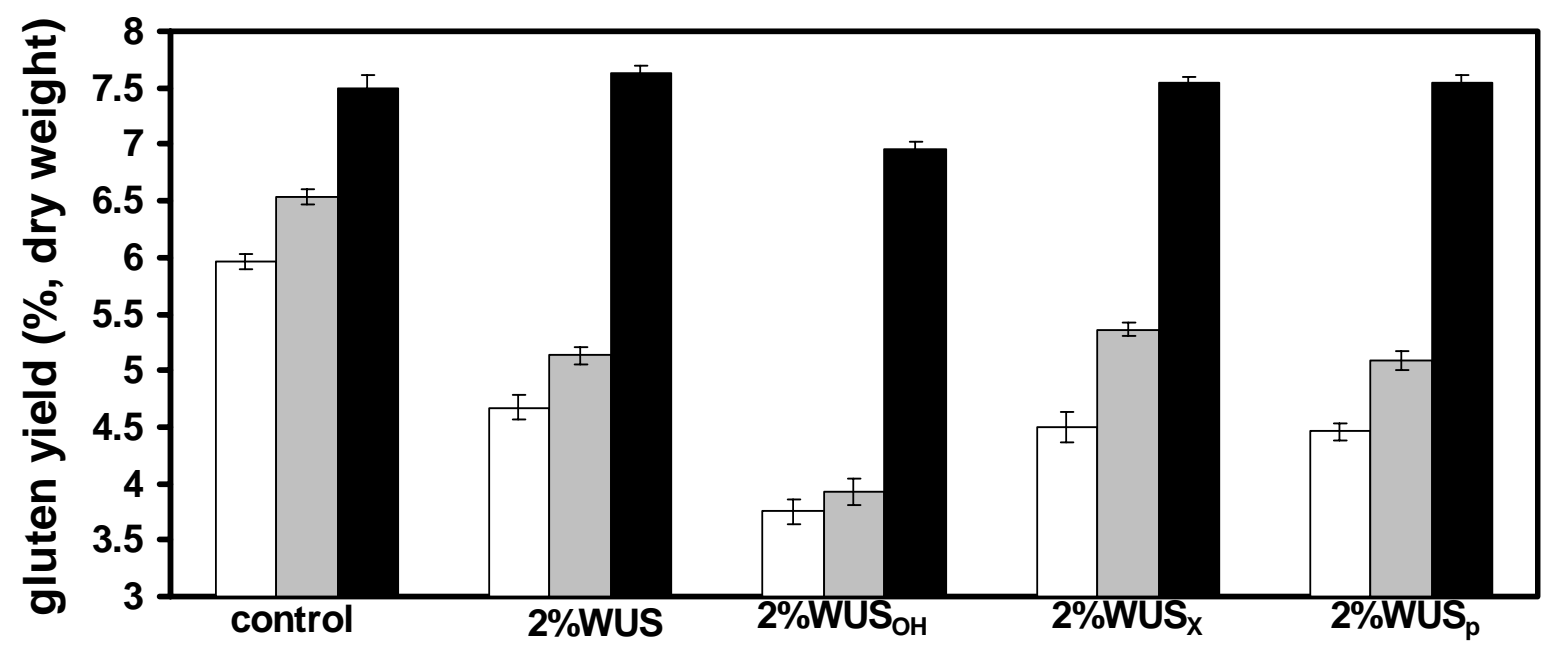

Figure 4.1 Effect of modified WUS on gluten yield at various conditions White column=control ( $3 \mathrm{~min} \mathrm{mix}, 7.3 \mathrm{~mL}$ water),

Grey column=increasing mixing time and water $(5 \mathrm{~min} \operatorname{mix}, 7.8 \mathrm{~mL}$ water $)$, Black column $=+100 \mathrm{ppm}$ xylanase $(3 \mathrm{~min}$ mix, $7.3 \mathrm{~mL}$ water $)$.

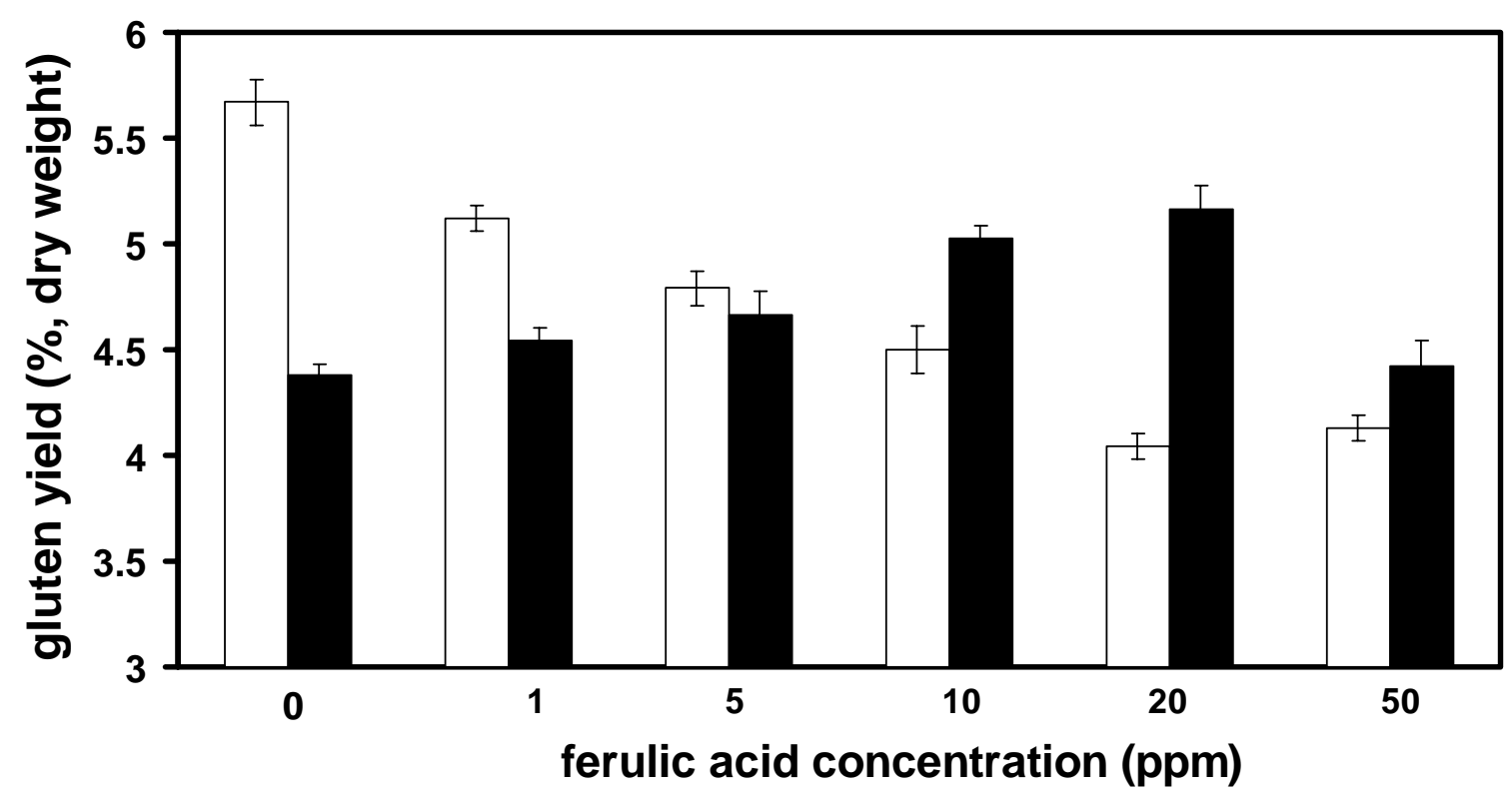

Figure 4.2 Effect of the concentration of FA on gluten yield

White column=control ( $3 \mathrm{~min} \operatorname{mix}, 7.3 \mathrm{~mL}$ water),

Black column=flour $+2 \%$ WUS ( 3 min mix, $7.3 \mathrm{~mL}$ water). 


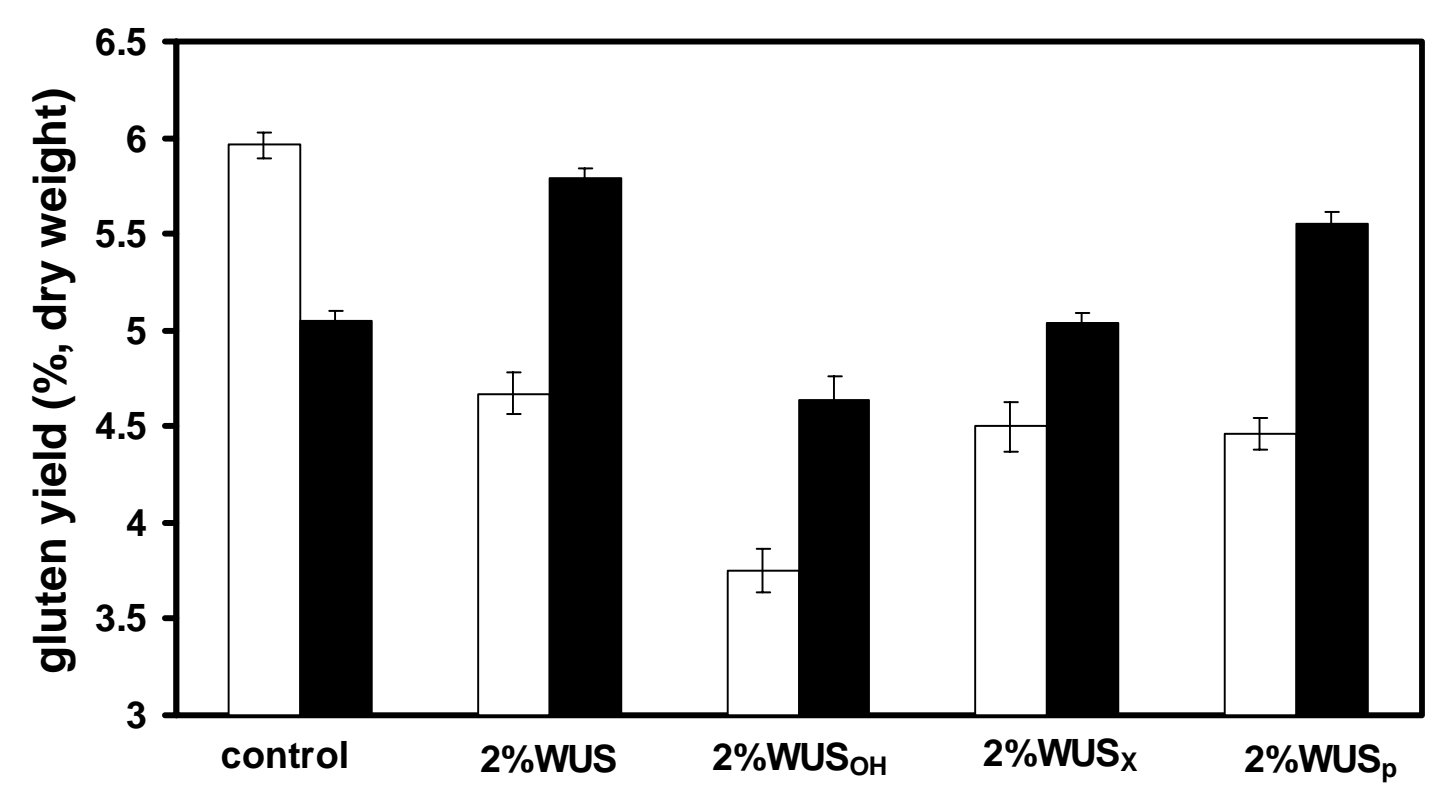

Figure 4.3 Effect of modified WUS and FA on gluten yield

White column=control ( $3 \mathrm{~min} \mathrm{mix}, 7.3 \mathrm{~mL}$ water), Black column=20ppm FA ( 3 min mix, $7.3 \mathrm{~mL}$ water $)$.

\subsubsection{Characterisation of dough and gluten samples}

\subsubsection{Dough properties and gluten quality ----Kieffer extensibility test}

Previously, we observed that effects of WEP on gluten quality were paralleled in dough properties. Therefore, in this study, modified WUS and free FA were added to the flour and dough samples were prepared under two different conditions using a Mixograph. The properties of dough were studied using the Kieffer extensibility rig (see Table 4.2).

Two parameters were used to characterise the extensigram: maximum resistance to extension ( $R_{\max }$ ) and extensibility at maximum resistance to extension ( $E$ at $R_{\max }$ ). $R_{\max }$ is an indicator of the strength of the dough. A higher $R_{\max }$ implies a stronger dough. Extensibility represents the deformation of the dough before it ruptures. The larger extensibility, the further the dough can be extended before it ruptures.

The data showed that addition of modified WUS led to an increase in $\mathrm{R}_{\max }$, the extent depending on the type of WUS. Adding modified WUS together with FA resulted in a comparable $\mathrm{R}_{\max }$. Increasing mixing time and mixing water decreased $\mathrm{R}_{\max }$ of dough with and without modified WUS. A strong correlation was observed between WHC of modified WUS and $\mathrm{R}_{\max }$ of dough at $3 \mathrm{~min} \operatorname{mix}, 50 \%$ water and at $5 \mathrm{~min} \operatorname{mix}, 55 \%$ water $\left(\mathrm{R}^{2}=0.90 .94\right.$ respectively). Since all experiments were carried out at fixed levels of water addition, this means that the WHC of the WUS used strongly influences the $\mathrm{R}_{\max }$ measured. 


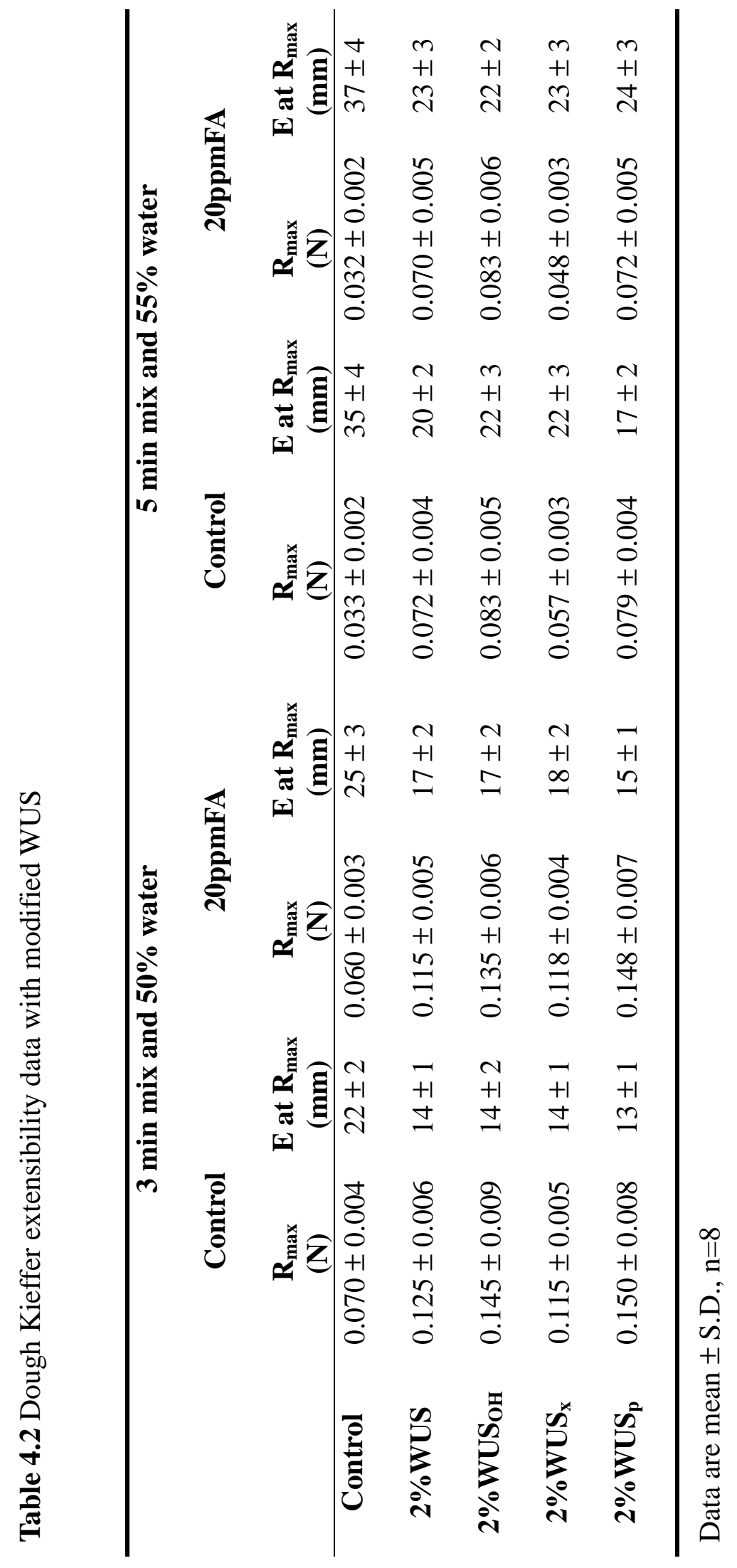


Addition of modified WUS decreased $\mathrm{E}$ at $\mathrm{R}_{\max }$ of dough to about a same value (22 $\mathrm{mm}$ vs ca $14 \mathrm{~mm}$ ). Adding modified WUS together with FA increased $\mathrm{E}$ at $\mathrm{R}_{\max }$ of dough ( $14 \mathrm{~mm}$ vs ca $17 \mathrm{~mm}$ ). Increasing mixing time and mixing water also led to an increase in $E$ at $R_{\max }$ of dough (14 mm vs ca $20 \mathrm{~mm}$ ). Adding FA under those conditions led to an even further increase in $\mathrm{E}$ at $\mathrm{R}_{\max }$ of dough ( $23 \mathrm{~mm}$ ).

WUS fractions were compared at constant weight. If we compare on the basis of equal additions of $\mathrm{AX}$, effects of $\mathrm{WUS}_{\mathrm{x}}$ and $\mathrm{WUS}_{\mathrm{OH}}$ were even more pronounced. However, comparison is more difficult due to large corrections for differences in water binding and mixing time (data not shown).

In chapter 2, we proposed both a direct and indirect effect of WUS on gluten formation and properties. The indirect effect refers to water holding by WUS. The direct effect refers to an interaction between $\mathrm{AX}$ and gluten formation. We hypothesized that FA plays an important role in the direct effect of WUS on dough properties and gluten yield. The indirect effect was confirmed by our results since $\mathrm{R}_{\max }$ is strongly related to WHC. In order to distinguish between the indirect and direct effects, $R_{\max }$ for control was adjusted to the same level as for WUS or WUS $\mathrm{W}_{\mathrm{x}}$ by decreasing mixing time and mixing water. Again, the increase in $E$ at $R_{\max }$ on FA addition was observed with control, WUS (Fig.4.4a) and $\mathrm{WUS}_{\mathrm{x}}$ (Fig.4.4b). These results indicate that FA mainly affects the extensibility of dough and not the resistance to extension of the dough.

The same effects were observed for the effect of FA on extensibility of gluten prepared in the presence of WUS and $\mathrm{WUS}_{\mathrm{x}}$ (see Fig.4.5). Addition of WUS (Fig.4.5 curve $A$ ) increased $R_{\max }$ and decreased $E$ at $R_{\max }$ of gluten compared to the control (Fig.4.5 curve $\mathrm{E})$. These results are in agreement with our previous findings ${ }^{12}$. Adding WUS together with FA (Fig.4.5 curve B) led to a comparable $\mathrm{R}_{\max }$ and a larger $\mathrm{E}$ at $\mathrm{R}_{\max }$ of gluten compared to only addition of WUS. Preincubation of WUS by xylanase resulted in a lower $R_{\max }$ and a larger $E$ at $R_{\max }$ of gluten compared to addition of WUS, but its $R_{\max }$ was still higher and its $E$ at $R_{\max }$ was still smaller than those of the control (Fig.4.5 curve C). This indicates that preincubation of WUS by xylanase can partly correct the negative effect of WUS on gluten properties although it cannot remove the negative effect of WUS on gluten yield. Again, addition of $\mathrm{WUS}_{\mathrm{x}}$ together with FA led to a comparable $\mathrm{R}_{\max }$ and a larger $\mathrm{E}$ at $\mathrm{R}_{\max }$ of gluten compared to only adding $\mathrm{WUS}_{\mathrm{x}}$ (Fig.4.5 curve D). Interestingly, $E$ at $\mathrm{R}_{\max }$ of gluten prepared in the presence of $\mathrm{WUS}_{\mathrm{X}}$ and FA is then even comparable to that of the control. Again, the increase in $\mathrm{E}$ at $\mathrm{R}_{\max }$ on FA addition was observed in control gluten (Fig.4.5 curveF). 

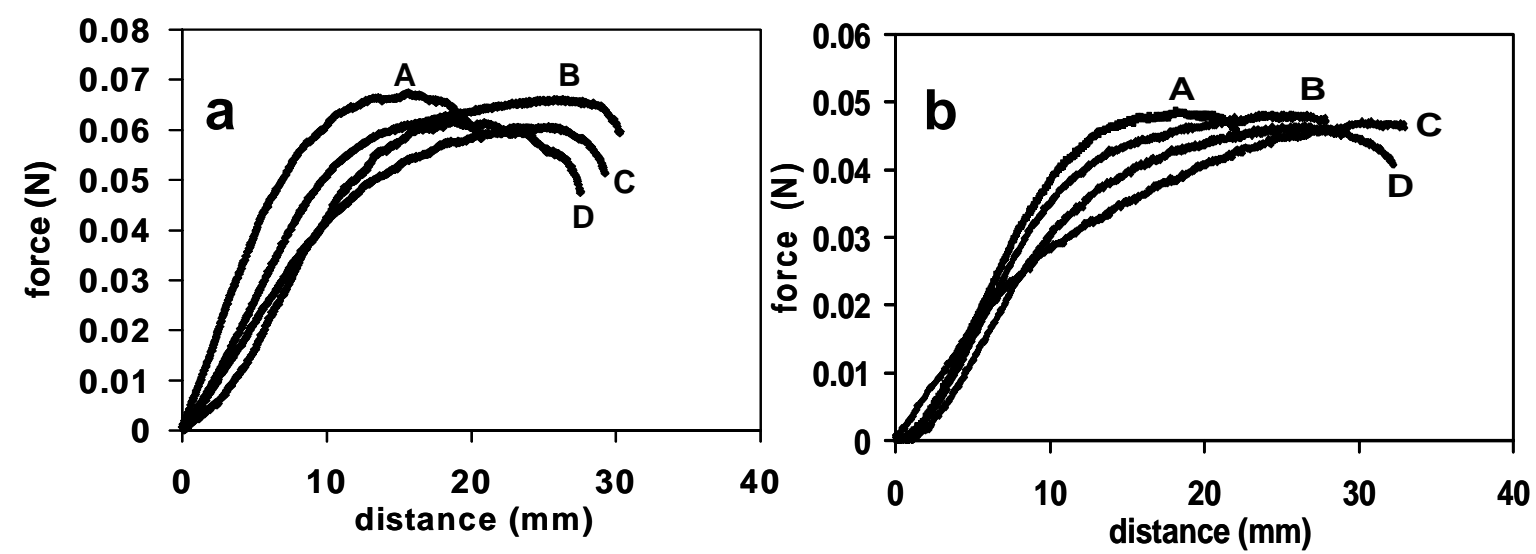

Figure 4.4 Effect of WUS, WUS ${ }_{\mathrm{x}}$ and FA on dough rheological properties ---Result of the Kieffer extensibility test

Fig.4.4a $A=2 \%$ WUS(5 min mix, 53\%water),

$\mathrm{B}=2 \%$ WUS $+20 \mathrm{ppmFA}$ ( 5 min mix, $53 \%$ water $)$,

$\mathrm{C}=$ control $+20 \mathrm{ppmFA}(3 \mathrm{~min}$ mix, $50 \%$ water $)$,

$\mathrm{D}=$ control ( 3 min mix, $50 \%$ water).

Fig. $4.4 \mathrm{~b} \mathrm{~A}=2 \% \mathrm{WUS}_{\mathrm{x}}(5 \mathrm{~min} \operatorname{mix}, 53 \%$ water $)$,

$\mathrm{B}=2 \% \mathrm{WUS}_{\mathrm{x}}+20 \mathrm{ppmFA}(5 \mathrm{~min} \operatorname{mix}, 53 \%$ water $)$,

$\mathrm{C}=$ control $+20 \mathrm{ppmFA}(3 \mathrm{~min} \operatorname{mix}, 51 \%$ water $)$,

$\mathrm{D}=$ control ( 3 min $\operatorname{mix}, 51 \%$ water).

\subsubsection{Gluten composition---Protein, starch and $A X$ yield}

The resulting gluten samples were analysed for their protein, starch and AX content to allow a better interpretation of gluten yield and Kieffer extensibility data. Results are presented in Table 4.3.

Just as with $\mathrm{WEP}^{40}$, addition of WUS or $\mathrm{WUS}_{\mathrm{X}}$ led to a significant decrease in protein yield and starch yield, therefore, a lower gluten yield (expressed as \% dm). Adding WUS or WUS $_{\mathrm{x}}$ together with FA improved protein yield and as a result, gluten yield. Interestingly, this was also accompanied with a significant increase in included starch (expressed as starch yield).

\subsubsection{Characterisation of GMP}

In order to find an explanation for the observed effect of WUS, WUS $\mathrm{x}_{\mathrm{x}}$ and FA on gluten properties, we studied the composition and rheological properties of GMP isolated from the different gluten samples. 


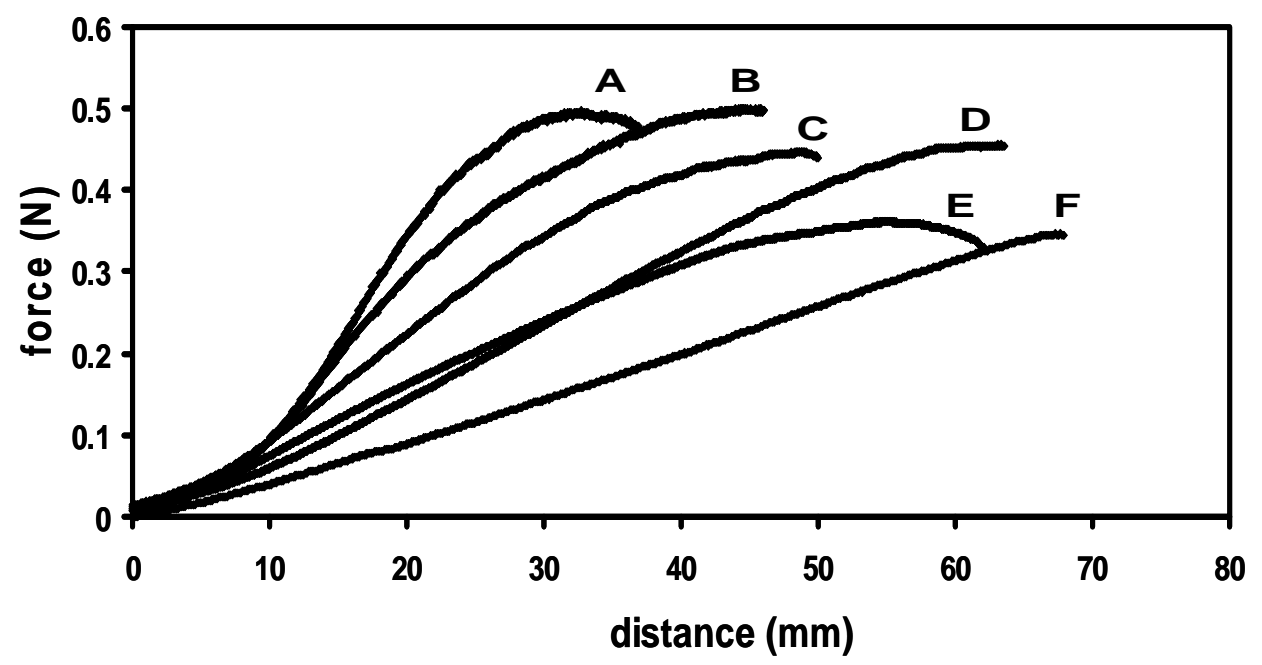

Figure 4.5 Effect of WUS, WUS ${ }_{\mathrm{x}}$ and FA on gluten rheological properties ---Result of the Kieffer extensibility test

$\mathrm{A}=2 \%$ WUS ( $3 \mathrm{~min}$ mix, $7.3 \mathrm{~mL}$ water),

$\mathrm{B}=2 \%$ WUS $+20 \mathrm{ppmFA}(3 \mathrm{~min} \operatorname{mix}, 7.3 \mathrm{~mL}$ water $)$,

$\mathrm{C}=2 \% \mathrm{WUS}_{\mathrm{x}}(3 \mathrm{~min} \operatorname{mix}, 7.3 \mathrm{~mL}$ water $)$,

$\mathrm{D}=2 \% \mathrm{WUS}_{\mathrm{x}}+20 \mathrm{ppm}$ FA ( $3 \mathrm{~min}$ mix, $7.3 \mathrm{~mL}$ water $)$,

$\mathrm{E}=$ control $(3 \mathrm{~min}$ mix, $7.3 \mathrm{~mL}$ water $)$,

$\mathrm{F}=$ control $+20 \mathrm{ppmFA}(3 \mathrm{~min} \operatorname{mix}, 7.3 \mathrm{~mL}$ water $)$.

\subsubsection{GMP isolation}

Results of GMP isolation are given in Table 4.4. Compared to the control, addition of WUS led to a lower GMP wet weight, but a higher GMP protein content, indicating a more concentrated gel. This result is in agreement with earlier findings ${ }^{12}$. Interestingly, when considering the extent of coagulation (EC), WUS addition did not lead to a lower EC value than that of the control. This means that compared to the control, the same amount of GMP protein is recovered from the flour, while the gluten yield was lower. Apparently, less SDS soluble protein is recorved in the gluten. When adding WUS and FA together, a higher GMP wet weight, GMP protein content and EC were obtained than only with WUS. A tentative explanations for this would be that added free FA could react with AX bound FA, either from WUS or wheat flour, to form di-ferulic acid. This prevents the further cross-linking between WUS and gluten protein or WUS and 'native' pentosans. Since prevention of these cross-links leads to a higher GMP protein recovery, we propose that this cross-linking negatively effects gluten formation. This hypothesis is supported by the findings of Oudgenoeg et al ${ }^{37,39}$ who observed that oxidative cross-linking of FA with $\mathrm{HRP}$ and $\mathrm{H}_{2} \mathrm{O}_{2}$ resulted in the formation of dehydrodimers of FA and by our previous paper in which this effect was demonstrated ${ }^{40}$. 


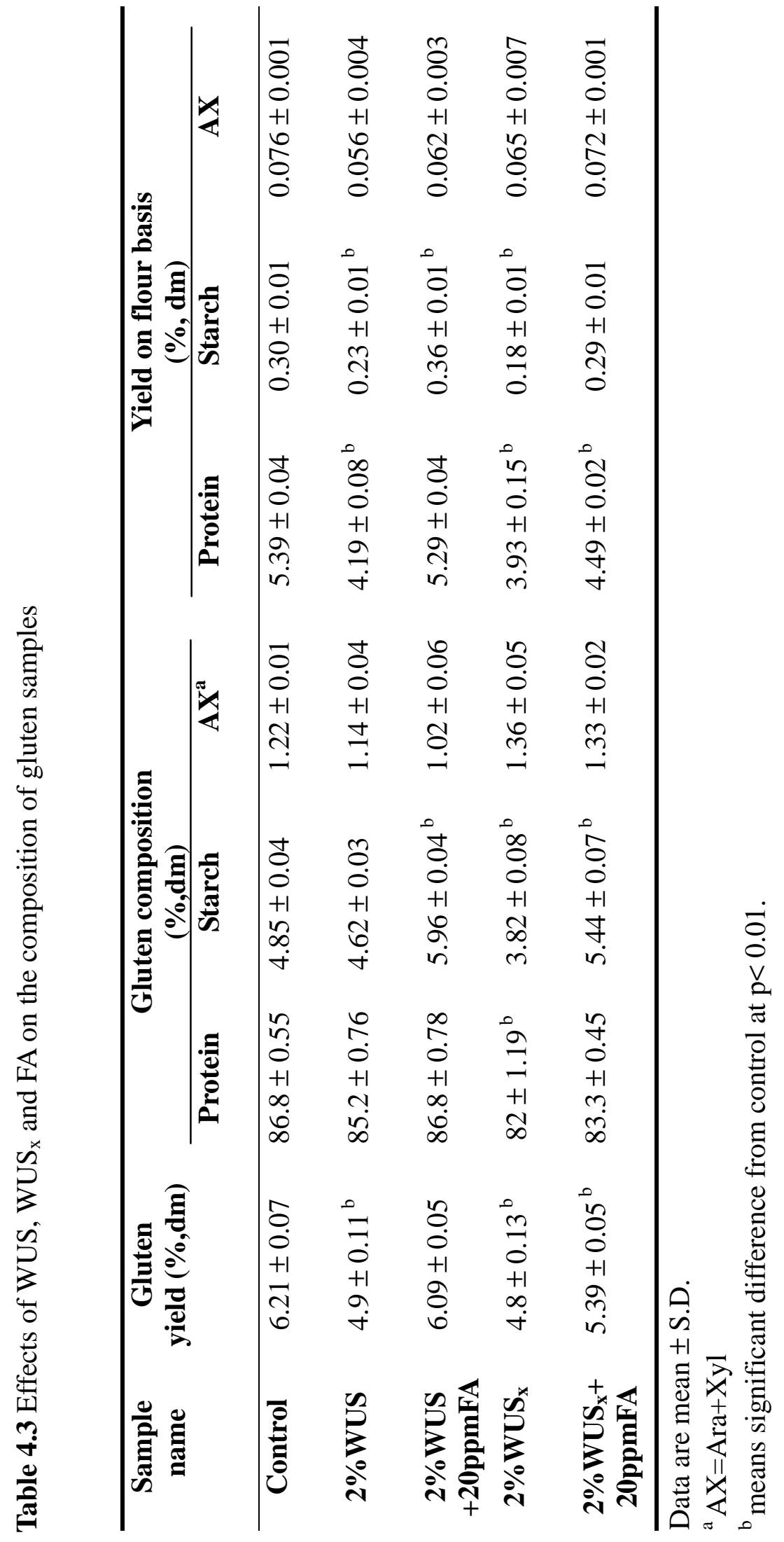


Xylanase is considered to be an effective tool in removing the negative effect of WUS. We investigated this role by pretreating WUS with a xylanase. This led to WUS $_{\mathrm{x}}$, having a lower AX content but a higher FA content (see Table 4.1). Our experiments show that this material is also able to negatively affect gluten formation. As with WUS, addition of WUS $_{\mathrm{x}}$ together with FA resulted in a higher GMP wet weight compared with only with WUS $_{\mathrm{x}}$, a higher GMP protein and a higher EC. This again points at an important role of FA. In this study, similar effects of xylanase and FA (added together with WUS or WUSx) on gluten formation were observed, xylanase by removing the interacting complex, FA by preventing an interaction.

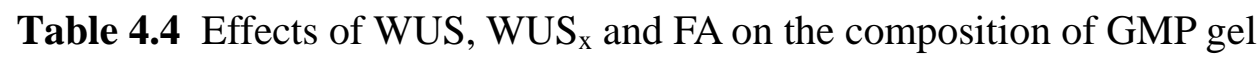

\begin{tabular}{ccccc}
\hline Sample & Gluten yield & $\begin{array}{c}\text { GMP } \\
\text { wet weight } \\
\text { name }\end{array}$ & $\begin{array}{c}\text { GMP } \\
\text { protein } \\
(\mathbf{\%}, \mathbf{d m})\end{array}$ & EC \\
\hline control & $10.62 \pm 0.08$ & $25.5 \pm 0.4$ & $10.2 \pm 0.1$ & 100 \\
$\mathbf{2 \% W U S}$ & $8.77 \pm 0.07$ & $22.6 \pm 0.7$ & $13.7 \pm 0.2$ & 98 \\
$\mathbf{2 \% W U S + 2 0 p p m F A}$ & $9.74 \pm 0.05$ & $23.4 \pm 0.6$ & $13.8 \pm 0.2$ & $115^{\text {a }}$ \\
2\%WUS & $9.19 \pm 0.08$ & $26.5 \pm 0.6$ & $12.2 \pm 0.1$ & 108 \\
$\mathbf{2 \% W U S}_{\mathbf{x}}+\mathbf{2 0 p p m F A}$ & $9.56 \pm 0.05$ & $27.3 \pm 0.5$ & $12.7 \pm 0.2$ & $120^{\text {a }}$ \\
\hline
\end{tabular}

Data $=$ mean \pm S.D.

$\mathrm{EC}$ is defined as the relative amount of GMP protein that can be isolated from wheat flour. (see Experimental, LSD $<10 \%$ )

${ }^{a}$ indicates significant difference from control.

\subsubsection{GMP rheological properties}

Further detail on the background of gluten quality differences was obtained by studying GMP rheology (Fig.4.6). The storage modulus G' (Fig. 4.6a), a measure of the stiffness of the gel, is governed by both GMP protein concentration and its structural properties ${ }^{43}$. Hence, interpretation of effects of gluten preparation on $G^{\prime}$ is difficult. Addition of WUS to the dough led to a higher G' of the GMP than that of the control (25.0 vs $13.9 \mathrm{~Pa}$ ), indicating a stiffer gel, but the protein concentration of GMP was also higher, which will be responsible for at least part of the higher G'. This result is in agreement with 
our previous study ${ }^{12}$. Addition of WUS together with FA to the dough resulted in a lower G' of the GMP than that if only WUS was added, but still higher than G' of the control. The protein concentration of GMP was about the same for both addition of WUS and WUS together with FA, indicating that the structure of both GMP has to be different.

Addition of $\mathrm{WUS}_{\mathrm{x}}$ or $\mathrm{WUS}_{\mathrm{x}}$ together with FA to the dough resulted in G' of the GMP gels comparable to that of the control while the protein concentration in these gels was higher than for the control. This indicates that pretreating WUS by xylanase led to a weaker gel of the resulting GMP likely as a result of a difference in gel structure. The results do not allow us to conclude if such differences in gel structure are at the molecular scale or at a macroscopic length scale.

The phase angle delta (see Fig. 4.6b), which is equal to the arctangent of the ratio of the loss modulus G" over the storage modulus G', is an indicator of the ratio of viscous to elastic behavior of the gel. A low delta implies a more elastic gel structure. Delta is less dependent on protein concentration than $\mathrm{G}^{\prime}$ and gives some information on the structure of the glutenin network.
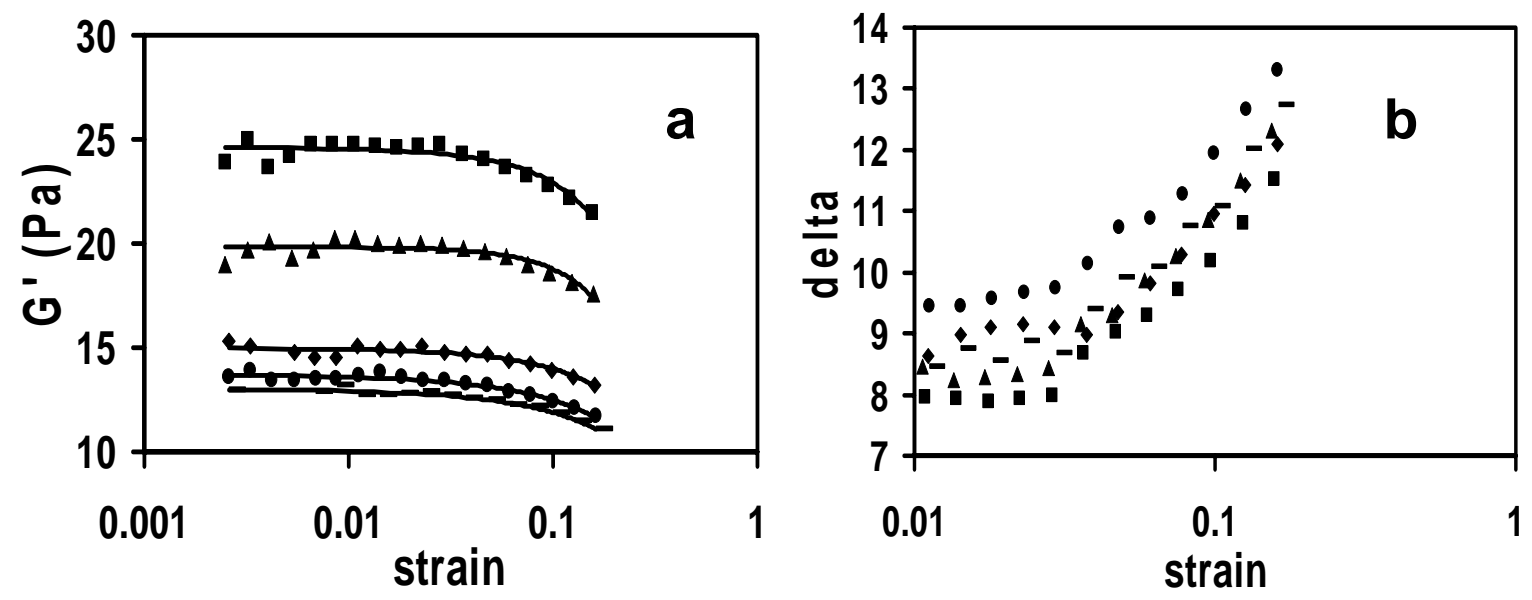

Figure 4.6 Effect of WUS, WUS ${ }_{x}$ and FA on GMP rheological properties Fig. 4.6a Effect of WUS, WUS ${ }_{x}$ and FA on G' of GMP Fig. 4.6b Effect of WUS, WUS ${ }_{\mathrm{x}}$ and FA on delta of GMP

- control, - $2 \%$ WUS, $\Delta 2 \% \mathrm{WUS}+20 \mathrm{ppmFA}$, $2 \% \mathrm{WUS}_{\mathrm{x}}$ $2 \% \mathrm{WUS}_{\mathrm{x}}+20 \mathrm{ppmFA}$

Addition of WUS led to a lower delta than that of the control, indicating a more elastic GMP gel structure. This result is consistent with our previous paper ${ }^{12}$. For the other conditions delta was in between the results obtained for the GMP gel isolated from the control gluten and from the gluten to which WUS was added. 
In summary, the GMP rheological results ( $\mathrm{G}^{\prime}$, delta) demonstrated differences in structure between GMP gels isolated from gluten to which WUS, WUS $\mathrm{W}_{\mathrm{x}}$ and FA was added. It is a question if these differences can explain the differences in dough or gluten rheological properties observed. Fig.4.6 shows that the GMP gels are already broken down at small deformations, orders of magnitude lower than the deformations taking place in the Kieffer extensibility test. The differences observed in Fig 4.6 relate to differences in the ratio of elastic/viscous nature of the gels and in the stiffness of the glutenin network and therefore have no direct causal relation to the differences in extensibility of gluten. This requires further study. Nevertheless, Fig.4.6 demonstrates that the differences in gluten formation as caused by adding modified WUS do affect the structure of the glutenin network. This may also affect large deformation properties.

\subsection{Conclusions}

In literature WEP are often considered to have a positive effect on bread-making ${ }^{14}$, whereas WUS are regarded to have a negative effect ${ }^{2,13}$. As we understand it, the positive effect of WEP is more based on an interpretation of the positive effect of pentosanase. Also, in a recent review of Courtin et al $^{44}$ different effects (from negative to positive) are cited of adding pentosans to flour. In this study, WUS, just like WEP ${ }^{40}$, also show an FA mediated negative effect on gluten yield and properties. Pretreatment of WUS by $\mathrm{NaOH}$, xylanase, $\mathrm{HRP}$ and $\mathrm{H}_{2} \mathrm{O}_{2}$ cannot correct its negative effect on gluten yield, but addition of xylanase or free FA during gluten separation does. Our data with $\mathrm{WUS}_{\mathrm{x}}$ indicate that the positive effect of xylanase on gluten yield is due to removing the interference of WUS with gluten formation rather than to modification of WUS. As with WEP ${ }^{40}$, FA plays a key role in removing the negative effect of WUS on gluten yield and properties. The difference between WEP and WUS is that WUS have a higher water binding capacity, which is reflected in a higher $\mathrm{R}_{\max }$ and a smaller $\mathrm{E}$ at $\mathrm{R}_{\max }$ of dough and gluten in the presence of WUS. The effect of WUS on $\mathrm{R}_{\max }$ of dough or gluten can be related to the WHC of WUS. The effect of WUS on $\mathrm{E}$ at $\mathrm{R}_{\max }$ can be related to a FA mediated reaction. In chapter 3 we demonstrated that addition of FA together with WEP led to a more extensible gluten than it only with WEP. In this chapter, we observed the same phenomenon when adding FA together with WUS. Although it is generally believed that WEP and WUS behave differently, from this study, we conclude a common mechanism. Both WEP and WUS negatively affect dough properties and gluten quality. However, the difference in dough and gluten extensibility caused by addition of FA can not be explained in terms of GMP rheological properties. Further study is still needed to explain these observations. 


\section{Acknowledgements}

The financial support of this research work by CSM Bakery Supplies Division Europe, Amylum Europe N.V. and Cargill B.V is gratefully acknowledged.

\section{References}

1. D’Appolonia, B. L. and Gilles, K.A. Pentosans associated with gluten. Cereal Chemistry 48 (1971) 427-436.

2. Jelaca, S.L. and Hlynka, I. Effect of wheat-flour pentosans in dough, gluten and bread. Cereal Chemistry 49 (1972) 489-495.

3. Hoseney, R.C. Functional properties of pentosans in baked goods. Food Technology 1 (1984) 114-117.

4. Amado,R. and Neukom, H. In 'New approaches to research on cereal carbohydrates' (R.D. Hill and L. Munck, eds.) Elseviser Sciences Publ., Amsterdam (1985) pp 241-251.

5. Meuser, F. and Suckow, P. In 'Chemistry and physics of baking'. (M.V.Blanshard, P.J. Frazier and T. Galliard, eds.), The Royal Society of Chemistry, London (1986) pp 42-61.

6. Jelaca, S.L. and Hlynka, I. Water-binding capacity of wheat-flour crude pentosans and their relation to mixing characteristics of dough. Cereal Chemistry 48 (1971) 211-222.

7. Kim, S.L. and D'Appolonia, B.L. Bread staling studies. III, Effect of pentosans on dough, bread and bread staling rate. Cereal Chemistry 54 (1977) 225-229.

8. Michniewicz, J., Biliaderis, C.G. and Bushuk, W. Water-insoluble pentosans of wheat Composition and some physical properties. Cereal Chemistry 67 (1990) 434-439.

9. Michniewicz, J., Biliaderis, C.G. and Bushuk, W. Effect of added pentosans on some physical and technological characteristics of dough and gluten. Cereal Chemistry $\mathbf{6 8}$ (1991) 252-258.

10. Courtin, C.M., Bulck, K.V. and Delcour, J.A.Understanding arabinoxylan functionality in bread-making. $84^{\text {th }}$ AACC Meeting (Seattle, 1999).

11. Denli, E. And Ercan, R. Effect of added pentosans isolated from wheat and rye grain on some properties of bread. European Food Research Technology 212 (2001) 374-376.

12. Wang, M-W, Hamer, R.J., Vliet, T.van., Gruppen, H., Marseille, J.P. Weegels, P.L. Effect of Water Unextractable Solids on Gluten Formation and Properties: Mechanistic Considerations. Journal of Cereal Science 37 (2003) 55-64.

13. Hanh, P.P. and Rasper, V. The effect of nonstarchy polysaccharides from yam, sorghum, and millet flours on the rheological behavior of wheat doughs. Cereal Chemistry $\mathbf{5 1}$ 
(1974) 734-750.

14. Rouau, X., EI Hayek, M. L., and Moreau, D. Effect of an enzyme preparation containing pentosanases on the bread-making quality of flours in relation to changes in pentosan properties. Journal of Cereal Science 19 (1994) 259-272.

15. Medcalf, D.G. and Gilles, K.A. Comparison of chemical composition and properties between hard red spring and durum wheat endosperm pentosans. Cereal Chemistry 45 (1968) 550-556.

16. McCleary, B.V., Gibson, T.S., Allen, H. and Gams, T.C. Enzymic hydrolysis and industrial importance of barley B-glucans and wheat flour pentosans. Starch/Starke 38 (1986) 433-437.

17. Weegels, P.L., Marseille, J.P., and Hamer, R.J. Enzymes as a processing aid in the separation of wheat flour into starch and gluten. Starch/ Staerke 44 (1992) 44-48.

18. Rouau, X. Investigation into the effect of an enzyme preparation for baking on wheat flour dough pentosans. Journal of Cereal Science 18 (1993) 145-157.

19. Rouau, X and Moreau, D. Modification of some physicochemical properties of Wheat flour pentosans by an enzyme complex recommended for baking. Cereal Chemistry $\mathbf{7 0}$ (1993) 626-632.

20. Courtin, C.M., Roelants, A. and Delcour, J.A. Fractionation-Reconstitution experiments provide insight into the role of endoxylanases in bread-making. Journal of Agricultural and Food Chemistry 47 (1999) 1870-1877.

21. Hilhorst, R, Dunnewind, B., Orsel, R., Stegeman, P., Vliet, T.van, Gruppen, H.and Schols, H.A. Baking performance, rheology, and chemical composition of wheat dough and gluten affected by xylanase and oxidative enzymes. Journal of Food Science 64 (1999) 808-813.

22. Gruppen, H., Kormelink, F.J.M.,Voragen, A.G. J. Enzymic degradation of waterunextractable cell wall material and arabinoxylans from wheat flour. Journal of Cereal Science 18 (1993) 129-143.

23.Faush, H., Kundig, W., Neukom, H. Ferulic acid as a component of a glycoprotein from wheat flour. Nature 199 (1963) 287.

24. Geissmann, T., Neukom, H. A note on ferulic acid as a component of the waterinsoluble pentosans of wheat flour. Cereal Chemistry 50 (1973) 414-416.

25. Sosulski, F., Krygier, K. and Hogge, L. Free, esterified and insoluble-bound phenolic acid. 3. Composition of phenolic acids in cereal and potato flours. Journal of Agricultural and Food Chemistry 30 (1982) 337-340.

26. Jackson, G.M.and Hoseney, R.C. Effect of endogenous phenolic acids on the mixing 
properties of wheat flours doughs. Journal of Cereal Science 4 (1986) 79-85.

27. Geissmann, T. and Neukom, H. On the composition of the water-soluble wheat flour pentosans and their oxidative gelation. Lebensmittel Wissenschaft und Technologie 6 (1973) 59-62.

28. Neukom, H., and Markwalder, H.U. Oxidative gelation of wheat flour pentosans: A new way of cross-linking polymers. Cereal Foods World 23 (1978) 374-376.

29. Hoseney, R.C. and Faubion, J.M. A mechanism for the oxidative gelation of wheat flour water-soluble pentosans. Cereal Chemistry 58 (1981) 421-424.

30. Izydorczyk, M.S., Biliaderis, C.G. and Bushuk, W. Oxidative gelation studies of water-soluble pentosans from wheat. Journal of Cereal Science 11 (1990) 153-69.

31. Moore, A.M., Martinez-Munoz, I. and Hoseney, R.C. Factors affecting the oxidative gelation of wheat water-solubles. Cereal Chemistry 67 (1990) 81-84.

32. Vinkx, C.J.A., VanNieuwenhove, C. G. and Delcour, J.A. Physicochemical and functional properties of rye non-starch polysaccharides III Oxidative gelation of a fraction containing water-soluble pentosans and protein. Cereal Chemistry 68 (1991) 617-622.

33. Girhammar, U. and Nair, B.M. Isolation, separation and characterization of water soluble non-starch polysacchrides from wheat and rye. Food Hydrocolloids 6 (1992) 285-299.

34. Figueroa-Espinoza, M.C. and Rouau, X. Oxidative cross-linking of pentosans by a fungal laccase and horseradish peroxidase: Mechanism of linkage between feruloylated arainoxylans. Cereal Chemistry 75 (1998) 259-265.

35. Schooneveld-Bergmans, M.E.F., Dignum, M.J.W., Grabber, J.H., Beldman, G. and Voragen, A.G. J. Studied on the oxidative cross-linking of feruloylated arabinoxylans from wheat flour and wheat bran. Carbohydrate Polymers 38 (1999) 309-317.

36. Labat, E., Morel, M.H. and Rouau, X. Effect of laccase and ferulic acid on wheat flour dough. Cereal Chemistry 77 (2000) 823-828.

37. Oudgenoeg, G., Hilhorst, R., Piersma, S.R., Boeriu, C.G., Gruppen, H., Hessing, M., Voragen, A.G., Laane, C. Peroxidase-mediated cross-linking of a tyrosine-containing peptide with ferulic acid. Journal of Agricultural and Food Chemistry 49 (2001) 2503-2510.

38. Labat, E., Morel, M.H. and Rouau, X. Effect of laccase and manganese peroxidase on wheat gluten and pentosans during mixing. Food Hydrocolloids 15 (2001) 47-52.

39. Oudgenoeg, G., Dirksen, E., Ingemann, S., Hilhorst, R., Gruppen, H., Boeriu, C.G., Piersma, S.R, Berkel, W.J.H. van, Laane, C. and Voragen, A.G. J. Horseradish 
peroxidase catalyzed oligomerization of ferulic acid on a template of a tyrosion-containing tripeptide. Journal of Biological chemistry 277 (2002) 21332-21340.

40. Wang, M-W, Hamer, R.J., Vliet, T.van.and Oudgenoeg, G. Interaction of water extractable pentosans with gluten protein: Effect on dough properties and gluten quality. Journal of Cereal Science 36 (2002) 25-37.

41. Robertson, J.A. and Eastwood, M.A. An investigation of the experimental conditions which could affect water holding capacity of dietary fibre. Journal of the Science of Food and Agriculture 32 (1981) 819-825.

42. Gruppen, H., Hamer, R.J. and Voragen, A.G. J. Water-unextractable cell wall material from wheat flour. I. Extraction of polymers with alkali. Journal of Cereal Science 16 (1992) 41-51.

43. van Vliet, T. Factors determining small-deformation behaviour of gels. In ' Food Emulsions and Foams interfaces, interactions and stability' (eds. E. Dickinson and J.M. Rodriguez Patino ) The Royal Society of Chemistry. (1999) pp 307-317.

44. Coutin, C.M. and Delcour, J.A. Arabinoxylans and endoxylanase in wheat flour bread-making. Journal of Cereal Science 35 (2002) 225-243. 


\title{
5
}

\section{How gluten properties are affected by pentosans}

\begin{abstract}
During the wet separation of starch and gluten, both water extractable pentosans (WEP) and water unextractable solids (WUS) have a negative effect on gluten yield. Gluten properties are also affected: the gluten becomes less extensible. In this study we aim to find an explanation for the differences in gluten properties observed. In comparison to the control, addition of WUS or WEP resulted in less gluten with a higher maximum resistance to extension $\left(R_{\max }\right)$ and a smaller extensibility at maximum resistance $(E$ at $\mathrm{R}_{\max }$ ). The corresponding glutenin macropolymer (GMP) gel was more elastic, with a larger specific volume of the GMP particles and a smaller tendency of these particles to aggregate. In contrast, the use of xylanase or ferulic acid (FA) resulted in a higher gluten yield and a larger $E$ at $R_{\max }$ of gluten. Here, the GMP was characterised by a more viscous gel structure, a smaller specific volume of the GMP particles and a larger tendency of GMP particles to aggregate. Correlations between gluten properties $\left(R_{\max }, E\right.$ at $\left.R_{\max }\right)$ and GMP particle properties ([ $\left.\eta], K^{\prime}\right)$ were observed. Based on these observations, we propose a possible explanation for the effect of pentosans on gluten formation and properties. Both a physical effect and a chemical effect are involved. The physical effect is related to viscosity and likely also to depletion attraction between protein particles. The chemical effect is related to a FA mediated effect and 'controls' the tendency of the particles to aggregate $\left(\mathrm{K}^{\prime}\right)$. The contribution of physical and chemical effects leads to a partial agglomeration of GMP particles and shifts the GMP particle size distribution to a higher value. Since GMP particle properties could be directly related to gluten rheological properties, this explains the change in quality observed.
\end{abstract}

Wang, M-W, van Vliet, T. and Hamer, R.J. Journal of Cereal Science submitted. 


\subsection{Introduction}

Gluten properties are largely responsible for the end-use quality of wheat in many food products ${ }^{1}$. Understanding the factors affecting gluten properties is therefore of extreme importance. Pentosans, despite their low content (2-3\%) in wheat flour, are very important in determining dough-handling properties and bread-making quality ${ }^{2-3}$. These components may affect gluten properties by interacting with the gluten proteins ${ }^{4-9}$. Chapter 2-4 reported that pentosans negatively influenced the formation of gluten. Pretreatment of pentosans by xylanase did not remove this effect, but addition of xylanase or ferulic acid (FA) during gluten extraction did. Both direct (interaction) and indirect (water binding) effects of pentosans were proposed. The indirect effect was reflected in a lower gluten yield and an increased resistance against extension of gluten and can be corrected by adding more water before mixing or addition of xylanase. The direct effect was reflected in a lower extensibility of gluten and can be corrected by addition of FA or xylanase. We proposed that FA was involved in the interaction of pentosans with gluten. Using a miniature gluten starch separation system, we $\mathrm{e}^{10-12}$ demonstrated that FA is a key factor controlling the effect of WEP and WUS on gluten yield and properties. However, it is not clear why not only gluten yield but also gluten properties are changed. Therefore, in this study we aim to find an explanation for the differences in gluten properties observed by studying gluten properties and the glutenin macropolymer (GMP) fraction of the gluten in more detail.

GMP (SDS insoluble glutenin) is an important component in gluten determining to a large extent its rheological properties. GMP content and properties also strongly correlate

with dough properties and loaf volume ${ }^{13-16}$. On the other hand, rheological properties of a GMP gel were found to be related to both the size and concentration of the contained glutenin particles ${ }^{17}$.

In the present study, we prepared gluten samples under different conditions using various additions that could influence gluten formation. Gluten samples were isolated from one wheat flour in the presence of WEP, WUS, WEP $_{x}$ (WEP modified by xylanase), without and with FA added and xylanase, respectively. The resulting samples were extensively characterized, in an effort to link gluten rheological properties to glutenin network properties.

\subsection{Experimental}

\subsubsection{Materials}

Soissons flour (untreated, milled using Multomat mill, extraction rate 78\%, protein 
$10.38 \%$, ash $0.55 \%$ ) was kindly donated by TNO, Zeist, the Netherlands.

Water unextractable solids, WUS (-) (not treated with amylase, hereafter called WUS) were isolated from wheat flour as described previously ${ }^{11}$. The AX, starch and protein content of the WUS were $47.1 \pm 0.5 \%, 26.4 \pm 0.2 \%$ and $19 \pm 2 \%$ respectively.

Water soluble pentosans, WEP, were purchased from Megazyme (medium viscosity: 27cSt, 2,000,000 Da > average molecular weight (MW) > 500,000 Da, lot 90601).

$\mathrm{WEP}_{\mathrm{x}}\left(\mathrm{MW}_{\text {glucose }}<\mathrm{MW}<10,000 \mathrm{Da}\right)$ was prepared by hydrolysing WEP with xylanase as described previously ${ }^{10}$.

Xylanase (Shearzyme 500 L, batch CDN00020) was purchased from NOVO Nordisk.

Ferulic acid $\left(\mathrm{FA}, \mathrm{C}_{10} \mathrm{H}_{10} \mathrm{O}_{4}\right)$ was obtained from Sigma.

All other chemicals used were of analytical grade or better.

\subsubsection{Analytical methods}

Protein content $(\mathrm{N} \times 5.7)$ was determined using the Dumas method as described previously ${ }^{10}$.

Starch content was measured enzymatically using the test kit supplied by Boehringer, Mannheim.

AX content was analysed using the alditol acetate method with inositol as internal standard as described previously ${ }^{10}$.

\subsubsection{Characterisation of gluten samples}

The gluten yield of dough was determined and gluten samples were prepared using a modified Glutomatic 2200 system (Perten, modified by TNO) as described previously ${ }^{10}$. In this system conditions were chosen to sensitively measure effects on gluten formation and not to obtain a maximal amount of gluten, Mixing time and water addition used were 3 min and $6.1 \mathrm{~mL}$ respectively.

Gluten rheological properties were measured using a Kieffer extensibility rig fitted onto a Texture Analyser equipped with a $5 \mathrm{~kg}$ load cell as described previously ${ }^{10}$. Maximum resistance to extension $\left(\mathrm{R}_{\max }\right)$ and extensibility at maximum resistance to extension ( $E$ at $R_{\max }$ ) of gluten were determined from the force versus displacement curve.

\subsubsection{Characterisation of GMP gel}




\subsubsection{GMP isolation}

Wet gluten was directly frozen in liquid nitrogen and freeze-dried. The freeze-dried gluten sample $(3 \mathrm{~g})$ was dispersed in $75 \mathrm{~mL}$ petroleum ether, mixed for $20 \mathrm{~min}$ and centrifuged $\left(18,900 \times \mathrm{g}, 10 \mathrm{~min}\right.$ at $\left.5^{\circ} \mathrm{C}\right)$. The whole procedure was repeated. Petroleum ether residues in the defatted gluten sample were evaporated by placing the sample overnight in a fume hood. The defatted freeze-dried gluten sample $(80 \mathrm{mg})$ was dispersed in $10 \mathrm{~mL} \mathrm{5 \% (w/v)} \mathrm{SDS} \mathrm{solution} \mathrm{and} \mathrm{ultracentrifuged}\left(69,000 \times \mathrm{g}, 30 \mathrm{~min}\right.$ at $\left.20^{\circ} \mathrm{C}\right)$. The supernatant was discarded and the gel-like layer found on top of the starch pellet (called GMP) was collected and weighed as GMP wet weight.

The protein content of GMP gel was determined using the Dumas method after drying the GMP gel at $80^{\circ} \mathrm{C}$ for $2 \mathrm{~h}$.

In addition to Gluten Yield, we defined a new parameter, the extent of coagulation (EC). EC is defined as the relative amount of GMP protein that is extracted from wheat flour:

$$
E C=\frac{Y_{s} \cdot W_{s} \cdot P_{s}}{Y_{c} \cdot W_{c} \cdot P_{c}} \times 100
$$

where: $\mathrm{Y}=$ gluten yield $(\mathrm{g} / \mathrm{g}$ flour $)$

$\mathrm{W}=\mathrm{GMP}$ wet weight $(\mathrm{g} / \mathrm{g}$ gluten $)$

$\mathrm{P}=\mathrm{GMP}$ protein content $(\mathrm{mg} / \mathrm{g}$ wet GMP)

$\mathrm{s}=$ sample

$\mathrm{c}=$ control

\subsubsection{Rheology}

Rheometer measurements were performed using a Bohlin VOR rheometer (Bohlin, Sweden) as described previously ${ }^{11}$. The storage modulus (G'), loss modulus (G") and phase angle (delta, $\delta$ ) of GMP gel were recorded.

\subsubsection{Characterisation of GMP dispersion}

\subsubsection{Dispersion of GMP}

Fresh GMP gel (5 g wet weight) was redispersed in $50 \mathrm{~mL} 1.5 \%(\mathrm{w} / \mathrm{v})$ SDS solution and gently rotated using a L28 Testtube rotator (LABINCO BV. the Netherlands) overnight to get a GMP dispersion. Serial dilutions of the GMP dispersion in $1.5 \%$ SDS solution were used for the intrinsic viscosity measurements.

\subsubsection{Viscosity measurement}


Viscosity was measured as described previously ${ }^{10}$. The flow time of the GMP dispersion was measured at $25 \pm 0.1^{\circ} \mathrm{C}$ using an Ubbelohde capillary viscometer. The protein concentration of the GMP dispersion was determined using the Dumas method. The relative viscosity $\left(\eta_{\text {rel }}=\right.$ flow time of sample/flow time of solvent $)$ and specific viscosity $\left(\eta_{\mathrm{sp}}=\eta_{\mathrm{rel}}-1\right)$ were calculated with $1.5 \%$ (w/v) SDS solution as the solvent. Reduced viscosity $\left(\eta_{\text {red }}=\eta_{\text {sp }} /\right.$ protein concentration of GMP dispersion) was plotted against the protein concentration of GMP dispersion and extrapolated to zero concentration using the Martin equation to determine the intrinsic viscosity $[\eta](\mathrm{mL} / \mathrm{g})^{18}$. [ ] of GMP dispersion provides information on the average voluminosity of glutenin particles. The so-called Huggins constant ( $\mathrm{K}^{\prime}$ ) was calculated from the slope divided by [ $\eta$ ] ${ }^{19}$. K' of GMP dispersion gives information on the tendency of glutenin particles to aggregate.

\subsection{Results and discussion}

\subsubsection{Characterisation of gluten samples}

\subsubsection{Gluten yield}

Gluten yield data are given in Table 5.1. In agreement with our previous results ${ }^{10-12}$, addition of WUS or WEP or $\mathrm{WEP}_{\mathrm{x}}$ during gluten separation decreased gluten yield. In contrast, addition of free FA together with WUS or WEP or $\mathrm{WEP}_{\mathrm{x}}$ could correct almost completely for the lower gluten yield in the presence of WEP or $\mathrm{WEP}_{\mathrm{x}}$, but not in the presence of WUS. Addition of xylanase significantly increased gluten yield.

\subsubsection{Chemical characterisation---chemical composition}

Gluten samples were analysed for their content of protein, starch and AX to allow a better interpretation of yield and Kieffer extensibility data. Results are also given in Table 5.1 .

Compared to their respective controls, addition of WUS or WEP or $\mathrm{WEP}_{\mathrm{x}}$ all led to a significant decrease in protein yield, indicating less agglomeration of gluten protein. Addition of xylanase or of FA together with WUS or WEP or $\mathrm{WEP}_{\mathrm{x}}$ all resulted in an increase in protein yield, pointing at a better agglomeration of gluten protein than in the absence of xylanase or FA. 


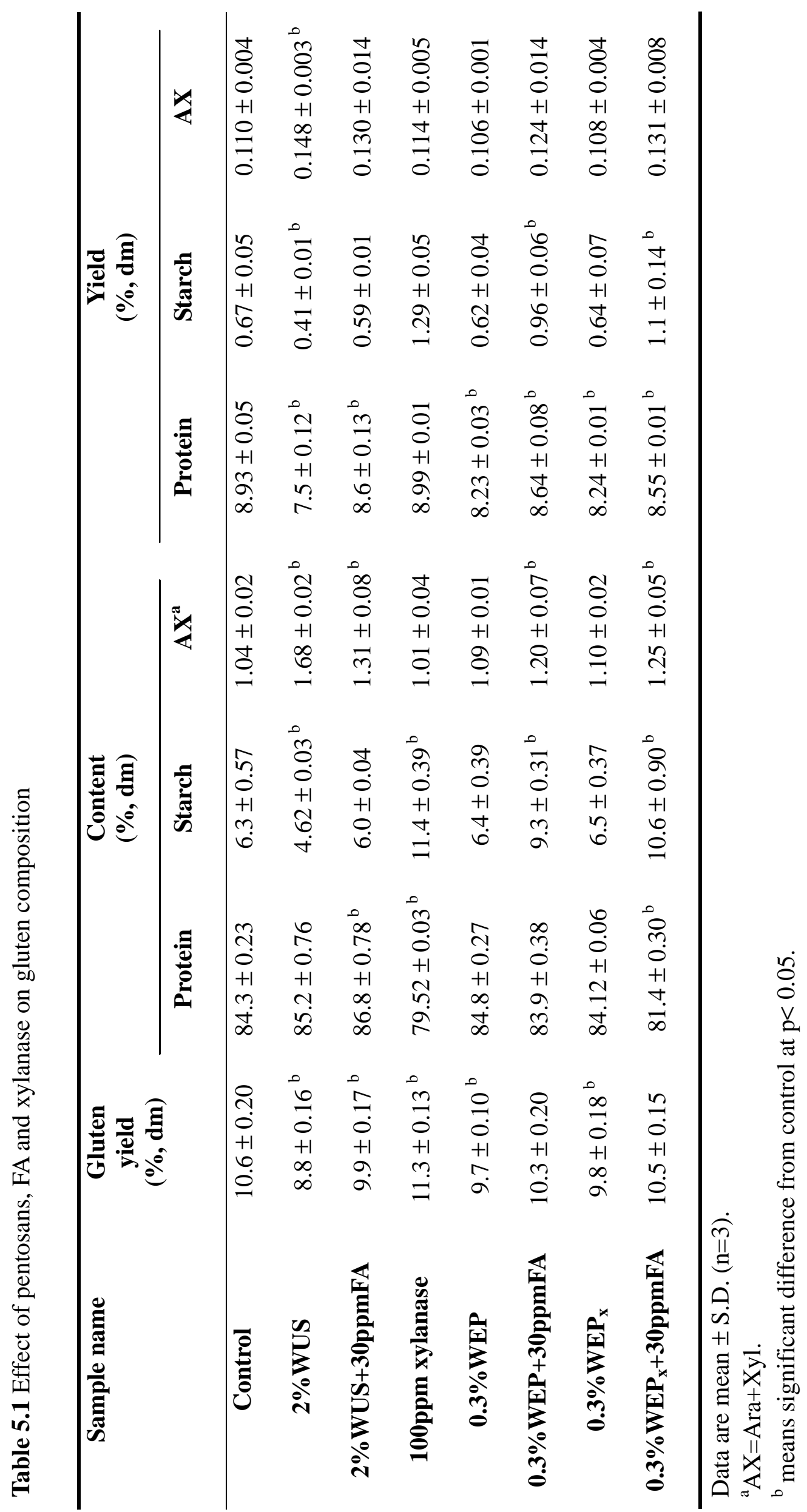


Adding WUS or WEP also led to a decrease in starch yield, which demonstrates that less starch is entrapped in the gluten network resulting in a more pure gluten. In contrast, adding FA together with WUS or WEP or $\mathrm{WEP}_{\mathrm{x}}$ or xylanase resulted in an increase in starch yield compared with the samples without xylanase or FA, which reveals more starch being entrapped in the gluten network and therewith a less pure gluten. The differences in starch yield may lie in the differences in agglomeration rate of gluten protein. According to Weegels et $\mathrm{al}^{20-21}$, a lower agglomeration rate of gluten protein led to less starch entrapped in the gluten network and vice versa.

No significant differences in AX yield were observed for all conditions except that addition of WUS gave a higher AX yield. This means that WUS or WEP or $\mathrm{WEP}_{\mathrm{x}}$ are not preferentially bound to gluten. This is all in accordance with previous finding ${ }^{10-12}$.

\subsubsection{Physical characterisation -----Kieffer extensibility test}

The rheological properties of gluten samples were studied using the Kieffer extensibility rig (Table 5.2).

Table 5.2 Effect of pentosans, FA and xylanase on gluten properties

\begin{tabular}{|c|c|c|}
\hline $\begin{array}{c}\text { Sample } \\
\text { Name }\end{array}$ & $\begin{array}{r}\mathbf{R}_{\max } \\
(\mathbf{N}) \\
\end{array}$ & $\begin{array}{c}\mathbf{E} \text { at } \mathbf{R}_{\max } \\
(\mathrm{mm})\end{array}$ \\
\hline Control & $0.29 \pm 0.02$ & $97 \pm 5$ \\
\hline $2 \% \mathrm{WUS}$ & $0.42 \pm 0.03^{\mathrm{a}}$ & $75 \pm 4^{\mathrm{a}}$ \\
\hline $2 \%$ WUS+30ppmFA & $0.41 \pm 0.03^{\mathrm{a}}$ & $87 \pm 5$ \\
\hline 100ppm xylanase & $0.27 \pm 0.02$ & $116 \pm 5^{a}$ \\
\hline $0.3 \% \mathrm{WEP}$ & $0.39 \pm 0.02^{\mathrm{a}}$ & $77 \pm 4^{\mathrm{a}}$ \\
\hline 0.3\%WEP+30ppmFA & $0.38 \pm 0.03^{\mathrm{a}}$ & $91 \pm 4$ \\
\hline $0.3 \% \mathrm{WEP}_{\mathrm{x}}$ & $0.30 \pm 0.03$ & $88 \pm 4$ \\
\hline $0.3 \% \mathrm{WEP}_{\mathrm{x}}+30 \mathrm{ppmFA}$ & $0.31 \pm 0.03$ & $98 \pm 5$ \\
\hline
\end{tabular}

Data are mean \pm S.D.

${ }^{a}$ means significant difference from control at $\mathrm{p}<0.05$.

Two parameters were used to characterise the extensigram: maximum resistance to extension ( $R_{\max }$ ) and extensibility at maximum resistance to extension ( $E$ at $R_{\max }$ ). $R_{\max }$ is an indicator of the strength of the dough. A higher $R_{\max }$ implies a stronger dough. 
Extensibility gives the deformation of the dough before it ruptures. The larger the extensibility, the more the dough can be extended before it ruptures.

Addition of WUS or WEP typically produced a gluten with a higher $\mathrm{R}_{\max }$ and a smaller $\mathrm{E}$ at $\mathrm{R}_{\max }$. In contrast, addition of xylanase resulted in a larger $\mathrm{E}$ at $\mathrm{R}_{\max }$ of gluten. Adding FA together with WUS or $\mathrm{WEP}_{\text {or }} \mathrm{WEP}_{\mathrm{x}}$ all gave a gluten with a comparable $\mathrm{R}_{\max }$ and a larger $E$ at $\mathrm{R}_{\max }$ than if WUS or WEP or $\mathrm{WEP}_{\mathrm{x}}$ were added alone. These results are consistent with our previous findings for gluten isolated from different wheat cultivars ${ }^{10-12}$.

\subsubsection{Characterisation of the GMP gel}

\subsubsection{GMP yield and composition}

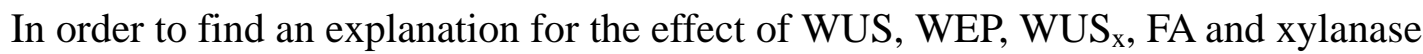
on the gluten properties observed, we isolated GMP from each gluten sample and studied both chemical composition and rheological properties. The results for GMP yield and composition are presented in Tables 5. 3.

The data showed that GMP yield (wet weight) paralleled gluten yield $\left(\mathrm{R}^{2}=0.79\right)$. Compared with the control, addition of WUS or WEP led to a lower GMP wet weight and a higher protein concentration of GMP gel, indicating a more concentrated gel. The EC was however comparable to the control, pointing at a comparable GMP protein recovery. Addition of WUS or WEP led to a lower total protein yield. Therefore, the ratio between GMP protein yield and total protein yield was higher than the control, which means that the resulting gluten contains less non GMP protein and the ratio of glutenin to gliadin is probably increased. According to Uthayakumaran $\mathrm{et}^{22} \mathrm{al}^{2}$, at constant protein content, an increase in the ratio of glutenin to gliadin is associated with an increase in $\mathrm{R}_{\max }$ and a decrease in extensibility. Although this finding was based on studies with dough, we see a clear similarity with our results for gluten. It may explain to some extent why addition of WUS or WEP produced a gluten with a higher $\mathrm{R}_{\max }$ and a lower $\mathrm{E}$ at $\mathrm{R}_{\max }$.

Addition of xylanase resulted in a higher GMP wet weight and a higher GMP protein concentration. Therefore, the EC was higher than the control, which means a higher GMP protein recovery than the control. The ratio between GMP protein yield and total protein yield was also higher than the control. This cannot explain why addition of xylanase gave a more extensible gluten than the control. 


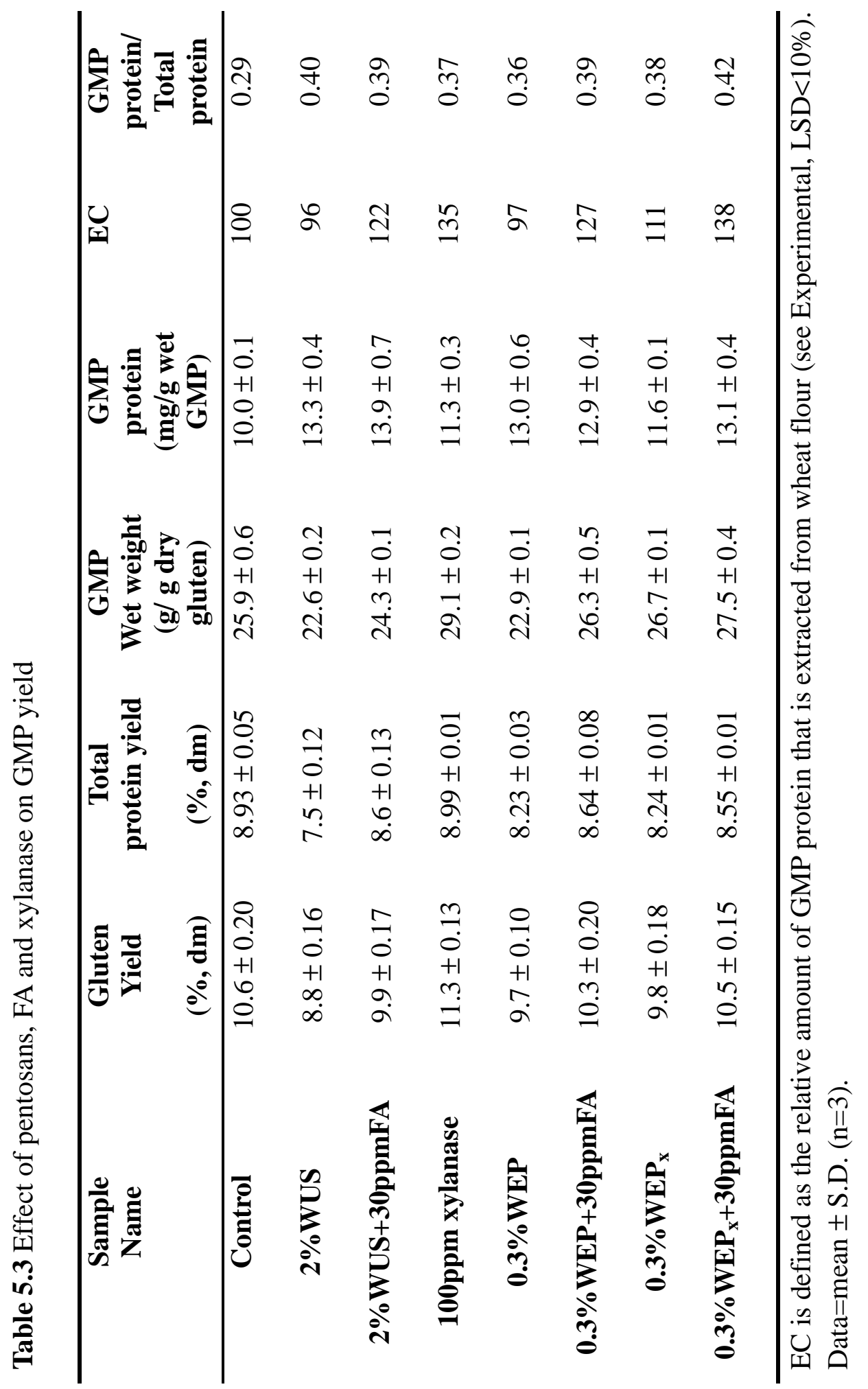




\subsubsection{GMP properties}

The rheological properties of GMP are shown in Figs. 5.1 and 5.2.
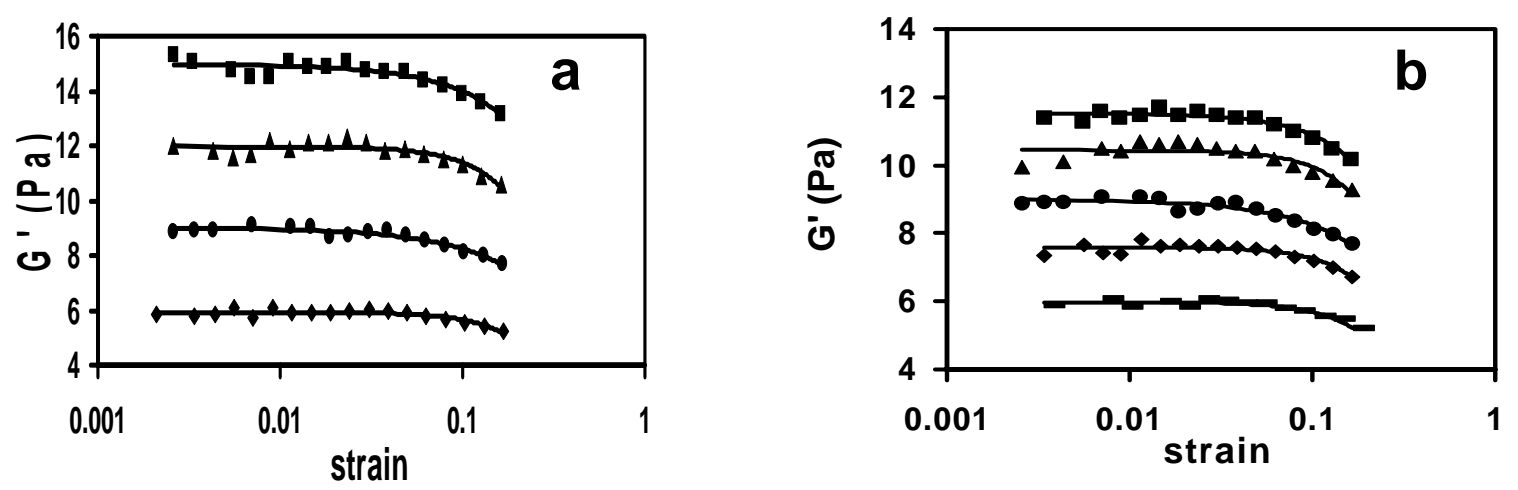

Figure 5.1 Effect of pentosans, FA and xylanase on G' of GMP gel

Fig. 5.1a Effect of WUS, FA and xylanase on G' of GMP gel

- control, - $2 \%$ WUS, \ $2 \%$ WUS+30ppmFA, $\bullet 100 \mathrm{ppm}$ xylanase.

Fig. 5.1b Effect of WEP, WEP $_{x}$ and FA on G' of GMP gel

- $0.3 \% \mathrm{WEP}$,

$\Delta 0.3 \% \mathrm{WEP}+30 \mathrm{ppm}$ FA, $-0.3 \% \mathrm{WEP}_{\mathrm{x}}$

$0.3 \% \mathrm{WEP}_{\mathrm{x}}+30 \mathrm{ppm}$ FA.
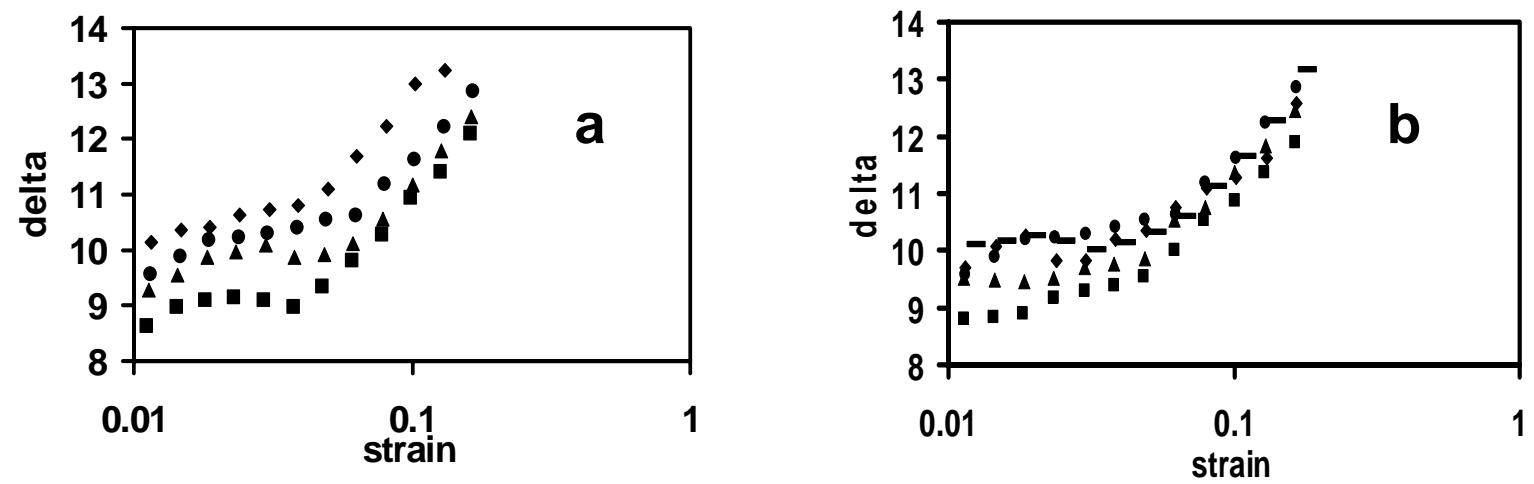

Figure 5.2 Effect of pentosans, FA and xylanase on delta of GMP gel

Fig. 5.2a Effect of WUS, FA and xylanase on delta of GMP gel

Fig. 5.2b Effect of WEP, $W_{E P}$ and FA on delta of GMP gel

For an explanation of the symbols see Fig.5.1.

The G' of GMP from gluten prepared in the presence of xylanase $\left(\mathrm{GMP}_{\mathrm{xylanase}}\right.$, Fig.5.1a) was lower than G' of the control, while the GMP protein content was higher. This points at a weaker gel caused by structural differences between these gels and the control. 


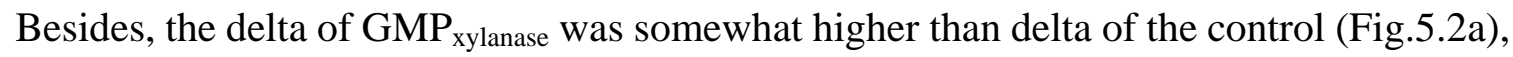
which indicates a somewhat more viscous structure of the gel.

The G' of GMP from gluten prepared in the presence of WUS and FA (GMP wUS+FA, Fig.5.1a) or WEP and FA (GMP WEP+FA, Fig.5.1b) was lower than the G' of GMP WUS $_{\text {or }}$ GMP $_{\text {WEP }}$, but still higher than G' of the control. However, the protein concentrations were about the same as of $\mathrm{GMP}_{\text {wUS }}$ or GMP $\mathrm{WEP}_{\mathrm{W}}$. This indicates that a difference in structure among the three gels. Also, the delta of GMP ${ }_{\text {WUS+FA }}$ (Fig.5.2a) or GMP WEP+FA (Fig.5.2b) was somewhat higher than delta of $\mathrm{GMP}_{\mathrm{WUS}}$ or GMP $\mathrm{WEP}_{\mathrm{WEP}}$ but still lower than delta of control.

The G' of GMP from gluten prepared in the presence of $\mathrm{WEP}_{\mathrm{x}}\left(\mathrm{GMP}_{\text {WEPx }}\right.$, Fig.5.1b) or FA together with $\mathrm{WEP}_{\mathrm{x}}\left(\mathrm{GMP}_{\mathrm{WEPx}+\mathrm{FA}}\right.$, Fig.5.1b) was also lower than G' of the control, while the GMP protein content was higher. This points at a weaker gel caused by structural differences between these gels and the control. No large differences in delta between the control, or GMP ${ }_{\text {WEPx }}$ or GMP WEPx+FA, were observed (Fig.5.2b).

\subsubsection{Characterisation of GMP dispersion}

Above, we discussed that rheological properties of a GMP gel were found to be related to both the size and concentration of the contained particles ${ }^{17}$. Therefore, viscometric characterisation of GMP dispersion was carried out to characterise the particles forming the GMP gel network. Results are given in Fig.5.3 and Table 5.4.
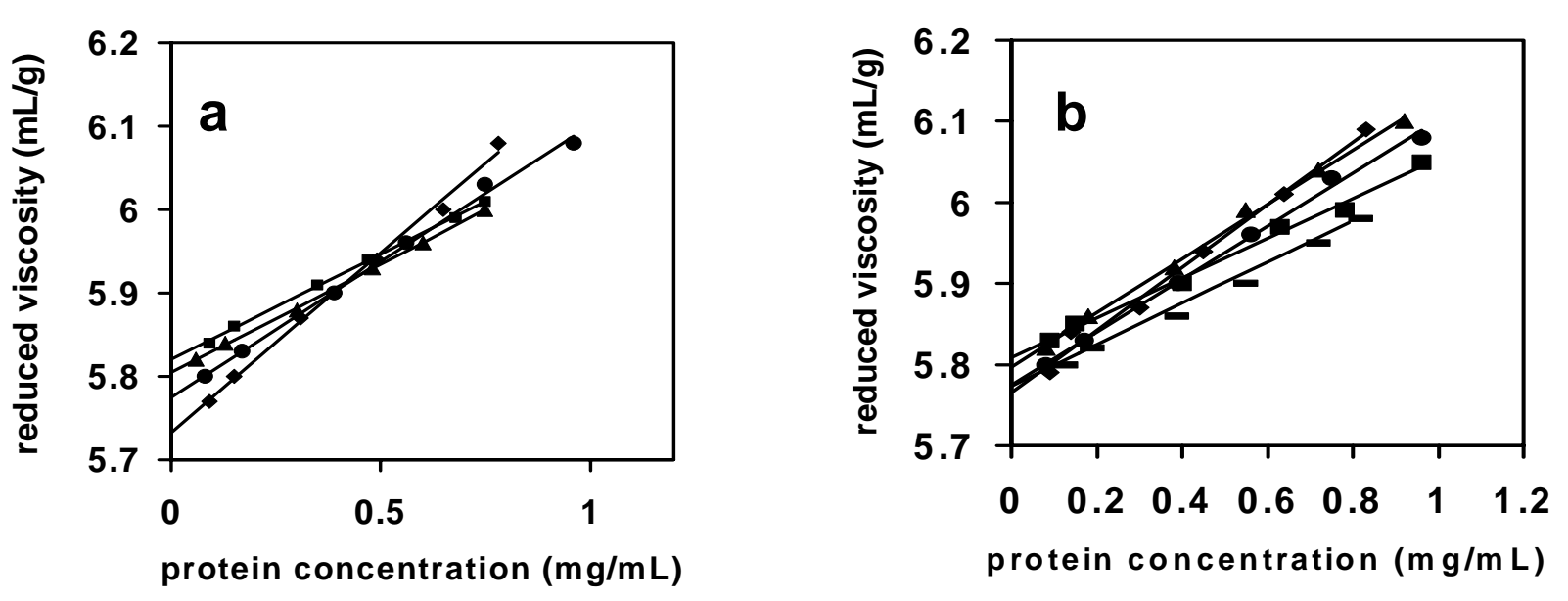

Figure 5.3 Effect of pentosans, FA and xylanase on reduced viscosity of GMP dispersion (For an explanation of the symbols see Fig.5.1)

Fig. 5.3a Effect of WUS, FA and xylanase on reduced viscosity of GMP dispersion Fig. 5.3b Effect of WEP, $\mathrm{WEP}_{\mathrm{x}}$ and FA on reduced viscosity of GMP dispersion 
The intercept of the curve represents the intrinsic viscosity [ $\eta]$ that is related to the average particle voluminosity (the hydrodynamic volume per unit of mass). The slope of the curve is negatively related to the voluminosity and positively to the interaction constant of dilute suspension of spheres ${ }^{23}$. A very small slope in combination with a larger $[\eta]$ indicates a lower tendency to aggregate. A steep slope in combination with a smaller [ $\eta$ represents a larger tendency to aggregate. The Huggins constant $K$ ', the ratio of slope divided by $[\eta]$, gives an idea about their aggregation behaviour of the dispersed particles. The higher K', the stronger the tendency to aggregate.

Table 5.4 Effect of pentosans, FA and xylanase on the voluminosity and aggregation properties of GMP dispersion

\begin{tabular}{|c|c|c|c|}
\hline $\begin{array}{c}\text { Sample } \\
\text { name }\end{array}$ & $\begin{array}{c}{[\eta]} \\
(\mathbf{d L} / \mathbf{g})\end{array}$ & $\begin{array}{l}\text { Viscosity } \\
\text { slope }\end{array}$ & $\mathbf{K}^{\prime}$ \\
\hline Control & $3.22 \pm 0.01$ & $0.33 \pm 0.02$ & $1.02 \pm 0.06$ \\
\hline $2 \%$ WUS & $3.37 \pm 0.06$ & $0.25 \pm 0.05$ & $0.7 \pm 0.13$ \\
\hline $2 \%$ WUS+30ppmFA & $3.32 \pm 0.01$ & $0.26 \pm 0.03$ & $0.78 \pm 0.09$ \\
\hline 100ppm xylanase & $3.09 \pm 0.06$ & $0.43 \pm 0.01$ & $1.39 \pm 0.05$ \\
\hline 0.3\%WEP & $3.33 \pm 0.01$ & $0.25 \pm 0.03$ & $0.75 \pm 0.09$ \\
\hline 0.3\% WEP+30ppmFA & $3.29 \pm 0.00$ & $0.34 \pm 0.01$ & $1.03 \pm 0.02$ \\
\hline $0.3 \% \mathrm{WEP}_{\mathrm{x}}$ & $3.22 \pm 0.04$ & $0.26 \pm 0.01$ & $0.81 \pm 0.03$ \\
\hline $0.3 \% \mathrm{WEP}_{\mathrm{x}}+30 \mathrm{ppmFA}$ & $3.19 \pm 0.04$ & $0.39 \pm 0.02$ & $1.22 \pm 0.09$ \\
\hline
\end{tabular}

Data $=$ mean \pm S.D. $(n=2)$.

Addition of WUS or WEP led to an increase in [ $\eta$ ], a decrease in slope and $\mathrm{K}^{\prime}$ compared to the control, indicating a larger specific volume of GMP particles and a lower tendency to aggregate. On the other hand, addition of xylanase or of FA together with WUS or WEP resulted in a decrease in [ $\eta$ ], an increase in slope and $K^{\prime}$ compared to their control, respectively, pointing at a smaller specific volume of the GMP particles and a larger tendency to aggregate. No large differences in $[\eta]$ were observed among GMP $\mathrm{WEPx}_{\text {, }}$ 
$\mathrm{GMP}_{\mathrm{WEPx}+\mathrm{FA}}$ and the control. However, $\mathrm{K}$ ' shows some interesting differences, particularly on addition of FA.

\subsubsection{Relations between gluten properties and GMP particle properties}

The analysis of data for gluten and GMP properties reveals some clear correlations between rheological characteristics of the gluten $\left(R_{\max }\right.$ and $E$ at $\left.R_{\max }\right)$ and characteristics of the GMP gel and of the GMP particles (Table 5.5 ).

Table 5.5 Correlations $\left(\mathrm{R}^{2}\right)$ between gluten parameters and GMP parameters

\begin{tabular}{|c|c|c|c|c|c|c|}
\hline & $\begin{array}{c}\text { Gluten } \\
\text { yield }\end{array}$ & $\mathbf{R}_{\max }$ & $\mathbf{E}$ at $R_{\max }$ & $\mathrm{G}^{\prime}$ & $\begin{array}{c}\text { Delta } \\
\text { intercept }\end{array}$ & {$[\eta]$} \\
\hline $\mathbf{R}_{\max }$ & -0.59 & & & & & \\
\hline$E$ at $R_{\max }$ & 0.95 & -0.65 & & & & \\
\hline $\mathrm{G}^{\prime}$ & -0.58 & 0.85 & -0.58 & & & \\
\hline $\begin{array}{c}\text { Delta } \\
\text { intercept }\end{array}$ & 0.63 & -0.72 & 0.23 & -0.66 & & \\
\hline$[\eta]$ & -0.77 & 0.87 & -0.89 & 0.82 & -0.82 & \\
\hline $\mathbf{K}^{\prime}$ & 0.77 & -0.54 & 0.89 & -0.44 & 0.52 & -0.77 \\
\hline
\end{tabular}

Table 5.5 shows that gluten yield correlates with both gluten parameter $\left(E\right.$ at $\left.R_{\max }\right)$ and GMP particle parameters $\left([\eta], K^{\prime}\right) . R_{\max }$ of gluten correlates with both GMP rheological parameters (G', delta intercept) and [ $\eta], E$ at $R_{\max }$ of gluten correlates with [ $\left.\eta\right]$ and $K^{\prime}$, but not with $G^{\prime}$ and delta intercept. G' of GMP gel correlates with [ $\left.\eta\right]$. The correlation between $G^{\prime}$ and $[\eta]$ observed is in agreement with the findings of Don et al ${ }^{17}$ for GMP isolated from wheat flour of different cultivars. This is quite logical. A higher [ $\eta]$ implies a higher volume fraction of particles in the GMP gel and therewith, for these dilute systems, a higher $G^{\prime}$. It stands to reason that no correlations were found between $E$ at $R_{\max }$ and $G^{\prime}$ and delta intercept since Fig. 5.2 shows that GMP gels are already broken down at small deformation, orders of magnitude lower than the deformations taking place in the Kieffer extensibility test. Moreover, the differences observed in Fig. 5.1 and 5.2 are relatively small differences in the ratio of elastic/viscous nature of the gels and in the stiffness of the glutenin network. So, no direct causal relations are expected between these differences and the differences in $\mathrm{E}$ at $\mathrm{R}_{\max }$ of gluten. It is likely that both are to same 
extent related to the same properties of the gluten particles, including their aggregation behaviour. In this respect it is all the more intriguing that [ $\eta]$ and $K$ ', related to the properties of glutenin particles do correlate with $E$ at $R_{\max }$, and not with $G$ ' or delta intercept. The differences in gluten properties observed on addition of pentosans, FA and xylanase are related to differences in voluminosity and aggregation properties of the particles forming the GMP gel.

\subsubsection{A possible explanation for the effects of pentosans on gluten formation and} properties

Based on our observations we propose a possible explanation for the effects of pentosans on gluten formation and properties. This explanation is based on the hyperaggregation model (Fig. 1.4) and the assumption that similar conditions of prior dough development apply to all experiments.

The presence of particles in flour is possibly related to their initial deposition in the wheat endosperm during kernel filling. Our results show that similar GMP particles are still present in gluten. This observation underlines the hyperaggregation model in which particles that are formed (level 2) physically aggregate to form gluten (level 3). Our explanation is based on this transition between level 2 and level 3. We propose three effects: viscosity, depletion attraction and a FA mediated effect modifying Van der Waals attraction between particles. Viscosity is a general effect limiting aggregation rate and hence gluten yield. The effect of viscosity stands to reason. Generally, hindering aggregation processes not only leads to fewer particles but also to particles of a smaller size. This is clearly not observed in our experiments, since $[\eta]$ is increased. For this reason we propose a depletion attraction effect. Depletion attraction is related to the ratio in size of pentosans on the one hand and GMP particles on the other. As we know from Don et $\mathrm{al}^{17}$, GMP particles are very polydisperse and range from $0.5-300 \mu \mathrm{m}$. Depletion attraction will favour aggregation of particles an order of magnitude larger than pentosans $([\eta]=$ $3.44 \mathrm{dL} / \mathrm{g}^{10}$ ) leading to a relative abundance of larger particles in the resulting gluten $\left([\eta]_{\text {wus }}>[\eta]_{\text {control }}\right)$. When the large pentosans are degraded by xylanase, both viscosity and depletion effects will disappear leading to both a higher gluten yield and a lower average voluminosity $\left([\eta]_{\text {xylanase }}<[\eta]_{\text {control }}\right.$ ). The FA mediated effect indeed assumes a chemical cross-linking reaction between GMP particles and pentosans. We have not directly demonstrated such a reaction, but in all cases where this reaction is possible (WUS, WEP, $\mathrm{WEP}_{\mathrm{x}}$ ), $\mathrm{K}^{\prime}$ is decreased. In all cases, where such a reaction is prevented (with FA, xylanase) $\mathrm{K}^{\prime}$ is increased. We assume that $\mathrm{K}^{\prime}$ reflects the Van der Waals attraction 
between GMP particles. Apparently, an interaction of pentosans via FA with GMP particles lowers the Van der Waals attraction. Preventing the interaction by xylanase or FA increases the Van der Waals attraction. The various observations are schematically depicted in Fig.5.4.

a Control

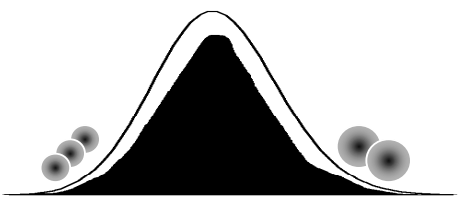

b WUS

C Xylanase

d WEP $_{\mathbf{x}}$

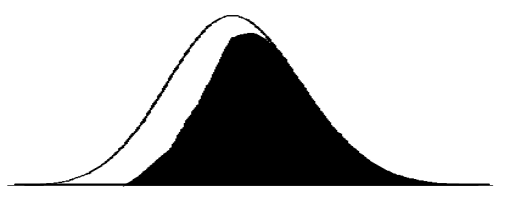

$\mathrm{GY}_{\mathrm{s}}<\mathbf{G Y _ { \mathrm { c } }}$

$\mathbf{R}_{\text {maxs }}>\mathbf{R}_{\text {maxc }}$

$E_{s}<E_{c}$

$\mathbf{G Y}_{\mathrm{s}}>\mathbf{G Y _ { \mathbf { c } }}$
$\mathbf{R}_{\mathrm{mass}}<\mathbf{R}_{\mathrm{maxc}}$

$E_{s}>E_{c}$

$G Y_{s}<G Y_{c}$

$\mathbf{R}_{\text {maxs }}=\mathbf{R}_{\text {maxc }}$

$E_{s}<E_{c}$
$\mathrm{EC}_{\mathrm{c}}$

$[\eta]_{c}$

$\mathbf{K}_{\mathrm{c}}^{\prime}$

$\mathrm{EC}_{\mathrm{s}}=\mathrm{EC}_{\mathrm{c}}$

$[\eta]_{s}>[\eta]_{c}$

$\mathbf{K}_{\mathrm{s}}^{\prime}<\mathbf{K}_{\mathrm{c}}$

$\mathrm{EC}_{\mathrm{s}}>\mathrm{EC}_{\mathrm{c}}$

$[\eta]_{s}<[\eta]_{c}$

$\mathbf{K}_{\mathrm{s}}>\mathrm{K}_{\mathrm{c}}$

$\mathrm{EC}_{\mathrm{s}}>\mathrm{EC}_{\mathrm{c}}$

$[\eta]_{s}=[\eta]_{c}$

$\mathbf{K}^{\prime}{ }_{\mathrm{s}}<\mathbf{K}_{\mathrm{c}}^{\prime}$

Figure 5.4. Various observations for the effects of pentosans on gluten formation and properties

The black area indicates the GMP protein recovery (EC).

$\mathrm{GY}=$ gluten yield, $\mathrm{c}=$ control, $\mathrm{s}=$ sample.

As observed in Table 5.6, gluten property parameters $\left(\mathrm{R}_{\max }, \mathrm{E}\right.$ at $\left.\mathrm{R}_{\max }\right)$ correlate with GMP particle parameters ( $\left.[\eta], K^{\prime}\right)$, this explains why gluten properties are affected by pentosans.

\subsection{Conclusions}

In this study we used the different effect of WUS, WEP, WEP, FA and xylanase to prepare from one wheat cultivar a series of gluten samples with different properties. Extensive characterisation of these samples in terms of gluten and GMP properties revealed important relations between gluten rheological properties $\left(R_{\max }, E\right.$ at $\left.R_{\max }\right)$ and

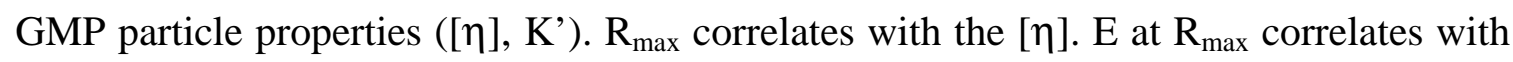
both $[\eta]$ and K'. In addition, GMP particle characterisation revealed characteristic 
differences between gluten samples indicating a possible mechanism for the action of pentosans and xylanase. Based on these observations, we could present a possible explanation for the effect of pentosans on gluten formation and properties. Both a physical and a chemical effect are involved. The physical effect is related to viscosity and likely also to depletion attraction between protein particles. The chemical effect is related to an FA mediated effect and 'controls' the tendency of the particles to aggregate ( $\mathrm{K}$ ') and hence gluten yield. This could explain how pentosans cause a partial agglomeration of gluten and shift the GMP particle size distribution in gluten to a higher value. Since GMP particle properties could be directly related to gluten rheological properties, this explains the change in quality observed. The explanation presented above is only based on the results for one wheat cultivar, additional experiments are required to validate it.

\section{Acknowledgements}

The financial support of this research work by CSM Bakery Supplies Division Europe, Amylum Europe N.V. and Cargill B.V is gratefully acknowledged.

We are also grateful to Johan Plijter and Clyde Don for valuable discussions and to Wim Lichtendonk for excellent technical assistance in GMP isolation and the rheological measurements.

\section{References}

1. MacRitchie, F. Wheat proteins: characterization and role in flour functionality. Cereal Food World 44 (1999) 188-193.

2. Delcour, J. A., Vanhamel, S., and Hoseney, R.C. Physicochemical and functional properties of rye nonstarch polysaccharides. II Impact of a fraction containing water-solubles pentosans and proteins on gluten-starch loaf volumes. Cereal Chemistry 68 (1991) 72-76.

3. Michniewicz, J., Biliaderis, C. G., and Bushuk, W. Effect of added pentosans on some physical and technological characteristics of dough and gluten. Cereal Chemistry 68 (1991) 252-258.

4. Jelaca, S.L. and Hlynka, I. Effect of wheat-flour pentosans in dough, gluten and bread. Cereal Chemistry 49 (1972) 489-495.

5. Jelaca, S.L. and Hlynka, I. Water-binding capacity of wheat -flour crude pentosans and their relation to mixing characteristics of dough. Cereal Chemistry 48 (1971) 211-222.

6. Kim, S.L. and D'Appolonia, B.L. Bread staling studies. III, Effect of pentosans on 
dough, bread and bread staling rate. Cereal Chemistry 54 (1977) 225-229.

7. Michniewicz, J., Biliaderis, C.G. and Bushuk, W. Water-insoluble pentosans of wheat: Composition and some physical properties. Cereal Chemistry 67 (1990) 434-439.

8. Michniewicz, J., Biliaderis, C.G. and Bushuk, W. Effect of added pentosans on some physical and technological characteristics of dough and gluten. Cereal Chemistry 68 (1991) 252-258.

9. Courtin, C.M., Bulck, K.V. and Delcour, J.A. Understanding arabinoxylan functionality in bread-making. $84^{\text {th }}$ AACC Meeting (Seattle, 1999).

10. Wang, M-W, Hamer, R.J., van Vliet, T. and Oudgenoeg, G. Interaction of water extractable pentosans with gluten protein: Effect on dough properties and gluten quality. Journal of Cereal Science 36 (2002) 25-37.

11. Wang, M-W, Hamer, R.J., van Vliet, T., Gruppen, H., Marseille, J.P. Weegels, P.L. Effect of water unextractable solids on gluten formation and properties: Mechanistic considerations. Journal of Cereal Science 37 (2003) 55-64.

12. Wang, M-W, Oudgenoeg, G., van Vliet, T. and Hamer, R.J. Interaction of water unextractable solids with gluten protein: Effect on dough properties and gluten quality. Journal of Cereal Science in press.

13. Weegels, P.L., Hamer, R.J. and Schofield, J.D. Depolymerisation and re-polymerisation of wheat glutenin during dough processing. I. Relationships between glutenin macropolymer content and quality parameters. Journal of Cereal Science 23 (1996) 103-111.

14. Pritchard, P.E. The glutenin fraction (gel protein) of wheat protein: A new tool in the prediction of baking quality. Aspects of Applied Biology 36 (1993) 75-84.

15. Moonen, J. H. E., Scheepstra, A.and Graveland, A. Use of the SDS-sedimentation test and SDS-polyacrylamide gel electrophoresis for screening breeder' samples of wheat for bread-making quality. Euphytica 31 (1982) 677-690.

16. Sapirstein, H.D. and Suchy, J. SDS-protein gel test for prediction of bread loaf volume. Cereal Chemistry 76 (1999) 164-172.

17. Don, J.A.C., Lichtendonk, W.J., Plijter, J.J. and Hamer, R.J. Understanding the link between GMP and dough I: from glutenin particles in flour towards developed dough. Journal of Cereal Science in press.

18. Sakai, T. Extrapolation procedures for intrinsic viscosity and for Huggins constant K'. Journal of Polymer Science 6 (1968) 1659-1672.

19. Huggins, M. The viscosity of dilute solutions of long-chain molecules. IV. Dependence on concentration. Journal of American Chemical Society 64 (1942) 
2716-2718.

20. Weegels, P.L., Marseille, J.P. and Hamer, R.J. Enzymes as a processing aid in the separation of wheat flour into starch and gluten. Starch/ Staerke 44 (1992) 44-48.

21. Weegels, P.L., Marseille, J.P. and Hamer, R.J. Small scale separation of wheat flour into starch and gluten. Starch/Staerke 40 (1988) 342-346.

22. Uthayakumaran, S., Gras, P.W., Stoddard, F.L. and Bekes, F. Effect of varying protein content and glutenin-to-gliadin ratio on the functional properties of wheat dough. Cereal Chemistry 76 (1999) 389-394.

23. Kruif, de C. G. Supra-aggregates of casein micelles as a prelude to coagulation. Journal of Dairy Science 81 (1998) 3019-3028. 


\title{
6
}

\section{Interaction of water unextractable solids and xylanase with gluten protein: Effect of wheat cultivars}

\begin{abstract}
In chapter 5 we proposed a possible explanation why gluten properties changed on addition of pentosans. However, this explanation was based on data for only one wheat cultivar. In this chapter it is validated based on data for three wheat cultivars, Scipion, Soissons and Amazon, differing in technological quality from weak to strong. In addition to the standard techniques used for characterizing gluten and glutenin macropolyer (GMP) yield, composition and properties, a new technique (particle size analysis) was applied that provides further detail on GMP particle size distribution. The results support the explanation proposed before. The same trend for the effect of WUS and xylanase on gluten and GMP yield, composition and properties was observed for the three wheat cultivars as found before. However, the effects of WUS and xylanase affected gluten yield and properties much stronger for Scipion and Soissons than for Amazon. Amazon flour contains more protein and less pentosans. The analysis of GMP particles demonstrates that the volume surface average particle diameter $\mathrm{D}_{3,2}$ of GMP particles from Amazon wheat is larger than those from Scipion and Soissons. Amazon has the ability to form larger and more sticky particles. We propose these factors could help explain why pentosans and xylanase have a smaller effect on its gluten yield and properties.
\end{abstract}

Wang, M-W, van Vliet, T. and Hamer, R.J. Journal of Cereal Science submitted. 


\subsection{Introduction}

Wheat flour used for the production of gluten and starch may vary both in protein quality and fiber content. The latter, often isolated as water unextractable solids (WUS), mainly consist of pentosans. Many papers ${ }^{1-6}$ reported that pentosans from various wheat cultivars, differ greatly in molecular size, structure and physiochemical properties. It is generally accepted that these pentosans affect dough properties ${ }^{7-12}$. In chapter 5 we propose a possible explanation in which pentosans affect the ability of glutenin macropolymer (GMP, SDS insoluble glutenin) particles to agglomerate ${ }^{13}$. The partial agglomeration of GMP particles leads to a different size distribution of GMP and hence the different rheological properties of gluten observed. However, this explanation was based on data for only one wheat cultivar ${ }^{13}$. In order to verify it, the effect on gluten isolation and properties was studied for the addition of WUS and xylanase to three wheat cultivars, Scipion, Soissons, and Amazon, differing in technological quality from weak to strong. GMP gel was isolated from the resulting gluten samples and characterised in terms of its chemical composition and properties. Dilute dispersions of the GMP gel were characterised in terms of their average particle voluminosity and size, and aggregation behaviour. The observed effects of WUS and xylanase on gluten yield, gluten and GMP composition and properties of the three wheat cultivars will be discussed in light of the proposed explanation.

\subsection{Experimental}

\subsubsection{Materials}

Scipion, Soissons and Amazon flour (untreated, Scipion and Soissons were milled using a Multomat mill, the extraction rate and ash content $76.8 \%$ and $0.52 \%$ for Scipion, $78.0 \%$ and $0.55 \%$ for Soissons respectively; Amazon was milled using a laboratory Buhler mill, extraction rate $76.3 \%$ ) were kindly donated by TNO, Zeist, the Netherlands.

WUS (-) (without treating by amylase, hereafter called WUS) were isolated from wheat flour as described previously. ${ }^{14}$

Xylanase (Shearzyme 500 L, batch CDN00020) was purchased from NOVO Nordisk. All other chemicals used were of analytical grade or better.

\subsubsection{Analytical methods}

Protein content was determined using the Dumas method as described previously ${ }^{14}$.

Starch content was measured enzymatically using the test kit supplied by Boehringer, Mannheim.

AX content was analysed using the alditol acetate method with inositol as internal 
standard as described previously ${ }^{14}$.

\subsubsection{Characterisation of gluten samples}

The gluten yield of dough was determined and gluten samples were prepared using a modified Glutomatic 2200 system (Perten, modified by TNO) as described previously ${ }^{14}$. The mixing time and dough water addition used for Scipion, Soissons and Amazon flour were $3 \mathrm{~min}$ and $6.0 \mathrm{~mL}, 3 \mathrm{~min}$ and $6.1 \mathrm{~mL}, 6 \mathrm{~min}$ and $7.5 \mathrm{~mL}$, respectively.

Gluten rheological properties were measured using a Kieffer extensibility rig fitted onto a Texture Analyser equipped with a $5 \mathrm{~kg}$ load cell as described previously ${ }^{14}$.

\subsubsection{Characterisation of GMP gel}

\subsubsection{GMP isolation}

A freeze-dried gluten sample ( $3 \mathrm{~g}$ ) was dispersed in $75 \mathrm{~mL}$ petroleum ether, mixed for $20 \mathrm{~min}$ and centrifuged $\left(18,900 \times \mathrm{g}, 10 \mathrm{~min}\right.$ at $\left.5{ }^{\circ} \mathrm{C}\right)$. The whole procedure was repeated. Petroleum ether residues in the defatted gluten samples were evaporated for overnight in a fume hood.

Defatted gluten sample (80 mg) was dispersed in $10 \mathrm{~mL} 1.5 \%(\mathrm{w} / \mathrm{v})$ SDS solution and ultracentrifuged $\left(69,000 \times \mathrm{g}, 30 \mathrm{~min}\right.$ at $\left.20{ }^{\circ} \mathrm{C}\right)$. The supernatant was discarded and the gel-like layer found on top of the starch pellet (called GMP) was weighed as GMP wet weight.

The protein content of GMP gel was determined using the Dumas method after drying GMP gel at $80^{\circ} \mathrm{C}$ for $2 \mathrm{~h}$.

Extent of coagulation (EC) is defined as the relative amount of GMP protein that can be isolated from wheat flour as described previously ${ }^{13}$.

$$
E C=\frac{Y_{s} \cdot W_{s} \cdot P_{s}}{Y_{c} \cdot W_{c} \cdot P_{c}} \times 100
$$

where: $\mathrm{Y}=$ gluten yield $(\mathrm{g} / \mathrm{g}$ flour $)$

$\mathrm{W}=\mathrm{GMP}$ wet weight $(\mathrm{g} / \mathrm{g}$ gluten $)$

$\mathrm{P}=\mathrm{GMP}$ protein content $(\mathrm{mg} / \mathrm{g}$ wet GMP)

$\mathrm{s}=$ sample

$\mathrm{c}=$ control

\subsubsection{Rheometer measurement}

Rheological measurements were performed using a Bohlin VOR rheometer (Bohlin, 
Sweden) as described previously ${ }^{14}$.

\subsubsection{Characterisation of GMP dispersion}

\subsubsection{Viscosity measurement}

Viscosity of the GMP dispersion was determined at $25 \pm 0.1^{\circ} \mathrm{C}$ using an Ubbelohde capillary viscometer as described previously ${ }^{13}$.

\subsubsection{Particle size distribution}

The particle size of GMP dispersions was measured using a LS 230 Particle Size Analyzer (Beckman Coulter). The measurement is based on light scattering to determine particle size distribution. This model incorporates Coulter's patented PIDS (Polarization Intensity Differential Scattering) technique to extend the dynamic range into the submicron region. Particle sizes over the range from 0.04-2000 $\mu \mathrm{m}$ can be determined. The optical system of LS 230 Particle Size Analyzer consist of an illumination source, a sample chamber in which the particles are illuminated, a Fourier lens system to focus the scattered light and 151 photo detectors that record the scattered light intensity patterns. This system also includes an integrated software program that provides instrument control and data presentation and storage. Fraunhofer diffraction theory was used to calculate the particle size distribution of the GMP dispersion from the scattered light intensity pattern assuming a spherical particle shape for the particles.

$5 \mathrm{~mL}$ of GMP dispersion was transferred to the suspension water (above the signal level) in the sample vessel. Two samples cells are used, one for the diffraction measurement and one for the PIDS measurement through which the samples are pumped. The amount of sample solution required depends on the signals of obscuration and PIDS. The obscuration signal for diffraction should be $8-12 \%$ and the PIDS signal should be $50-60 \%$.

The measured particle size distribution of the GMP dispersions ranged from 1-100 $\mu \mathrm{m}$. However, a GMP dispersion still contains some starch particles in the range from 1-10 $\mu \mathrm{m}$. In order to correct for the effect of the starch particles on the particle size distribution of GMP particles, $5 \mathrm{~mL}$ GMP dispersion was reduced with $1 \mathrm{~mL} 0.1 \mathrm{M} \mathrm{Na}_{2} \mathrm{SO}_{3}$ for $30 \mathrm{~min}$ at ambient temperature. Next, the particle size distribution of the reduced GMP dispersion was measured again. The measured particle size distribution of the GMP dispersion was obtained by subtracting the measured curve of the reduced GMP dispersion from the measured curve of the unreduced GMP dispersion. The volume surface average particle 
diameter $\mathrm{D}_{3,2}$ was calculated using this corrected distribution.

\subsection{Results and discussion}

\subsubsection{Composition of wheat flour}

The composition of the three wheat flour samples is given in Table 6.1. The data showed that the protein content of Amazon flour was much higher than that of Scipion and Soissons flour; while the AX content was much lower. The ratio of arabinose over xylose was somewhat higher for Amazon flour than for Scipion and Soissons flour, pointing at a higher branched structure of the AX.

\subsubsection{Characterisation of gluten samples}

\subsubsection{Gluten yield}

The results of gluten yield and composition of gluten samples isolated from the three flours in the presence of WUS and xylanase are presented in Table 6.2. Of the three control samples, gluten isolated from Amazon flour gave a much higher protein yield than for Scipion and Soissons (ca $20 \%$ vs ca 9-11\%).

Table 6.1 The composition of the three wheat flour samples

\begin{tabular}{cccc}
\hline $\begin{array}{c}\text { Wheat flour } \\
\text { samples }\end{array}$ & $\begin{array}{c}\text { Protein } \\
(\mathbf{d m}, \boldsymbol{\%})\end{array}$ & $\begin{array}{c}\mathbf{A X}^{\mathrm{a}} \\
(\mathbf{d m}, \boldsymbol{\%})\end{array}$ & Ara/Xyl \\
\hline Scipion & $9.44 \pm 0.04$ & $1.65 \pm 0.05$ & 0.69 \\
Soissons & $10.38 \pm 0.06^{\mathrm{c}}$ & $1.83 \pm 0.04$ & 0.66 \\
Amazon & $16.90 \pm 0.47$ & $1.26 \pm 0.03$ & 0.74 \\
& & & \\
\hline${ }^{\mathrm{a}}$ AX= Ara+Xly & & \\
${ }^{\mathrm{b}}$ Data are mean \pm S.D. $(\mathrm{n}=3)$ &
\end{tabular}

For all cultivars, addition of WUS decreased gluten yield; whereas addition of xylanase increased gluten yield. Those results are in agreement with the findings of Michniewicz et al ${ }^{15}$ and results presented in our previous papers ${ }^{13-14,16}$. However, the relative decrease and increase in yield for the three cultivars differs. The decrease in gluten 
yield for Scipion, Soissons and Amazon on addition of WUS was 15\%, 14\% and 7\% respectively; while the increase on addition of xylanase was $8 \%, 7 \%$ and $5 \%$ respectively, indicating that addition of WUS affects gluten yield far stronger for Scipion and Soissons than for Amazon. The higher protein content and the lower pentosans conent of Amazon flour (see Table 6.1) could perhaps explain the lower response of Amazon. Similar results were obtained by Weegels et $\mathrm{al}^{17-18}$ and Cleemput ${ }^{19}$ for other cultivars.

\subsubsection{Chemical characterisation---chemical composition}

Protein, starch and AX content of the gluten samples are also presented in Table 6.2. Soissons gluten samples gave a higher starch yield whereas starch yield was lowest for Scipion gluten. Addition of WUS led to a decrease in protein yield for all three cultivars and a decrease in starch yield for Scipion and Soissions. Surprisingly, adding WUS resulted in a significant increase in starch yield of Amazon gluten. For all cultivars, addition of xylanase increased the gluten protein yield; however, this was accompanied by a significant increase in starch yield. No large differences in AX yield were observed except that addition of WUS gave a somewhat higher AX yield for Scipion and Soissons than their respective controls. Effects of WUS and xylanase addition for Soissons flour are in agreement with our previous results ${ }^{13}$.

\subsubsection{Physical characterisation -----Kieffer extensibility test}

The rheological properties of gluten samples were studied using the Kieffer extensibility rig (Table 6.3). In general, it is found that $\mathrm{R}_{\max }$ does not always correlate with the protein content of flour, but is invariably correlated with SDS unextractable polymeric protein content ${ }^{20}$. Gupta et al ${ }^{21}$ studied the total and SDS unextractable polymeric protein of a set of 74 recombinant inbred lines. The correlation between $\mathrm{R}_{\max }$ and total polymeric protein content was very low $\left(\mathrm{R}^{2}=0.18\right)$; while the correlation between $\mathrm{R}_{\max }$ and SDS unextractable polymeric protein content was significant $\left(\mathrm{R}^{2}=0.86\right)$. For a broad range of cultivars, extensibility, unlike $\mathrm{R}_{\max }$, depends on flour protein content and correlates highly with the percentage flour polymeric protein; this parameter accounts for $74 \%$ of the variation $^{22}$.

In agreement with our previous findings for one cultivar ${ }^{13-14,16}$, the results demonstrated that for all cultivars, addition of WUS typically produced a gluten with a higher $\mathrm{R}_{\max }$ and a lower $\mathrm{E}$ at $\mathrm{R}_{\max }$. However, the relative increase in $\mathrm{R}_{\max }$ and decrease in $\mathrm{E}$ at $\mathrm{R}_{\max }$ for the three cultivars was different. The increase in $\mathrm{R}_{\max }$ for Scipion, Soissons and Amazon was $36 \%, 32 \%$ and $6 \%$ respectively and the decrease in $\mathrm{E}$ at $\mathrm{R}_{\max }$ was $24 \%, 25 \%$ 


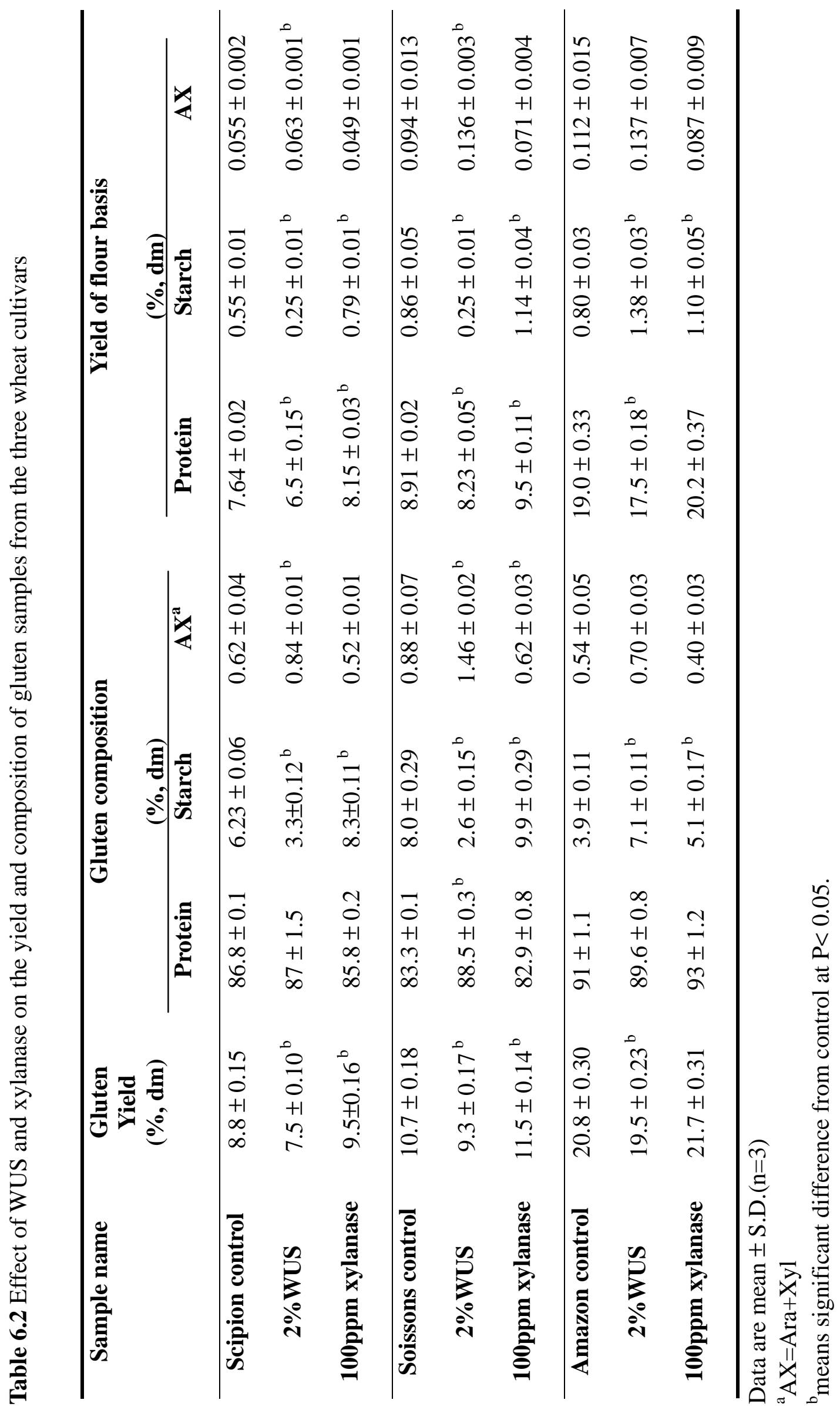


yield was higher than the control, which means that the resulting gluten contains less non-GMP protein. and 9\% respectively. This indicates that addition WUS affects not only gluten yield but also gluten properties much stronger for Scipion and Soissons than for Amazon gluten. In contrast to WUS, addition of xylanase produced a gluten with a lower $\mathrm{R}_{\max }$ and a larger $\mathrm{E}$ at $\mathrm{R}_{\max }$. Whereby similar as for WUS, the relative effect depends on the cultivars. The decrease in $\mathrm{R}_{\max }$ for Scipion, Soissons and Amazon was 17\%, $16 \%$ and $4 \%$ respectively and the increase in $\mathrm{E}$ at $\mathrm{R}_{\max }$ was $24 \%, 25 \%$, and $4 \%$ respectively.

Table 6.3 Effect of WUS and xylanase on the properties of gluten from the three wheat cultivars

\begin{tabular}{ccc}
\hline Sample name & $\begin{array}{c}\mathbf{R}_{\max } \\
(\mathbf{N})\end{array}$ & $\begin{array}{c}\mathbf{E} \text { at } \mathbf{R}_{\max } \\
(\mathbf{m m})\end{array}$ \\
\hline Scipion control & $0.36 \pm 0.02$ & $89 \pm 5$ \\
2\%WUS & $0.49 \pm 0.03^{\mathrm{a}}$ & $68 \pm 3^{\mathrm{a}}$ \\
100ppm xylanase & $0.30 \pm 0.02^{\mathrm{a}}$ & $110 \pm 6^{\mathrm{a}}$ \\
\hline Soissons control & $0.38 \pm 0.02$ & $93 \pm 5$ \\
2\%WUS & $0.50 \pm 0.03^{\mathrm{a}}$ & $70 \pm 4^{\mathrm{a}}$ \\
100ppm xylanase & $0.32 \pm 0.02^{\mathrm{a}}$ & $116 \pm 6^{\mathrm{a}}$ \\
\hline Amazon control & $0.51 \pm 0.03$ & $110 \pm 6$ \\
2\%WUS & $0.54 \pm 0.04$ & $100 \pm 5$ \\
100ppm xylanase & $0.49 \pm 0.03$ & $115 \pm 6$ \\
\hline
\end{tabular}

\subsubsection{Characterisation of GMP gel}

\subsubsection{GMP isolation}

GMP wet weight, GMP protein content and EC of the GMP isolated from the resulting gluten samples are given in Table 6.4.

For all cultivars, addition of WUS led to a lower GMP wet weight, a higher GMP protein content, indicating a more concentrated gel. The EC was however comparable to the control, pointing at a comparable GMP protein recovery. Addition of WUS led to a 


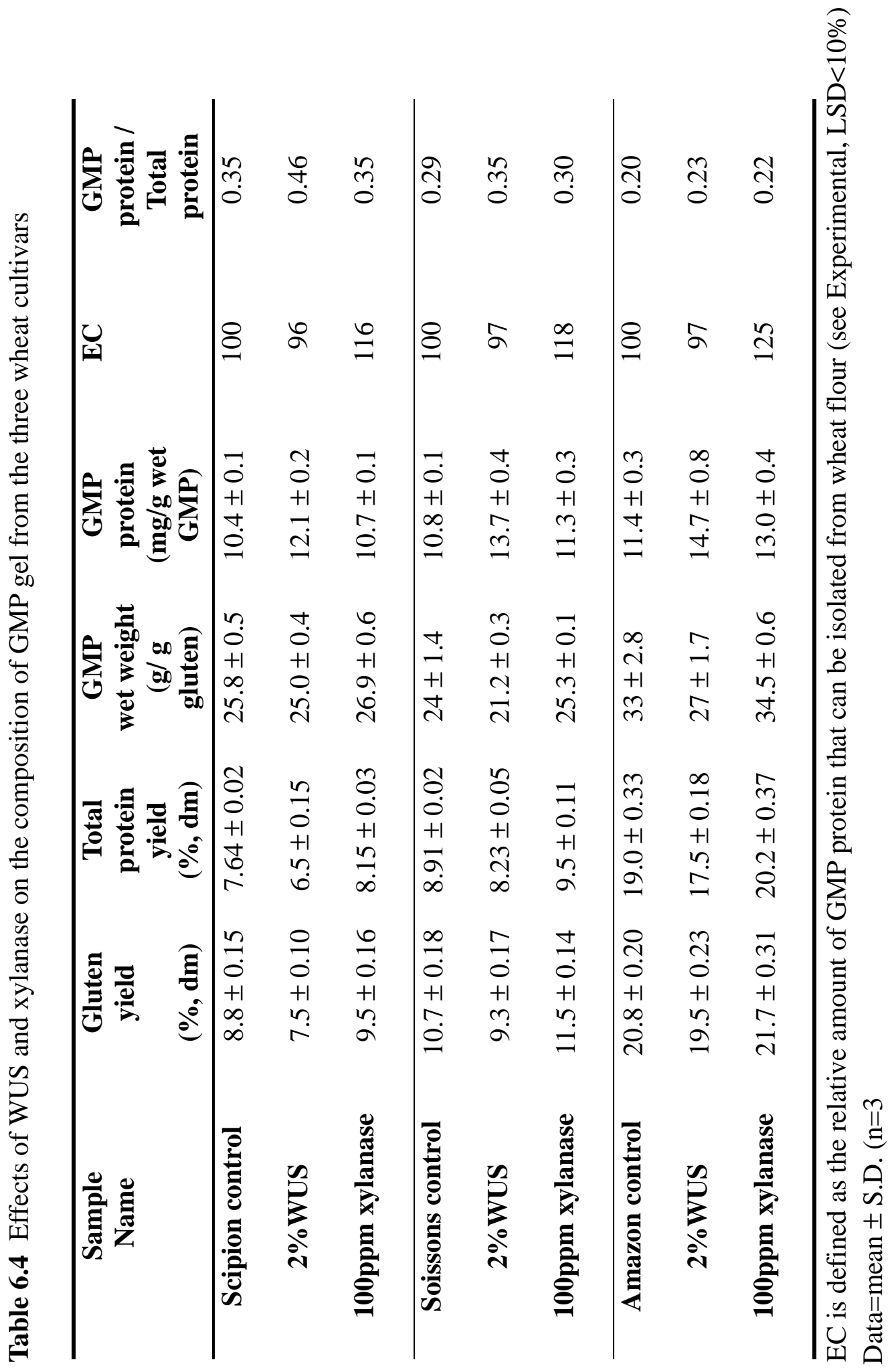


lower total protein yield. Therefore, the ratio between GMP protein yield and total protein.

For all cultivars, adding xylanase resulted in a higher GMP wet weight, a higher GMP protein content and a higher EC, which means a higher GMP protein recovery. However, the increase in EC (16,18 and 25 for Scipion, Soissons and Amazon respectively) on addition of xylanase was different. However, the ratios between GMP protein yield and total protein yield were comparable to the control.

\subsubsection{Rheological properties of GMP gel}

The rheological properties of GMP gels are shown in Fig. 6.1 and 6.2. The storage modulus (G', Fig.6.1), a measure of the stiffness of the gel, is governed by both GMP protein concentration and its structural properties ${ }^{23}$.

In agreement with our previous results ${ }^{13-14,16}$, addition of WUS led to a higher G', indicating a stiffer gel; while addition of xylanase resulted in a lower G', pointing at a weaker gel.
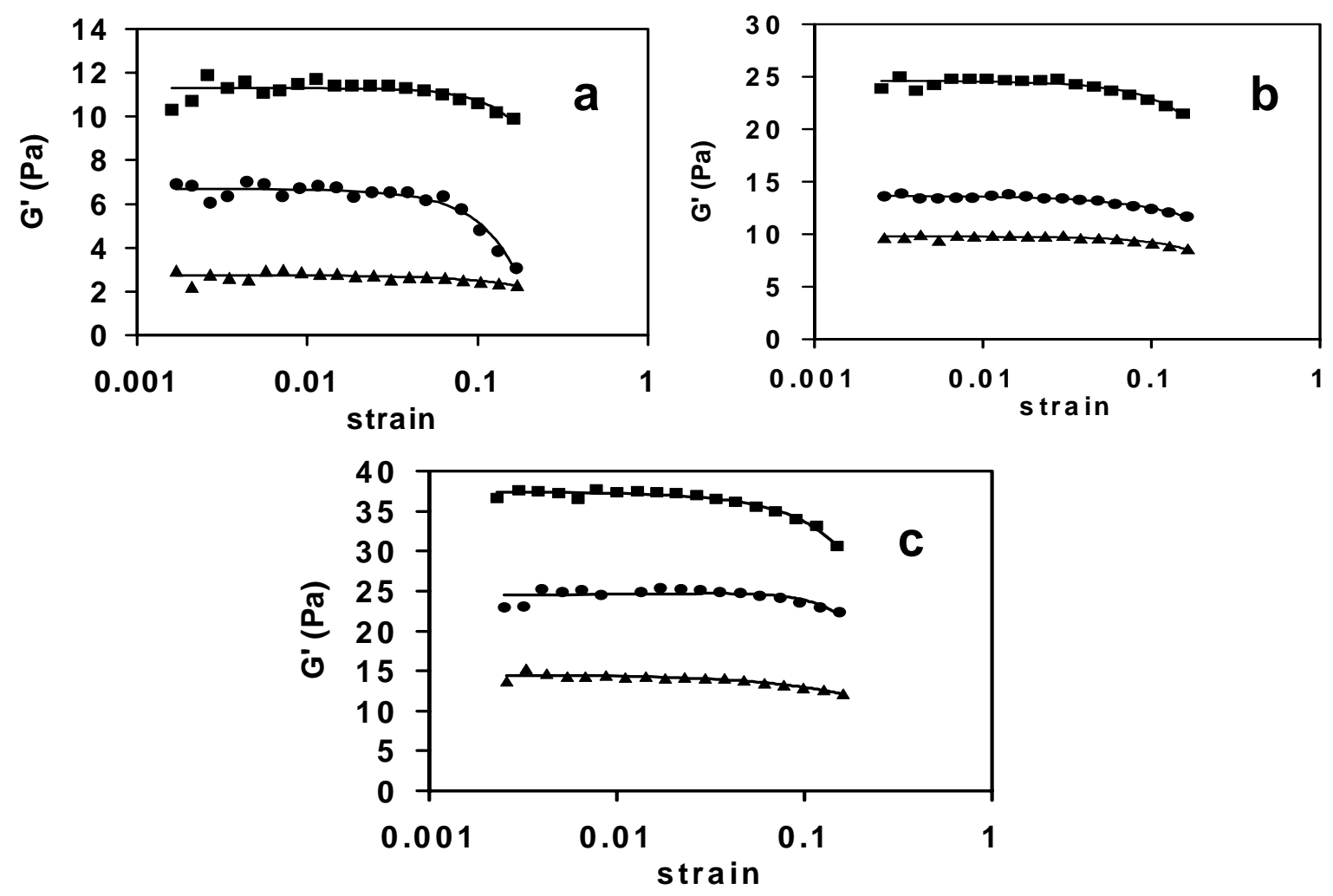

Figure 6.1. Effect of WUS and xylanase on G' versus strain of the GMP gels for the three wheat cultivars

Fig. 6.1a Scipion Fig. 6.1b Soissons Fig.6.1c Amazon

control,

\ 100 ppm xylanase. 
The phase angle delta (Fig.6.2), equal to the arctangent of the loss modulus (G') over the storage modulus (G'), is an indicator of the ratio of viscous to elastic behavior of gel. A low delta implies a more elastic gel structure. For all cultivars, addition of WUS led to a lower delta, indicating a more elastic GMP gel structure; whereas addition of xylanase resulted in a higher delta, pointing at a more viscous GMP gel structure.
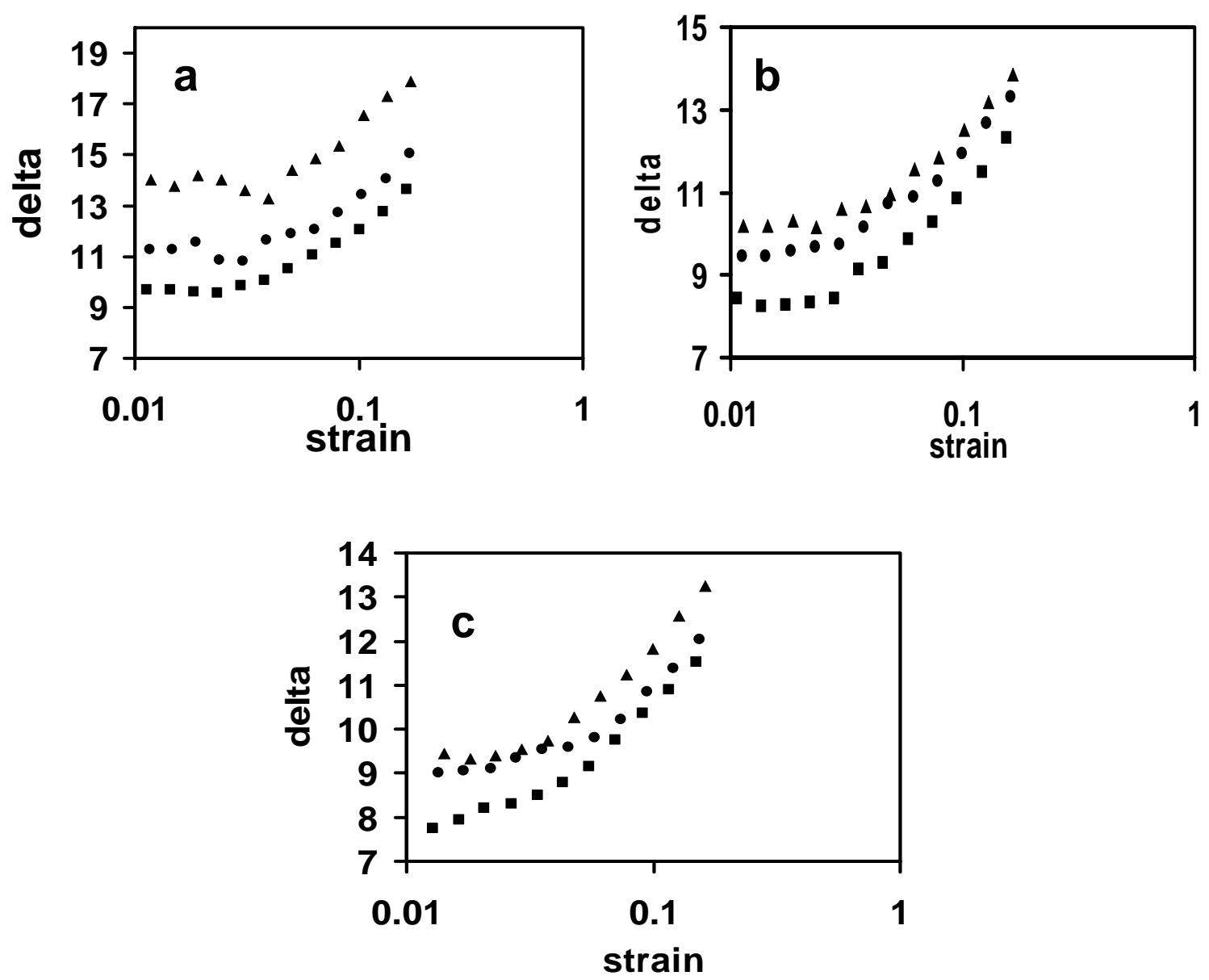

Figure 6.2. Effect of WUS and xylanase on delta versus strain of the GMP gels from the three wheat cultivars

Fig. 6.2a Scipion Fig. 6.2b Soissons Fig.6.2c Amazon

For an explanation of the symbols see Fig.6.1.

\section{3.4 Characterisation of GMP dispersion}

\subsubsection{Intrinsic viscosity of GMP dispersion}

Viscometric characterisation of GMP gel dispersion was carried out to allow a better understanding of the different gluten properties observed. Results are shown in Fig.6.3 and Table 6.5. 

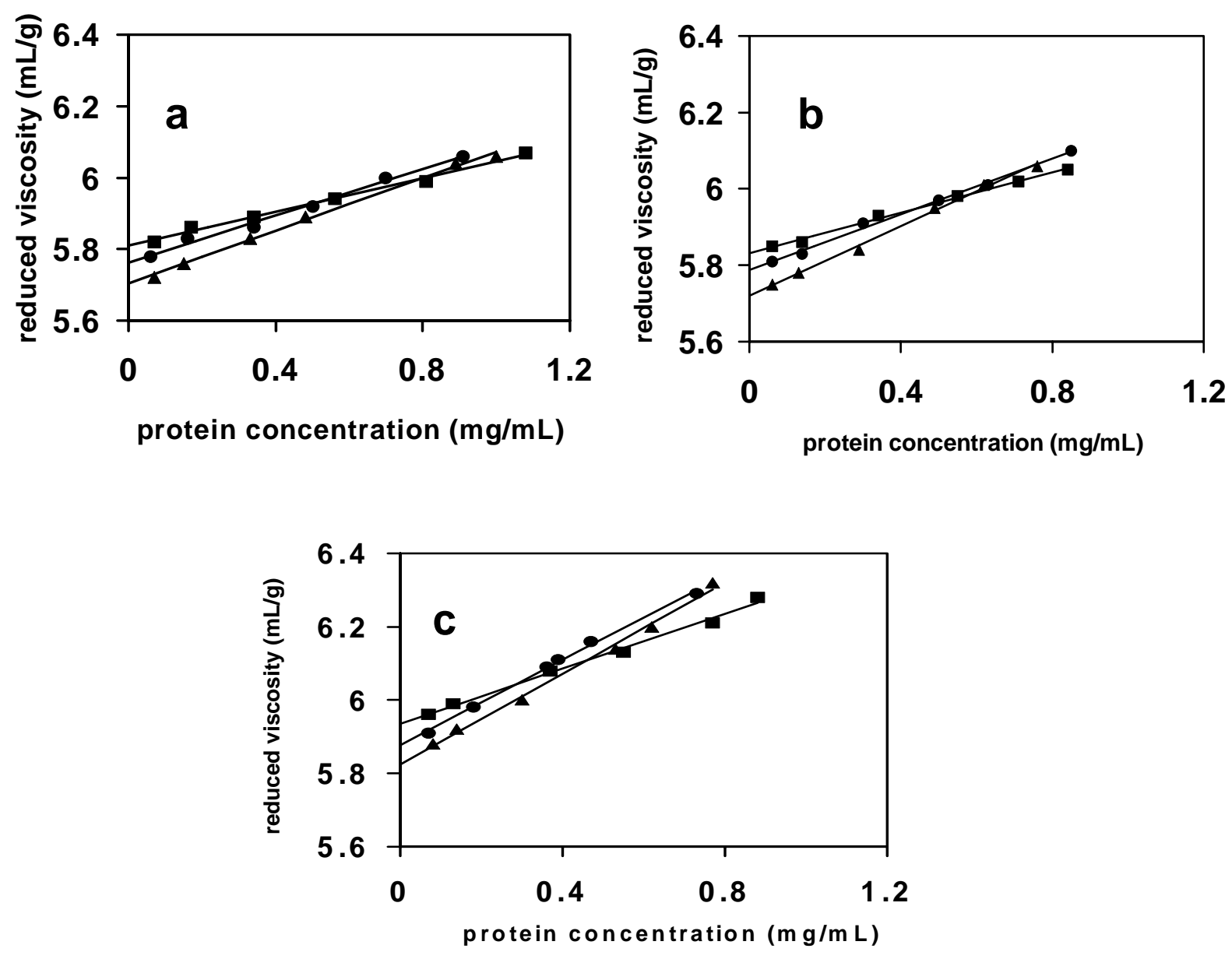

Figure 6.3. Effect of WUS and xylanase on the reduced viscosity as a function of protein concentration for GMP dispersion isolated from the three wheat cultivars

Fig. 6.3a Scipion Fig. 6.3b Soissons Fig.6.3c Amazon

For an explanation of the symbols see Fig.6.1.

The intercept of the curve represents the intrinsic viscosity [ $\eta]$ that is related to the average particle voluminosity (the hydrodynamic volume per unit of mass). The slope of the curve is negatively related to the voluminosity and positively to the interaction constant of dilute suspension of spheres ${ }^{24}$. A very small slope in combination with a larger $[\eta]$ indicates a lower tendency to aggregate. A steep slope in combination with a smaller $[\eta]$ represents a larger tendency to aggregate. The Huggins constant K', the ratio of slope divided by $[\eta]$, gives an indication about their aggregation behaviour.

For all cultivars, adding WUS led to an increase in $[\eta]$ and a decrease in the slope and $\mathrm{K}$, indicating a larger specific volume of the GMP particles and a smaller tendency to aggregate. In contrast, xylanase resulted in a decrease in $[\eta]$ and an increase in slope and $\mathrm{K}$ ', pointing at a smaller specific volume of GMP particles and a larger tendency to aggregate. 
Table 6.5 Effect of WUS and xylanase on the intrinsic viscosity and particle size of GMP dispersion from the three wheat cultivars

\begin{tabular}{ccccc}
\hline $\begin{array}{c}\text { Sample } \\
\text { name }\end{array}$ & $\begin{array}{c}\text { Intrinsic } \\
\text { viscosity } \\
(\mathbf{d L} / \mathbf{g})\end{array}$ & $\begin{array}{c}\text { Viscosity } \\
\text { slope }\end{array}$ & $\mathbf{K}^{\prime}$ & $\mathbf{D}_{\mathbf{3}, \mathbf{2}}$ \\
\hline Scipion control & 3.18 & 0.33 & 1.04 & 10 \\
$\mathbf{2 \%}$ WUS & 3.34 & 0.23 & 0.69 & 16 \\
100ppm xylanase & 3.00 & 0.37 & 1.23 & 6 \\
\hline Soissons control & 3.26 & 0.37 & 1.13 & 20 \\
2\%WUS & 3.41 & 0.26 & 0.76 & 26 \\
100ppm xylanase & 3.05 & 0.46 & 1.51 & 26 \\
\hline Amazon control & 3.57 & 0.58 & 1.62 & 38 \\
2\%WUS & 3.78 & 0.37 & 0.98 & 24 \\
\hline 100ppm xylanase & 3.39 & 0.62 & 1.83 & \\
\hline
\end{tabular}

Don et $\mathrm{al}^{25}$ reported that the rigidity of the GMP gel from flour and dough at small deformation $\left(\mathrm{G}^{\prime}\right)$ can be related to the concentration and average voluminosity of the GMP particles $\left(\mathrm{G}^{\prime}=\left(\mathrm{C}_{\mathrm{gel}} \times[\eta]\right)^{3.3}, \mathrm{R}^{2}=0.95\right)$. Taking this model, we predicted $\mathrm{G}^{\prime}$ of GMP gel isolated from our 9 gluten samples. We also found a strong correlation between predicted G' and measured $G^{\prime}\left(R^{2}=0.88\right)$. This indicates that $G^{\prime}$ of GMP gel isolated from gluten also follows this model.

\subsubsection{Particle size distribution of GMP gel dispersion}

According to Don et $\mathrm{al}^{25}$, it is likely that aggregation of GMP particles has a link with particle size distribution and more specifically the available particle surface area. Therefore, particle sizes of GMP dispersion were determined. The results are shown in Fig.6.4 and Table 6.5. The volume surface average particle diameter $D_{3,2}$, a measure of the available particle surface area per volume of particles is often used to characterise the particle size of dispersions. 

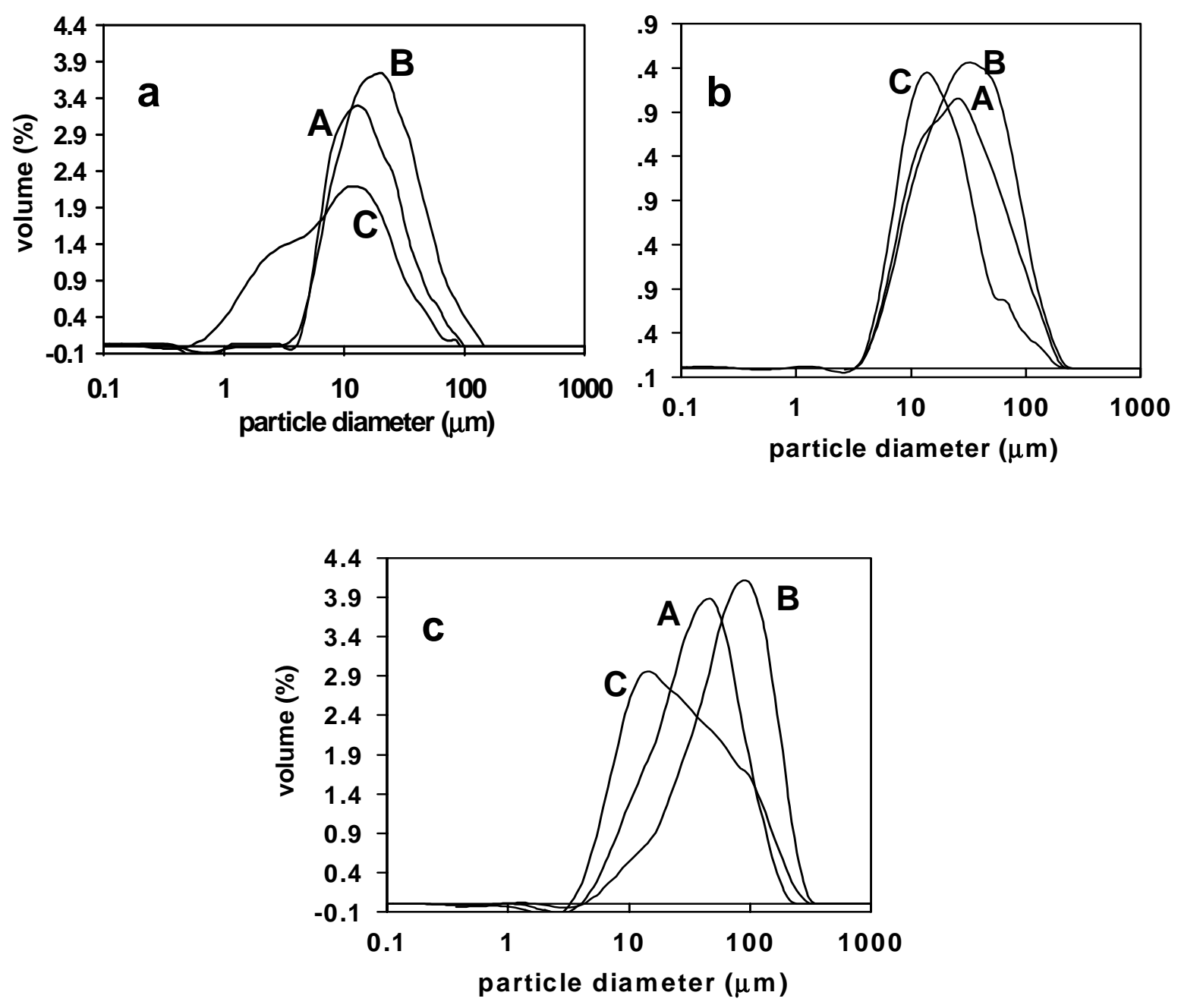

Figure 6.4. Effect of WUS and xylanase on particle size of GMP dispersion isolated from the three wheat cultivars

The curves represent a volume distribution and not number distribution.

Fig. 6.4a Scipion Fig. 6.4b Soissons Fig.6.4c Amazon

$\mathrm{A}=$ control, $\quad \mathrm{B}=2 \% \mathrm{WUS}, \quad \mathrm{C}=100 \mathrm{ppm}$ xylanase.

For all cultivars, addition of WUS led to a shift to larger particles; whereas addition of xylanase resulted in a shift to smaller particles (Fig.6.4 and Table 6.5). The $\mathrm{D}_{3,2}$ values in Table 6.5 are in agreement with our results of viscometric characterisation of GMP gel dispersions. The $\mathrm{D}_{3,2}$ of GMP particles isolated from Amazon flour (ca $26 \mu \mathrm{m}$ ) was larger than those from Scipion flour (ca $10 \mu \mathrm{m}$ ) and Soissons flour (ca $20 \mu \mathrm{m})$. This may well be one of the reasons why Amazon flour was less affected in terms of gluten yield and properties when WUS is added. 
6.3.5 Validating the explanation for the effect of pentosans on gluten formation and properties

In chapter 5, we proposed that addition of WUS negatively affects the aggregation of small GMP particles. This explanation was based on results obtained with only one cultivar, Soissons. Also, at that time we could not support this explanation with actual data of the size distribution of GMP particles. In Fig. 6.4 we now show actual size distributions. The resulting gluten contains GMP particles with a higher voluminosity (Table 6.5, larger $[\eta])$ and a smaller tendency to agglomerate (Table 6.5, lower K'). Our measurements confirm that under these conditions less small particles of GMP are recovered leading to a larger $\mathrm{D}_{3,2}$. The fact that this shift towards larger particle diameters occurs with all three cultivars again points at a depletion attraction effect of pentosans on GMP particle agglomeration. Again, we think the lower K' reflects the lower Van der Waals attraction between GMP particles. Apparently, an interaction of WUS via FA with GMP particles lowers the Van der Waals attraction. This in turn explains a lower gluten yield. This clearly fits the explanation proposed before ${ }^{13}$. The validated observations are schematically given in Fig.6.5.

a Control
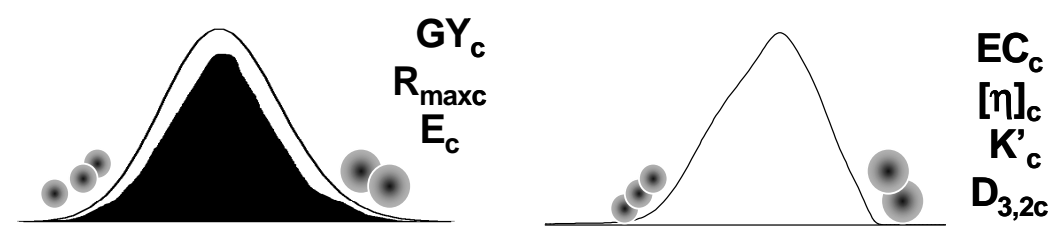

$\mathrm{EC}_{\mathrm{c}}$

$[\eta]_{c}$

$D_{3,2 c}$

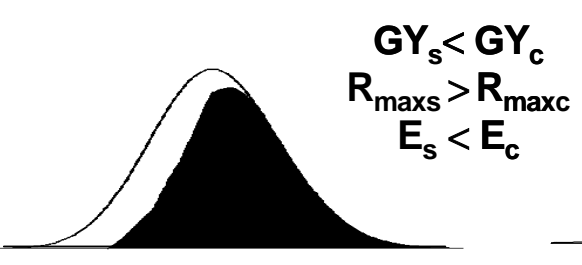

$E C_{s}=E C_{c}$ $[\eta]_{s}>[\eta]_{c}$ $\mathbf{K}_{s}^{\prime}<K^{\prime}$

b WUS
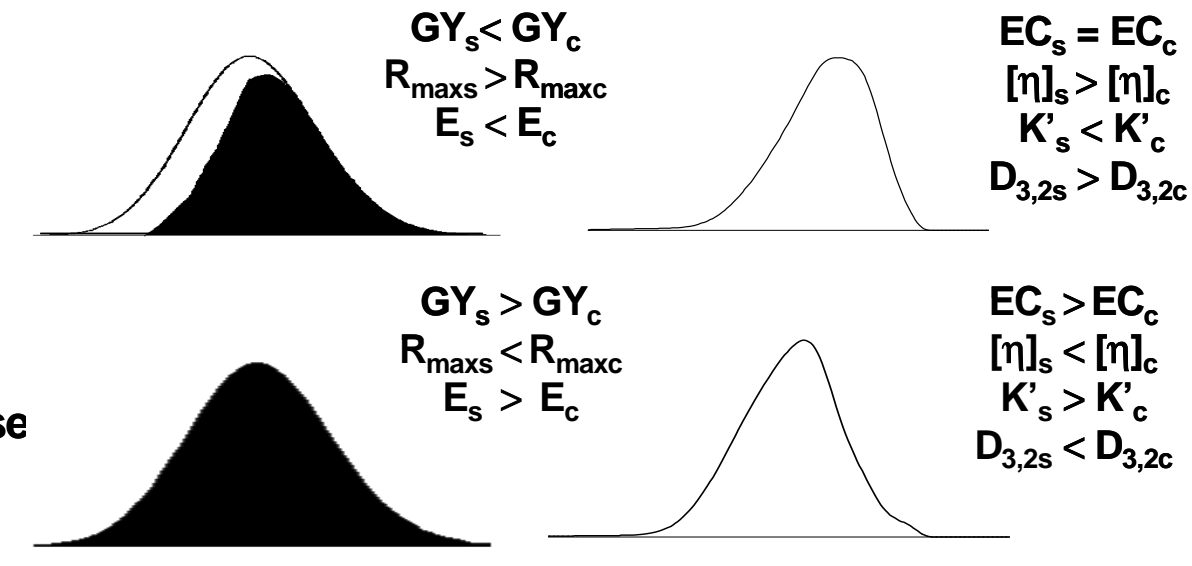

$E_{s}>E_{c}$

$[\eta]_{s}<[\eta]_{c}$

$\mathrm{K}_{\mathrm{s}}^{\prime}>\mathrm{K}_{\mathrm{c}}^{\prime}$

C Xylanase

$D_{3,2 \mathrm{~s}}<D_{3,2 \mathrm{c}}$

Figure 6.5. The validated observations for the effects of pentosans on gluten formation and properties

The black area of the left side curves indicates the GMP protein recovery (EC). The right side curves represent the particle size distribution of the GMP particles.

$\mathrm{GY}=$ gluten yield, $\mathrm{c}=$ control, $\mathrm{s}=$ sample. 
Addition of WUS leads to a shift of the particle size distribution (Fig.6.5b) to the right side compared to the control (Fig.6.5a). We propose that pentosans do not as much affect the growth of particles but hinder the further agglomeration of especially smaller particles to end up in the gluten.

Our results also demonstrate that for all cultivars addition of xylanase to wheat flour results in a higher gluten yield and a more extensible gluten (lower $\mathrm{R}_{\max }$ and larger $\mathrm{E}$ at $R_{\max }$ ). The resulting GMP particles have a smaller voluminosity (smaller [ $\left.\eta\right]$ ) and a larger tendency of particles to agglomerate (higher K'). Now, also smaller particles of GMP are recovered. This is also in agreement with the explanation proposed ${ }^{13}$. Addition of xylanase results in a shift in the maximum of the particle size distribution in Fig.6.5c to the left side compared to the control (Fig.6.5a).

In chapter 5 we also discussed correlations between the various parameters for Soissons ${ }^{13}$. A correlation table based on data for three cultivars is presented in Table 6.6 including data for $\mathrm{D}_{3,2}$. Compared with those for only Soissons in chapter 5 , the correlations between $R_{\max }$ and [ $\left.\eta\right], E$ at $R_{\max }$ and $K^{\prime}, G^{\prime}$ and [ $\left.\eta\right]$ are confirmed but not anymore those between $E$ at $R_{\max }$ and [ $\eta$ ], delta intercept with $R_{\max }$ and [ $\eta$ ]. Interestingly, we observed that $D_{3,2}$ correlated with $R_{\max }, G^{\prime}$, delta intercept and [ $\eta$ ].

Table 6.6 Correlations $\left(\mathrm{R}^{2}\right)$ between gluten parameters and GMP parameters for the three wheat cultivars

\begin{tabular}{|c|c|c|c|c|c|c|}
\hline & $\mathbf{R}_{\max }$ & $\mathbf{E}$ at $R_{\max }$ & $\mathrm{G}^{\prime}$ & $\begin{array}{c}\text { Delta } \\
\text { intercept }\end{array}$ & {$[\eta]$} & $\mathbf{K}^{\prime}$ \\
\hline$E$ at $R_{\max }$ & -0.24 & & & & & \\
\hline $\mathrm{G}^{\prime}$ & 0.61 & -0.05 & & & & \\
\hline $\begin{array}{c}\text { Delta } \\
\text { intercept }\end{array}$ & -0.67 & 0.10 & -0.67 & & & \\
\hline$[\eta]$ & 0.85 & 0.07 & 0.83 & -0.67 & & \\
\hline $\mathbf{K}^{\prime}$ & -0.02 & 0.82 & 0.03 & 0.01 & -0.01 & \\
\hline $\mathbf{D}_{\mathbf{3 , 2}}$ & 0.71 & 0.02 & 0.93 & -0.80 & 0.87 & 0.01 \\
\hline
\end{tabular}

\subsection{Conclusions}

The aim of this study was to confirm and extend our earlier findings (chapter 5), which were based on experiments with one wheat variety. Here, three wheat cultivars of 
very different technological quality were used. With regard to the effect of WUS and xylanase, the same effects were observed for all cultivars pointing at a general effect. The key observation that GMP average particle size was affected by pentosans was confirmed using Coulter Laser analysis, a new technique allowing us to measure particle size distributions. The correlations between $\mathrm{R}_{\max }$ and [ $\eta$ ], $\mathrm{E}$ at $\mathrm{R}_{\max }$ and $\mathrm{K}$ ' were also confirmed, validating our explanation for the effect of pentosans on gluten properties. However, we also observed that the size of the effect was not the same. Amazon was clearly less affected by addition of pentosans or xylanase than the other two cultivars. Amazon significantly differs from Scipion and Soissons, it has a higher protein content and a lower content of pentosans. Both aspects promote the formation of gluten and perhaps explain the smaller effect of added pentosans and xylanase. The very high $D_{3,2}$ of Amazon however could offer an additional explanation for the smaller effect. Amazon apparently lacks smaller GMP particles. Effects of depletion attraction would be smaller. Also, our results show that Amazon has the ability to form more sticky particles than Soissons and Scipion (Table 6.5). Even when WUS is present, the resulting $\mathrm{K}^{\prime}$ for Amazon is still at the same level of Scipion control [K' 0,98 (Amazon plus WUS) vs 1,04 (Scipion control)]. Perhaps these particle properties also allow us to better understand the different responses of wheat cultivars to these additions observed so often.

\section{Acknowledgements}

The financial support of this research work by CSM Bakery Supplies Division Europe, Amylum Europe N.V. and Cargill B.V is gratefully acknowledged.

\section{References}

1. Medcalf, D.G., D'Appolonia, B.L. and Gilles, K.A. Comparison of chemical composition and properties between hard red spring and durum wheat endosperm pentosans. Cereal Chemistry 45 (1968): 539-549.

2. D'Appolonia, B.L. and Macarthur, L.A. Comparison of starch, pentosans and sugars of some conventional height and semidwarf hard red spring wheat flours. Cereal Chemistry 52 (1975): 230-239.

3. Lineback, D.R., Kakuda, N. and Tsen, C.C. Carbohydrate composition of water-soluble pentosans from different types of wheat flours. Journal of Food Science 42 (1977): 461-467.

4. Ciacco, C.F. and D'Appolonia, B.L. Characterization of pentosans from different wheat flour classes and of their gelling capacity. Cereal Chemistry 59 (1982):96-99. 
5. Izydorczyk, M., Biliaderis, C.G. and Bushuk, W. Physical properties of water-soluble pentosans from different wheat varieties. Cereal Chemistry 68 (1991): 145-150.

6. Bettge, A.D. and Morris, C.F. Relationships among grain hardness, pentosan fractions and end-use quality of wheat. Cereal Chemistry 77 (2000): 241-247.

7. Jelaca, S.L. and Hlynka, I. Effect of wheat-flour pentosans in dough, gluten and bread. Cereal Chemistry 49 (1972) 489-495.

8. Jelaca, S.L. and Hlynka, I. Water-binding capacity of wheat -flour crude pentosans and their relation to mixing characteristics of dough. Cereal Chemistry 48 (1971) 211-222.

9. Kim, S.L. and D'Appolonia, B.L. Bread staling studies. III, Effect of pentosans on dough, bread and bread staling rate. Cereal Chemistry 54 (1977) 225-229.

10. Michniewicz, J., Biliaderis, C.G. and Bushuk, W. Water-insoluble pentosans of wheat: Composition and some physical properties. Cereal Chemistry 67 (1990) 434-439.

11. Michniewicz, J., Biliaderis, C.G. and Bushuk, W. Effect of added pentosans on some physical and technological characteristics of dough and gluten. Cereal Chemistry 68 (1991) 252-258.

12. Courtin, C.M., Bulck, K.V. and Delcour, J.A. Understanding arabinoxylan functionality in bread-making. $84^{\text {th }}$ AACC Meeting (Seattle, 1999).

13. Wang, M-W, van Vliet, T. and Hamer, R.J. How gluten properties are affected by pentosans. Journal of Cereal Science submitted.

14. Wang, M-W, Hamer, R.J., van Vliet, T., Gruppen, H., Marseille, J.P., Weegles, P.L. Effect of water unextractable solids on gluten formation and properties: Mechanistic considerations. Journal of Cereal Science 37 (2003) 55-64.

15. Michniewicz, J., Biliaderis, C.G. and Bushuk, W. Effect of added pentosans on some physical and technological characteristics of dough and gluten. Cereal Chemistry $\mathbf{6 8}$ (1991) 252-258.

16. Wang, M-W, Oudgenoeg, G., van Vliet, T. and Hamer, R.J. Interaction of water unextractable solids with gluten protein: Effect on dough properties and gluten quality. Journal of Cereal Science in press.

17. Weegels, P.L., Marseille, J.P. and Voorpostel, A.M.B. Enzymes as a processing aid in the separation of wheat into starch and gluten. In 'Gluten Proteins' (Bushuk, W. Tkachuk, R. Eds). American Association Cereal Chemist. Inc. St. Paul, Minnesota, USA.(1991) pp 199-203.

18. Weegels, P.L., Marseille, J.P. and Hamer, R.J. Enzymes as a processing aid in the 
separation of wheat flour into starch and gluten. Starch/ Staerke 44 (1992) 44-48.

19. Cleemput, G. Characterisation of water-extractable nonstarch polysaccharides and non-starch polysaccharides hydrolysing enzymes in Europen wheat flours. Ph.D thesis, Leuven, Belgium. (1996).

20. MacRitchie, F. Wheat proteins: characterization and role in flour functionality. Cereal Food World 44 (1999) 188-193.

21. Gupta, R.B., Khan, K. and MacRitchie, F. Biochemical basis of flour properties in bread wheats. I. Effects of variation in quantity and size distribution of polymeric proteins. Journal of Cereal Science 18 (1993) 23-41.

22. Bangur, R., Batey, I. L., McKenzie, E. and MacRitchie, F. Dependence of extensograph parameters on wheat protein composition measured by SE-HPLC. Journal of Cereal Science 25 (1997) 237-241.

23. van Vliet, T. Factors determining small-deformation behaviour of gels. In ' Food Emulsions and Foams interfaces, interactions and stability' (eds. E. Dickinson and J.M. Rodriguez Patino) The Royal Society of Chemistry. (1999) pp 307-317.

24. Kruif, de C. G. Supra-aggregates of casein micelles as a prelude to coagulation. Journal of Dairy Science 81 (1998) 3019-3028.

25. Don, J.A.C., Lichtendonk, W.J., Plijter, J.J. and Hamer, R.J. Understanding the link between GMP and dough I: from glutenin particles in flour towards developed dough. Journal of Cereal Science in press. 
Chapter 6 


\title{
7
}

\section{Evidence that pentosans and xylanase affect the re-agglomeration of the gluten network}

\begin{abstract}
The formation of gluten is the result of, first, breakdown of gluten structures during mixing and, second, re-agglomeration of gluten protein structures. So far, effects of pentosans and enzymes on mixing and re-agglomeration have not been studied separately. With a small modification of the TNO Glutomatic system, we can add pentosans, xylanase or other additives after the first mixing step. This allows us to study the effect of these additions on gluten aggregation separately. In this chapter we observed that re-aggregation of gluten protein starts immediately after the first mixing step during the dough dilution phase. Addition of pentosans or xylanase during this phase results in the same or even stronger effects on gluten formation as observed earlier. With xylanase, addition prior to dough mixing can lead to overdose effects. This is not observed when xylanase is added later during the agglomeration phase. Our experimental set up also allows us to distinguish between physical (viscosity, depletion attraction) and chemical effects of pentosans on gluten formation. This confirms that the effect of WEP is only partly related to a viscosity effect. A ferulic acid (FA) related interaction is more important here. The resulting gluten contains GMP particles of a higher average voluminosity than the control. Apparently, pentosans especially affect the agglomeration of GMP particles to gluten. When WEP interference is prevented, by xylanase or FA, aggregation during the dilution phase is more extensive. The resulting gluten is characterised by a lower average GMP particle size. These differences can be linked to differences in gluten rheological properties. We conclude that pentosans and xylanase mainly act during the re-agglomeration of gluten following the breakdown of gluten structures during mixing. Both act on the ability of GMP particles to form gluten, affecting both gluten yield and gluten rheological properties. Effects of pentosans and xylanase on gluten are paralleled by effects on dough. Similar effects on especially dough extensibility were observed. Effects on strain hardening parameters were not significant.
\end{abstract}

Wang, M-W, van Vliet, T. and Hamer, R.J. Journal of Cereal Science submitted. 


\subsection{Introduction}

Wheat water extractable pentosans (WEP) have been studied for about 50 years since they were discovered as a component in the grains of wheat and other cereals. In that time cereal scientists have markedly increased their knowledge of the structure, properties and functionality of WEP. However, also contradictory results regarding the functionality of WEP have been published. Reported effects of WEP on bread-making strongly vary from non-existent ${ }^{1-2}$ or minor ${ }^{3}$ to positive ${ }^{4-8}$. The different results may depend on their gross content in flour, their water extractability and fine structure ${ }^{9-12}$. The effects of WEP on gluten yield and properties were rarely studied. Michniewicz et $\mathrm{al}^{13}$ and chapter 3 and 5 stated that WEP negatively affect gluten yield. In addition, we demonstrated that adding WEP to wheat flour led to a gluten with a higher maximum resistance to extensibility $\left(R_{\max }\right)$ and a smaller extensibility at maximum resistance $\left(E \text { at } R_{\max }\right)^{14-15}$.

Nowadays, wheat pentosans are becoming more and more important in view of the increased use of 'dark' (high pentosans containing) flour for the production of wheat bakery and gluten products. Therefore, it is really necessary to further investigate the mechanisms of the interaction of WEP and xylanase with gluten protein.

Xylanases have been found to be a valuable tool for studying WEP functionality in bread-making, gluten and starch separation. It has been reported that addition of xylanases to wheat flour could improve dough handling properties ${ }^{16-19}$, oven spring ${ }^{20}$, loaf volume and crumb structure ${ }^{16-21}$. Besides, Weegels et $\mathrm{al}^{22}$, Courtin et al ${ }^{23}$ and chapter 2, 4-6 have proven that xylanases are very efficient to correct the negative effects of pentosans on gluten yield $^{15,24-26}$. Because of their ability to modify WEP functionality, xylanases are being widely used in the bakery and gluten industry.

However, analysis of the literature mentioned above shows that in spite of the number of papers published on WEP and xylanase, no definite mechanisms for the interaction of WEP and xylanase with gluten protein were reported. Several theories exist to explain the effect of WEP and xylanase. But some of them are disputed.

Chapter 3 proposed that WEP interfere with gluten formation both in a direct and an indirect way. WEP would interfere indirectly by competing for water and thus changing conditions for gluten development. This leads to a lower gluten yield and a gluten with an increased $\mathrm{R}_{\max }$. This effect can be corrected for completely by adding more water or adding xylanase before mixing ${ }^{14}$. According to Maat et al ${ }^{16}$, xylanase can act by reducing the water binding capacity of WEP thus inducing water redistribution in dough. Indeed, we have demonstrated that xylanase lowers the optimal amount of water needed for maximal gluten yield ${ }^{24}$. Labat et al ${ }^{27}$ suggested an indirect effect of WEP that would be caused by 
their ability to form a network limiting the movement of glutenin proteins and formation of larger aggregates. The beneficial action of xylanases would then be related to breakdown of this WEP network.

In addition, we have found that arabinoxylan (AX) bound ferulic acid (FA), a major component of WEP, is involved in the direct effect of WEP on gluten formation ${ }^{14}$. This direct effect is reflected in a lower extensibility of dough and gluten. Addition of free FA leads to both a higher gluten yield and a more extensible dough and gluten. We assume that the AX bound FA moieties can act in two ways ${ }^{14}$. Firstly, by cross-linking WEP, which leads to a higher viscosity in the liquid phase. Many authors ${ }^{28-37}$ reported such an effect. We have proven that this also occurs during flour processing in the modified Glutomatic system $^{14}$. However, we regard this effect on gluten formation to be indirect, because it is viscosity mediated and can be corrected for by adding more water before mixing. Also, it does not occur in WEP of a low molecular weight. The second way by which AX bound FA can act, is by directly linking to gluten proteins ${ }^{29-30,38}$. This influence on gluten structure formation cannot be corrected for by adding more water before mixing ${ }^{14}$ and is characterised by a decrease in dough/gluten extensibility. In chapter 5 we have suggested that such interaction modified the Van der Waals attraction between particles, which is reflected in a lower $\mathrm{K}^{\prime}$.

However, Hilhorst et $\mathrm{al}^{18}$ declared that no evidence was found that xylanase specifically removed WEP from gluten. Also, Labat et al ${ }^{37,39}$ reported that no covalent complex between AX and protein could be detected in mixed and oxidised gluten/WEP, and overmixed doughs. Labat et $\mathrm{al}^{39}$ proposed that soluble FA esters are likely to react with proteins during mixing and would be involved in gluten breakdown during overmixing rather than feruloylated $\mathrm{AX}$.

The formation of gluten is the result of, first, breakdown of gluten structures during mixing and, second, re-agglomeration of gluten protein structures. So far, effects of pentosans and enzymes on mixing and re-agglomeration have not been studied separately. This may be due to both water binding and mixing conditions changed by addition of pentosans and xylanase to flour.

In addition, strain hardening tends to be an important factor in the gas retention abilities of wheat flour doughs ${ }^{40}$. Janssen et al reported ${ }^{41}$ that gluten and flour doughs showed strain hardening behaviour in biaxial extension, which means that a relatively more extended gluten or dough film has a higher resistance to deformation than a relatively thicker, less extended film. Gluten and flour doughs made from a wheat variety with a good bread-making performance showed a higher resistance to compression and more 
strain hardening than gluten made from a poor baking wheat.

In this chapter a modification of the TNO Glutomatic system allowed us to add WEP and xylanase during the re-agglomeration phase. Dough strain hardening was also determined. Evidence regarding WEP and xylanase affecting the re-agglomeration of the gluten network will be presented and the effects of WEP and xylanase on gluten and dough properties will be discussed.

\subsection{Experimental}

\subsubsection{Materials}

Scipion, Soissons and Amazon flour (untreated, different batch as we used before ${ }^{15}$ ) were kindly donated by TNO, Zeist, the Netherlands.

WEP preparation (medium viscosity: 27cSt, 2,000,000 Da $>$ average molecular weight $(\mathrm{MW})>500,000 \mathrm{Da}, \mathrm{FA}=0.09 \%$ ) was supplied by Megazyme (lot 20401).

Xylanase (Shearzyme 500 L, batch CDN00020) was purchased from NOVO Nordisk.

FA was obtained from Sigma.

Dextran $\left(\mathrm{T}_{500}, \mathrm{MW}=500,000 \mathrm{Da}\right)$ was purchased from Pharmacia.

$\left.\mathrm{WEP}_{\mathrm{x}}\left(\mathrm{MW}_{\text {glucose }}<\mathrm{MW}<10,000 \mathrm{Da}, \mathrm{FA}=0.13 \%\right)\right)$ was prepared by preincubating WEP with xylanase as described previously ${ }^{14}$.

$\mathrm{WEP}_{\mathrm{OH}}(\mathrm{MW}$ comparable to $\mathrm{WEP}, \mathrm{FA}=0.03 \%)$ ) was prepared by preincubating WEP with $\mathrm{NaOH}$ as described previously ${ }^{14}$.

All other chemicals used were of analytical grade or better.

\subsubsection{Analytical methods}

Protein content was determined using the Dumas method as described previously ${ }^{14}$.

Starch content was measured enzymatically using the test kit supplied by Boehringer, Mannheim.

AX content was analysed using the alditol acetate method with inositol as internal standard as described previously ${ }^{14}$.

\subsubsection{Characterisation of gluten and dough samples}

\subsubsection{Gluten yield}

The gluten yield of dough was determined and gluten samples were prepared using a modified Glutomatic 2200 system (Perten, modified by TNO) as described previously 
${ }^{24}$.We modified it again. We now installed a two-way valve from Pharmacia in the diluting system (Fig.7.1). This allows us to change the dilution solution by simply turning the valve. The valve prevents contaminations between the different dilution solutions. The dilution solutions were thermostatted at constant temperature to ensure reproducible results. The scheme of this modified Glutomatic system is shown in Fig.7.1. The mixing time and mixing water used for isolating Scipion, Soissons and Amazon gluten samples were 3 min and $6.0 \mathrm{~mL}, 3 \mathrm{~min}$ and $6.1 \mathrm{~mL}, 6 \mathrm{~min}$ and $7.5 \mathrm{~mL}$, respectively.

\subsubsection{Gluten and dough properties}

Gluten and dough rheological properties were measured using a Kieffer extensibility rig fitted onto a Texture Analyser equipped with a $5 \mathrm{~kg}$ load cell as described previously ${ }^{14}$. Soissons gluten samples were prepared using the modified Glutomatic system. The conditions used were the same as for the gluten yield test. Soissons dough samples were prepared using a mixograph (National Manufacturing Co.). Soissons flour was mixed with $50 \%$ water $(0.2 \% \mathrm{NaCl})$ on flour basis for $3 \mathrm{~min}$ at ambient temperature.

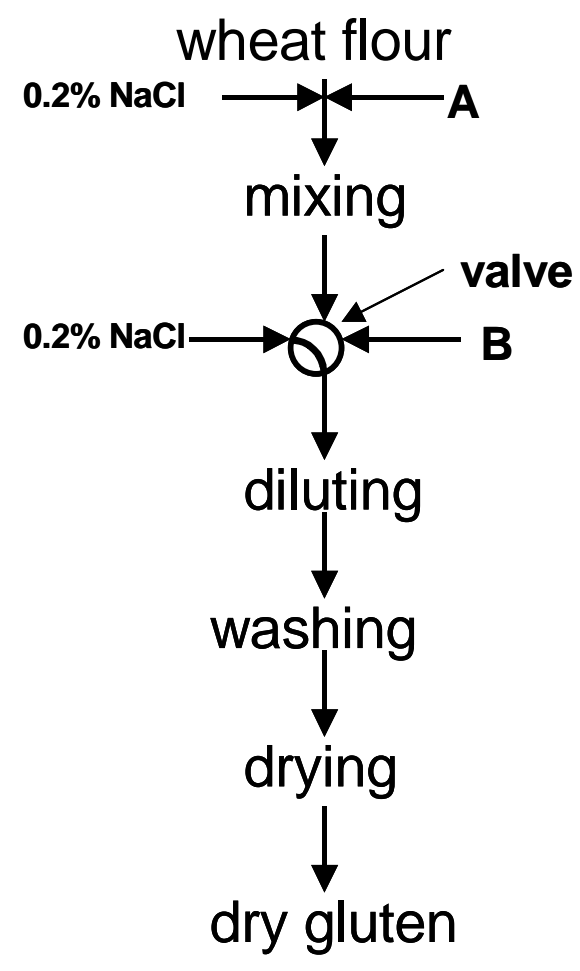

Figure 7. 1. Scheme of TNO Glutomatic system

This system allows to add reagents before mixing (A) or directly after mixing (B) instead of the normal $0.2 \% \mathrm{NaCl}$ solution.

$\mathrm{A}=\mathrm{WEP}, \mathrm{WEPx}$, xylanase, WEP+FA respectively,

$\mathrm{B}=\mathrm{WEP}, \mathrm{WEPx}$, xylanase, WEP+FA, dextran in $0.2 \% \mathrm{NaCl}$ solution respectively. 


\subsubsection{Characterisation of GMP gel}

\subsection{Defatting gluten samples}

A freeze-dried gluten sample $(3 \mathrm{~g})$ was dispersed in $75 \mathrm{~mL}$ petroleum ether, mixed for $20 \mathrm{~min}$ and centrifuged $\left(18,900 \times \mathrm{g}, 10 \mathrm{~min}\right.$ at $\left.5^{\circ} \mathrm{C}\right)$. The whole procedure was repeated. Petroleum ether residues in the defatted gluten samples were evaporated for overnight in a fume hood.

\subsection{GMP isolation}

Defatted gluten sample (80 mg) was dispersed in $10 \mathrm{~mL} \mathrm{1.5 \% (w/v)} \mathrm{SDS} \mathrm{solution} \mathrm{and}$ ultracentrifuged $\left(69,000 \times \mathrm{g}, 30 \mathrm{~min}\right.$ at $\left.20^{\circ} \mathrm{C}\right)$. The supernatant was discarded and the gel-like layer found on top of the starch pellet (called GMP) was weighed as GMP wet weight.

\subsection{Protein content of GMP gel}

The protein content of GMP gel was determined using the Dumas method after drying the GMP gel at $80^{\circ} \mathrm{C}$ for $2 \mathrm{~h}$.

\subsection{Extent of coagulation of GMP}

Extent of coagulation (EC) is defined as the relative amount of GMP protein that can be isolated from wheat flour as described previously ${ }^{15}$.

$$
E C=\frac{Y_{s} \cdot W_{s} \cdot P_{s}}{Y_{c} \cdot W_{c} \cdot P_{c}} \times 100
$$

where: $\mathrm{Y}=$ gluten yield (g/g flour)

$\mathrm{W}=\mathrm{GMP}$ wet weight $(\mathrm{g} / \mathrm{g}$ gluten)

$\mathrm{P}=\mathrm{GMP}$ protein content $(\mathrm{mg} / \mathrm{g}$ wet GMP)

$\mathrm{s}=$ sample

$\mathrm{c}=$ control

\subsection{Rheometer measurement}

Rheological measurements were performed using a Bohlin VOR rheometer Bohlin, Sweden) as described previously ${ }^{24}$. 


\subsubsection{Characterisation of glutenin marcopolymer (GMP) dispersion}

\subsection{Voluminosity of GMP dispersion}

Viscosity of GMP dispersion was determined at $25 \pm 0.1^{\circ} \mathrm{C}$ using an Ubbelohde capillary viscometer as described previously ${ }^{14-15}$.

\subsection{Particle size of GMP dispersion}

Particle size of GMP dispersion was measured using a LS 230 Particle Size Analyzer (Beckman Coulter) as described previously ${ }^{26}$.

\subsubsection{Biaxial extension tests}

\subsection{Sample preparation}

Soissons flour dough (7 $\mathrm{g}$ ) was prepared in a mixograph (3 min mix and 50\% water addition) and placed in a lubricated Teflon cylinder (diameter $20 \mathrm{~mm}$, height $20 \mathrm{~mm}$ ). The dough was covered with a lubricated Teflon plunger that just fitted in the cylinder to prevent drying out. After 30 minutes the sample was allowed to slide out of the cylinder.

\subsection{Biaxial extension tests}

Biaxial extension tests were performed with a Texture Analyser equipped with a $5 \mathrm{~kg}$ load cell. The cylindrical dough was compressed uniaxially between two Teflon plates

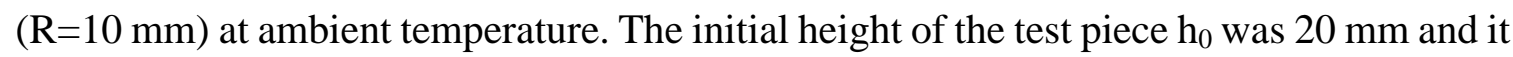
was compressed to a final height of $1 \mathrm{~mm}$. Deformation and force $\mathrm{F}$ were recorded at three different speeds of the moving upper plate ( $v=5,12$ and $120 \mathrm{~mm} / \mathrm{min})$. Results are mean values of two measurements on at least two different dough pieces (at least four measurements in total).

\subsection{Calculating strain hardening constant and strain rate thinning constant}

Strain hardening constant was calculated based on the following formula ${ }^{43}$ :

Stress $\sigma$ as $\sigma=F_{t} /\left(\pi R^{2}\right)$; Hencky strain $\varepsilon_{\mathrm{H}}$ and relative deformation rate $\dot{\varepsilon}$ as $\varepsilon_{H}=$ $-\ln \left(h_{t} / h_{0}\right)$ and $\dot{\varepsilon}_{H}=d \varepsilon_{H} / d t=d h /\left(h_{t} d t\right)=v / h_{t}$, respectively, where $\mathrm{h}_{\mathrm{t}}=$ height at time $\mathrm{t}$; biaxial strain $\varepsilon_{\mathrm{B}}$ and biaxial strain rate $\dot{\varepsilon}_{\mathrm{B}}$ as $\varepsilon_{B}=\varepsilon_{H} / 2$ and $\dot{\varepsilon}_{B}=\dot{\varepsilon}_{H} / 2$, respectively; strain hardening constant $y$ and strain rate thinning constant $z$ as $y=\partial \ln \sigma / \partial \varepsilon_{\mathrm{B}}\left(\dot{\varepsilon}_{\mathrm{B}}=0.01 \mathrm{~s}^{-1}\right)$ and $z=\partial \ln \sigma / \partial$ $\dot{\varepsilon}_{B}\left(\varepsilon_{\mathrm{B}}=0.5\right)$. 


\subsection{Results and discussion}

\subsubsection{Particle size of GMP}

Particle size characterisation of a GMP dispersion isolated from Amazon flour, dough, diluted dough and gluten was carried out to study the changes in glutenin particle size during mixing, diluting and washing in the modified Glutomatic system (Fig.7. 2).

The average particle size of the GMP dispersion from dough is the smallest among the four curves (Fig.7.2, B), indicating that mixing leads to break down of GMP particle size. This result is in agreement with findings of Weegels et $\mathrm{al}^{44}$ and Don et $\mathrm{al}^{45}$. The average particle size of GMP dispersion from diluted dough is larger than that from dough (Fig.7.2, C vs B), indicating that gluten protein starts to re-agglomerate during the dilution phase. The average particle size of the GMP dispersion from gluten is still larger than that from diluted dough (Fig.7.2, D vs C), which means that gluten protein continues to re-agglomerate during the washing phase. However, it does not reach to the original particle size of GMP isolated from flour (Fig.7.2, A), which demonstrates that gluten protein does not completely aggregate after mixing.

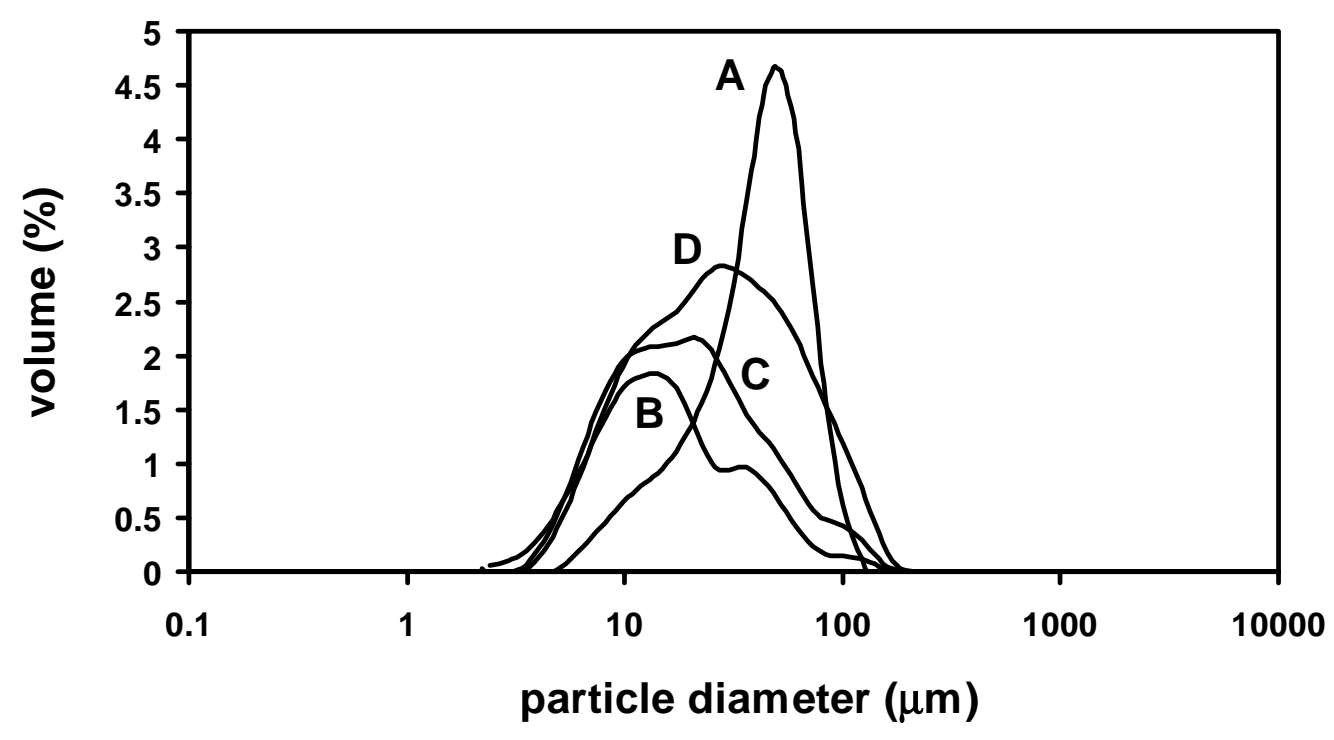

Figure 7.2. Particle size distribution of GMP dispersion from Amazon flour, dough, diluted dough and gluten

$\mathrm{A}=\mathrm{GMP}$ from flour,

$\mathrm{B}=$ GMP from dough (directly after 6 min mixing),

$\mathrm{C}=$ GMP from diluted dough (directly after $5 \mathrm{~min}$ diluting),

$\mathrm{D}=\mathrm{GMP}$ from gluten ((directly after 5min washing). 


\subsubsection{Effect on gluten yield}

7.3.2.1 Comparison of the effect of WEP, FA and xylanase addition before mixing and during the dilution phase

Particle size characterisation of the GMP dispersion isolated from Amazon flour, dough, diluted dough and gluten indicated that gluten proteins started to re-agglomerate during the dilution phase. In chapter 5 we hypothesized that WEP, FA and xylanase act by affecting gluten re-agglomeration. Therefore, we compared the effects of WEP or FA or xylanase when added to wheat flour before mixing or during the dilution phase by using the modified Glutomatic system (Fig.7.3 and Fig.7.4 a and 7.4 b).

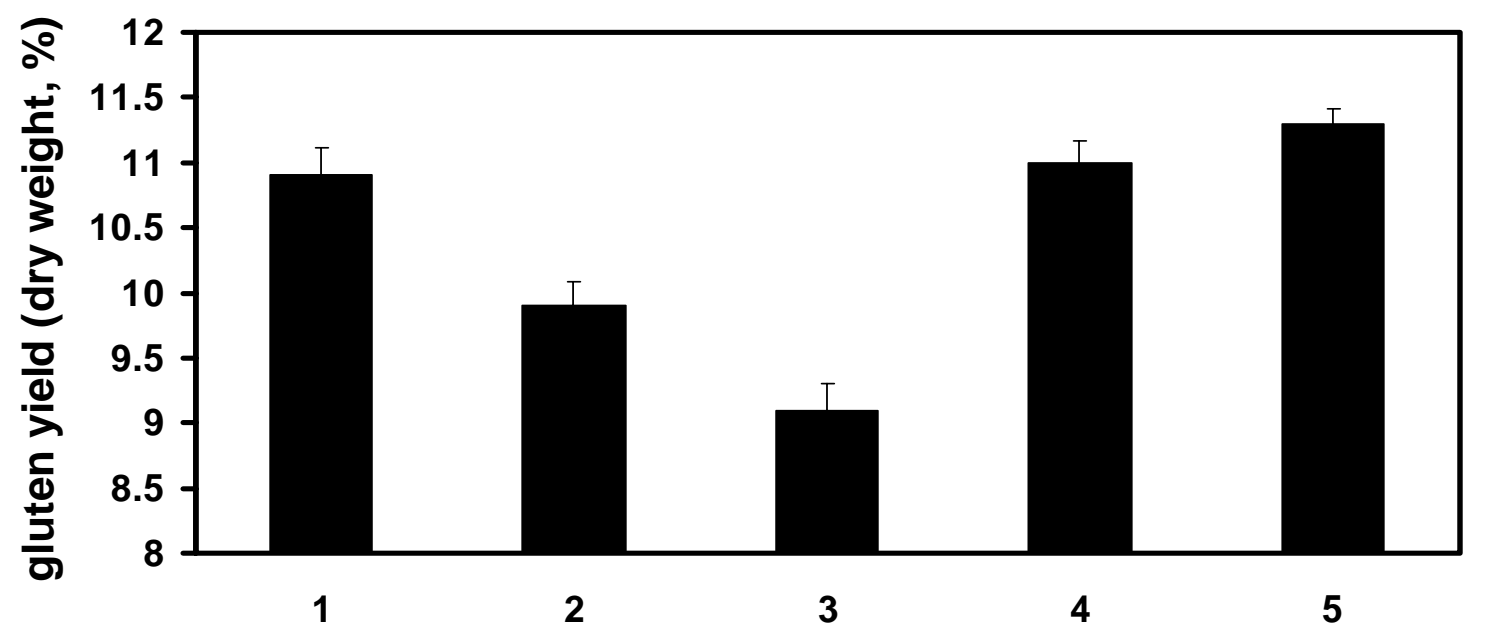

Figure 7.3. Effect of WEP and FA added before mixing or during diluting to Soissons flour on gluten yield

$1=$ control, $2=0.3 \% \mathrm{WEP}$ (before mixing), $3=0.3 \% \mathrm{WEP}$ ( during dilution phase), $4=0.3 \% \mathrm{WEP}+50 \mathrm{ppmFA}$ (before mixing),$\quad 5=0.3 \% \mathrm{WEP}+50 \mathrm{ppmFA}$ (during dilution phase), $\mathrm{n}=3$.

The results showed that WEP affected gluten yield far more negatively when added to Soissons flour during the dilution phase than when added before mixing (Fig. 7.3, 3 vs 2). This is consistent with our findings mentioned above that during the dilution phase gluten protein starts to re-agglomerate and with our hypothesis that WEP affect gluten re-agglomeration. Also, FA more efficiently corrected the negative effect of WEP when added during the dilution phase than when added before mixing (Fig. 7.3, 5 vs 4 ). This result is in agreement with the finding by Oudgenoeg et $\mathrm{al}^{38}$ who reports on tyrosine-FA cross-linking that addition of FA in small portions is more effective than adding a high concentration at one time. The same also plays a role here since the relatively slow 
addition of FA during the dilution phase prevents the negative effect of WEP on gluten yield more efficiently than when added in one portion (higher concentration) before mixing.

Addition of xylanase to Scipion flour (weak flour) during the dilution phase proved also to be more efficient in improving gluten yield than adding before mixing (Fig.7.4a). From the dose-response data in Fig.7.4a it is also clear that addition of xylanase after mixing does not give the typical overdose effect when adding xylanase before mixing (black column vs white column). This effect is related to the release of water (as a result of pentosan degradation) making mixing less efficient. The effects of xylanase added to Amazon flour (strong flour) during the dilution phase on gluten yield were also stronger than addition before mixing, but less than for Scipion flour (Fig.7.4b). This may be due to the fact that Amazon flour contains less WEP. No overdose effect was observed here.
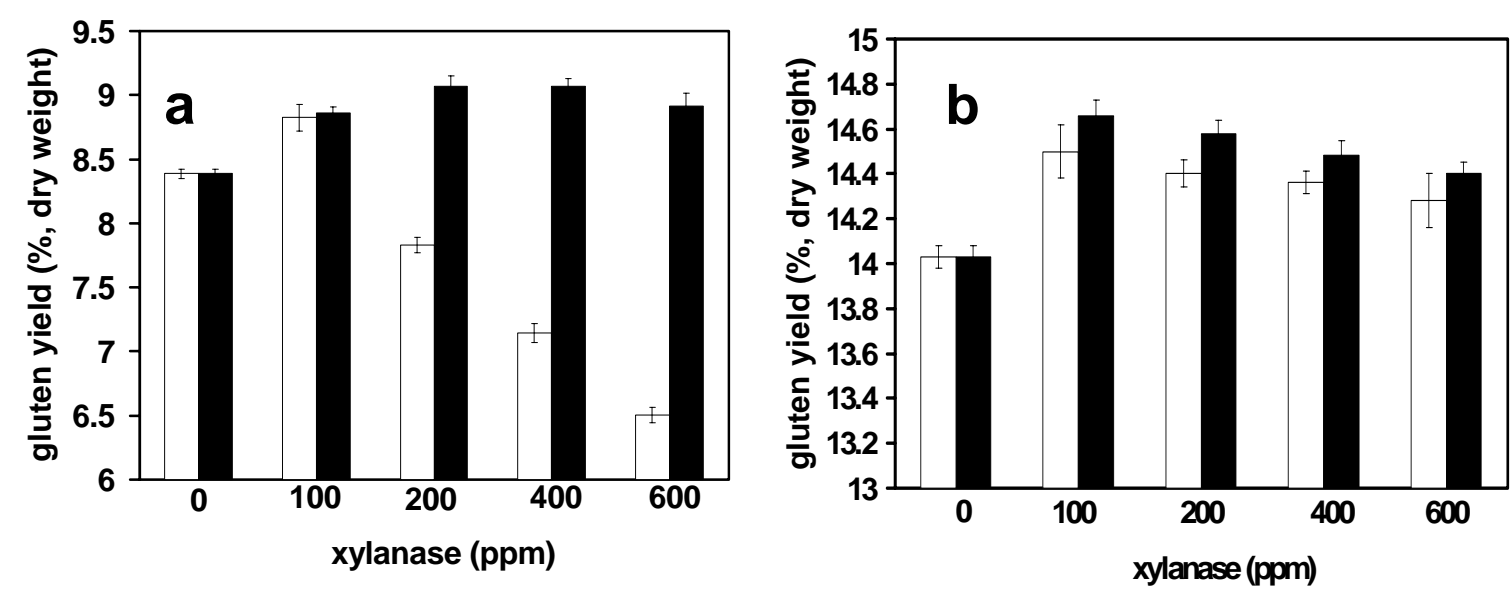

Figure 7.4. Effect of xylanase added before mixing or during diluting to Scipion and Amazon flour on gluten yield

Fig. 7. 4a Scipion control (3 min of mix and $6 \mathrm{~mL}$ water)

Fig. 7. 4b Amazon control (6 min of mix and $7.5 \mathrm{~mL}$ water)

White column=before mixing, Black column=during the dilution phase.

\subsubsection{Effect of WEP, WEP ${ }_{O H}, F A$ and dextran addition during the dilution phase}

In order to distinguish between the effect of the viscosity and the FA related effect of pentosans, gluten yield was determined after addition of WEP, WEP $\mathrm{OH}_{\mathrm{H}}, \mathrm{WEP}+\mathrm{FA}$ and dextran, respectively. In all cases, concentrations were chosen to obtain a dilution solution of the same viscosity as the diluent containing WEP (Fig.7.5).

Addition of WEP during the dilution phase led to a lower gluten yield (Fig.7.5, curve 
A). Gluten yield decreased with the increasing amount of WEP added. We assume that the AX bound FA moieties can act in two ways ${ }^{14}$. Firstly, by cross-linking WEP, which leads to a higher viscosity in the liquid phase. The second way, by which AX bound FA can act, is by directly linking to gluten proteins ${ }^{29-30,38}$.

Dextran was also added (Fig.7.5, curve D) in an attempt to mimick only WEP's viscosity. Dextran also negatively affected gluten yield, but far less than WEP. The negative effect of dextrans added at higher amounts on gluten yield must be mainly due to its effect on viscosity, since dextran does not contain FA.

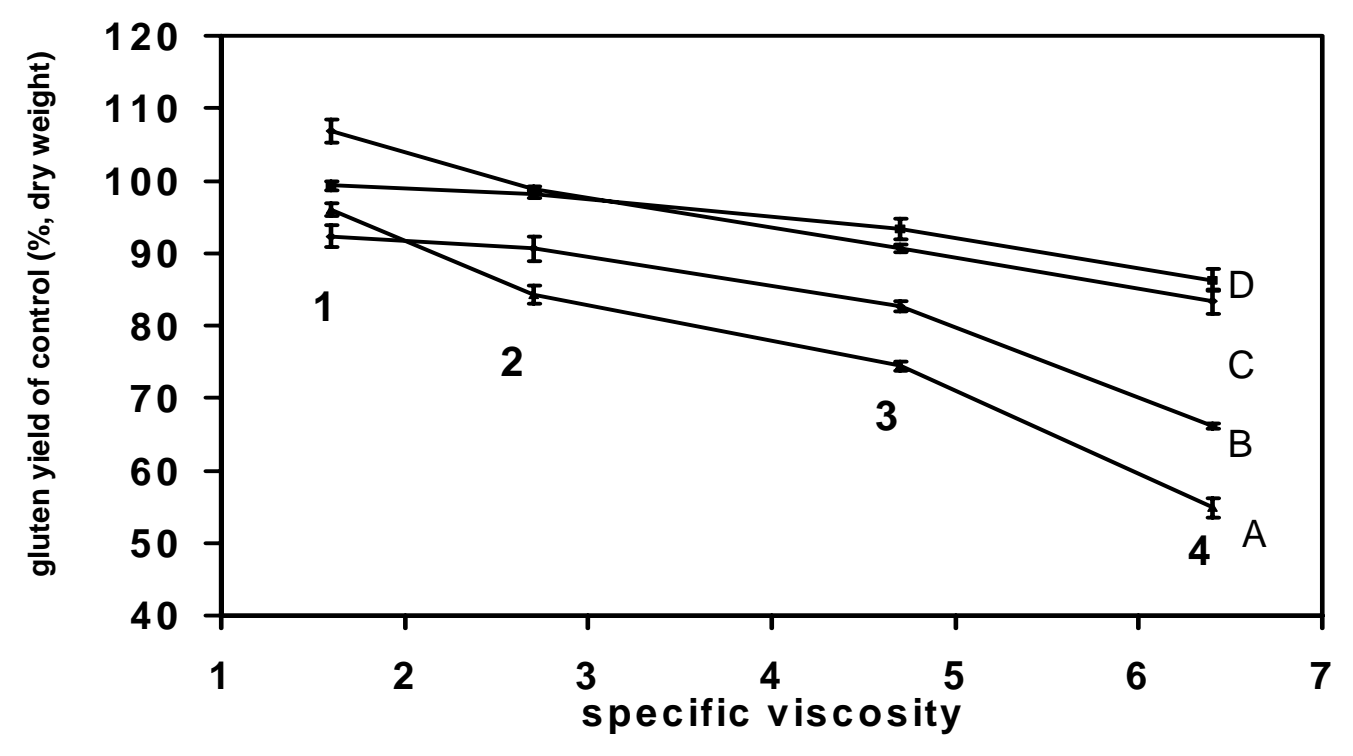

Figure7.5. Effect of $\mathrm{WEP}, \mathrm{WEP}_{\mathrm{OH}}, \mathrm{FA}$ and dextran added during diluting to Scipion flour on gluten yield

Gluten yield as a function of the specific viscosity of the dilution solutions $\mathrm{A}=\mathrm{WEP}, \mathrm{B}=\mathrm{WEP}_{\mathrm{OH}}, \mathrm{C}=\mathrm{WEP}+\mathrm{FA}, \mathrm{D}=$ dextran.

Concentration 2: $0.3 \% \mathrm{WEP}, 0.3 \% \mathrm{WEP}_{\mathrm{OH}}, 0.3 \% \mathrm{WEP}+50 \mathrm{ppm}$ FA, $1.7 \%$ dextran.

In order to diminish the role of $\mathrm{FA}$, both $\mathrm{WEP}_{\mathrm{OH}}$ (less FA containing compared to WEP) and FA together with WEP were added. $\mathrm{WEP}_{\mathrm{OH}}$ (Fig.7.5, curve B) also negatively affected gluten yield, although a larger addition of $\mathrm{WEP}_{\mathrm{OH}}$ was less harmful to gluten yield than addition of WEP. This may be due to a lower FA content of $\mathrm{WEP}_{\mathrm{OH}}$. Similar to what is seen in Fig.7.3, addition of WEP together with FA corrects the negative effect of WEP on gluten yield (Fig.7.5, curve C), but only to the level of what we assume is the viscosity effect. Addition of a low amount of WEP together with FA resulted in a higher gluten yield than the control. Those results demonstrate that the direct effect (FA) is the stronger one compared to indirect effect (viscosity). 


\subsubsection{Effect on gluten composition and quality}

The changes in gluten composition and quality on addition of pentosans and xylanase during the dilution phase were studied further by investigating gluten samples prepared from Soissons flour in the presence of WEP, $\mathrm{WEP}_{\mathrm{x}}$, xylanase, WEP+FA and dextran, respectively for addition before mixing and during the dilution phase (Table 7.1).

The results on gluten chemical composition and quality showed that adding WEP, $\mathrm{WEP}_{\mathrm{x}}$, xylanase, WEP+FA during dilution phase changed gluten composition and quality in the same way but to larger extent than adding them before mixing.

Interestingly, addition of dextran led to a lower gluten yield and protein yield, but a significant higher "starch" yield in gluten than the control. Since the test kit used did not distinguish between starch and dextran we assume this is dextran. The resulting gluten sample was characterised to have a higher $\mathrm{R}_{\max }$ and a comparable $\mathrm{E}$ at $\mathrm{R}_{\max }$ compared with the control. Both viscosity and depletion attraction effects of dextran may explain a lower gluten yield and a higher $\mathrm{R}_{\max }$ caused by dextran. Since dextran does not contain FA, no FA mediated effect exists here. This may explain a comparable $\mathrm{E}$ at $\mathrm{R}_{\max }$ to the control.

\subsubsection{Effect on GMP composition and properties}

An effect of WEP, WEP , xylanase, WEP+FA and dextran added during the dilution phase on gluten protein network structure could not be ruled out. Therefore, the composition and rheological properties of GMP were determined. Results are shown in Table 7.2 and Table 7.3.

The results on GMP composition and properties showed that adding WEP, $\mathrm{WEP}_{\mathrm{x}}$, xylanase, WEP+FA during the dilution phase also changed GMP composition and properties in the same way but to larger extent than adding them before mixing. Interestingly, adding dextran during the dilution phase gave a lower EC, a stiffer and more elastic gel, a larger specific volume of GMP particles and a smaller tendency to aggregate than the control. This observation supports our explanation (chapter 5) that both viscosity and depletion effect play a role when very high molecular weight polysaccharides are added.

\subsubsection{Effect on dough extensibility}

Soissons dough properties were also assessed by Kieffer extensibility rig (Table 7.4).

The results showed that the effects of pentosans and xylanase on dough properties (Table 7.4) paralleled the effects on gluten properties (Table 7.1). 


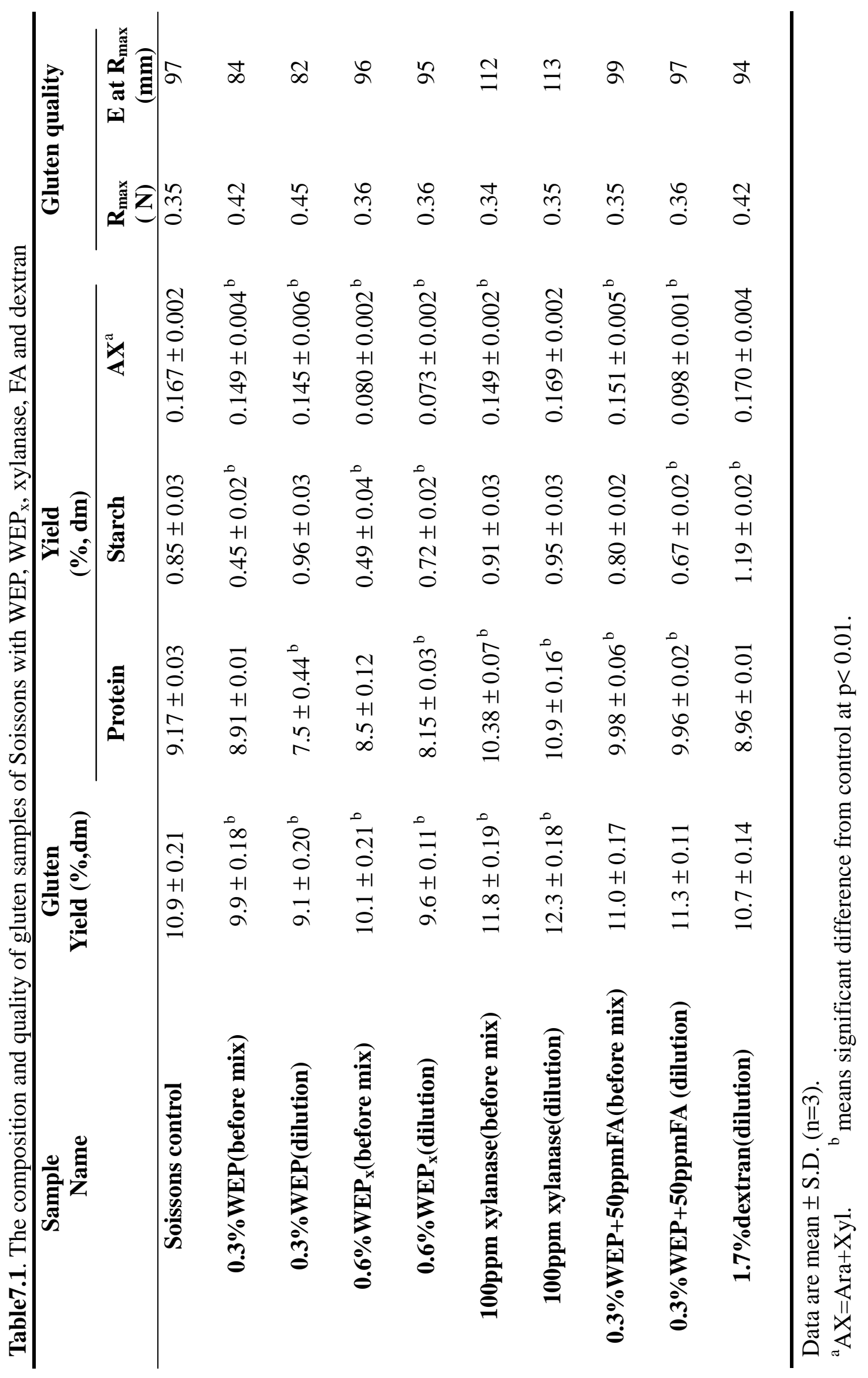




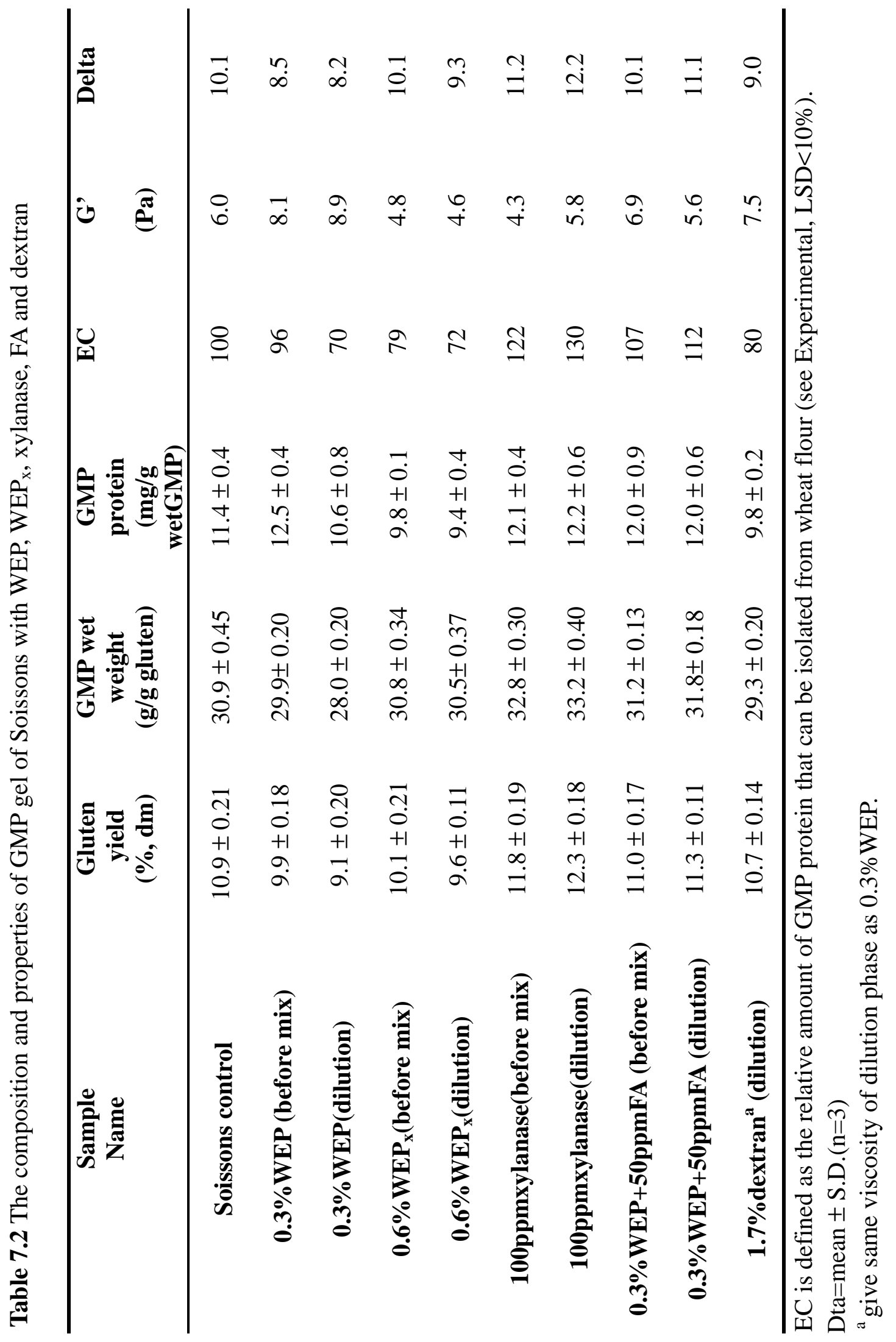


Table 7.3 The particle size of GMP dispersion of Soissons with WEP, $\mathrm{WEP}_{\mathrm{x}}$, xylanase, FA and dextran

\begin{tabular}{|c|c|c|c|}
\hline Sample name & $\begin{array}{c}[\eta]] \\
(\mathrm{dL} / \mathrm{g})\end{array}$ & $\mathbf{K}^{\prime}$ & $\begin{array}{l}\mathbf{D}_{3,2} \\
(\mu \mathbf{m})\end{array}$ \\
\hline Soissons control & 3.20 & 1.00 & 19 \\
\hline 0.3\%WEP (before mix) & 3.28 & 0.86 & 20 \\
\hline 0.3\%WEP (dilution) & 3.44 & 0.34 & 23 \\
\hline $0.6 \% \mathrm{WEP}_{\mathrm{x}}$ (before mix) & 3.21 & 0.88 & 17 \\
\hline $\operatorname{0.6\% } \mathrm{WEP}_{\mathrm{x}}$ (dilution) & 3.19 & 0.92 & 16 \\
\hline 100ppmxylanase (before mix) & 3.16 & 1.13 & 15 \\
\hline 100ppmxylanase (dilution) & 3.15 & 1.20 & 15 \\
\hline 0.3\% WEP+50ppmFA (before mix) & 3.26 & 1.00 & 19 \\
\hline 0.3\% WEP+50ppmFA (dilution) & 3.21 & 0.96 & 16 \\
\hline $1.7 \%$ dextran (dilution) & 3.30 & 0.72 & 22 \\
\hline
\end{tabular}

Addition of WEP led to a higher $\mathrm{R}_{\max }$ and a smaller $\mathrm{E}$ at $\mathrm{R}_{\max }$ of dough than the control. Since we did not correct for water addition, this probably led to a difference in $\mathrm{R}_{\max }$ with WEP compared with the control. From our earlier study we know that the difference in $\mathrm{E}$ at $\mathrm{R}_{\max }$ with WEP cannot be corrected when we corrected for water binding. Adding $\mathrm{WEP}_{\mathrm{x}}$ resulted in a comparable properties to the control. Addition of xylanase gave a comparable $\mathrm{R}_{\max }$ and a larger $\mathrm{E}$ at $\mathrm{R}_{\max }$ compared with the control. Addition of FA together with WEP led to a dough a comparable $\mathrm{R}_{\max }$ but a larger $\mathrm{E}$ at $\mathrm{R}_{\max }$ than addition of only WEP. Addition of dextran resulted in a somewhat higher $\mathrm{R}_{\max }$ and a comparable $\mathrm{E}$ at $\mathrm{R}_{\max }$ to the control.

\subsubsection{Effect on dough strain hardening}

Strain hardening tends to be an important factor related to the quality of the dough to retain gas. Therefore, biaxial extension tests on Soissons flour dough samples were carried out (Table 7.4 and Fig.7.6).

It was observed that the stress required to deform the dough and gluten increased with increasing strain at comparable strain rates. This effect is known as strain hardening ${ }^{40}$. 
Strain hardening is defined as the phenomenon where the stress increases more than proportionally to the strain (at constant strain rate and increasing strain) ${ }^{40}$. Stress and strain hardening are important factors for bread crumb structure. Stress is most important at the beginning of proofing, while strain hardening is more important at the end. Higher initial stress probably lowers disproportion but also decreases loaf volume. The higher the strain hardening, the better the stability against rupture of dough films between gas cells ${ }^{45}$.

Table 7.4 Results of Kieffer and biaxial extension test for Soissons flour dough

\begin{tabular}{|c|c|c|c|c|c|}
\hline $\begin{array}{c}\text { Sample } \\
\text { name }\end{array}$ & $\begin{array}{r}\mathbf{R}_{\max } \\
(\mathrm{N})\end{array}$ & $\begin{array}{c}\mathbf{E} \text { at } \\
\mathbf{R}_{\max } \\
(\mathbf{m m})\end{array}$ & $\begin{array}{c}\text { Stress }^{\mathbf{a}} \\
(\mathbf{P a})\end{array}$ & $y$ & $z$ \\
\hline $\begin{array}{l}\text { Soissons } \\
\text { control }\end{array}$ & $0.15 \pm 0.01$ & $31 \pm 1$ & $8.5 \pm 0.18$ & $1.81 \pm 0.06$ & $0.31 \pm 0.01$ \\
\hline 0.3\%WEP & $0.22 \pm 0.02^{b}$ & $25 \pm 1^{b}$ & $8.61 \pm 0.02$ & $2.05 \pm 0.08$ & $0.34 \pm 0.01$ \\
\hline $0.6 \%$ WEP $_{x}$ & $0.17 \pm 0.01$ & $29 \pm 1$ & $8.46 \pm 0.00$ & $2.03 \pm 0.05$ & $0.31 \pm 0.00$ \\
\hline $\begin{array}{c}\text { 100ppm } \\
\text { xylanase }\end{array}$ & $0.15 \pm 0.01$ & $36 \pm 2^{b}$ & $8.25 \pm 0.06$ & $2.1 \pm 0.18$ & $0.31 \pm 0.01$ \\
\hline $\begin{array}{c}0.3 \% \text { WEP+ } \\
50 p p m F A\end{array}$ & $0.20 \pm 0.01$ & $31 \pm 1$ & $8.57 \pm 0.06$ & $2.0 \pm 0.15$ & $0.32 \pm 0.01$ \\
\hline $1.7 \%$ dextran & $0.20 \pm 0.01$ & $29 \pm 1$ & $8.31 \pm 0.01$ & $2.4 \pm 0.20^{b}$ & $0.32 \pm 0.01$ \\
\hline
\end{tabular}

The addition dosages are based on flour weight base.

${ }^{a}$ stress at $\varepsilon_{\mathrm{B}}=0.1$.

${ }^{\mathrm{b}}$ means significant difference from control at $\mathrm{p}<0.05$.

Addition of WEP, $\mathrm{WEP}_{\mathrm{x}}$ and FA together with WEP led to a somewhat higher initial stress than the control. In contrast, addition of xylanase and dextran resulted in a somewhat lower initial stress than the control. All additions increased stress at larger strain. As a result, strain hardening is stronger to a varying extent. However, no significant differences in strain hardening strain rate thinning were observed except that addition of dextran led to a significant increase in strain hardening compared to the control. Both higher viscosity and depletion attraction of dextran may contribute to the higher strain hardening of dough prepared in the presence of dextran. Van Vliet et al ${ }^{45}$ showed that when $y+2 z>2$ dough 
films between gas cells are stable against rupture during the baking stage for conditions as during the Dutch bread making process. Within limits, the higher these values the stronger the so-called 'repairing' mechanism in dough films against local thinning and the lesser coalescence of gas cells will occur. Table 7.4 showed that at room temperature all values are clearly above 2 , indicating a good stability against rupture as we expected since Soissons flour is supposed to be a good baking flour.

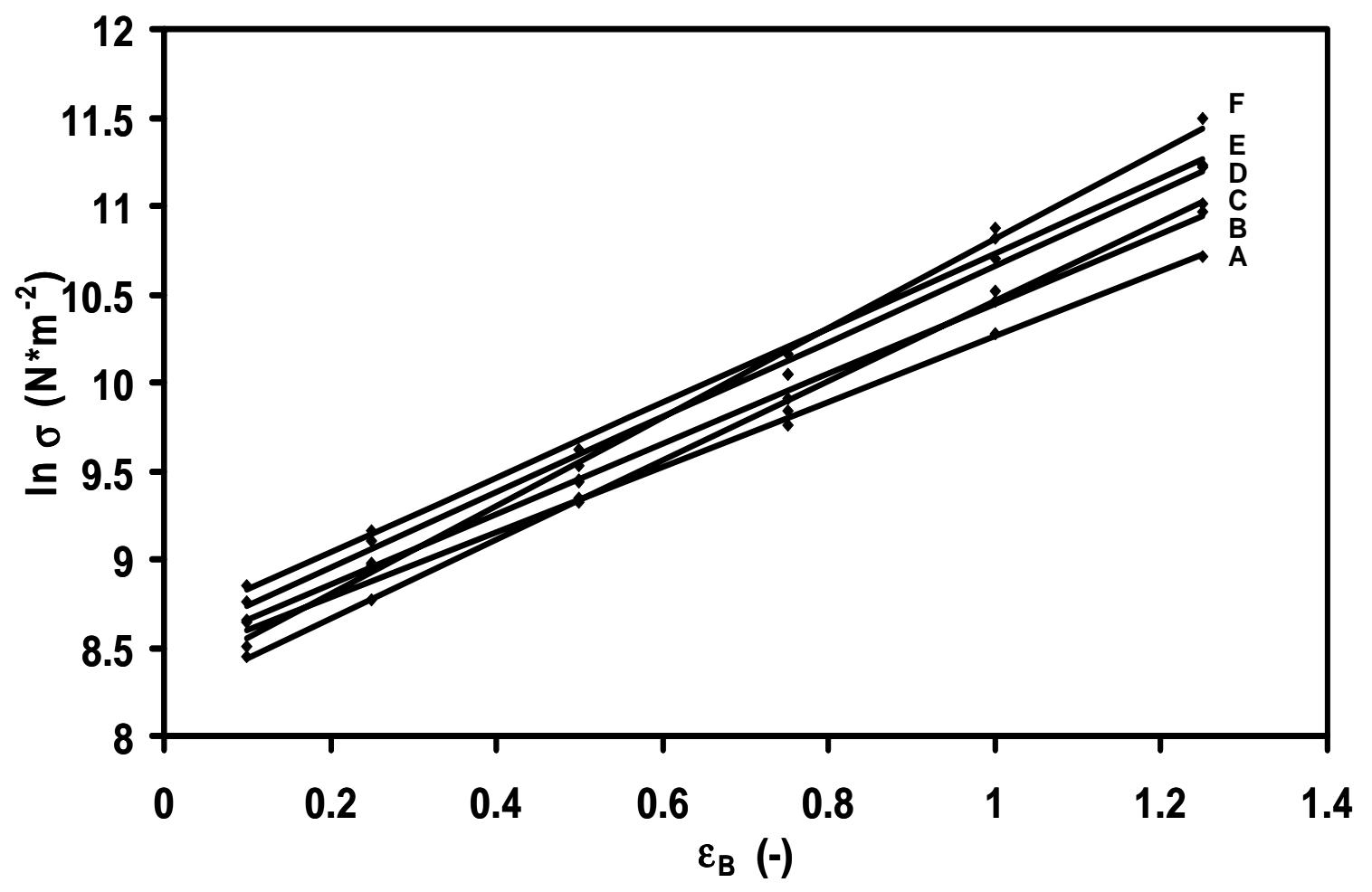

Figure 7.6 Biaxial stress as a function of the strain for Soissons dough for various additions $\left(\dot{\varepsilon}_{\mathrm{B}}=0.01 \mathrm{~s}^{-1}\right)$

The slope represents the strain hardening.

$\mathrm{A}=$ control, $\mathrm{B}=\mathrm{WEP}_{\mathrm{x}}, \mathrm{C}=\mathrm{xylanase}, \mathrm{D}=\mathrm{WEP}+\mathrm{FA}, \mathrm{E}=\mathrm{WEP}, \mathrm{F}=$ dextran.

\subsection{Conclusions}

In this chapter we have observed that gluten re-agglomeration mainly happens during the dilution and the wash phase of the TNO Glutomatic, when gluten and starch are separated. We have demonstrated that pentosans only need to be present during this phase to hinder gluten agglomeration. This is only partly related to a viscosity effect. The FA related interaction is more important here. The resulting gluten contains GMP particles of a higher average voluminosity than the control. Apparently, pentosans especially affect the agglomeration of GMP particles to gluten. When pentosan interference is prevented by 
xylanase or FA, aggregation during the dilution phase is more extensive. The resulting gluten is characterised by a lower average GMP particle size. These differences can be linked to differences in gluten rheological properties. We conclude that pentosans and xylanase mainly act during the agglomeration of gluten following the breakdown of gluten structures during mixing. Both act on the ability of GMP particles to form gluten, affecting both gluten yield and gluten rheological properties. Similar effects were observed on dough extensibility, effects on strain hardening were not yet significant. Our experiments with dough suggest that the mechanism proposed for the action of pentosans also applies to dough.

\section{Acknowledgements}

The financial support of this research work by CSM Bakery Supplies Division Europe, Amylum Europe N.V. and Cargill B.V is gratefully acknowledged. We are also grateful to Katja Grolle for excellent technical assistance in strain hardening measurements.

\section{References}

1. Hoseney, R.C., Finney, K.F., Pomeranz, Y. and Shogren, M.D. Functional and biochemical properties of wheat flour components. II. Role of water-solubles. Cereal Chemistry 46 (1969) 117-125.

2. Kim, S.L. and D’Appolonia, B.L. Bread staling studies.III. Effect of pentosans on dough, bread and bread staling rate. Cereal Chemistry 54 (1977) 225-229.

3. D'Appolonia, B. L., Gilles, K.A. and Medcalf, D.G. Effect of water-soluble pentosans on gluten-starch loaves. Cereal Chemistry 47 (1970) 194-204.

4. Jelaca, S.L. and Hlynka, I. Effect of wheat-flour pentosans in dough, gluten and bread. Cereal Chemistry 49 (1972) 489-495.

5. Hanh, P.P. and Rasper, V. The effect of nonstarchy polysaccharides from yam, sorghum, and millet flours on the rheological behavior of wheat doughs. Cereal Chemistry $\mathbf{5 1}$ (1974) 734-750.

6. Biliaderis, C.G., Izydorczyk, M.S. and Rattan,O. Effect of arabinoxylans on bread-making quality of wheat flours. Food Chemistry 5 (1995) 165-171.

7. Courtin, C.M. and Delcour, J.A. Physicochemical and breadmaking characteristics of low molecular weight wheat derived arabinoxylans. Journal of Agricultural and Food Chemistry 46 (1998) 4066-4073.

8. Denli, E.and Ercan, R. Effect of added pentosans isolated from wheat and rye grain on 
some properties of bread. Europe Food Research Technology 212 (2001) 374-376.

9. Ciacco, C.F. and D' Appolonia, B.L. Characterization of pentosans from different flour classes and of their gelling capacity. Cereal Chemistry 59 (1982) 96-100.

10. Ciacco, C.F. and D'Appolonia, B.L. Characterization and gelling capacity of water-soluble pentosans isolated from different mill streams. Cereal Chemistry 59 (1982)163-166.

11. Izydorczyk, M.S., Biliaderis, C.G. and Bushuk, W. Comparison of the structure and composition of water-soluble pentosans from different wheat varieties.Cereal Chemistry 68 (1991) 139-144.

12. Izydorczyk, M.S., Biliaderis, C.G. and Bushuk, W. Physical properties of watersoluble pentosans from different wheat varieties. Cereal Chemistry 68 (1991) 145-150.

13. Michniewicz, J., Biliaderis, C.G. and Bushuk, W. Effect of added pentosans on some physical and technological characteristics of dough and gluten. Cereal Chemistry $\mathbf{6 8}$ (1991) 252-258.

14. Wang, M-W, Hamer, R.J., van Vliet, T. and Oudgenoeg, G. Interaction of water extractable pentosans with gluten protein: Effect on dough properties and gluten quality. Journal of Cereal Science 36 (2002) 25-37.

15. Wang, M-W, van Vliet, T. and Hamer, R.J. How gluten properties are affected by pentosans. Journal of Cereal Science submitted.

16. Maat, J., Roza, M,Verbakel, J., Santos da Silva, J.M., Bosse, M., Egmond, M.R., Hagemans, M.L.D.,v. Gorcom, R.F.M., van, Hessing, J.G.M., Hondel, C.A.M.J.J. van de and Rotterdam, C. van. Xylanase and their application in bakery. in 'Xylans and Xylanases', Progress in Biotechnology Series Vol.7, (J.Visser, G. Beldman, M.A.Kusters-van Someren, and A.G.J. Voragen, eds.), Elsevier, Amsterdam (1992) pp349-360.

17. Rouau, X., EI Hayek, M. L., and Moreau, D. Effect of an enzyme preparation containing pentosanases on the bread-making quality of flours in relation to changes in pentosan properties. Journal of Cereal Science 19 (1994) 259-272.

18. Hilhorst, R, Dunnewind, B., Orsel, R., Stegeman, P., van Vliet, T., Gruppen, H.and Schols, H.A. Baking performance, rheology, and chemical composition of wheat dough and gluten affected by xylanase and oxidative enzymes. Journal of Food Science 64 (1999) 808-813.

19. Courtin, C.M., Gelders, G.G.and Delcour, J.A. The use of two endoxylanases with different substrate selectivity provides insight into the functionality of arabinoxylans in wheat flour bread-making. Cereal Chemistry 78 (2001) 564-571. 
20. Sprossler, B.G. Xylanase in baking. In 'The first Europen symposium on enzymes and grain processing' (S.A.G.F. Angelino et al., eds.), TNO Nutrition and Food Research Institute, Zeist, The Netherlands (1997) pp177-187.

21. Courtin, C.M., Roelants, A. and Delcour, J.A. Fractionation-Reconstitution experiments provide insight into the role of endoxylanases in bread-making. Journal of Agricultural and Food Chemistry 47 (1999) 1870-1877.

22. Weegels, P.L., Marseille, J.P. and Hamer, R.J. Enzymes as a processing aid in the separation of wheat flour into starch and gluten. Starch/ Staerke 44 (1992) 44-48.

23. .Christophersen, C., Andersen, E., Jakobsen, T.S. and Wagner, P. Xylanases in wheat separation. Starch/ Staerke 49 (1997) 5-12.

24. Wang, M-W, Hamer, R.J., van Vliet, T., Gruppen, H., Marseille, J.P. and Weegles, P.L. Effect of water unextractable solids on gluten formation and properties: Mechanistic considerations. Journal of Cereal Science 37 (2003) 55-64.

25. Wang, M-W, Oudgenoeg, G, van Vliet T. and Hamer, R.J. Interaction of water unextractable solids with gluten protein: Effect on dough properties and gluten quality. Journal of Cereal Science in press.

26. Wang, M-W, van Vliet, T. and Hamer, R.J. Interaction of water unextractable solids and xylanase with gluten protein: Effect of wheat cultivars. Journal of Cereal Science submitted.

27. Labat, E., Morel, M.H. and Rouau, X. Effect of laccase and manganese peroxidase on wheat gluten and pentosans during mixing. Food Hydrocolloids 15 (2001) 47-52.

28. Geissmann, T. and Neukom, H. On the composition of the water-soluble wheat flour pentosans and their oxidative gelation. Lebensmittel Wissenschaft und Technologie 6 (1973) 59-62.

29. Neukom, H. and Markwalder, H.U. Oxidative gelation of wheat flour pentosans: A new way of cross-linking polymers. Cereal Foods World 23 (1978) 374-376.

30. Hoseney, R.C. and Faubion, J.M. A mechanism for the oxidative gelation of wheat flour water-soluble pentosans. Cereal Chemistry 58 (1981) 421-424.

31. Izydorczyk, M.S., Biliaderis, C.G. and Bushuk, W. Oxidative gelation studies of water-soluble pentosans from wheat. Journal of Cereal Science 11 (1990) 153-169.

32. Moore, A.M., Martinez-Munoz, I. and Hoseney, R.C. Factors affecting the oxidative gelation of wheat water-solubles. Cereal Chemistry 67 (1990) 81-84.

33. Vinkx, C.J.A., VanNieuwenhove, C. G. and Delcour, J.A. Physicochemical and functional properties of rye non-starch polysaccharides III Oxidative gelation of a fraction containing water-soluble pentosans and protein. Cereal Chemistry 68 (1991) 
617-622.

34. Girhammar, U. and Nair, B.M. Isolation, separation and characterization of water soluble non-starch polysacchrides from wheat and rye. Food Hydrocolloids 6 (1992).

35. Figueroa-Espinoza, M.C. and Rouau, X. Oxidative cross-linking of pentosans by a fungal laccase and horseradish peroxidase: Mechanism of linkage between feruloylated arainoxylans. Cereal Chemistry 75 (1998) 259-265.

36. Schooneveld-Bergmans, M.E.F., Dignum, M.J.W., Grabber, J.H., Beldman, G. and Voragen, A.G. J. Studied on the oxidative cross-linking of feruloylated arabinoxylans from wheat flour and wheat bran. Carbohydrate Polymers 38 (1999) 309-317.

37. Labat, E., Morel, M.H. and Rouau, X. Effect of laccase and ferulic acid on wheat flour dough. Cereal Chemistry 77 (2000) 823-828.

38. Oudgenoeg, G., Hilhorst, R., Piersma, S.R., Boeriu, C.G., Gruppen, H., Hessing, M., Voragen, A.G. J. and Laane, C. Peroxidase-mediated cross-linking of a tyrosine-containing peptide with ferulic acid. Journal of Agricultural and Food Chemistry 49 (2001) 2503-2510.

39. Labat, E., Rouau, X. and Morel, M.H. Effect of flour water-extractable pentosans on molecular association in gluten during mixing. Lebensmittel-Wissenschaft und Technologie 35 (2002) 185-189.

40. van Vliet, T., Janssen, A.M., Bloksma, A.H. and Walstra, P. Strain hardening of dough as a requirement for gas retention. Journal of Texture Studies 23 (1992) 439-460.

41. Janssen, A.M. Obelick andKatepwa wheat gluten. A study of factors determining bread making performance. Ph.D Thesis, State University Groningen, Groningen, The Netherland (1992).

42. Kokelaar, J.J. van Vliet, T. and Prins, A. Strain hardening properties and extensibility of flour and gluten doughs in relation to breadmaking performance. Journal of Cereal Science 24 (1996)199-214.

43. van Vliet, T. Physical factors determining gas cell stability in a dough during breadmaking. In 'Bubbles in Food' (G.M.Campbell, C.Webb, S.S. Pandiella and K. Niranjan, eds), Eagan Press, St. Paul, USA (1998) pp121-127.

44. Weegels, P.L., Hamer, R.J. and Schofield, J.D. Depolymerisation and re-polymerisation of wheat glutenin during dough processing. I. Relationships between glutenin macropolymer content and quality parameters. Journal of Cereal Science 23 (1996) 103-111.

45. Don, J.A.C., Lichtendonk, W.J., Plijter, J.J. and Hamer, R.J. Understanding the link between GMP and dough I: from glutenin particles in flour towards developed dough. 
Chapter 7

Journal of Cereal Science in press. 


\section{8}

General discussion 
Pentosans have been studied for about 50 years since they were discovered as a component in the grains of wheat and other cereals. In that time cereal scientists have markedly increased their knowledge of the structure, properties and functionality of pentosans. However, also contradictory results regarding the functionality of pentosans have been published, strongly varying from non-existent ${ }^{1-2}$ or minor ${ }^{3}$ to positive ${ }^{4-8}$ effects of pentosans on bread-making. The different results may depend on their gross content in flour, their water extractability and fine structure ${ }^{9-12}$. The effects of pentosans on gluten yield and properties were rarely studied. Several theories exist to explain the effects of pentosans and pentosan modifying enzymes ${ }^{13-14}$, but some of them are disputed ${ }^{15-16}$. Nowadays, wheat pentosans are becoming more and more important in view of the increased use of 'dark' (high pentosans containing) flour for the production of wheat bakery and gluten products. Therefore, to understand how pentosans affect gluten formation and properties is very important.

The aim of this thesis is to clarify the mechanism of action of pentosans on gluten formation and properties. Here, we will present a general discussion on the effects of pentosans on gluten formation and properties based on both literature data and the experimental results presented in the previous chapters.

Non-starch polysaccharides (NSP) originate from the cell wall of the aleurone and endosperm of the wheat kernel and represent different polysaccharides, which are built up of pentose sugars [named pentosans, mainly arabinoxylanase (AX)] and hexose sugars. Pentosans are usually divided into water extractable pentosan (WEP, mainly water extractable AX) and water unextractable solids (WUS, mainly water unextractable AX), which comprise $25 \%$ and $75 \%$ of all pentosans present in wheat flour respectively ${ }^{17}$.

WEP exhibit some rather unique physical properties. The ability to immobilise water ${ }^{18-20}$ and to form viscous solutions or gels by covalent cross-linking ${ }^{21-23}$ are important attributes that have direct functional implications for gluten separation. The water holding capacity (WHC) of pentosans probably affects the distribution of moisture among dough constituents and thereby affects the rheological properties of dough. WUS are reported to have higher WHC than WEP and also to be amenable to further cross-linking via FA residues in the polymeric matrix ${ }^{24}$. WEP are generally believed to have a positive effect on breadmaking quality ${ }^{14}$, while WUS are considered to have a negative effect ${ }^{25-26}$. However, our results show that both WUS (chapter 2) and WEP (chapter 3) affect gluten and glutenin macropolymer (GMP) yield, composition and properties in a similar fashion. Pretreatment of WEP (chapter 3) and WUS (chapter 4) with xylanase does not remove the negative effect on gluten yield, but addition of xylanase (chapter 2) or ferulic acid (FA) 
(chapter 3 and 4) during gluten extraction does. Added pentosans hinder gluten agglomeration when present during the dilution phase (chapter 7). This is only partly related to a viscosity effect. FA related interaction is more important here. We conclude that pentosans and xylanase mainly act during the re-agglomeration of gluten following the breakdown of gluten structures during mixing. Both act on the ability of GMP particles to form gluten, affecting both gluten yield and gluten rheological properties. Based on these observations, we propose that pentosans interfere with gluten formation in both an indirect and a direct way (chapter 3). The indirect effect is related to water availability. The direct effect is related to an interaction between pentosans and gluten in which FA plays an important role. We hypothesize that FA is involved in the interaction of pentosans with gluten. We assume that the AX bound FA moieties can act in two ways (chapter 3 ). Firstly, by cross-linking WEP, which leads to a higher viscosity in the liquid phase. Many authors ${ }^{21-23}$ reported such an effect. We have proven that this also occurs during flour processing in the modified Glutomatic system (chapter 3). However, we regard this effect on gluten formation to be indirect, because it is viscosity mediated and can be corrected for by adding more water before mixing. The second way, by which AX bound FA can act, is by directly linking to gluten proteins. This occurs when WEP fragments with low molecular weight $\left(\mathrm{WEP}_{\mathrm{x}}\right.$, WEP treated by xylanase) are added to flour ${ }^{16,21-22}$. This influence on gluten structure formation cannot be corrected for by adding more water before mixing (chapter 3).

The indirect effect is supported by Maat ${ }^{13}$ et al who reported pentosans can indirectly affect gluten formation by competing for water. Pentosan modfying enzymes can then act by reducing the water binding capacity of pentosans thus inducing water redistribution. Concerning a possible direct effect, conflicting reports have been published. Labat ${ }^{15}$ et al reported that no covalent complex between $\mathrm{AX}$ and protein could be detected in mixed and oxidised gluten/WEP. They declared that the indirect effect of pentosans could be caused by their ability to form a network, limiting the movement of glutenin proteins towards a larger aggregate ${ }^{15}$. Also, they proposed that soluble FA esters are likely to react with proteins during mixing and would be involved in gluten breakdown during overmixing rather than feruloylated $\mathrm{AX}^{27}$. However, Oudgenoeg et al ${ }^{16}$ presented positive evidence for a FA mediated AX- protein cross-linking reaction.

The identification of chemical cross-links between GMP particles and pentosans was outside the scope of this thesis. We therefore cannot provide direct evidence that there is a direct cross-linking between pentosans and glutenin protein. We have however obtained the following evidence that points however into such a direction: 
- Effects of pentosans can be correlated with their content of FA (chapter 3).

- Pentosan fragments, $\mathrm{WEP}_{\mathrm{x}}$, lead to a lower extensibility and lower K'.

- Prevention of cross-linking by addition of free FA specifically corrects for the effect of pentosans on extensibility and $\mathrm{K}$ '.

- The effect of FA and xylanase on the K' of GMP particles can be best explained on the basis of a change in their mutual physical interactions suggesting a modification of the surface of GMP particles.

A further study was carried out to understand why not only gluten yield but also gluten properties were changed by pentosans (chapter 5). The results demonstrated that the interference of WUS or WEP with gluten formation caused an incomplete aggregation of gluten protein, which was reflected in a larger average GMP particle size and a smaller tendency of these particles to aggregate. The resulting gluten contained less smaller GMP particles. When this interference was prevented by xylanase or FA, aggregation was more complete, which was reflected in a smaller average GMP particle size and a larger tendency of these particles to aggregate (higher K'). Now, also smaller GMP particles were recovered.

The same trend was found with three wheat cultivars of very different qualities ranging from weak (Scipion) to strong (Amazon) (chapter 6). We observed however that Amazon was clearly less affected by addition of pentosans or xylanase than the other two cultivars. Amazon significantly differs from Scipion and Soissons in that it has a higher protein content and a lower content of pentosans. Both aspects promote the formation of gluten and perhaps explain the smaller effect of added pentosans and xylanase. The very high $\mathrm{D}_{3,2}$ and $\mathrm{K}$ ' of Amazon however offer a new explanation for the smaller effect. Amazon has the ability to form larger and stickier particles. We propose this could also be a reason why pentosans and xylanase have a small effect on gluten yield and properties with Amazon. This observation could lead to a more general explanation for different effects of pentosans on different wheat cultivars.

Correlations between gluten properties and GMP particle parameters were observed pointing at a possible explanation for the change in gluten properties. Maximum resistance against extension $\left(\mathrm{R}_{\max }\right)$ of gluten is best predicted by the average GMP particle voluminosity and size $\left([\eta], \mathrm{D}_{3,2}\right)$, while extensibility at maximum resistance against extension ( $\mathrm{E}$ at $\mathrm{R}_{\max }$ ) is best predicted by the tendency of the GMP particles to aggregate (K'). Based on our observations, we propose a possible explanation for the effect of pentosans on gluten formation and properties. Both a physical effect and a chemical effect are involved. The physical effect is related to viscosity and likely also depletion attraction 
between protein particles. Viscosity is a general effect limiting aggregation rate and hence gluten yield. Depletion attraction is related to the ratio in size of pentosans on the one hand and GMP particles on the other. The chemical effect is related to FA and 'controls' the tendency of the particles to aggregate ( $\mathrm{K}^{\prime}$ ) and hence also gluten yield. We assume $\mathrm{K}^{\prime}$ reflects the physical interaction e.g Van der Waals attraction and steric repulsion between glutenin particles. In our explanation pentosans do not so much affect the growth of these particles directly after mixing, but hinder the further agglomeration of especially smaller particles to end up in the gluten. The partial agglomeration of GMP particles will result in turn in GMP with a different GMP particle size distribution and properties and gluten with changed rheological properties.

The findings in this thesis are of particular relevance to the gluten/starch industry. This industry is using more and more flour of high extraction rate, containing more pentosans. The mechanisms for the effects of pentosans and xylanase on gluten formation and properties proposed here will be helpful for a better understanding of the effects of pentosans and pentosan modifying enzymes on dough properties. We believe this will be quite relevant to the bakery industry.

\section{References}

1. Hoseney, R.C., Finney, K.F., Pomeranz, Y. and Shogren, M.D. Functional and biochemical properties of wheat flour components. II. Role of water-solubles. Cereal Chemistry 46 (1969) 117-125.

2. Kim, S.L. and D'Appolonia, B.L. Bread staling studies. III. Effect of pentosans on dough, bread and bread staling rate. Cereal Chemistry 54 (1977) 225-229.

3. D'Appolonia, B. L., Gilles, K.A. and Medcalf, D.G. Effect of water-soluble pentosans on gluten-starch loaves. Cereal Chemistry 47 (1970) 194-204.

4. Jelaca, S.L. and Hlynka, I. Effect of wheat-flour pentosans in dough, gluten and bread. Cereal Chemistry 49 (1972) 489-495.

5. Hanh, P.P. and Rasper, V. The effect of nonstarchy polysaccharides from yam, sorghum, and millet flours on the rheological behavior of wheat doughs. Cereal Chemistry $\mathbf{5 1}$ (1974) 734-750.

6. Biliaderis, C.G., Izydorczyk, M.S. and Rattan, O. Effect of arabinoxylans on bread-making quality of wheat flours. Food Chemistry 5 (1995) 165-171.

7. Courtin, C.M. and Delcour, J.A. Physicochemical and breadmaking characteristics of low molecular weight wheat derived arabinoxylans. Journal of Agricultural and Food Chemistry 46 (1998) 4066-4073. 
8. Denli, E.and Ercan, R. Effect of added pentosans isolated from wheat and rye grain on some properties of bread. Europe Food Research Technology 212 (2001) 374-376.

9. Ciacco, C.F. and D' Appolonia, B.L. Characterization of pentosans from different flour classes and of their gelling capacity. Cereal Chemistry 59 (1982) 96-100.

10. Ciacco, C.F. and D'Appolonia, B.L. Characterization and gelling capacity of water-soluble pentosans isolated from different mill streams. Cereal Chemistry 59 (1982)163-166.

11. Izydorczyk, M.S., Biliaderis, C.G. and Bushuk, W. Comparison of the structure and composition of water-soluble pentosans from different wheat varieties. Cereal Chemistry 68 (1991) 139-144.

12. Izydorczyk, M.S., Biliaderis, C.G. and Bushuk, W. Physical properties of watersoluble pentosans from different wheat varieties. Cereal Chemistry 68 (1991) 145-150.

13. Maat, J., Roza, M,Verbakel, J., Santos da Silva, J.M., Bosse, M., Egmond, M.R., Hagemans, M.L.D.,v. Gorcom, R.F.M., van, Hessing, J.G.M., Hondel, C.A.M.J.J. van de and Rotterdam, C. van. Xylanase and their application in bakery. in 'Xylans and Xylanases', Progress in Biotechnology Series Vol.7, (J.Visser, G. Beldman, M.A.Kusters-van Someren, and A.G.J. Voragen, eds.), Elsevier, Amsterdam (1992) pp349-360.

14. Rouau, X., Ei-Hayek, M-L and Moreau, D. Effect of an enzyme preparation containing pentosanases on the bread-making quality of flours in relation to changes in pentosan properties. Journal of Cereal Science 19 (1994) 259-272.

15. Labat, E., Morel, M.H. and Rouau, X. Effect of laccase and manganese peroxidase on wheat gluten and pentosans during mixing. Food Hydrocolloids 15 (2001) 47-52.

16. Oudgenoeg, G., Hilhorst, R., Piersma, S.R., Boeriu, C.G., Gruppen, H., Hessing, M., Voragen, A.G. J. and Laane, C. Peroxidase-mediated cross-linking of a tyrosine-containing peptide with ferulic acid. Journal of Agricultural and Food Chemistry 2001) 2503-2510.

17. Meuser, F. and Suckow, P. In 'Chemistry and physics of baking'. (M.V.Blanshard, P.J. Frazier and T. Galliard, eds.), The Royal Society of Chemistry, London (1986) pp 42-61.

18. Jelaca, S.L. and Hlynka, I. Water-binding capacity of wheat-flour crude pentosans and their relation to mixing characteristics of dough. Cereal Chemistry 48 (1971) 211-222.

19. Patil, S.K., Tsen, C.C. and Lineback, D.R. Water-soluble pentosans of wheat flour. I. Viscosity properties and molecular weights estimated by gel filtration. Cereal Chemistry 52 (1975) 44-56. 
20. Rouau, X and Moreau, D. Modification of some physicochemical properties of Wheat flour pentosans by an enzyme complex recommended for baking. Cereal Chemistry 70 (1993) 626-632.

21. Geissmann, T. and Neukom, H. On the composition of the water-soluble wheat flour pentosans and their oxidative gelation. Lebensmittel Wissenschaft und Technologie 6 (1973) 59-62.

22. Hoseney, R.C. and Faubion, J.M. A mechanism for the oxidative gelation of wheat flour water-soluble pentosans. Cereal Chemistry 58 (1981) 421-424.

23. Izydorczyk, M.S., Biliaderis, C.G. and Bushuk, W. Oxidative gelation studies of water-soluble pentosans from wheat. Journal of Cereal Science 11 (1990) 153-169.

24. Michniewicz, J., Biliaderis, C.G. and Bushuk, W. Water-insoluble pentosans of wheat: Composition and some physical properties. Cereal Chemistry 67 (1990) 434-439.

25. Hanh, P.P. and Rasper, V. The effect of nonstarchy polysaccharides from yam, sorghum, and millet flours on the rheological behavior of wheat doughs. Cereal Chemistry $\mathbf{5 1}$ (1974) 734-750.

26. Hoseney, R.C. Functional properties of pentosans in baked goods. Food Technology 1 (1984) 114-117.

27. Labat, E., Rouau, X. and Morel, M.H. Effect of flour water-extractable pentosans on molecular association in gluten during mixing. Lebensmittel-Wissenschaft und Technologie 35 (2002) 185-189. 
Summary 
When a wheat flour-water dough is gently washed in an excess of water, soluble proteins and starch are removed and a rubbery mass, gluten (Latin for glue) is obtained. Usually, gluten consists of 75-85\% protein (dry weight), depending on the thoroughness of washing, the remainder being 10-15\% carbohydrates (mainly starch) and 5-10\% lipids. The formation of the gluten network plays a pivotal role in determining the end-use quality of wheat in many food products. It stands to reason that wheat flour protein composition strongly affects the properties of gluten network. Changes in the quantity and properties of especially polymeric proteins are reflected in changes in gluten rheological properties. Although the content of pentosans, divided into water unextractable solids (WUS) and water extractable pentosans (WEP), in wheat flour is low $(1-2 \% \mathrm{w} / \mathrm{w})$, these polymers play an important role in the structure formation of gluten. The mechanism of this interaction is however far from clear. Therefore, the aim of this thesis is to clarify the mechanism of action of pentosans on gluten formation and properties.

In chapter 2 a miniaturised set-up for gluten-starch separation was used to systematically study the effect of WUS on the formation and properties of gluten. The results showed that WUS not only have a negative effect on gluten yield, but also affect gluten and glutenin macropolymer (GMP) composition and rheological properties. The negative effect of WUS on gluten yield could be compensated in part by increasing mixing time and mixing water. Adding xylanase can completely counteract the effect of WUS. On the basis of these results we hypothesize that WUS interfere with gluten formation in both a direct and an indirect way. WUS interfere indirectly by competing for water and thus changing conditions for gluten development. This effect can be corrected for in part by the combination of adding more $0.2 \% \mathrm{NaCl}$ solution during dough mixing and a longer mixing time. The particulate nature of WUS requires that the direct effect occurs through an interaction between WUS particles and gluten particles. Both effects of WUS can be counteracted through the use of xylanase.

Chapter 3 studies the effects of modified WEP on gluten yield, dough properties, gluten quality and composition. The results show that WEP interfere with gluten formation in both a direct and an indirect way. WEP interfere indirectly by competing for water and thus changing conditions for gluten development. This results in a lower gluten yield and an increased resistance of gluten against extension. The effect on gluten yield can be corrected completely by adding more $0.2 \% \mathrm{NaCl}$ solution during dough mixing. There is however also a direct effect of WEP on gluten formation. This effect is reflected in a lower extensibility of dough and gluten that cannot be corrected by adding more $0.2 \% \mathrm{NaCl}$ solution during dough mixing. It is demonstrated that the effect on extensibility of dough 
and gluten is related to the ferulic acid (FA) content of WEP. Also, addition of free FA leads to a more extensible dough and gluten together with a higher gluten yield. We propose that WEP bound FA plays a key role in determining this effect of WEP. Our results also provide an indication that the effect of WEP on extensibility of dough and gluten may partly be due to cross-linking between protein and WEP.

In chapter 4 we studied how WUS affect the process of gluten formation. To this end, WUS were modified with $\mathrm{NaOH}$, xylanase, horseradish peroxidase (HRP)/ $\mathrm{H}_{2} \mathrm{O}_{2}$, respectively. Effects of modified WUS on gluten yield, dough properties, and gluten and GMP composition and properties were studied. The results showed that addition of WUS to wheat flour led to a lower gluten yield and gluten starch yield, a higher maximum resistance to extension $\left(R_{\max }\right)$ and a lower extensibility at maximum resistance $\left(E\right.$ at $\left.R_{\max }\right)$ of gluten and a more concentrated and elastic GMP gel. Pretreatment of WUS by $\mathrm{NaOH}$, xylanase, $\mathrm{HRP}$ and $\mathrm{H}_{2} \mathrm{O}_{2}$ cannot correct its negative effect on gluten yield, but addition of xylanase or free FA during gluten separation can remove or prevent the negative effect of WUS on gluten yield. Compared to addition of only WUS, addition of WUS and FA together to wheat flour resulted in a higher gluten yield, a higher $E$ at $R_{\max }$ of gluten, and a less concentrated and elastic GMP gel. Similar to WEP, FA bound WUS plays a key role in the effect of WUS on gluten yield and properties. It appears that there is a common mechanism regarding the effect of WUS and WEP that the oxidative cross-linking during gluten formation could be prevented by FA addition. The difference between both is that WUS have a higher water binding capacity, which is reflected in a higher $R_{\max }$ of dough and gluten in the presence of WUS.

Chapter 5 aims to find an explanation for the differences in gluten properties observed. To achieve this, different pentosan preparations, WEP, WUS, WEP $_{\mathrm{x}}$ (xylanase modified WEP), FA and xylanase were used in a series of gluten starch separation experiments. These additions did not only affect gluten yield, but also gluten properties. In order to understand these changes, the major network forming polymer, GMP gel was extracted and its properties were studied. Addition of WUS or WEP resulted in a lower gluten yield and a higher $R_{\max }$ and a smaller $E$ at $R_{\max }$ of gluten containing less non-GMP protein, a more elastic GMP gel, a larger specific volume of the GMP particles and a smaller tendency of these particles to aggregate. In contrast, the use of xylanase or FA resulted in a higher gluten yield and a larger $E$ at $R_{\max }$ of gluten. Here, the GMP was characterised by a more viscous gel structure, a smaller specific volume of the GMP particles and a larger tendency of GMP particles to aggregate. Correlations between gluten properties $\left(\mathrm{R}_{\max }\right.$, E at $\left.\mathrm{R}_{\max }\right)$ with GMP particle properties ([$\left.\left.\eta\right], \mathrm{K}^{\prime}\right)$ were observed. Based 
on these observations, we propose a possible explanation for the effect of pentosans on gluten formation and properties. Both a physical and a chemical effect are involved. The physical effect is related to viscosity and likely also depletion attraction. Viscosity is a general effect limiting aggregation rate and hence gluten yield. Depletion attraction is related to the ratio in size of pentosans on the one hand and glutenin particles on the other. The chemical effect is related to FA and 'controls' the tendency of the particles to aggregate $\left(\mathrm{K}^{\prime}\right)$ and hence also gluten yield. This explanation comes down to that pentosans do not so much affect the growth of GMP particles after mixing but mainly hinder the further agglomeration of especially smaller particles to end up in the gluten. This will lead to a partial agglomeration of GMP particles, resulting in turn in GMP with different glutenin particle size distribution and properties. Since GMP particle properties could be directly related to gluten rheological properties, this explains the change in quality observed.

Chapter 6 validates the proposed explanation for the effects of pentosans on gluten formation and properties using three wheat cultivars Scipion, Soissons and Amazon, differing in technological quality from weak to strong. In addition to the standard techniques used for characterizing gluten and GMP yield, composition and properties, results of a new technique (particle size analysis) did directly confirm the increase and decrease in average particle size of GMP when WUS and xylanase was added to wheat flour respectively. These results support our proposed explanation. The same trend for the effect of WUS and xylanase on gluten and GMP yield, composition and properties was observed for three wheat cultivars of widely differing technological qualities. However, the effects of WUS and xylanase affected gluten yield and properties much stronger for Scipion and Soissons than for Amazon. Amazon flour contains more protein and less pentosans than the other cultivars. The analysis of GMP particles demonstrates that the volume surface average particle diameter $\mathrm{D}_{3,2}$ of GMP particles and $\mathrm{K}$ ' from Amazon wheat is larger than those from Scipion and Soissons. Amazon has the ability to form larger and more sticky particles. We propose this also could help explain why Amazon is less affected in terms of gluten yield and properties when WUS and xylanase are present.

The formation of gluten is the result of, first, breakdown of gluten structures during mixing and, second, re-agglomeration of gluten protein structures. So far, effects of pentosans and enzymes on mixing and re-agglomeration have not been studied separately. In chapter 7 a modification of the TNO Glutomatic allowed us to add pentosans, xylanase and other additives during the re-agglomeration phase. In addition, dough strain hardening was also determined. The results demonstrate that gluten re-agglomeration mainly 
happens during the dilution and the wash phase of the TNO Glutomatic when gluten and starch are separated thus explaining the effects being stronger when adding pentosans and xylanase during the diluting phase than before mixing. Added pentosans hinder gluten agglomeration when present only during this phase. This is only partly related to a viscosity effect. FA related interaction is more important here. The resulting gluten contains glutenin particles of a higher average voluminosity than the control. Apparently, pentosans hinder the agglomeration of GMP particles with non-glutenin particles to gluten and not the formation of GMP particles. When pentosan interference is prevented, by xylanase or FA, aggregation during the dilution phase is more extensive. The resulting gluten is characterised by much more smaller glutenin particles. These differences also lead to differences in gluten rheological properties. We conclude that pentosans and xylanase mainly act during the re-agglomeration of gluten following the breakdown of gluten structures during mixing. Both act on the ability of GMP particles to form gluten, affecting both gluten yield and gluten rheological properties. Effects of pentosans and xylanase on gluten are paralleled by effects on dough. Similar effects on especially dough extensibility were observed. Effects on strain hardening parameters were not significant. 
Samenvatting 
Als een deeg van tarwebloem en water voorzichtig wordt gewassen met extra water, worden oplosbare eiwitten en zetmeel verwijderd en ontstaat er een taaie massa, gluten (Latijn voor kleefstof). Gluten bestaat gewoonlijk uit 75- 85\% eiwit (op basis van droog gewicht), afhankelijk van de zorgvuldigheid van het wassen. Het resterende gedeelte bestaat uit 10-15\% koolhydraten (voornamelijk zetmeel) en 5-10\% lipiden. Bij menging van bloem met water in een verhouding van globaal 1:1, zoals bij de broodbereiding, wordt een netwerk gevormd door het gluten, met daarin de zetmeelkorrels gedispergeerd. De vorming van zo'n gluten netwerk is belangrijk voor de uiteindelijke geschiktheid van de tarwe voor vele voedingsproducten. Het spreekt vanzelf dat de eiwitsamenstelling van de tarwebloem de eigenschappen van het glutennetwerk sterk beïnvloedt. Veranderingen in de hoeveelheid en de eigenschappen van vooral de hoogpolymere eiwitten beïnvloeden duidelijk de reologische eigenschappen van het gluten. Hoewel het gehalte aan pentosanen, verdeeld in niet in water extraheerbare, vaste deeltjes (WUS) en water-extraheerbare pentosanen (WEP) in tarwebloem laag is $(1-2 \% \mathrm{w} / \mathrm{w})$, spelen deze polysacchariden toch een belangrijke rol in de vorming van het glutennetwerk. Het mechanisme van deze interactie is echter verre van duidelijk. Het doel van dit proefschrift is daarom het verduidelijken van het mechanisme van de werking van pentosanen m.b.t. de vorming van gluten en de eigenschappen ervan.

In hoofdstuk 2 werd een sterk verkleinde opstelling voor het scheiden van gluten-zetmeel gebruikt om het effect van WUS op de vorming en eigenschappen van gluten systematisch te bestuderen. Uit de resultaten bleek dat WUS niet alleen een negatief effect hebben op de hoeveelheid gevormde gluten, ze beïnvloeden ook de samenstelling en reologische eigenschappen van het gluten en de glutenine macropolymeren (GMP). Het negatieve effect van WUS op de vorming van gluten kan gedeeltelijk gecompenseerd worden door de kneedtijd te verlengen en meer water te gebruiken tijdens het kneden. Het toevoegen van xylanase doet het effect van WUS totaal te niet. Gebaseerd op deze resultaten hebben wij als hypothese gesteld dat WUS glutenvorming belemmeren op zowel een directe als een indirecte manier. WUS belemmeren de vorming indirect door water te binden en zodoende de voorwaarden voor glutenontwikkeling te veranderen. Dit indirecte effect kan gedeeltelijk gecorrigeerd worden door het toevoegen van meer $0.2 \%$ $\mathrm{NaCl}$ oplossing tijdens het mengen van het deeg in combinatie met langer kneden. Het deeltjeskarakter van WUS vereist dat het directe effect te maken heeft met een interactie tussen WUS-deeltjes en glutendeeltjes. Beide effecten van WUS kunnen worden tegengegaan door het gebruik van xylanase.

In hoofdstuk 3 worden de effecten bestudeerd van veranderde WEP op de vorming 
van gluten, deegeigenschappen en kwaliteit en samenstelling van het gluten. De resultaten laten zien dat WEP de vorming van gluten zowel op een directe als een indirecte manier belemmeren. Ze belemmeren de vorming indirect door water te binden en zodoende de voorwaarden voor de ontwikkeling van gluten te veranderen. Dit resulteert in een lagere glutenproductie en een verhoogde weerstand van gluten tegen uitrekking. Toevoegen van meer $0.2 \% \mathrm{NaCl}$ oplossing tijdens het kneden van het deeg corrigeert volledig voor dit effect op de vorming van gluten. Er is echter ook een direct effect van WEP op de glutenvorming. Dit effect blijkt uit een lagere uitrekbaarheid van het deeg en de gluten en kan niet gecorrigeerd kan worden door meer $0.2 \% \mathrm{NaCl}$ oplossing toe te voegen tijdens het kneden van het deeg. Er is aangetoond dat het effect op uitrekbaarheid van deeg en gluten verband houdt met het gehalte aan ferulazuur (FA) van WEP. Toevoeging van vrij FA zorgt voor een meer uitrekbaar deeg en gluten en een grotere hoeveelheid gevormd gluten. Op grond hiervan hebben we als werkhypothese aangenomen dat FA gebonden aan WEP een centrale rol speelt bij dit effect van WEP. Onze resultaten duiden er ook op dat het effect van WEP op de uitrekbaarheid van deeg en gluten deels het resultaat kan zijn van de vorming van een binding tussen het eiwit en WEP.

In hoofdstuk 4 bestudeerden wij hoe WUS het proces van glutenvorming beïnvloeden. Hiervoor werden de eigenschappen van WUS veranderd door incubatie met respectievelijk $\mathrm{NaOH}$, xylanase en mierikswortel peroxidase ( $\mathrm{HRP}) / \mathrm{H}_{2} \mathrm{O}_{2}$, De effecten van veranderde WUS op glutenvorming, -deeg en -eigenschappen en GMPsamenstelling en eigenschappen werden bestudeerd. De resultaten toonden aan dat toevoeging van WUS aan tarwebloem leidde tot een lagere hoeveelheid gevormd gluten en een grotere maximum weerstand tegen uitrekking $\left(R_{\max }\right)$ en een lagere uitrekbaarheid bij maximum weerstand ( $E$ bij $R_{\max }$ ) van het gluten en een geconcentreerder en meer elastisch GMP gel. Voorbehandeling van WUS met $\mathrm{NaOH}$, xylanase, $\mathrm{HRP}$ en $\mathrm{H}_{2} \mathrm{O}_{2}$ kan het negatieve effect op glutenproductie niet corrigeren, maar toevoeging van xylanase of vrij FA tijdens glutenscheiding kan het negatieve effect van WUS op de glutenvorming voorkomen. Vergeleken met de toevoeging van alleen maar WUS, resulteerde de toevoeging aan tarwebloem van WUS en FA samen in een grotere hoeveelheid gevormd gluten, een hoger E bij $R_{\max }$ van het gluten, en een minder geconcentreerd en meer elastisch GMP gel. Evenals bij WEP, speelt FA, gebonden aan WUS, een belangrijke rol in het effect van WUS op glutenopbrengst en -eigenschappen. Het blijkt dat er een gemeenschappelijk mechanisme is m.b.t. het effect van WUS en WEP waarbij de oxidatieve vorming van bindingen tussen WUS en WEP bestanddelen en gluten tijdens de vorming van gluten waarschijnlijk voorkomen kan worden door FA toe te voegen. Het verschil tussen beiden is 
dat WUS een grotere waterbindingscapaciteit hebben, hetgeen tot uitdrukking komt in een hogere $\mathrm{R}_{\max }$ van deeg en gluten als daar extra WUS aan zijn toegevoegd.

Het doel van Hoofdstuk 5 is om een verklaring te vinden voor de waargenomen verschillen in gluteneigenschappen. Hiervoor werden verschillende pentosaanpreparaten, WEP, WUS, WEP $_{\mathrm{x}}$ (door xylanase gewijzigd WEP), FA en xylanase toegevoegd aan de bloem voor het scheiden van het gluten en het zetmeel. Deze toevoegingen beïnvloedden niet alleen de vorming van gluten, maar ook de eigenschappen ervan. Om deze veranderingen te begrijpen werd het belangrijkste netwerk vormende polymeer, de GMP fractie, geïsoleerd en de eigenschappen ervan bestudeerd. Toevoeging van WUS of WEP leidde tot een lagere opbrengst aan gluten en een grotere $R_{\max }$ en een kleiner $E$ bij $R_{\max }$ van het gluten. Dit gluten bevat ook minder niet-GMP eiwit en geeft een meer elastisch GMP gel met een groter specifiek volume van de GMP deeltjes, die minder geneigd zijn te aggregeren. Het gebruik van xylanase of FA daarentegen, leidde tot de vorming van meer gluten dat gekenmerkt werd door een grotere $\mathrm{E}$ bij $\mathrm{R}_{\max }$. De GMP heeft dan een meer viskeuze gelstructuur. Het specifiek volume van de GMP deeltjes is kleiner en ze vertonen een sterkere neiging om te aggregeren. Er werden correlaties waargenomen tussen gluteneigenschappen $\left(R_{\max }, E\right.$ at $R_{\max }$ ) en GMP deeltjeseigenschappen (respectievelijk [ $\eta$ ] en K'). Gebaseerd op deze waarnemingen kwamen wij tot een mogelijke verklaring voor het effect van pentosanen op de vorming en eigenschappen van gluten. Het gaat hier om zowel een fysisch als een chemisch effect. Het fysisch effect heeft betrekking op viscositeit en waarschijnlijk ook op depletie attractie. Viscositeit is een algemeen effect dat de aggregatiesnelheid vertraagd en daarmee ook glutenvorming. Depletie attractie heeft te maken met de verhouding in grootte van de pentosanen en gluteninedeeltjes. Het chemisch effect is gerelateerd aan FA en 'regelt' de neiging van de deeltjes om te aggregeren ( $K$ ') en zo ook glutenvorming. Deze verklaring komt er op neer dat pentosanen niet zozeer invloed hebben op de groei van GMP deeltjes na het mengen, maar dat ze vooral de verdere aggregratie van in het bijzonder de kleinere deeltjes tot grotere afscheidbare glutendeeltjes belemmeren. Dit leidt tot een onvolledige aggregatie van GMP deeltjes, hetgeen op zijn beurt resulteert in GMP met een andere deeltjesgrootteverdeling en andere deeltjes eigenschappen. Aangezien de eigenschappen van de GMP deeltjes direct gerelateerd kunnen worden aan de reologische eigenschappen van gluten, verklaart dit de waargenomen verandering in kwaliteit.

Hoofdstuk 6 valideert de voorgestelde verklaring voor het effect van pentosanen op vorming en eigenschappen van gluten door dit effect voor drie verschillende tarwerassen te bestuderen, nl. Scipion, Soissons and Amazon. Deze rassen variëren wat technologische 
kwaliteit betreft van 'weak' tot 'very strong'. Naast de standaardtechnieken die gebruikt werden in de vorige hoofdstukken om gluten en GMPproductie, -samenstelling en -eigenschappen te karakteriseren, bevestigen de resultaten van een nieuwe techniek (analyse van GMP deeltjesgrootte) direct de toename en afname van de gemiddelde deeltjesgrootte van GMP, als respectievelijk WUS of xylanase aan de tarwebloem werd toegevoegd. Dezelfde trend m.b.t. de effecten van WUS en xylanase op gluten- en GMPproductie, -samenstelling en -eigenschappen, werd waargenomen voor de verschillende rassen. De effecten van WUS en xylanase beïnvloedden glutenvorming en eigenschappen echter veel sterker voor Scipion en Soissons dan voor Amazon. Amazonbloem bevatte echter meer eiwit en minder pentosanen dan de andere twee rassen. De analyse van GMP deeltjes toonde verder aan dat $\mathrm{D}_{3,2}$ (de gemiddelde verhouding tussen volume en oppervlakte van de deeltjes) en de K' van de GMP deeltjes van Amazontarwe groter is dan die van Scipion en Soissons. Amazon heeft het vermogen om grotere en meer plakkerige deeltjes te vormen. Wij stellen voor dat dit ook een (deel van de) verklaring zou kunnen zijn waarom de aanwezigheid van WUS en xylanase minder invloed zou hebben op glutenvorming en -eigenschappen vanuit Amazonbloem.

De vorming van gluten is het resultaat van in eerste instantie het kapotmaken van de glutenstructuren in de bloem tijdens het mengen en, ten tweede, van de terugvorming van gluteneiwitstructuren daarna. Tot nu toe konden de effecten van pentosanen en enzymen op kneden en terugvormen niet afzonderlijk bestudeerd worden. In hoofdstuk 7 stelde een modificatie van de TNO Glutomatic ons in staat om pentosanen, xylanase en andere additieven toe te voegen tijdens de terugvormingsfase. Bovendien werd het zogenaamde strain hardening gedrag van deeg bepaald. De resultaten laten zien dat glutenterugvorming vooral plaatsvindt tijdens het verder verdunnen van het deeg en het uitwassen van het gluten in de TNO Glutomatic. Dit verklaart dat de effecten sterker zijn als pentosanen en xylanase worden toegevoegd tijdens de deze fase dan vóór het kneden. Toegevoegde pentosanen belemmeren glutenvorming ook als ze alleen tijdens de verdunnings/wasfase aanwezig zijn. Dit is slechts gedeeltelijk gerelateerd aan een viscositeitseffect, de FA gerelateerde interactie is hier belangrijker. Hert resulterende gluten bevatten GMP deeltjes van een grotere gemiddelde voluminositeit dan in het controle experiment. Klaarblijkelijk belemmeren pentosanen de agglomeratie van GMP deeltjes met niet-gluteninedeeltjes tot gluten en niet de terugvorming van de GMP deeltjes zelf. Als deze belemmering door pentosanen werd voorkomen door xylanase of FA, was de vorming tijdens de verdunning/wasfase meer compleet. Het resulterende gluten werd gekenmerkt door een gemiddeld kleinere afmeting van de GMP deeltjes. Deze verschillen leiden ook tot 
verschillen in de reologische eigenschappen van gluten. We concluderen dat pentosanen en xylanase vooral functioneren tijdens de terugvorming van gluten volgend op het kapotmaken van de oorspronkelijke GMP structuren tijdens het kneden. Beiden fungeren dankzij het vermogen van GMP deeltjes om gluten te vormen en beïnvloeden glutenvorming zowel als reologische eigenschappen van gluten. De waargenomen effecten van pentosanen en xylanase op gluten lopen parallel met de effecten ervan op deeg. Dit was vooral duidelijk wat betreft de uitrekbaarheid van het deeg. Effecten op 'strain hardening' parameters waren niet significant. 
戊聚糖对面筋形成及品质的影响

概述 
小麦面团在大量水的冲洗下, 可溶蛋白及淀粉被冲走, 剩下的似橡胶的团块, 称 面筋。取决于冲洗程度, 通常, 面筋含 75-85\%蛋白 (以干物质计), 10-15\%碳水化合物 (主要是淀粉) 及 $5-10 \%$ 类脂。面筋网络的形成对决定小麦制品的最终用途起到关键 的作用。言之有理，小麦粉蛋白成分严重影响面筋网络的品质。特别是聚合蛋白的 数量及质量的变化会体现在面筋流变品质的变化。小麦戊聚糖可分为水溶性及水不 溶性, 虽在小麦粉中的含量很低 (1-2\%), 但该聚合物对面筋网络的形成起到很重要 的作用。然而, 其作用机理尚不清楚。因此, 本论文的目的是澄清小麦戊聚糖对面筋 形成及品质的作用机理。

本论文的第二章报道采用面筋-淀粉分离的小型装置系统研究小麦水不溶性戊 聚糖对面筋形成及品质的影响。研究结果表明: 水不溶性戊聚糖不仅影响面筋产率, 而且影响面筋及麦谷蛋白大聚合物的成分及流变品质。可通过延长混合时间及增大 加水量部分克服水不溶性戊聚糖对面筋产率的负作用。添加木聚糖酶可完全克服水 不溶性戊聚糖对面筋产率的负作用。根据本研究结果推测: 戊聚糖以间接和直接的 方式影响面筋形成。间接方式影响面筋形成是通过戊聚糖与面筋蛋白质竞争吸水, 从而改变了面筋形成条件。可通过延长混合时间及增加和面加水量 $(0.2 \% \mathrm{NaCl})$ 来克 服其对面筋产率的负作用。小麦水不溶性戊聚糖颗粒的性质导致其直接作用通过其 颗粒与面筋蛋白颗粒的交互作用。木聚糖酶的使用可克服其对面筋形成的间接及直 接作用。

第三章研究变性小麦水溶性戊聚糖对面筋产率, 品质及成分的作用效果。结果 表明: 水溶性戊聚糖也是以间接和直接的方式影响面筋形成。间接方式影响面筋形 成是通过水溶性戊聚糖与面筋蛋白质竞争吸水, 从而改变了面筋形成条件。其结果 使面筋产率降低, 面筋抗延伸阻力增加。可通过增加和面加水量 $(0.2 \% \mathrm{NaCl})$ 来完全 克服其对面筋产率的负作用。水溶性戊聚糖对面筋形成的直接作用体现在使小麦面 团及面筋的延伸性缩小且不能通过增加和面加水量 $(0.2 \% \mathrm{NaCl})$ 来克服。研究表明: 水溶性戊聚糖对小麦面团及面筋的延伸性与小麦水溶性戊聚糖中的阿魏酸有关。添 加游离的阿魏酸使小麦面团及面筋的延伸性增大, 面筋产率提高。根据研究结果推 断: 水溶性成聚糖结合的阿魏酸对决定其作用效果起到了关键的作用。研究结果提 示：水溶性戊聚糖对小麦面团及面笳延伸性的作用效果或许部分由于其与面筋蛋白 的交联。

第四章研究小麦水不溶性戊聚糖如何影响面筋的形成。为此, 分别采用 $\mathrm{NaOH}$, 木聚糖酶及过氧化物酶对水不溶性戊聚糖变性, 继而研究变性的水不溶性成聚糖对 面筋产率, 面团品质, 面筋及麦谷蛋白大聚合物的成分及流变品质的作用效果。研究 结果表明: 添加水不溶性戊聚糖导致面筋产率及面筋淀粉产率下降, 面筋的最大抗 延伸阻力增加, 最大抗延伸阻力下的延伸性缩小, 麦谷蛋白大聚合物的浓度增加并 具有弹性结构。采用 $\mathrm{NaOH}$, 木聚糖酶及过氧化物酶对水不溶性成聚糖变性并不能克 
服其对面筋产率的负作用, 但在面筋分离中添加木聚糖酶或游离的阿魏酸可克服或 抑制其对面筋产率的负作用。与单独添加水不溶性龙聚糖相比, 同时添加水不溶性 戊聚糖与游离的阿魏酸导致面筋产率增加, 面筋的最大抗延伸阻力下的延伸性增大, 麦谷蛋白大聚合物的浓度降低并具有粘性结构。与水溶性戊聚糖相似, 水不溶性戊 聚糖结合的阿魏酸对决定其在面筋产率及品质的作用效果起到了关键的作用。关于 水不溶性戊聚糖及水溶性戊聚糖的作用效果似乎在面筋分离中存在着氧化交联, 且 可通过添加游离的阿魏酸抑制这样一个相同的作用机理。水不溶性及水溶性戊聚糖 的差别在于水不溶性戊聚糖具有较高的吸水能力, 体现在面团及面筋的最大抗延伸 阻力较高。

第五章目的是找出戊聚糖改变面筋品质的原因。为此, 在面筋分离中分别添加 不同的戊聚糖制品, 水溶性及水不溶性戊聚糖, 变性的水溶性戊聚糖 (采用木聚糖酶 变性), 阿魏酸及木聚糖酶制备一系列面筋制品。添加不同的戊聚糖制品不仅影响面 筋产率, 而且影响面筋品质。为深入了解面筋品质的改变, 着手分离并研究麦谷蛋白 大聚合物品质。分别添加水不溶性或水溶性戊聚糖均导致面筋产率下降, 面筋的最 大抗延伸阻力增加, 最大抗延伸阻力下的延伸性缩小, 面筋含有较少的非麦谷蛋白 大聚合物,麦谷蛋白大聚合物具有弹性结构, 其比体积较大, 结聚倾向较小。相反, 木 聚糖酶或游离阿魏酸的使用导致面筋产率增加, 面筋的最大抗延伸阻力下的延伸性 增大, 麦谷蛋白大聚合物具有粘性结构, 其比体积较小, 结聚倾向较大。研究发现面 筋品质 $\left(R_{\max }, E\right.$ at $\left.R_{\max }\right)$ 与麦谷蛋白大聚合物颗粒性质 $\left(\eta, K^{\prime}\right)$ 相关。根据研究结果推出 成聚糖对面筋形成及品质作用的可能解释。物理及化学作用均参与戊聚糖对面筋形 成及品质的作用。物理作用与粘度, 可能还有损耗引力有关。粘度是一个普遍的作 用, 可限制面筋结聚速率及面筋产率。损耗引力与戊聚糖及蛋白质粒度比例有关。 化学作用与阿魏酸有关且控制蛋白质结聚倾向 $\left(\mathrm{K}^{\prime}\right)$ 及面筋产率。该解释认为成聚糖 并不能很大程度上影响麦谷蛋白大聚合物粒度, 主要是阻止小颗粒蛋白质结聚成面 筋。从而使麦谷蛋白大聚合物颗粒部分结聚, 导致不同的谷蛋白粒度分布及品质。 因麦谷蛋白大聚合物颗粒性质可能与面筋流变品质直接有关, 从而解释了戊聚糖改 变面筋品质的现象。

第六章采用 Scipion, Soissons 及 Amazon 三种品质截然不同由弱到强小麦粉验 证推出的关于龙聚糖对面筋形成及品质作用的解释。除采用测定面筋及麦谷蛋白大 聚合物产率成分及品质的标准方法外, 采用新技术分析麦谷蛋白大聚合物颗粒的粒 度分布。该研究证实将水不溶性戊聚糖或木聚糖酶分别添加到小麦粉中导致麦谷蛋 白大聚合物颗粒的粒度增大或减小的结果。也证实推出的解释是正确的。研究发现 水不溶性戊聚糖及木聚糖酶对 Scipion, Soissons 及 Amazon 三种品质截然不同小麦 粉的作用趋势相同, 但对 Scipion, Soissons 小麦粉的面筋产率及品质的作用效果较 Amazon 小麦粉强。Amazon 小麦粉较其他二种小麦粉含有较多的蛋白质及较少的戊 
聚糖。麦谷蛋白大聚合物颗粒粒度分析结果显示 Amazon 小麦粉体积面积平均颗粒 直径 $\mathrm{D}_{3,2}$ 及 $\mathrm{K}^{\prime}$ 均大于 Scipion, Soissons 小麦粉。Amazon 小麦粉具有形成较高及较 粘颗粒的能力。这有助于解释为什么水不溶性成聚糖及木聚糖酶对 Amazon 小麦粉 的面筋产率及品质的作用效果较弱。

面筋的形成首先要在和面期间使面筋结构破坏, 其次, 要使面筋蛋白质结构重 新结聚。到目前为止, 未能分别研究在和面及重新结聚期间戊聚糖及酶的作用效果。 第七章报道对 TNO 面筋测定仪的改造可研究在面筋重新结聚期间添加戊聚糖, 酶及 其他添加剂的作用效果。此外, 检测了面团应变变硬指标。研究结果表明: 面筋的重 新 结聚主要发生在 TNO 面筋测定仪面筋与淀粉分离中的面团稀释与面筋洗涤期间, 因此, 解释了为什么在面团稀释期间添加戌聚糖或木聚糖酶的作用效果比在面团混 合期间要强。在面团稀释期间添加戊聚糖阻止面筋的重新结聚。部分由于粘度作用。 此阶段阿魏酸的交互作用更重要。面筋含有较大的麦谷蛋白大聚合物颗粒。很明显, 戊聚糖阻止非麦谷蛋白大聚合物结聚成面筋, 不能形成麦谷蛋白大聚合物颗粒。在 面团稀释期间添加木聚糖酶或游离阿魏酸可有效抑制戊聚糖的干扰作用。面筋中含 有较小的麦谷蛋白颗粒, 从而导致不同的面筋品质。研究结果表明戊聚糖或木聚糖 酶主要作用于面团经混合面筋结构破坏后的面筋蛋白质结构重新结聚期间。戊聚糖 及木聚糖酶均影响麦谷蛋白大聚合物颗粒结聚成面筋, 从而影响面筋产率及流变品 质。戊聚糖及木聚糖酶对面团的作用效果与面筋类似, 特别是对面团延伸性的作用 效果。戊聚糖及木聚糖酶对面团应变变硬作用效果不显著。 


\section{Curriculum vitae}

Mingwei Wang was born in the city of Hegang, Heilongjiang Province, China, on September 5, 1962. She graduated from Wuhan Polytechnic University and received a BSc degree majoring in Grain Engineering in 1984. Since then, she has been engaged in teaching and doing research with regard to grain processing and cereal quality analysis at Wuhan Polytechnic University. From 1990 to 1991 she studied the courses required to obtain an MSc degree in Food Science at Southern Yangtze University. She became a lecturer in 1992 and an associate professor in 1997. Throughout the fifteen years of research and teaching, she was granted a third place award by the science and technology program of the National Grain Storage Bureau, China; she authored and co-authored two books, published more than 30 papers in domestic specialized journals; and she received a third place award in a lecturing competition at Wuhan Polytechnic University, China. In 1999 she studied and did research as a visiting scholar at Wageningen University in the Netherlands. Subsequently, she continued her study and research, which is described in this thesis, at this university as a $\mathrm{PhD}$ fellow. During her $\mathrm{PhD}$ study, she published two papers in an international specialized journal and was granted the 2002 Walter Bushuk Best Student Paper Award during the AACC annual meeting in Canada. 


\section{List of publications}

\section{Publications in English}

1. Wang, Mingwei, van Vliet, T. and Hamer, R.J. Evidence that pentosans and xylanase affect the re-agglomeration of the gluten network. Journal of Cereal Science. Submitted.

2. Wang, Mingwei, van Vliet, T. and Hamer, R.J. Interaction of water unextractable solids and xylanase with gluten protein: Effect of wheat cultivars. Journal of Cereal Science. Submitted.

3.Wang, Mingwei, van Vliet, T. and Hamer, R.J. How gluten properties are affected by pentosans. Journal of Cereal Science. Submitted.

4. Wang, Mingwei, Oudgenoeg, G, van Vliet, T. and Hamer, R.J. 2003. Interaction of water unextractable solids with gluten protein: Effect on dough properties and gluten quality. Journal of Cereal Science. In press.

5. Wang, Mingwei, van Vliet, T. and Hamer, R.J. 2003. Influence of pentosans on the structure formation of gluten. Industrial proteins . 11(1):9-11

6. Wang, Mingwei, Hamer, R.J., van Vliet, T., Gruppen, H., Marseille, J.P. Weegels, P.L. 2003. Effect of water unextractable solids on gluten formation and properties: Mechanistic Considerations. Journal of Cereal Science. 37(1):55-64.

7. Wang, Mingwei, Hamer, R.J., van Vliet, T. and Oudgenoeg, G. 2002. Interaction of water extractable pentosans with gluten protein: Effect on dough properties and gluten quality. Journal of Cereal Science. 36(1):25-37.

8. Hamer, R. J., Wang, Mingwei, Vliet, T. van, Gruppen, H., Marseille, J.P. and Weegels, P.L. 2000. Effect of water unextractable solids (WUS) on gluten formation and properties: Mechanistic considerations. In 'Wheat Gluten--- proceedings of the $7^{\text {th }}$ International Gluten Workshop' (eds. P.R. Shewry and A.S. Tatham) Royal Society of Chemistry, Cambridge, UK. pp125-131.

\section{Major publications in Chinese}

1. Wang, Mingwei, Pan Congdao, Wei Yunxi, Lu Jing and $\mathrm{Hu}$ Cuifang. 2000. Development of high quality healthy bread flour. Journal of Cereal and Feed Industry. 153:8-10.

2. Wang, Mingwei, Pan Congdao, Wei Yunxi, Lu Jing and Hu Cuifang. 2000. Study on the compound quality improvement and nutrition fortification of wheat flour. Journal of Wuhan Polytechnic University. 59:1-5. 
3. Wang, Mingwei.1999. Requirement of steamed bread to wheat flour. Journal of the Chinese Cereals and Oils Association.14:8-27.

4.Wang, Mingwei, Pan Congdao, Fang Weian, Cui Juan and Qi Mingxia.1999. Research on compound application of bread improvers. Journal of Cereal and Feed Industry. 144:37-39.

5. Wang, Mingwei, Pan Congdao, Fang Weian, Cui Juan and Qi Mingxia.1999. A study on the compound quality improvement of flour strength improver. Journal of Cereal and Feed Industry. 142:1-3.

6. Wang, Mingwei, Pan Congdao, Fang Weian, Cui Juan and Qi Mingxia. 1999. Compound quality improvement of specialized bread flour. Journal of the Chinese Cereals and Oils Association. 14:14-18.

7. Wang, Mingwei. 1998. Up-to-date development of cereal quality analysis technology abroad. Journal of Cereal and Feed Industry. 136:1-3.

8. Wang, Mingwei.1997. Determination and Analysis of Cereal Quality. China Commercial Press, Beijing.

9. Wang, Mingwei. 1997. The new technology for wheat cleaning--- KOMBI-TECH SYSTEM. Journal of Wuhan Polytechnic University. 50: 34-38.

10. Wang, Mingwei. 1996. An elementary analysis of the new type full automatic roller mill. Journal of Cereal and Feed Industry. 112: 9-12.

11.Wang, Mingwei, Pan Congdao and Ding Wenping. 1996. Extraction of high-protein flour and research on its quality improvement. Journal of Wuhan Polytechnic University 46:25-28.

12. Wang, Mingwei. 1996. Analysis of Millishort system technology. Journal of Wuhan Polytechnic University. 44: 27-34.

13. Wang, Mingwei. 1996. The new technology of flour milling--- Short milling system. Journal of Cereal and Food Industry. 11: 15-20.

14.Wang, Mingwei. 1995. Eight roll rollermill and its application in flour milling. Journal of Cereal and Feed Industry. 96:15-17.

15. Wang, Mingwei.1995. The new technology for automatic control flour milling--Introduction of Optimizer system. Journal of Cereal and Feed Industry. 102: 25-26.

16. Wang, Mingwei. 1994. One new type of flour milling machine---Impact mill. Journal of Cereal and Food Industry. 91: 18-20.

17.Wang, Mingwei. 1994. The new method for wheat baking quality analysis---High performance liquid chromotograph. Journal of Cereal and Feed Industry. 89:4-5.

18.Wang, Mingwei, Wang Yinyuan and Pan Congdao.1993. Research on the rapid assessment of wheat baking quality. Journal of Cereal and Feed Industry.76: 8-10.

19.Wang, Mingwei, Pan Congdao ect.1993. The effect of flour strength improver on qualities of various wheat. Journal of Cereal and Feed Industry. 75:11-13. 